\title{
IN-PLANE SHEAR WALL PERFORMANCE AS AFFECTED BY COMPRESSED EARTH BLOCK SHAPE
}

\author{
A Thesis \\ presented to \\ the Faculty of California Polytechnic State University, \\ San Luis Obispo
}

\author{
In Partial Fulfillment \\ of the Requirements for the Degree \\ Master of Science in Civil and Environmental Engineering
}

by

Steven Ellis Ambers

March 2017 
(C) 2017

Steven Ellis Ambers

\section{ALL RIGHTS RESERVED}




\section{COMMITTEE MEMBERSHIP}

TITLE: In-Plane Shear Wall Performance as Affected by Compressed Earth Block Shape

AUTHOR: Steven Ellis Ambers

DATE SUBMITTED: $\quad$ March 2017

COMMITTEE CHAIR: $\quad$ Daniel C. Jansen, Ph.D., PE, F.ACI

Professor of Civil and Environmental Engineering

COMMITTEE MEMBER: Bing Qu, Ph.D., PE

Associate Professor of Civil and Environmental

Engineering

COMMITTEE MEMBER: Peter Laursen, Ph.D., PE

Associate Professor of Architectural Engineering 


\begin{abstract}
In-Plane Shear Wall Performance as Affected by Compressed Earth Block Shape

Steven Ellis Ambers
\end{abstract}

This thesis investigates the in-plane shear performance of full-scale walls made from compressed earth blocks. Compressed earth blocks are a type of masonry where the blocks are composed of compressed soil and typically dry-stacked without mortar. Prior research has demonstrated that the in-plane shear strength of these blocks falls far short of capacities predicted by conventional masonry building codes, requiring new testing to develop effective and safe designs for seismic conditions. This thesis specifically studies the effects of block type and the use of grouted shear keys at the block head joints.

Three full-scale walls were constructed and tested under in-plane, cyclic loading. To compare the effect of block type on shear strength, one wall was constructed from Rhino blocks as used by the Center for Vocational Building Technology, while another used V-Lock blocks designed by the Vermeer Corporation. Apart from differences in size and interlock mechanism, the standard Rhino blocks have shear keys at the head joints which are not present on the V-Lock blocks. To examine the effect of these shear keys, a third wall was built from Rhino blocks with the shear keys removed.

The two standard block types displayed no major difference in strength that could not be attributed to grouted area or the presence/absence of the head joint shear keys. The Rhino block wall with shear keys reached a higher peak load relative to the grouted area but experienced a brittle drop in capacity after peaking, while the other two walls exhibited an extended loading plateau after the initial peak. All walls failed with cracking and block sliding along the main diagonals, a failure mode similar to conventional masonry. Proposals are made for modifying the equations for shear capacity from the Masonry Standards Joint Committee (MSJC) 2013 code for use in designing compressed earth block shear walls.

Keywords: interlocking compressed earth block, dry-stack masonry, block type, Rhino block, V-Lock block, shear key, in-plane shear, racking 


\section{ACKNOWLEDGMENTS}

This thesis owes its existence to many, many people. Thank you to everyone who came out on the weekend to help with making blocks: Alejandro Cervantes, Matthew Susank, Nik Blanchette, Liam Cheney, Lindsay Otto, and the students of Sean Pringle's CE 259 class. Thanks also to Jeff San Nicholas, Kai Ling Liang, and Christopher Hurley for helping out with construction. This project took a lot of manual labor, and thank you all not only for contributing your time and effort but also for making it more enjoyable.

Thanks to David VanMuyden and CalPortland for donating the steel angle used to help anchor the testing slab to the lab floor. Thanks also to the Cal Poly student machine shop technicians for helping me to make the necessary holes in it.

Thanks to Geoffrey Wheeler from the Center for Vocational Building Technology for coming out to see my second wall test. It was great to talk with you, although I am sorry that we weren't testing a Rhino block wall that day.

Thanks to Xi Shen for transporting the slab to the ARCE lab and for making the equipment available the many times I needed to drill aluminum or cut threaded rod. Thanks also to Nephi Derbidge for getting me going with the miter saw to cut my blocks (and for saving me from almost making a mess of the geotechnical lab).

Thank you to Ray Ward for helping out with everything in the lab itself, from moving the slab into place to disposing of the remains of each wall. Thank you also for allowing me to use all of your instrumentation and for taking the time to calibrate everything and set up the data acquisition program.

Thank you to my family for encouraging me, supporting me, and patiently listening to my explanations of each stage of this research. Particular thanks to my father for also coming out to help construct my third wall.

Thank you to Dr. Bing Qu and Dr. Peter Laursen for serving on my thesis committee and for helping me work through this process. Thank you also Dr. Laursen for arranging for me to use the ARCE lab facilities and equipment for my main testing.

A massive thanks to Sean Pringle for all his help with every stage of work on this research. I seriously don't think I can thank you enough for always taking time to help me whenever I needed it, even in the midst of your own thesis. Without your help and coaching, I think I might still be figuring out how to make a good block.

Lastly, thank you very much to Dr. Dan Jansen not only for being my advisor but also for spending so much time helping me with construction, chasing down raw materials, and sharing your experience with compressed earth blocks. Your patience, guidance, and hands-on teaching were absolutely critical to this whole endeavor. 


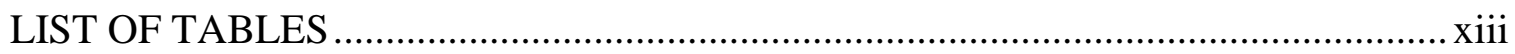

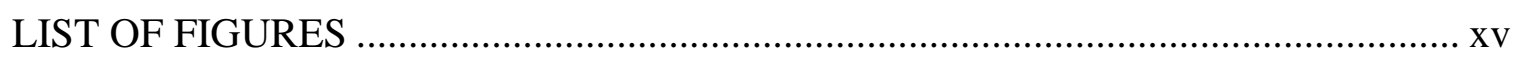

\section{CHAPTER}

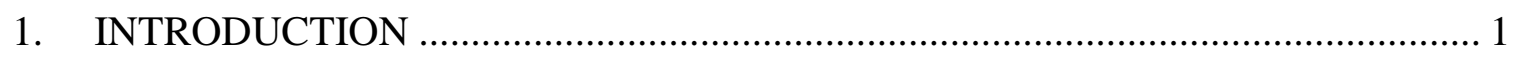

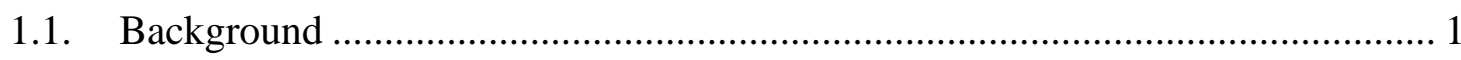

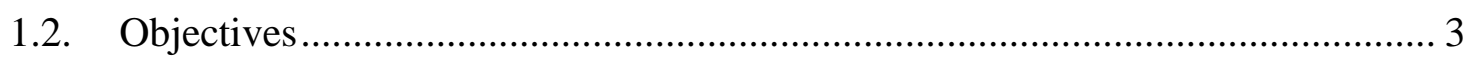

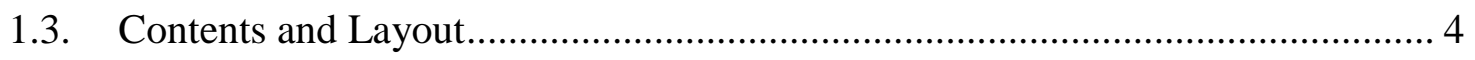

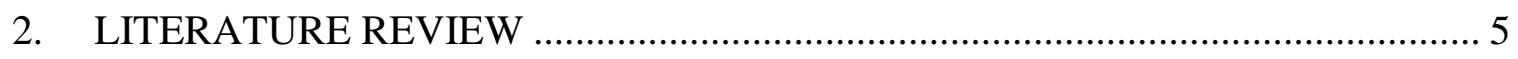

2.1. Material Properties of Compressed Earth Blocks ............................................... 5

2.2. Structural Behavior of Conventional Mortared Masonry …………………….... 9

2.3. Structural Behavior of Dry-Stack Masonry and Compressed Earth Blocks ...... 13

2.3.1. In-Plane Shear and Flexure................................................................... 16

2.4. MSJC Design Equations for In-Plane Loading ................................................. 19

2.4.1. Flexural Capacity …………………………….................................. 19

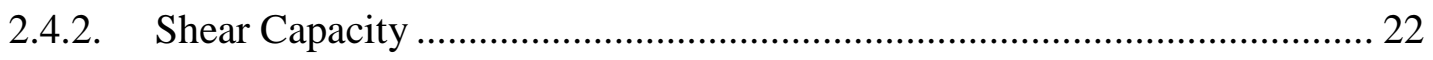

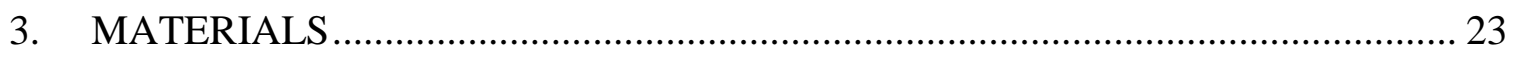

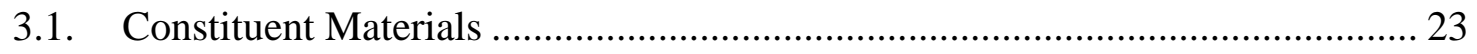

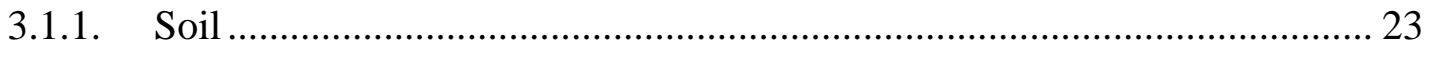

3.1.1.1. Material Properties ............................................................................... 24

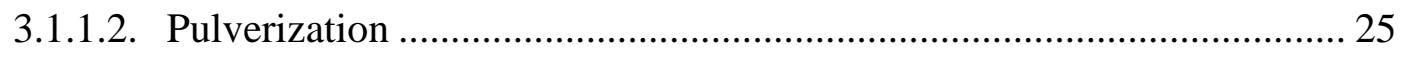

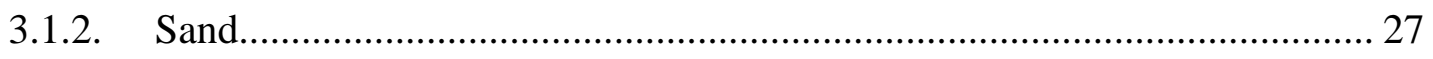




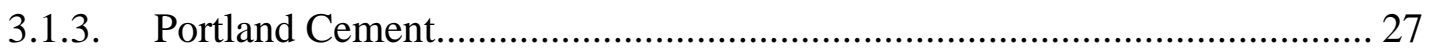

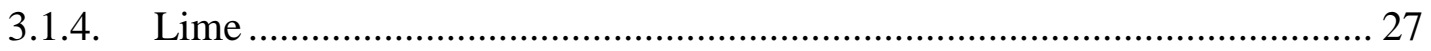

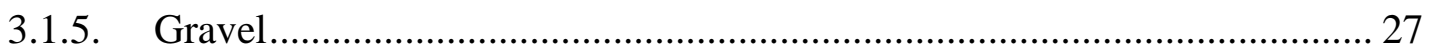

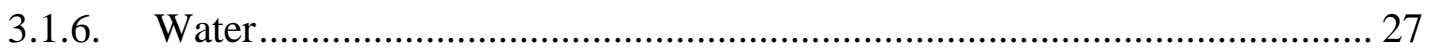

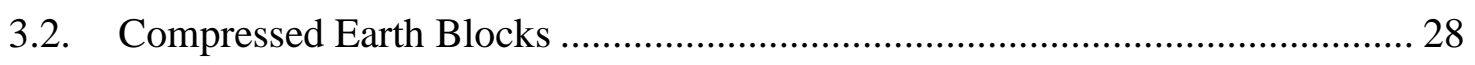

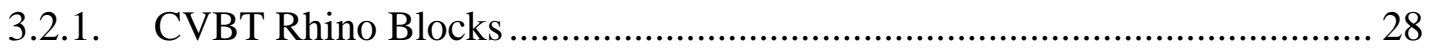

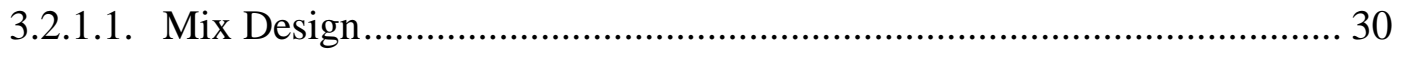

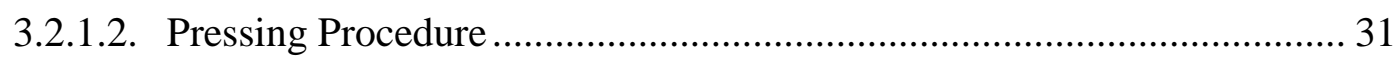

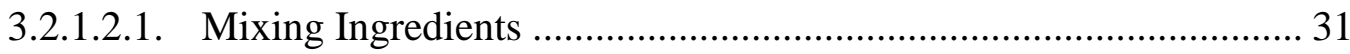

3.2.1.2.2. Cigar Test and Final Water Content ................................................. 33

3.2.1.2.3. Press Preparation ....................................................................... 34

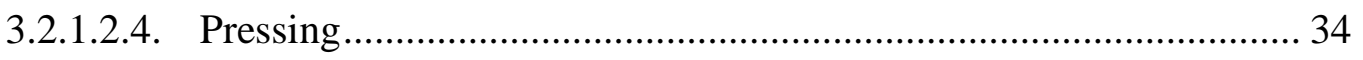

3.2.1.2.5. Penetrometer Test and Material Quantity Calibration....................... 35

3.2.1.2.6. Moisture Content Test ...................................................................... 37

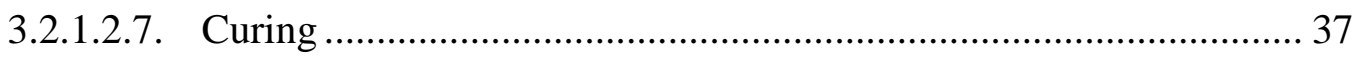

3.2.1.2.8. Special Techniques for Other Block Types ...................................... 38

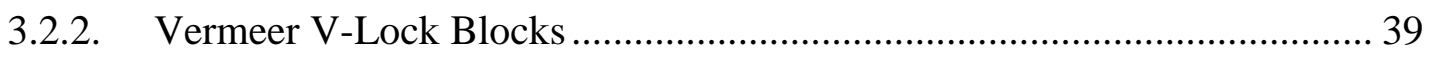

3.2.3. Pressing Procedure (adapted from Banker-Hix, 2014) ............................... 40

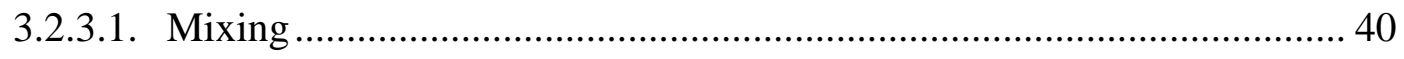

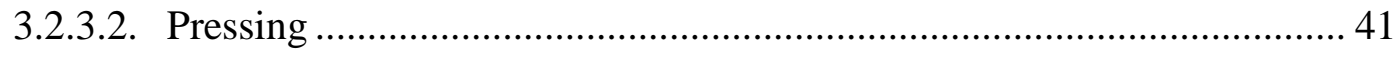

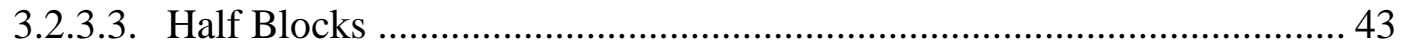

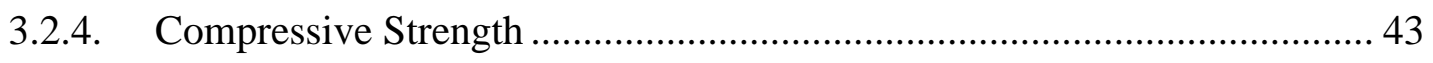

3.2.4.1. Single Blocks .................................................................................... 44 


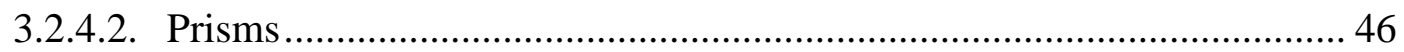

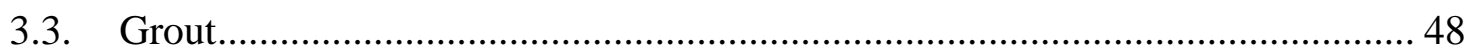

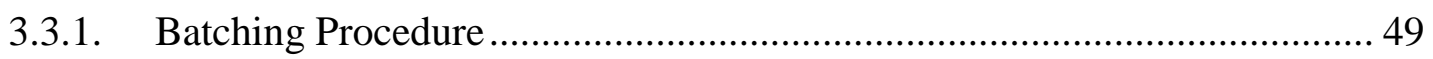

3.3.2. Compressive Strength Tests................................................................... 50

3.3.2.1. Non-Porous Cube Samples ................................................................... 51

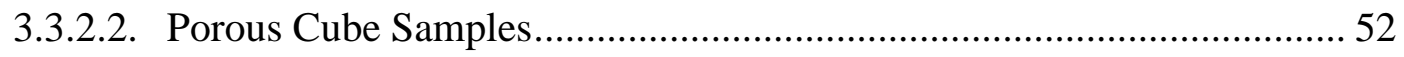

3.3.2.3. Porous Cylinder Samples ……………….............................................. 54

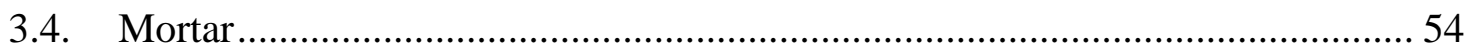

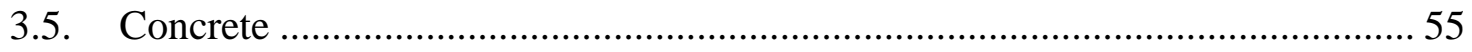

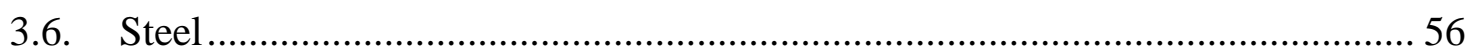

3.6.1. \#3 Deformed Reinforcing Bar .............................................................. 57

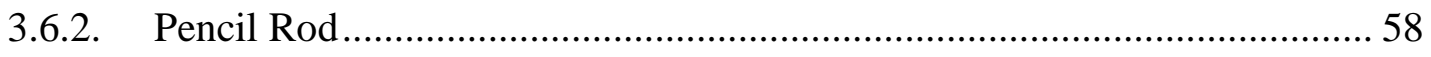

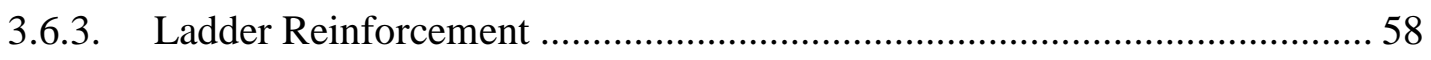

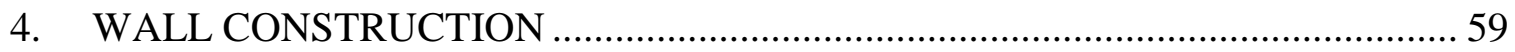

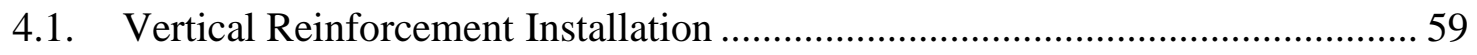

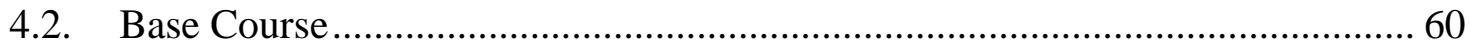

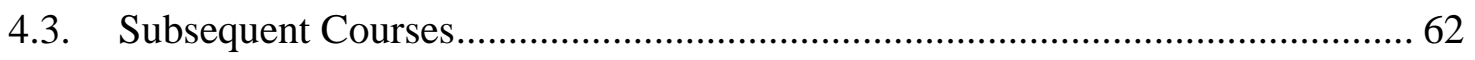

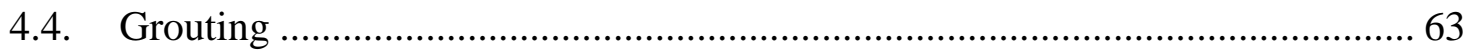

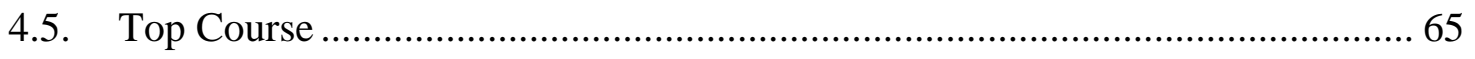

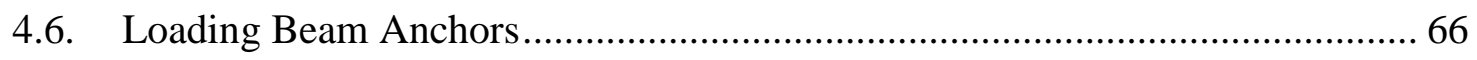

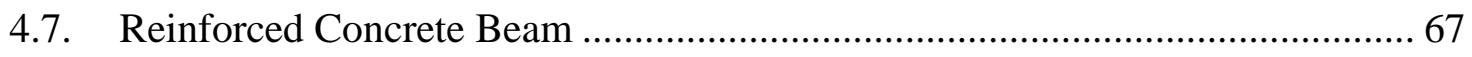

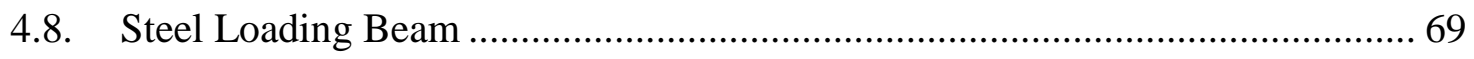

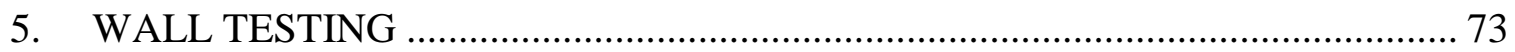




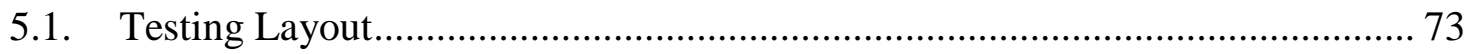

5.1.1. Loading Actuator ...................................................................................... 74

5.1.2. Out-of-Plane Lateral Bracing................................................................... 74

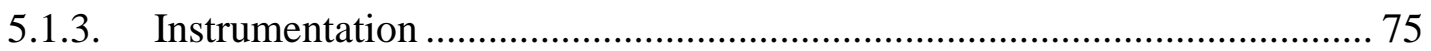

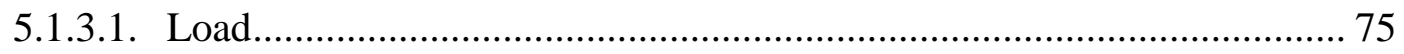

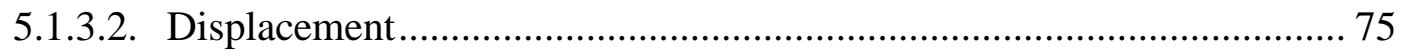

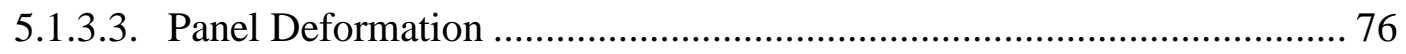

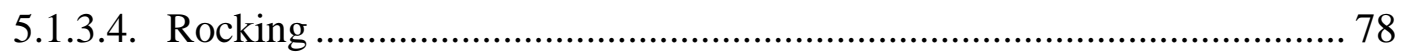

5.1.3.5. Foundation, Wall, and Loading Beam Slip ............................................ 79

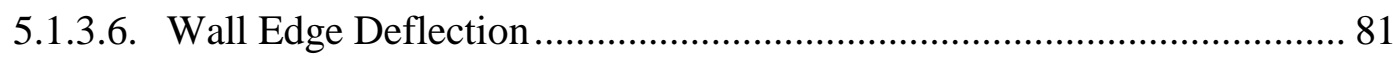

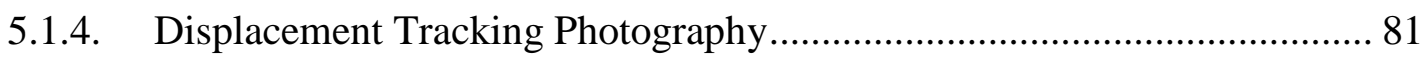

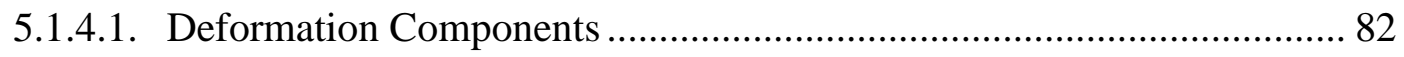

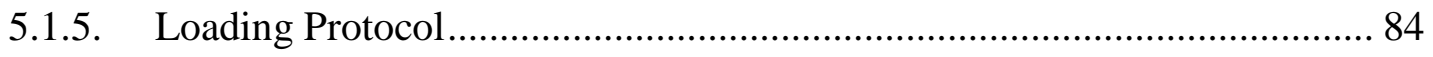

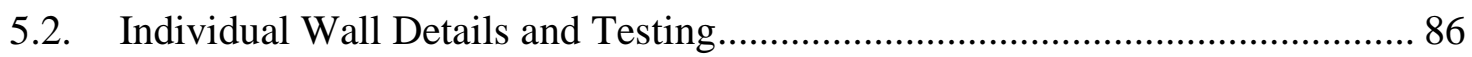

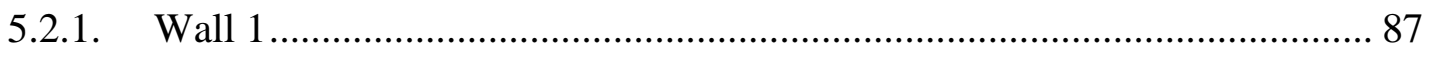

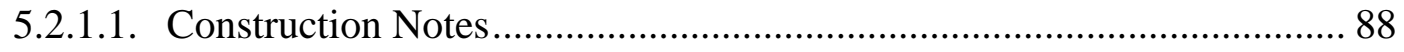

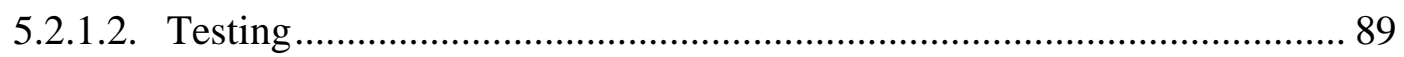

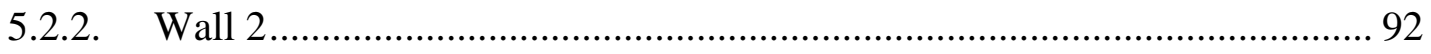

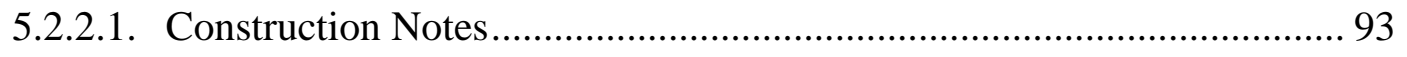

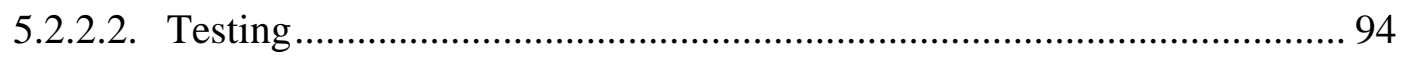

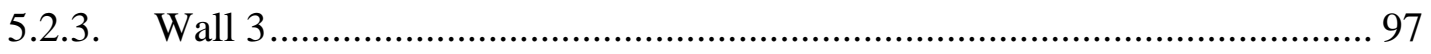

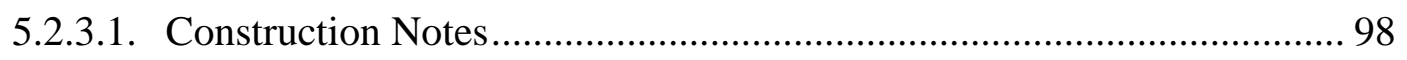

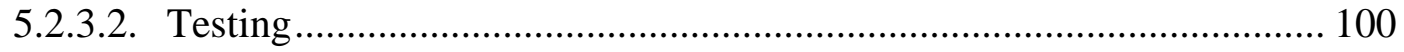




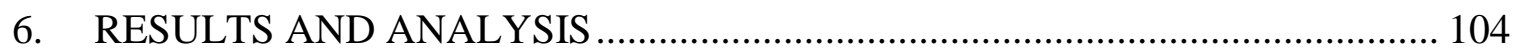

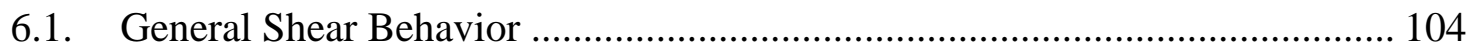

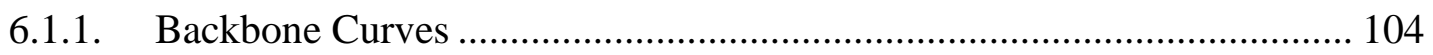

6.1.2. Deformation Components ........................................................................ 106

6.1.3. Photographic Displacement Analysis ....................................................... 108

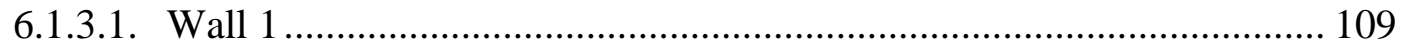

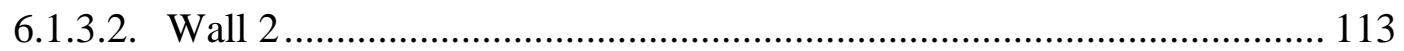

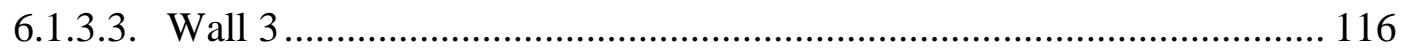

6.1.4. Common Behavioral Characteristics ....................................................... 121

6.1.5. Effect of Head Joint Shear Keys on Behavior ......................................... 122

6.1.6. Effect of Block Type on Behavior ......................................................... 123

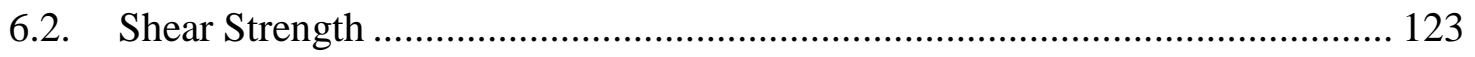

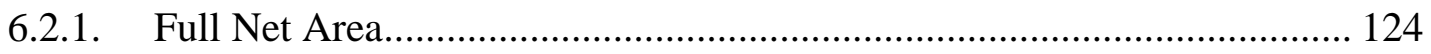

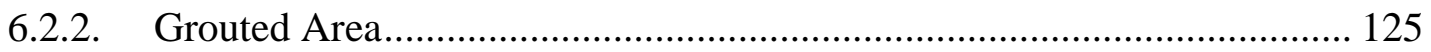

6.2.3. Effective Shear Area ........................................................................ 126

6.2.4. Block Participation Factor ……………………..................................... 128

6.2.5. Comparison to Partial Grouting ………………………….................... 129

6.2.6. Comparison to Diagonal Panel Tests ........................................................ 131

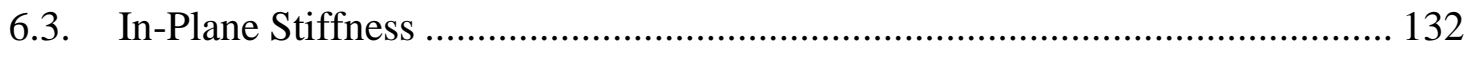

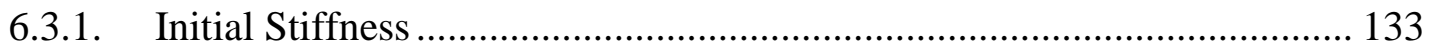

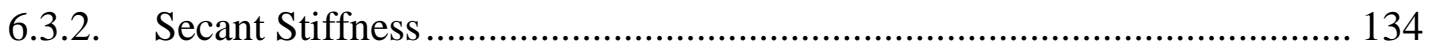

6.3.3. Secant Stiffness Components and Elastic/Shear Moduli .......................... 135

6.3.3.1. Flexural Stiffness …………............................................................ 135 
6.3.3.1.1. Flexural Modulus, Uncracked Moment of Inertia 136

6.3.3.1.2. Flexural Modulus, Cracked Moment of Inertia

6.3.3.2. Shear Stiffness........................................................................... 138

6.3.3.2.1. Comparison to Diagonal Panel Tests........................................ 139

6.4. Porous Grout Sample Method ................................................................ 139

7. CONCLUSIONS AND FUTURE RESEARCH …...................................... 141

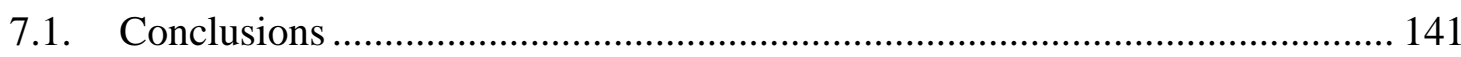

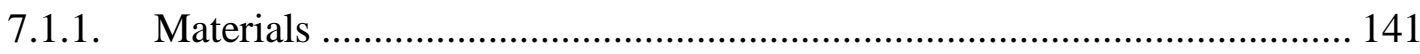

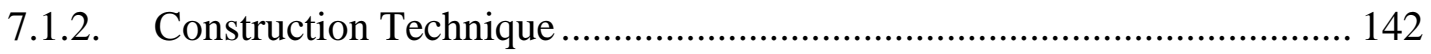

7.1.3. Experimental In-Plane Shear Testing ........................................... 142

7.2. Recommendations for Future Work ......................................................... 144

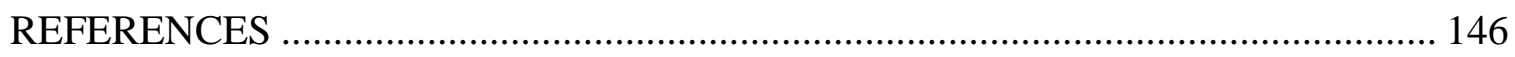

\section{APPENDICES}

APPENDIX A. DIGITAL IMAGE ANALYSIS ................................................ 151

APPENDIX B. SAND AND SOIL PROPERTIES …......................................... 153

B.1. Sand Testing Data Sheet (supplied by Hanson Aggregates) .......................... 153

B.2. Las Tablas Soil Testing (from Banker-Hix, 2014)...................................... 154

APPENDIX C. MATERIAL BATCH SHEETS ................................................. 158

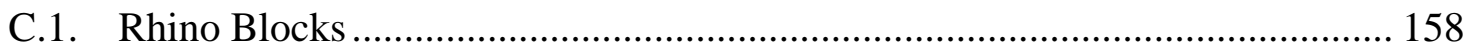

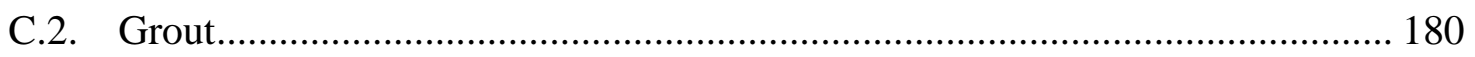

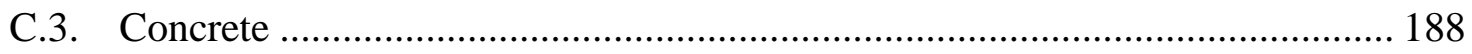


APPENDIX D. MATERIAL PROPERTY TEST RESULTS ................................. 190

D.1. Compressed Earth Blocks........................................................................ 190

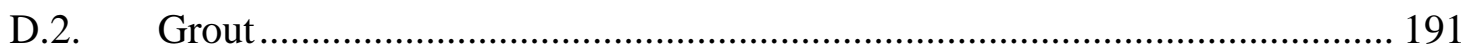

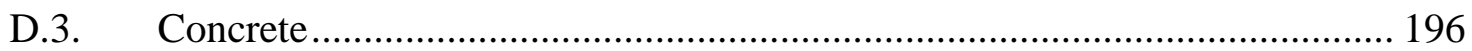

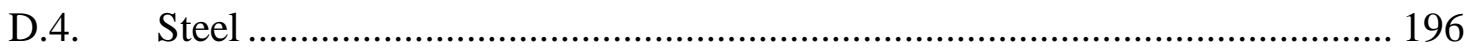




\section{LIST OF TABLES}

Table

Table 3.1: Las Tablas Soil Properties (from Banker-Hix, 2014) .................................. 24

Table 3.2: Las Tablas Grain Size (from Banker-Hix, 2014)......................................... 24

Table 3.3: Compressed Earth Block Compressive Strength ....................................... 44

Table 3.4: Non-Porous Cube Compressive Strength ............................................... 51

Table 3.5: Porous Cube Compressive Strength .......................................................... 51

Table 3.6: Porous Cylinder Compressive Strength................................................. 51

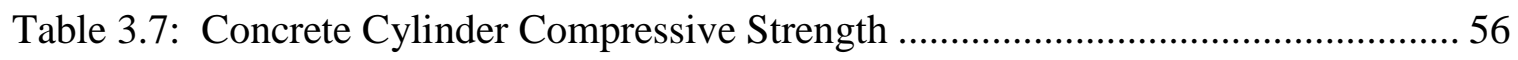

Table 3.8: Reinforcing Steel Material Properties ....................................................... 56

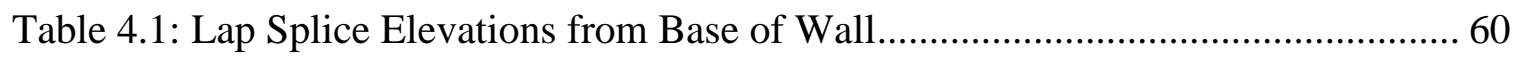

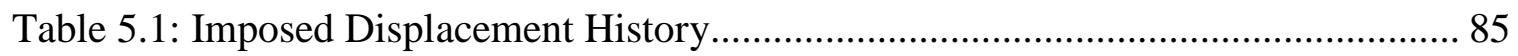

Table 5.2: Tested Wall Dimensions and Primary Experimental Factors ........................ 86

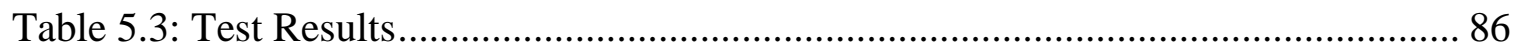

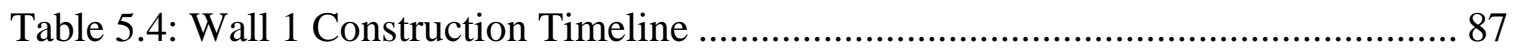

Table 5.5: Wall 2 Construction Timeline .................................................................. 92

Table 5.6: Wall 3 Construction Timeline .................................................................... 97

Table 6.1: Predicted and Experimental In-Plane Capacities, Based on Full Area.......... 124

Table 6.2: Predicted and Experimental In-Plane Capacities, Based on Grouted Area ... 125

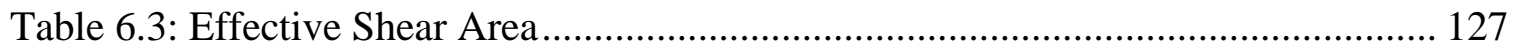

Table 6.4: Block Participation Factors..................................................................... 129

Table 6.5: Comparison of Shear Key Removal to Bland (2011) Partial Grouting ......... 130

Table 6.6: Comparison of Full-Scale Walls to Diagonal Panel Shear Strengths............ 131 


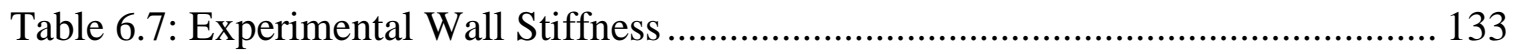

Table 6.8: Flexural Stiffness Components ............................................................. 135

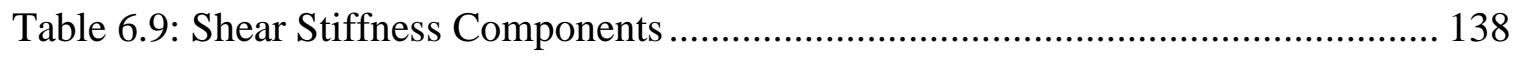

Table D.1: Individual Block Compressive Strength ............................................... 190

Table D.2: Compressed Earth Block Prism Compressive Strength.............................. 191

Table D.3: Non-Porous Cube Grout Compressive Strength ...................................... 192

Table D.4: Porous Grout "Cube" Compressive Strength ............................................ 193

Table D.5: Porous Grout Cylinder Compressive Strength......................................... 194

Table D.6: Concrete Compressive Strength.......................................................... 196

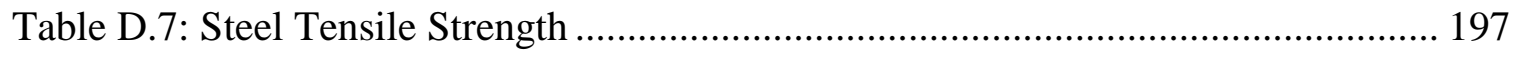




\section{LIST OF FIGURES}

Figure $\quad$ Page

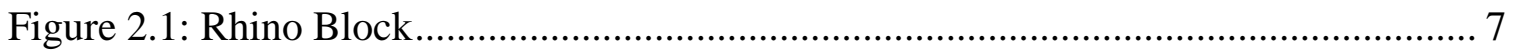

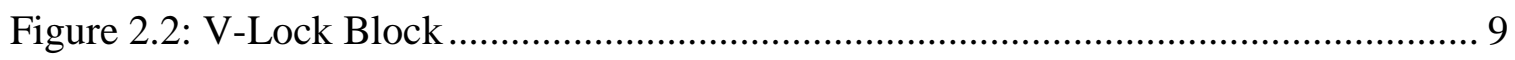

Figure 2.3: Lightly Reinforced Masonry Shear Failure (from Voon, 2007) ................... 11

Figure 2.4: Hydraform Block (from Ngowi, 2006) .................................................. 14

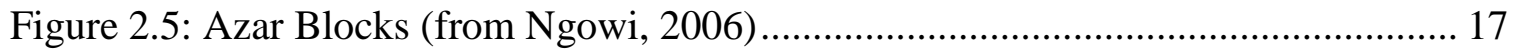

Figure 2.6: Properties, Stress, and Strain for Flexural Analysis (adapted from Bland,

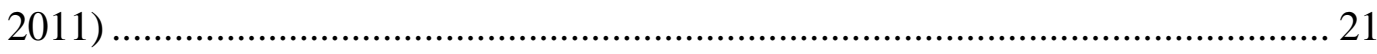

Figure 3.1: Las Tablas Site Map (adapted from Google, 2016) ................................... 23

Figure 3.2: Las Tablas Gradation (from Banker-Hix, 2014) ...................................... 25

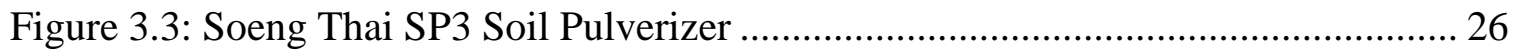

Figure 3.4: Drying and Pulverizing Soil (from Pringle, 2016) ................................... 26

Figure 3.5: Rhino Block, dimensions in cm (right from Wheeler, 2005) ........................ 28

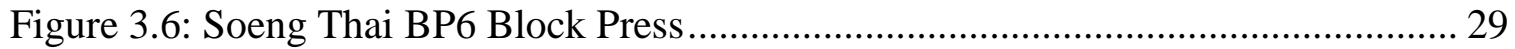

Figure 3.7: Rhino Block Variations and Typical Uses (from Wheeler, 2005) ................ 30

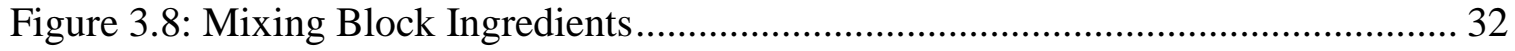

Figure 3.9: Flattened Pile with Added Water ...................................................... 32

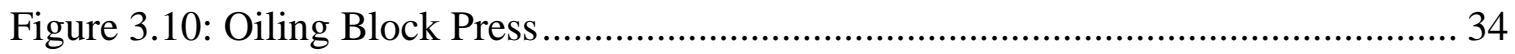

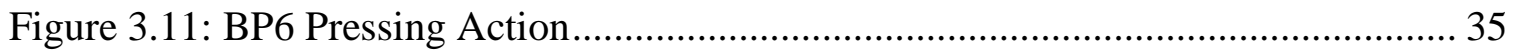

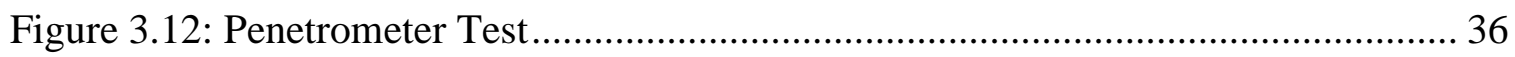

Figure 3.13: Channel Block Insert with Standard Pressing Plate .................................. 38

Figure 3.14: V-Lock Block, dimensions in cm (right adapted from Banker-Hix, 2014) . 39 
Figure 3.15: Concrete MD Mixer (from Banker-Hix, 2014) ......................................... 41

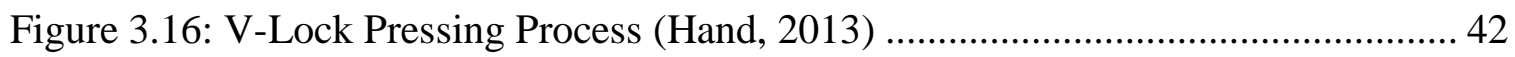

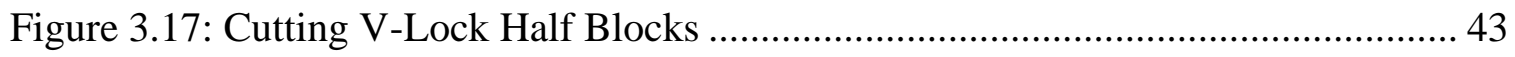

Figure 3.18: Single Rhino (left) and V-Lock (right) Block Tests................................. 44

Figure 3.19: Single-Block Conical Failure ........................................................... 45

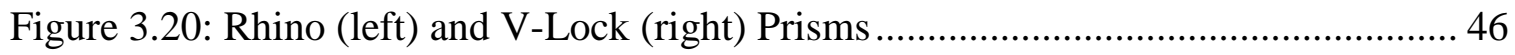

Figure 3.21: Rhino (left) and V-Lock (right) Prism Failures...................................... 48

Figure 3.22: Grout Slump Flow Test, Units in Inches ............................................ 49

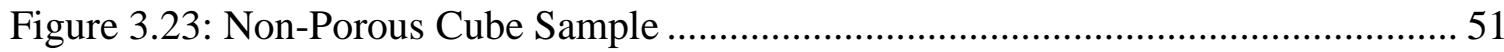

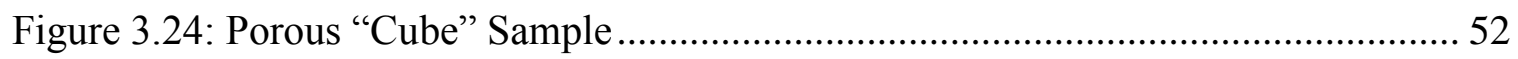

Figure 3.25: Casting a Porous Cube Sample ........................................................... 53

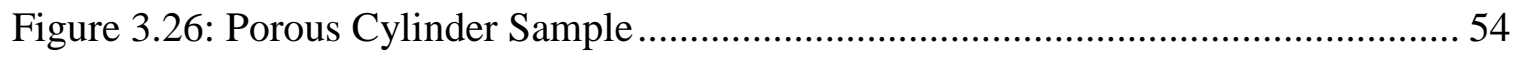

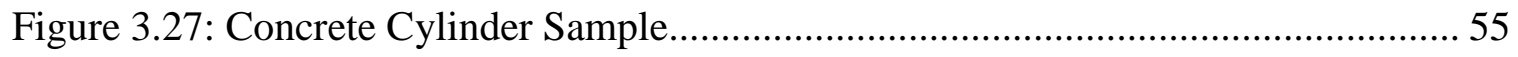

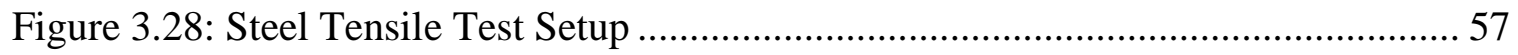

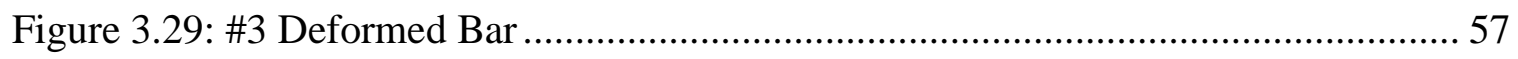

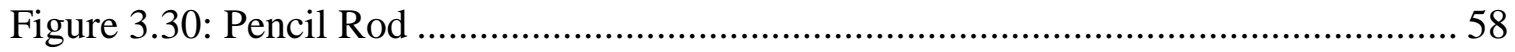

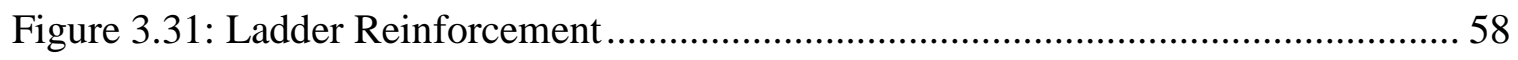

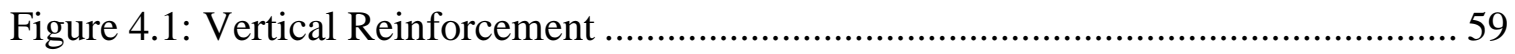

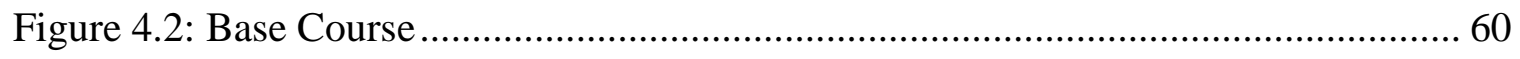

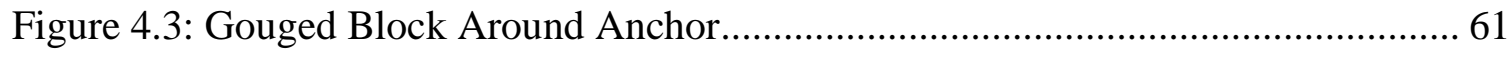

Figure 4.4: Inverted Channel Blocks as Base Course ............................................... 61

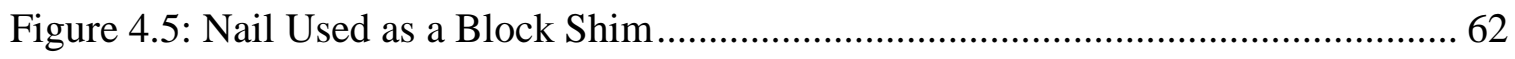

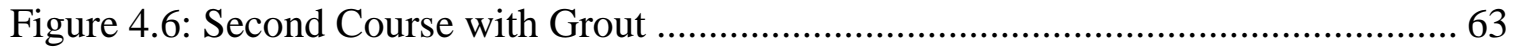




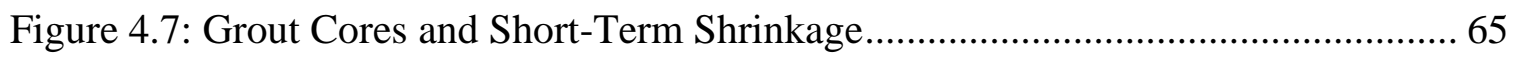

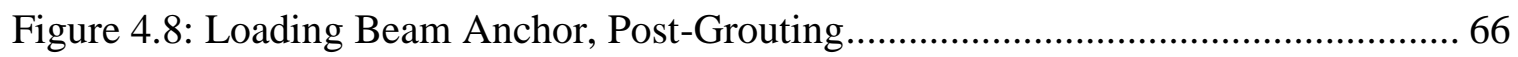

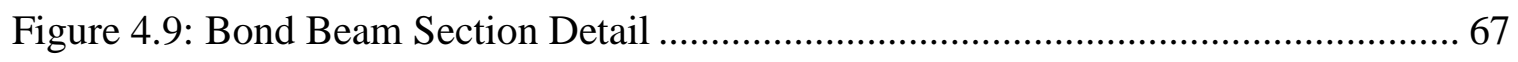

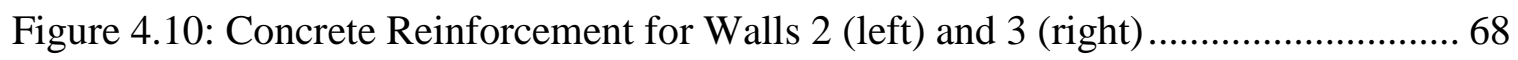

Figure 4.11: Freshy Poured Concrete Beam with Crosshatch Texture ........................... 69

Figure 4.12: Gypsum Cement Shear Keys ........................................................ 70

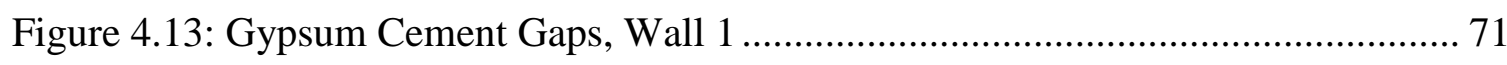

Figure 4.14: Gypsum Cement Remediation, During (left) and After (right) .................. 71

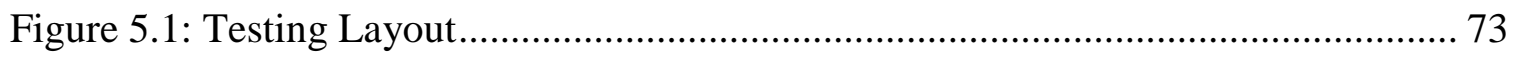

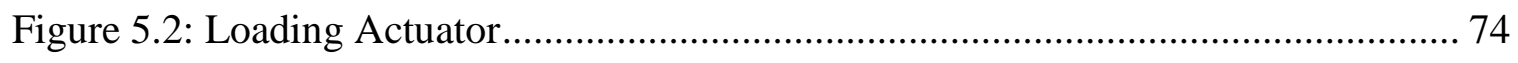

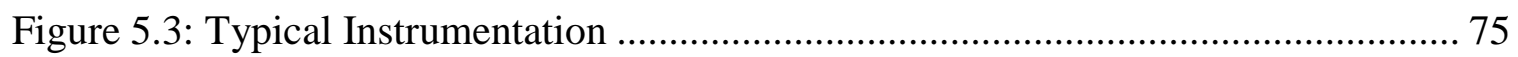

Figure 5.4: Displacement Instruments and Attachments to Loading Beam ................... 76

Figure 5.5: Panel Deformation Instruments on Wall 3 ........................................... 76

Figure 5.6: Panel Deformation Instrument Schematic (adapted from Voon, 2007) ........ 77

Figure 5.7: Deformation String Potentiometer with Rocking Linear Potentiometer....... 78

Figure 5.8: Rocking Instrument Schematic (adapted from Voon, 2007)....................... 79

Figure 5.9: Foundation/Floor Slip Instrument .................................................. 80

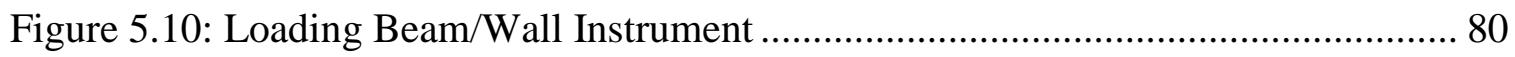

Figure 5.11: Non-Contact Optical Sensors …................................................... 81

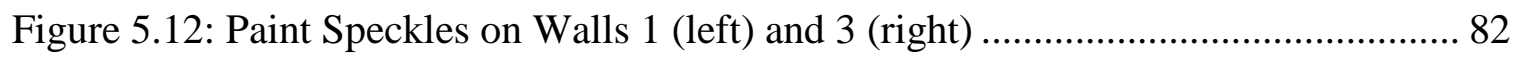

Figure 5.13: Image Analysis Points Used for Panel Deformation (Units in Pixels)........ 83

Figure 5.14: Partial Imposed Displacement History (adapted from Voon, 2007) ........... 85

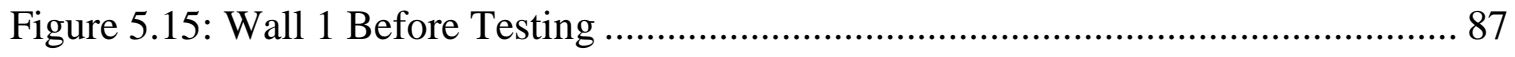


Figure 5.16: Channel Block Damage and Concrete Fill ............................................ 88

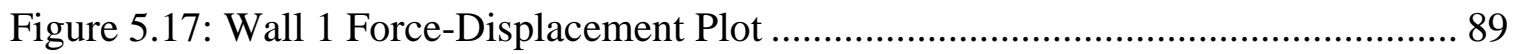

Figure 5.18: Diagonal Cracking Through Instrument Anchor.................................... 90

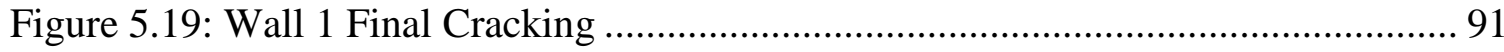

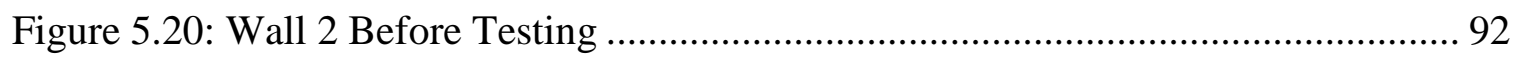

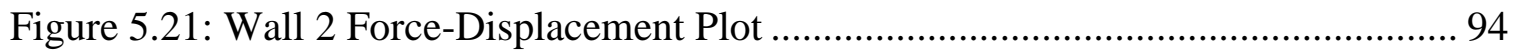

Figure 5.22: Wall 2 Cracking Through Grout Cores ................................................ 95

Figure 5.23: Wall 2 Split Upper Lap Splice .......................................................... 96

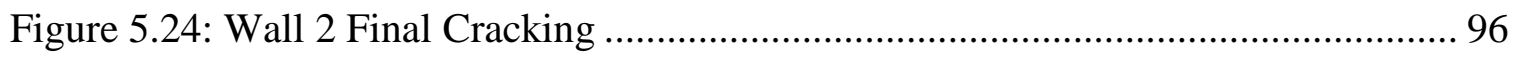

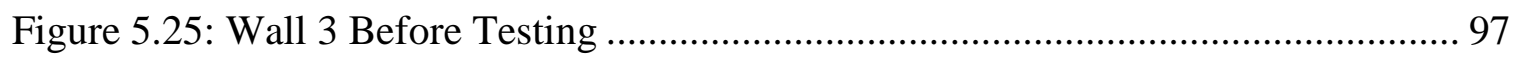

Figure 5.26: Wall 3 Continouous Voids Between Courses .......................................... 99

Figure 5.27: Cement Bag Scraps Used as Filler .................................................... 99

Figure 5.28: Wall 3 Force-Displacement Plot .................................................... 100

Figure 5.29: Wall 3 Block Cracking Around Core …............................................ 101

Figure 5.30: Wall 3 Lap Splice Splitting and Reinforcement Deformation .................. 102

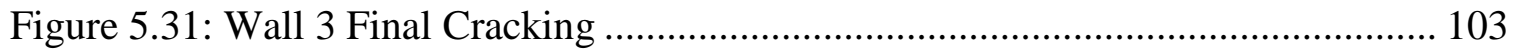

Figure 6.1: Backbone Curves for All Tested Walls .................................................. 104

Figure 6.2: Wall 1 Components with Respect to Measured Displacement ................... 107

Figure 6.3: Wall 2 Components with Respect to Sum........................................... 107

Figure 6.4: Wall 3 Components with Respect to Measured Displacement ................... 108

Figure 6.5: Selected Images for Wall 1 Displacement Analysis ............................... 109

Figure 6.6: Wall $1 u$ (left) and $v$ (right) Displacement Contours 16, 116, and $171 \ldots \ldots . .110$

Figure 6.7: Wall $1 u$ (left) and $v$ (right) Displacement Contours 264, 451, and 454 „.... 111 
Figure 6.8: Selected Images for Wall 2 Displacement Analysis 113

Figure 6.9: Wall $2 u$ (left) and $v$ (right) Displacement Contours 23, 463, and 725 ....... 114

Figure 6.10: Wall $2 u$ (left) and $v$ (right) Displacement Contours 1018 and $1023 \ldots \ldots . . .115$

Figure 6.11: Selected Images for Wall 3 Displacement Analysis ............................... 116

Figure 6.12: Wall $3 u$ (left) and $v$ (right) Displacement Contours 9, 196, and $294 \ldots \ldots . .117$

Figure 6.13: Wall $3 u$ (left) and $v$ (right) Displacement Contours 298, 428, and 431 ... 118

Figure 6.14: Image $9 v$ Contours Superimposed Over Original Image ....................... 119

Figure 6.15: Porous Grout Sample Strength Correlation for Wall 3 Samples................ 140

Figure A.1: Example Sub-Image Displacement (adapted from Lee, 2010) .................. 151

Figure A.2: Wall 3, Image $431 u$ (left) and $v$ (right) Displacement Contours ............... 152 


\section{INTRODUCTION}

\subsection{Background}

Compressed earth blocks are a relatively new construction technology with the potential to offer cheap, sustainable construction to regions of the world where highquality construction otherwise carries a premium cost. These blocks are typically pressed from soil mixed with relatively low amounts of cement, using readily available materials and labor to create sturdy units for construction. Many compressed earth block systems also allow construction without mortar, which further reduces the required materials while allowing rapid construction that does not require skilled labor. As they continue to be adopted worldwide, safe and effective use of these blocks requires detailed knowledge of their structural behavior.

Masonry and earth construction both date back as prehistoric construction techniques. Earth is one of the most ancient construction materials, first used in prehistoric times as a means of waterproofing simple wood shelters. Stone masonry is equally ancient, rooted in man-made caves created from piled stone. Earth, usually in the form of mud, continued to be used historically to supplement stone and wood in structures, with structures constructed entirely of mud when neither of these two primary materials was readily available. Earthen bricks came into use as a means of accelerating construction, improving over the extended drying time of a typical shaped mud wall. Archaeological evidence exists dating back 10,000 years of mud brick buildings in North Africa and the Middle East that reached up to ten stories in height. (Niroumand, Zain, Jamil, \& Niroumand, 2013; Masonry, 2016) 
Most modern masonry is mortared and uses either concrete masonry units or fired clay bricks. Steel-reinforced masonry walls can also form a structure's main seismic force resisting system. Recently, efforts to reduce the time and effort required for masonry construction have turned towards mortarless masonry systems, also referred to as "dry-stack masonry." Dry-stacking masonry is not new in and of itself; the Egyptian pyramids are a prime example of ancient dry-stack stone masonry. Modern dry-stack construction typically relies on some form of physical interlock between courses in place of the mortar beds of conventional masonry. This dramatically reduces the skill required in construction while successfully reducing construction time; one study concluded that dry-stack masonry experienced $80 \%-120 \%$ improvement in productivity over conventional masonry (Anand \& Ramamurthy, 2003).

Compressed earth blocks are a relatively recent application of soil as material in masonry construction. In contrast to earthen blocks created by drying or firing mud, compressed earth blocks are pressed into the desired shape, typically with either a manual or a hydraulic press. Portland cement or other cementitious materials are often mixed with the soil to increase the blocks' strength and stabilize the material. Not only is the cement content typically less than that of concrete, but interlocking block shapes also allow for dry-stack construction in lieu of cement-based mortar. This combined with the use of locally-sourced soil lowers construction costs while also decreasing the carbon footprint of the finished structure.

While the study of compressed earth blocks is often geared towards factors affecting unit compressive strength, relatively little research has examined their composite structural behavior, particularly how compressed earth block walls respond to 
seismic loads. Previous research (Bland, 2011) has indicated that directly applying existing code-based masonry design equations dramatically over-predicts the in-plane shear capacity of interlocking compressed earth block walls. The research in this thesis continues prior work examining the in-plane lateral capacity of full-scale walls (Bland, 2011; Stirling, 2011) as well as research on factors specifically affecting shear capacity (Pringle, 2016).

\subsection{Objectives}

This research sought to further examine the behavior of full-scale compressed earth block walls under in-plane cyclic loading. In particular, it focused on the effects of two main factors: block type, and the presence of grouted shear keys at the head joints. Numerous block designs exist, with a multitude of variations in factors like interlocking mechanism and size of the grout chambers. This study directly compared walls consisting of two block types: the Rhino block used by the Center for Vocational Building Technology (CVBT) and the V-Lock block designed by the Vermeer Corporation. A separate comparison studied the effect of grouted shear keys at the head joints, a feature present in some blocks like the Rhino block but absent in others like the V-Lock block. To study this, a third wall was also tested that consisted of Rhino blocks with the shear keys removed. A related goal was to ascertain whether the effect of either factor goes beyond simply increasing or decreasing the grouted area, previously concluded to be a key factor in shear capacity (Bland, 2011). Lastly, efforts were made to compare the test results to code-based predictions of shear capacity and propose modifications to allow for interlocking compressed earth block design. 


\subsection{Contents and Layout}

This thesis covers the relevant background, methods, results, analysis, and conclusions of these experiments. It is divided into the following seven chapters:

- Chapter 1 introduces the topic of compressed earth blocks and describes the primary research objectives.

- Chapter 2 reviews prior research covering the behavior of compressed earth blocks, dry-stack masonry, and conventional masonry, with an emphasis on studies of lateral capacity.

- Chapter 3 covers the materials used in this research, including both raw constituent materials (e.g. sand, soil, cement) and composite materials (e.g. compressed earth blocks, grout). This section also describes the production processes for composite materials along with test procedures used to determine material properties.

- Chapter 4 describes the typical construction procedure for each full-scale wall.

- Chapter 5 presents the testing procedure for each wall, including loading protocol and instrumentation. It also summarizes each wall's construction history and characteristics along with observations and irregularities for each test.

- Chapter 6 examines and analyzes the test results, examining each wall's behavior in depth and comparing the relative effects of the tested factors. This section also compares the experimental test results to code-based predictions.

- Chapter 7 summarizes the experimental conclusions and provides recommendations for future research. 


\section{LITERATURE REVIEW}

This chapter reviews and provides background on prior research on compressed earth blocks and conventional masonry structural behavior. Studies of lateral structural capacity are emphasized, but research on material properties and other structural behavior is also covered. Also included is an introduction to the in-plane loading provisions of the Masonry Standards Joint Committee (MSJC) 2013 code.

\subsection{Material Properties of Compressed Earth Blocks}

Many conventional masonry design equations feature block compressive strength as a design variable. Therefore, much research has been devoted to the methods used to evaluate the compressive strength of compressed earth blocks. Morel, Pkla, and Walker (2007) examined existing literature to evaluate testing strategies for solid, noninterlocking compressed earth blocks. Results from directly compressing a block until failure often were influenced by the fact that the platens compressing the block also confined the material at the contact surface, artificially increasing the recorded compressive strength. The precise effects depended on the geometry of the testing sample. Testing a specimen with height-to-width aspect ratio of five appeared to result in an effectively unconfined failure, but the size involved introduced effects from nonhomogeneous block composition. Correction factors based on aspect ratio may compensate for the confinement effects.

Another test examined was the RILEM test, which cuts a block in half, stacks and mortars the halves, and tests the resulting specimen in compression with the goal of duplicating results of cylinder tests. RILEM test results did not correlate well to individual block results, possibly because of effects of the mortar joint. An indirect test 
for compression is the three-point bending test, which is intended as a field test for tensile strength via bending but may actually fail from arching effects, which correlate to compression strength. Preliminary correlations have been made between this test and RILEM test results.

Compressive strength itself relates to several factors. Block strength closely relates to dry density, and higher cement content increases compressive strength. Strength also decreases with increased moisture content: Unstabilized blocks have zero strength when saturated, while saturated cement-stabilized blocks have half of their unsaturated strength.

Bales, Donahue, Fischer, Mellbom, and Pearson (2009) evaluated characteristics of interlocking compressed earth blocks, specifically the Rhino block design depicted in Figure 2.1 used by the Center for Vocational Building Technology (CVBT). The cement-stabilized blocks gained compressive strength in a trend similar to concrete over the first 28 days after pressing. Compressive tests were performed both on individual blocks and three-block-high prisms; the latter was performed both with and without grout in the blocks' grout key channels. The ratio of prism strength to block strength was 0.43 for grouted prisms and 0.37 for one ungrouted prism, less than typical values for interlocking dry-stack masonry. 


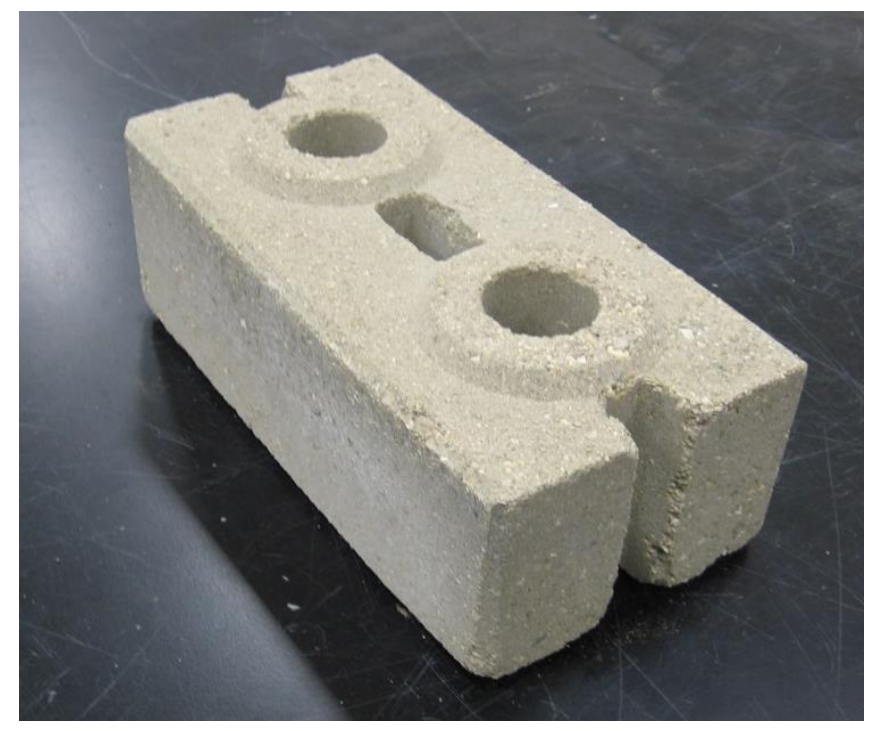

Figure 2.1: Rhino Block

Lateral shear tests were performed by loading the center block of a grouted, reinforced three-block prism in line with the block's longitudinal axis. In most cases, the interlocking mechanism did not fail, raising the question if the interlocking mechanism did anything to improve shear resistance. Specimens with steel reinforcement resisted $46 \%$ more load than those with bamboo reinforcement; the bamboo apparently expanded and contracted during curing, cracking the surrounding grout. The weakest samples were those with no reinforcement or grouting except in the head joint shear keys. Shear tests for non-interlocking, mortared compressed earth bricks did not perform well as the grouted interlocking blocks. The mortar did not bond well to the bricks, possibly because the blocks were not as porous as typical concrete blocks. Pullout tests of steel rebar grouted into the interlocking blocks resulted in a pullout of the grout column from the blocks along with a tensile failure of the grout column at the specimen base. Two bamboo rebar specimens de-bonded from the grout, while a third with a smaller crosssection failed in tension. 
As a case study for application in Malawi, Sturm, Ramos, and Lourenço (2015) evaluated an interlocking compressed earth block similar to the Rhino block but without the head joint grout keys. Compressive tests of compressed soil cylinders and individual blocks again demonstrated a rise in strength as the cement hydrated. An indirect tension test following standard EN 13286-42 indicated a ductile tension failure, but this was concluded to be an artifact of the test procedure. Compressive tests performed on multiblock prisms and $0.84 \mathrm{~m} \times 0.84 \mathrm{~m}$ wallettes demonstrated that the measured compressive strength in the wallettes was $48 \%, 23 \%$, and $61 \%$ of the measured compressive strength of the cylinders, blocks, and prisms, respectively. Three-point bending tests indicated that tensile strength was $5 \%$ and $9 \%$ of the compressive strength of the cylinders and blocks, respectively, although the method's validity as a test for tensile strength is disputed.

Dry interface friction between blocks was tested in a modified form of test standard EN 1052-3 by stacking three-block prisms, applying an axial confining load, and loading the middle block horizontally. Unlike Bales (2009), the interlocking indentations consistently broke on all test samples, indicating that the interlocking mechanism does play a significant role in frictional resistance. This was further verified by a linear regression of interface friction with respect to confining load, which indicated a non-zero friction when no axial load was applied. Dilatancy, the uplift of the masonry units during a shear failure, went from a positive value at low confining stresses to a negative value at high confining stresses. This was concluded to reflect different failure modes: At low confining stresses, the blocks slid over the interlocking indentations. At high stresses, the indentations crushed, and the friction at the interface wore away the surface of the blocks. 
Banker-Hix (2014) tested the effects of factors like clay content, cement content, and added fibers on block strength and durability. The test samples consisted of Vermeer V-Lock blocks, shown in Figure 2.2. The tested soil came from three separate sites, although most samples used the same Las Tablas soil as this thesis. (See Chapter 3 for further details.) Adding polypropylene fibers did not significantly improve block compressive strength or modulus of rupture, although they did result in a more ductile failure. Lower clay content resulted in stronger blocks, while increasing cement content resulted in a linear increase of compressive strength and modulus of rupture. Durability also increased with cement content, but the precise amount depended on the clay properties.

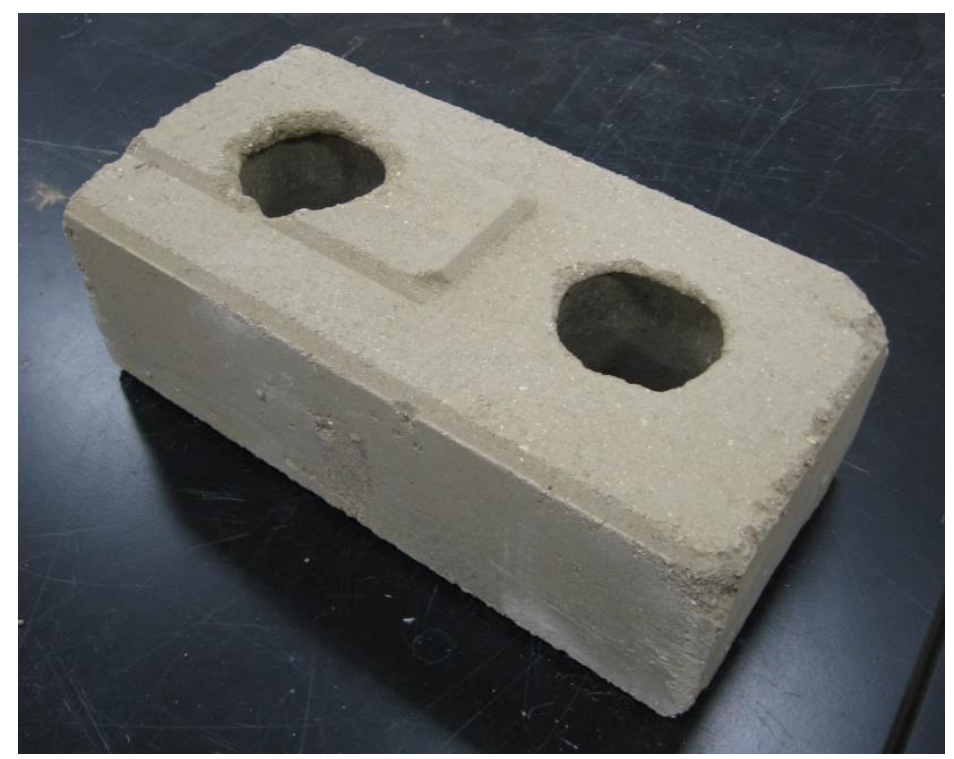

Figure 2.2: V-Lock Block

\subsection{Structural Behavior of Conventional Mortared Masonry}

Conventional mortared masonry is significantly better researched and understood than dry-stack construction. While dry-stack masonry of any form cannot directly substitute for conventional masonry, understanding the mechanics of conventional 
masonry provides a necessary starting point before investigating dry-stack construction. Shing, Noland, Klamerus, and Spaeh (1989) examined the seismic behavior of conventional reinforced masonry shear walls, analyzing data from 22 walls tested at the University of Colorado as part of the U.S.-Japan Coordinated Program for Masonry Building Research. Twenty-two $1.83 \mathrm{~m}$ x $1.83 \mathrm{~m}$ fully grouted walls were tested under cyclic in-plane loading. Sixteen were constructed with hollow concrete blocks, and six used hollow clay blocks. Testing demonstrated that flexural wall failures were significantly more ductile than brittle shear-dominated failures, and mixed shear-flexural failures tended to be ductile. Specimens incorporated differing quantities of vertical reinforcement, horizontal reinforcement, and applied axial load.

Flexural strength increased with increased axial load and vertical reinforcement. The mechanism of shear failure was more complicated than for a flexural failure: Cracking strength was mostly controlled by masonry tensile strength, but post-cracking strength involved effects from horizontal steel, aggregate interlock, uncracked compression zones, and vertical steel doweling. Cracking strength increased with higher axial loads but was not affected by the amount of horizontal steel. Effects on postcracking shear strength were inconsistent: Doubling the amount of horizontal reinforcement did not always significantly increase shear strength, although it did still improve hysteretic behavior. Increasing axial load could force a ductile mixed flexural/shear failure into a brittle shear failure, but increasing it further improved the ductility of the resulting shear failure.

Voon (2007) tested the in-plane cyclic performance of several masonry walls specifically intended to fail in shear to examine the effects of the quantity and distribution 
of horizontal reinforcement, the level of axial compression, the grouting pattern, and the height-to-length ratio. Increasing the horizontal shear reinforcement directly increased the maximum shear strength; lightly reinforced walls experienced an abrupt drop in load after cracking, while higher amounts of reinforcement were able to continue carrying load across the initial cracks. Walls with little reinforcement tended to fail with major Xshaped cracking as the original cracks continued to grow, as shown in Figure 2.3, while more significantly reinforced walls instead developed additional smaller cracks as loading increased. Similarly, using smaller, more tightly distributed bars also improved performance, resulting in a better stress distribution with many small cracks.

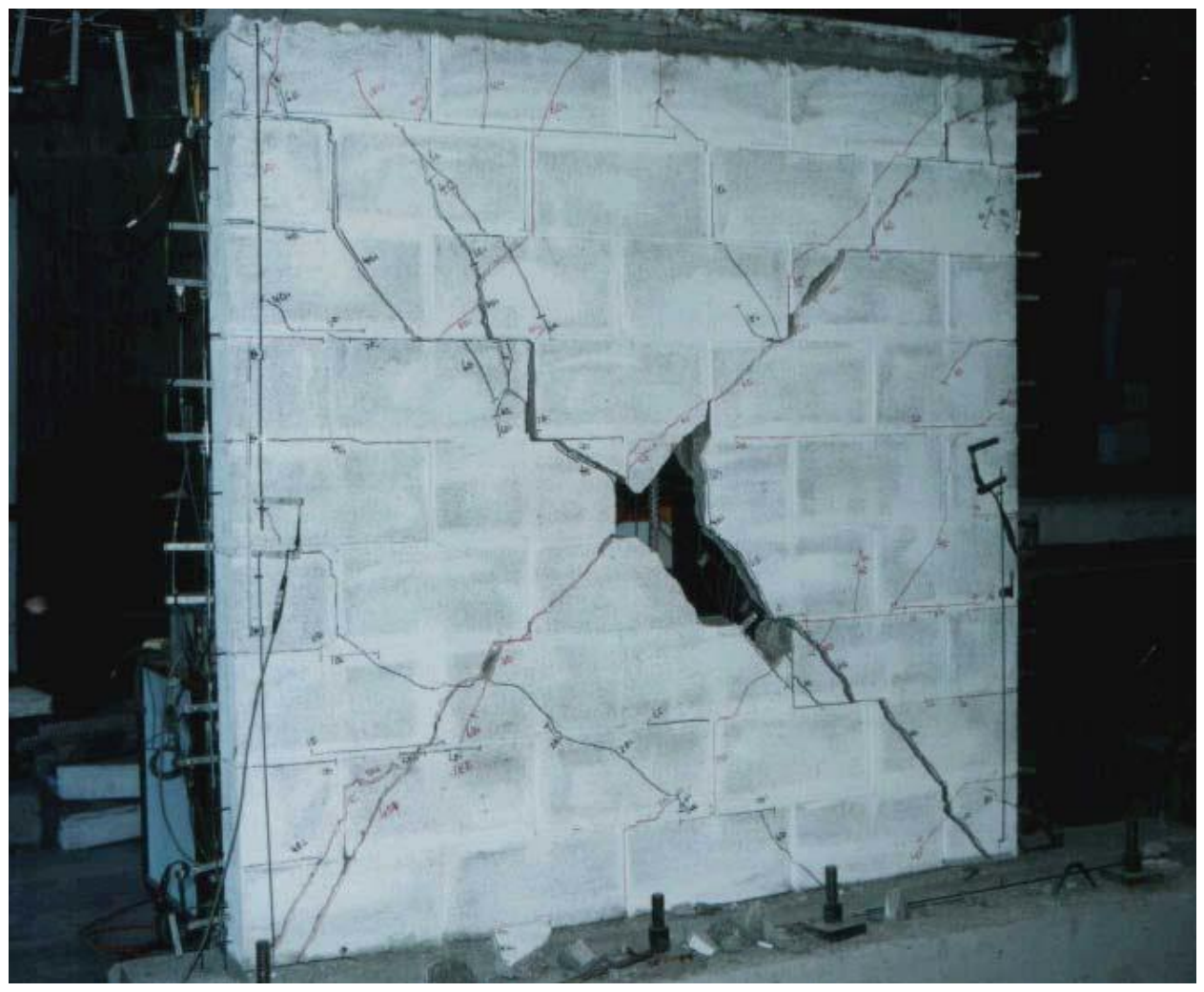

Figure 2.3: Lightly Reinforced Masonry Shear Failure (from Voon, 2007)

Increasing axial load delayed initial crack formation, but it also made the failure more brittle, contrary to the conclusions of Shing et al (1989). Partial grouting, the 
practice of grouting only the masonry cores that contain reinforcement, significantly reduced the strength of the walls, but the difference was less significant when comparing shear stress calculated with the net cross-sectional area rather than gross area. Reducing the height-to-width aspect ratio increased the masonry strength, increased the stiffness, and resulted in more abrupt strength degradation. A second series of tests examined the effects of window openings and detailing on shear strength, generating a correlation between opening depth and strength reduction.

Nolph and ElGawady (2012) compared the in-plane shear strength of full-size, partially grouted concrete masonry walls under cyclic loading to capacities predicted by the Masonry Standards Joint Committee (MSJC) design equations. Three walls tested effects of vertical reinforcement spacing, with approximately the same quantities of reinforcement spaced at either 1220,810 , or $610 \mathrm{~mm}$. The area of horizontal reinforcement remained constant for these specimens; two more walls featured additional horizontal reinforcement along with vertical reinforcement spaced at $1220 \mathrm{~mm}$. Larger spacing resulted in lower shear strength. The MSJC equations over-predicted shear strength for all specimens except for the wall with $610 \mathrm{~mm}$ vertical reinforcement. The walls with reinforcement spaced at 610 and $810 \mathrm{~mm}$ performed comparably to MSJC predictions with error less than $10 \%$, but all the walls with 1220 -mm reinforcement spacing failed to reach expected capacity with $19 \%$ error or greater. Adding horizontal reinforcement to the 1220 -mm walls only slightly increased shear strength, suggesting that there is a limit beyond which adding horizontal reinforcement has a limited effect. 


\subsection{Structural Behavior of Dry-Stack Masonry and Compressed Earth Blocks}

Relatively little work has been performed to evaluate the performance of compressed earth block walls, particularly under simulated seismic conditions. Jaafar, Alwathaf, Thanoon, Noorzaei, and Abdulkadir (2006) examined the behavior of the drystack interfaces in compression. Unlike the mortar of conventional masonry, dry-stack masonry blocks were said to be in contact with "virtual filler", properties like the roughness and texture at the interface. Two types of geometric imperfections were observed: Material roughness and variation in height of adjacent blocks. Compressive tests showed a nonlinear force-displacement interaction as the joints closed, effectively increasing the stiffness with higher loads. Tests of ungrouted prisms also showed higher deformation early in the testing process as the blocks seated; grouted prisms did not display this and also had more consistent test results. With grout, the joint closure was deemed a function of the bond between the blocks and the grout; the grouted samples experienced relatively little joint closure until the grout cores began to debond, resulting in large deformation at higher loads.

Research does not always distinguish between the structural behavior of dry-stack masonry (any masonry designed for use without mortared joints) and compressed earth blocks (specifically made from compressed soil). Ngowi (2006) explicitly tests performance of dry-stack masonry but implicitly deals with compressed earth blocks, in this case the Hydraform system which consists of solid blocks made from compressed soil, depicted in Figure 2.4. Compressive tests of full-scale walls resulted in brittle failure characterized by vertical splitting at the midpoint of the wall. The dry-stack 
compressive strength was about $60 \%$ of the strength of conventional masonry, attributed to the interlock system reducing the blocks' contact area.

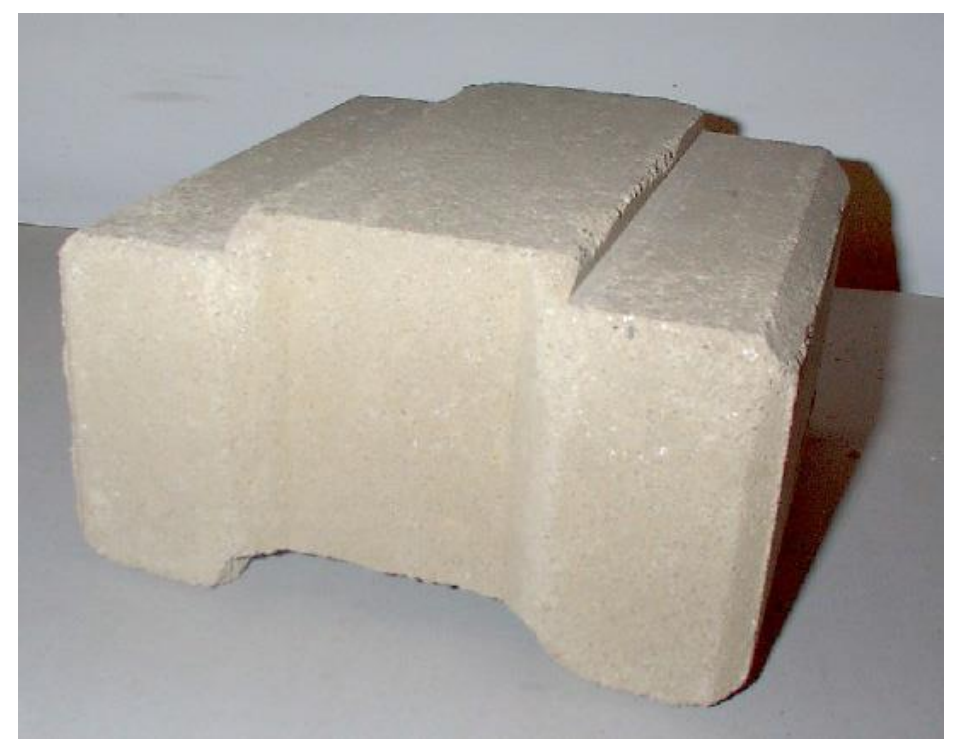

Figure 2.4: Hydraform Block (from Ngowi, 2006)

Walls as part of a one-room structure were also tested in monotonic, out-of-plane lateral loading. Failure was due to rotation of individual blocks, allowing the joints to open. Neither block strength nor depth of the interlocking mechanism significantly affected strength, possibly because of the low levels of axial load. Bonding every three courses with an acrylic adhesive did significantly improve strength, as did plastering one or both faces of the wall. Adding shallow channels at the bed joints allowed the addition of transverse reinforcement, effectively spanning between the intersecting walls; transversely reinforced walls with vertical grout columns at the wall intersections performed better than similar walls where the reinforcement was simply hooked into the intersecting walls. Shake table tests compared the performance of a single-story, oneroom, unreinforced dry-stack masonry house to a similar structure made of conventional masonry. The structures were subjected to sinusoidal loading of varying amplitudes (ranging from $0.5 \mathrm{~g}$ to $2 \mathrm{~g}$ ) and frequencies (ranging from $1 \mathrm{~Hz}$ to $10 \mathrm{~Hz}$ ). The dry-stack 
structure amplified the input accelerations less than the conventional masonry structure, attributable to its higher flexibility; it also closely followed the input motions of the shake table. The conventional masonry structure underwent rigid-body behavior related to rocking and uplift at higher accelerations. Out-of-plane failure was the most significant failure mode in the dry-stack structure due to "hinging" as the joints opened, resulting in partial wall collapse.

Elvin (2011) similarly performed shake table testing on a one-room, Hydraform dry-stack masonry structure with transverse reinforcement. This series of tests used a sequence of recorded ground motions from the El Centro, North Ridge, and Llolleo earthquakes, followed by sinusoidal motion of $5 \mathrm{~Hz}$ (corresponding to the original, undamaged structure's natural frequency) and $3 \mathrm{~Hz}$ (the damaged structure's approximate natural frequency). The sequence of recorded ground motions resulted in progressively greater damage, culminating in spalling of plaster, vertical cracking around the window and door openings, and open gaps in the walls. The sinusoidal $5 \mathrm{~Hz}$ motion cracked the plaster and opened gaps, while the $3 \mathrm{~Hz}$ sinusoidal motion caused visible out-of-plane wall deflections and extensive damage to the structure and individual blocks. It was judged that energy absorbed by shifting, cracking, and crushing of blocks allowed the structure to remain standing. Frictional sliding of the blocks also acted as an energy dissipation mechanism that does not exist in conventional masonry.

Herskedal (2012) examined out-of-plane flexural strength of interlocking compressed earth block walls composed of the CVBT Rhino block design. Three $1.1 \mathrm{~m}$ tall x $0.45 \mathrm{~m}$ wide cantilever walls examined the effects of exterior plaster and of lap splices in the vertical reinforcement. The control wall exceeded the flexural strength 
predicted by standard MSJC (2011) by $25 \%$. The lap splice did not significantly alter behavior, although it did double the wall stiffness. The plaster in the third wall altered the hysteretic cycle behavior by inhibiting rotation of the wall joints. Actual wall strength exceeded predictions by $15 \%$. Two $2.4 \mathrm{~m}$ high walls tested the effects of pilasters. The walls were pinned at the top and bottom, and out-of-plane loading was distributed over the face of the wall. The wall without a pilaster displayed a flexuredominated behavior, but it did not meet expected capacity because the base rotation exceeded that allowed by the connection. The wall with the pilaster also failed to meet expected capacity, failing in a combination of a shear failure and a lap splice failure, perhaps due to inadequate shear reinforcement in the pilaster in the vicinity of the lap splice. The pilaster did significantly increase out-of-plane stiffness of the wall.

\subsubsection{In-Plane Shear and Flexure}

In-plane lateral loading is of particular interest because masonry shear walls may compose the primary lateral force resisting system of a structure. Drysdale (2000) tested in-plane shear strength of full-scale walls constructed from Azar dry-stack concrete masonry, shown in Figure 2.5. The $2.4 \mathrm{~m}$ x $2.4 \mathrm{~m}$ walls contained vertical reinforcement welded to a steel base plate. One wall was loaded monotonically, while the other three underwent cyclic loading. All four walls failed with rupture of the reinforcing bars before any shear cracking developed, resulting only in a conservative lower bound on shear strength. The tests demonstrated levels of ductility consistent with conventional masonry. 

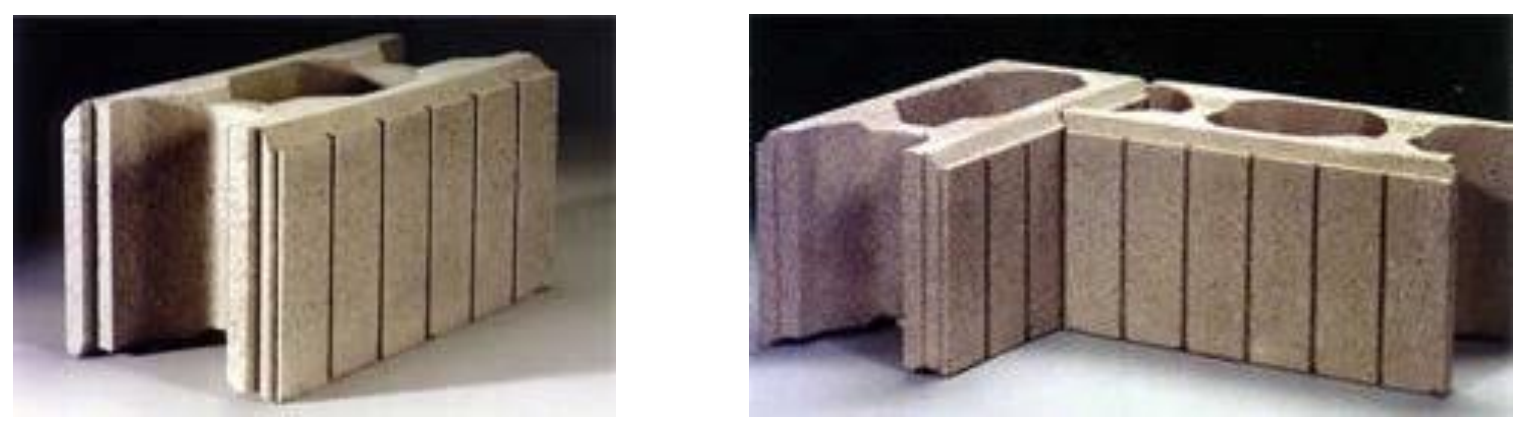

Figure 2.5: Azar Blocks (from Ngowi, 2006)

Bland (2011) tested the behavior of walls subjected to cyclic in-plane loading, specifically partially and fully grouted walls failing in shear and a fully grouted wall failing in flexure with additional transverse reinforcement. The walls were constructed using the Rhino block type used by the Center for Vocational Building Technology (CVBT). The shear strength of the partially-grouted wall was significantly lower than that predicted by standard MSJC (2008); the fully grouted wall's strength was significantly higher but still did not meet the code-predicted capacity. This suggested that MSJC (2008) could not be reliably used for shear capacity of interlocking compressed earth block walls, possibly because the shear transfer between block layers relies on friction and the interlocking mechanism rather than conventional mortar. It was suggested to adapt the MSJC shear equations to compressed earth block walls with a factor multiplied times the net cross-sectional area, 0.4 for fully grouted walls and 0.2 for partially grouted walls. The flexure-controlled wall experienced a more ductile failure than the shear-controlled walls; its capacity was predicted accurately and slightly conservatively by classical flexural theory and MSJC (2008).

Stirling (2011), a companion study to Bland (2011), examined the behavior of full-size walls failing in flexure under cyclic, in-plane loading. These walls also used the Rhino block design and examined the effects on flexural capacity of aspect ratio, 
presence of a flange, and presence of an opening. Increasing the height-to-width aspect ratio was found to increase ductility. A flange at one end of a wall increased wall strength when the flange was in tension but not when it was in compression; conversely, it moderately increased ductility when it was in compression but not when it was in tension. The window opening significantly reduced wall strength but did not affect ductility.

Pringle (2016) performed diagonal tension tests of small-scale interlocking compressed earth block wallettes to determine the effects of various factors on in-plane shear strength. The specimens tested the effects of block strength, grout strength, full/partial grouting, head joint shear key grouting, courses composed of channel blocks, and block type. Most samples used Rhino blocks, although one sample used Vermeer VLock blocks. Block strength was found to affect shear strength, although grout strength had a greater impact. Strength generally decreased with grouted area in a nonlinear manner. The head joint shear keys affected shear stiffness more than did the grouted cores. The sample with no grouted shear keys also experienced a second load peak later in the test after an initial peak and drop in load. Adding courses of channel blocks decreased strength in spite of the increased grout contact area provided by the blocks; it was not known whether this was because the channel blocks were potentially weaker or because of grout shrinkage. The V-Lock blocks, with larger grout cores, experienced an almost linear increase between grouted area and sample strength; they also had a more significant, brittle post-peak strength decrease. 


\subsection{MSJC Design Equations for In-Plane Loading}

The primary document adopted for conventional masonry design standards in the United States is developed by the Masonry Standards Joint Committee (MSJC) of The Masonry Society (TMS), the American Concrete Institute (ACI), and the Structural Engineering Institute of the American Society of Civil Engineers (SEI/ASCE). The document, Building Code Requirements for Masonry Structures, is cross-listed as TMS 402/ACI 530/ASCE 5 and is adopted as part of the International Building Code. It is accompanied by the document Specification for Masonry Structures (TMS 602/ACI 530.1/ASCE 6), defining requirements for materials and construction. The 2013 version used here shall hereafter be cited as MSJC (2013). Dry-stacked compressed earth blocks fail to meet many of the specification's requirements; compressed soil is not an approved material, mortar is explicitly required, and blocks often fail to meet the referenced ASTM C90 minimum compressive strength of $13.8 \mathrm{MPa}$. The provisions nevertheless may still provide useful starting points for predicting strength.

\subsubsection{Flexural Capacity}

Flexural capacity of reinforced masonry in MSJC (2013) using strength design methodology is based on the following assumptions, directly quoted from Section 9.3.2:

1. Strain compatibility exists between the reinforcement, grout, and masonry.

2. The nominal strength of reinforced masonry cross-sections for combined flexure and axial load is based on applicable conditions of equilibrium.

3. The maximum usable strain, $\varepsilon_{\max }$, at the extreme masonry compression fiber is 0.0035 for clay masonry and 0.0025 for concrete masonry. 
4. Strains in reinforcement and masonry are directly proportional to the distance from the neutral axis.

5. Compression and tension stress in reinforcement is $E_{s}$ multiplied by the steel strain, but not greater than $f_{y}$. Except as permitted in Section 9.3.3.5.1 (e) for determination of maximum area of flexural reinforcement, the compressive stress of steel reinforcement does not contribute to the axial and flexural resistance unless lateral restraining reinforcement is provided in compliance with the requirements of Section 5.3.1.4.

6. Masonry in tension does not contribute to axial and flexural strengths. Axial and flexural tension stresses are resisted entirely by steel reinforcement.

7. The relationship between masonry compressive stress and masonry strain is defined by the following:

Masonry stress of $0.80 f^{\prime} m$ is uniformly distributed over an equivalent compression stress block bounded by edges of the cross section and a straight line located parallel to the neutral axis and located at a distance $a=0.80 \mathrm{c}$ from the fiber of the maximum compressive strain. The distance $c$ from the fiber of maximum strain to the neutral axis shall be measured perpendicular to the neutral axis.

Figure 2.6 illustrates the application of these assumptions to a reinforced concrete masonry cross-section. Since compression rebar tends to buckle, its contribution is assumed to be negligible as specified in assumption 5 above. 


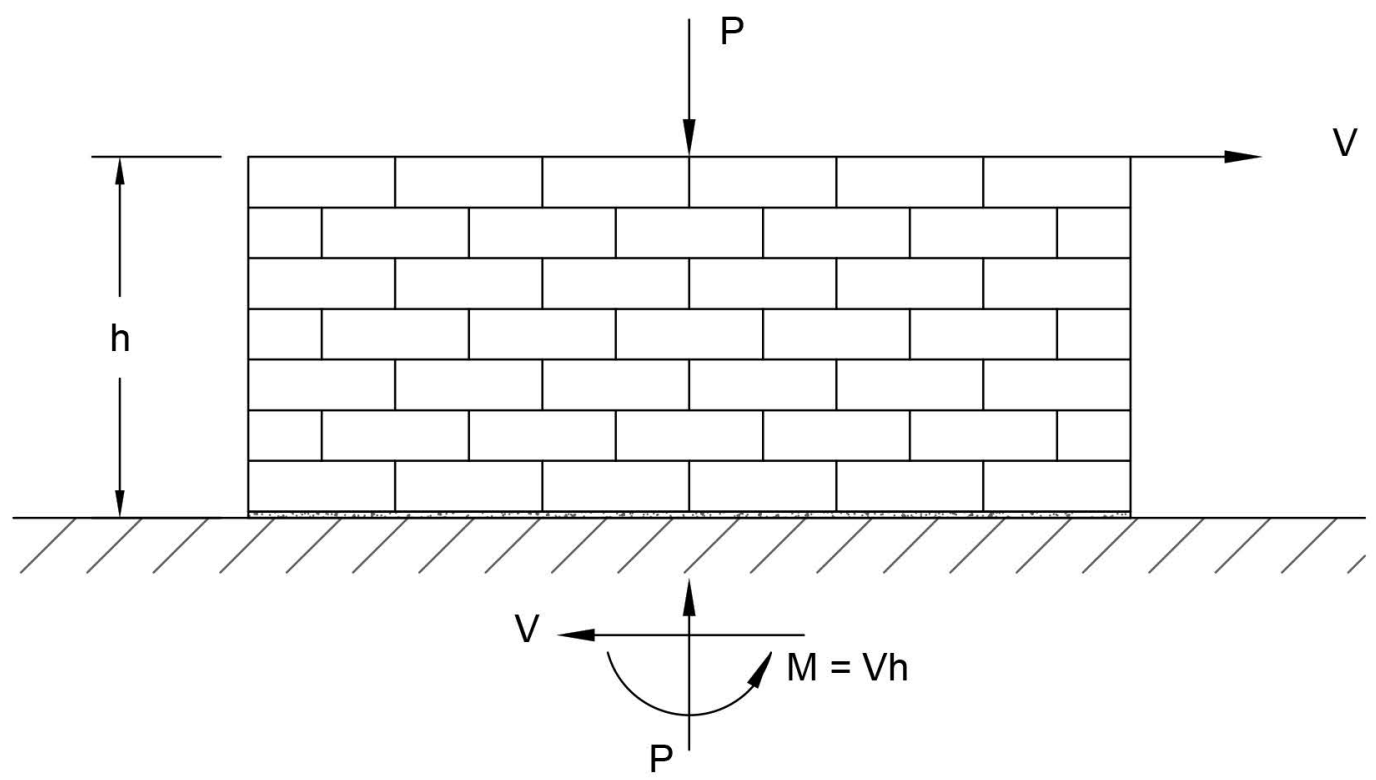

(a) Wall Free-Body Diagram

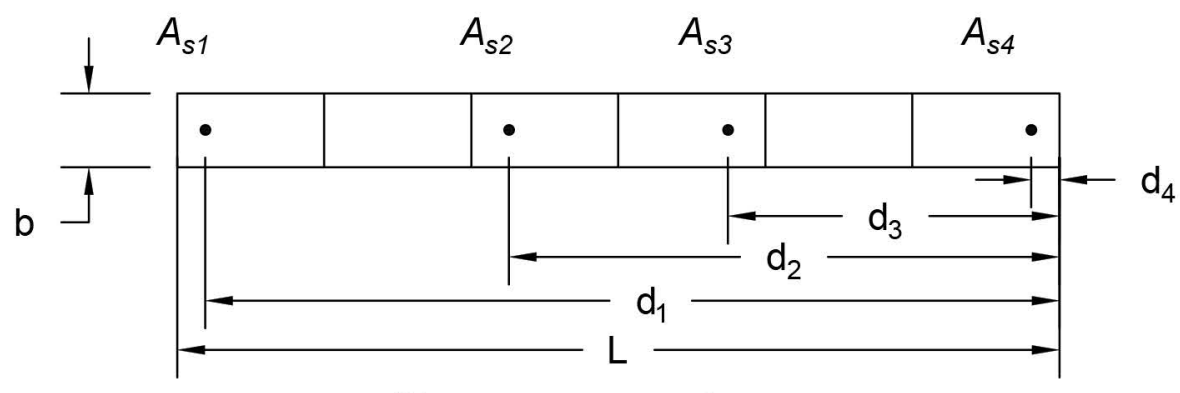

(b) Cross-Sectional Properties

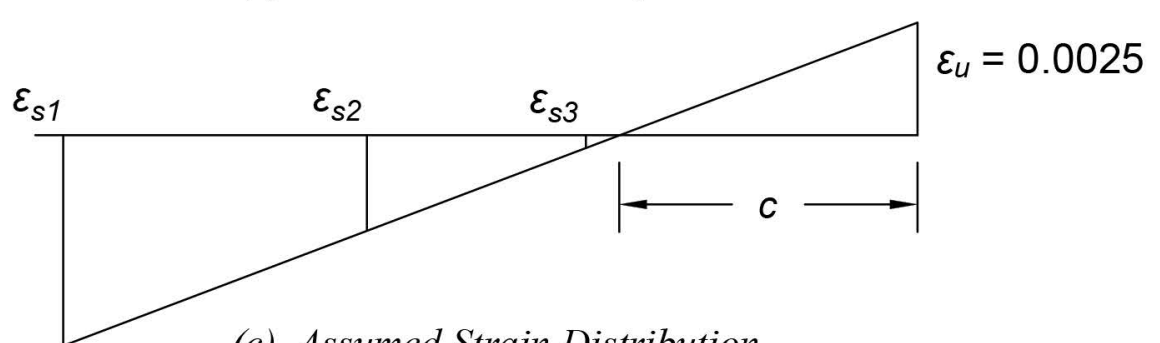

(c) Assumed Strain Distribution

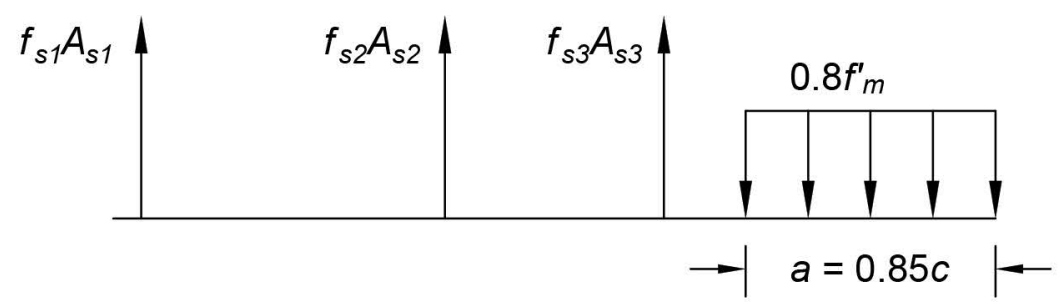

(d) Stress Distribution

Figure 2.6: Properties, Stress, and Strain for Flexural Analysis (adapted from Bland, 2011) 
Applying moment equilibrium about the centroid of the section results in:

$$
M_{n}=\sum_{i}^{n} f_{s i} A_{s i}\left(\frac{L}{2}-d_{i}\right)-0.8 f^{\prime}{ }_{m} a b\left(\frac{L}{2}-\frac{a}{2}\right)
$$

where $f_{s}$ is the reinforcement stress, $A_{s}$ is the area of reinforcement, and $f_{m}^{\prime}$ is the masonry compressive strength. All other parameters are illustrated in Figure 2.6. Since all the reinforcement may not have yielded,

$$
f_{s}=E_{s} \varepsilon_{s} \leq f_{y}
$$

$c$ may be found with the following equation, based on force equilibrium of the section:

$$
\begin{gathered}
\sum_{i}^{n} f_{s i} A_{s i}-0.8 f^{\prime}{ }_{m}(0.8 c) d+P_{u}=0 \\
\text { or } \quad c=\frac{\sum_{i}^{n} f_{s i} A_{s i}+P_{u}}{0.64 f^{\prime}{ }_{m} d}
\end{gathered}
$$

\subsubsection{Shear Capacity}

Unlike flexural capacity, shear capacity is predicted with empirical equations, from MSJC (2013) Section 9.3.4.1.2.1. Total shear strength is the sum of the contributions of the masonry and the steel, with units in pounds and inches:

$$
\begin{aligned}
& V_{n}=\left(V_{n m}+V_{n s}\right) \gamma_{g} \\
& V_{n m}=\left[4.0-1.75\left(\frac{M_{u}}{V_{u} d_{v}}\right)\right] A_{n v} \sqrt{f^{\prime}{ }_{m}}+0.25 P_{n} \\
& V_{n s}=0.5\left(\frac{A_{v}}{s}\right) f_{y} d_{v}
\end{aligned}
$$

where $A_{n v}$ is the net shear area, $d_{v}$ is depth in the direction of shear ( $L$ for the wall in Figure 2.6), $A_{v}$ is the cross-sectional area of shear reinforcement, $s$ is the spacing of shear reinforcement, and $\gamma_{\mathrm{g}}=1.0$ for fully grouted walls and 0.75 for partially grouted walls. 


\section{MATERIALS}

This chapter covers the materials used to construct each wall. Materials are divided into two main categories: Constituent materials (e.g. sand, soil, cement) and composite materials (e.g. compressed earth blocks, grout). Included are material properties, testing methods, and means of production where applicable.

\subsection{Constituent Materials}

This section provides information on the raw constituent materials that were in turn used to create the composite materials (grout, blocks, etc.) used in testing.

\subsubsection{Soil}

The soil used in the compressed earth blocks was collected from a construction site near Las Tablas Road in Templeton, California; Figure 3.1 illustrates the location. It was delivered to the Cal Poly campus in December 2013 and has since been stockpiled outside, loosely covered with a flexible plastic sheet. Banker-Hix (2014) and Pringle (2016) both previously used this soil, referred to as "Las Tablas soil."

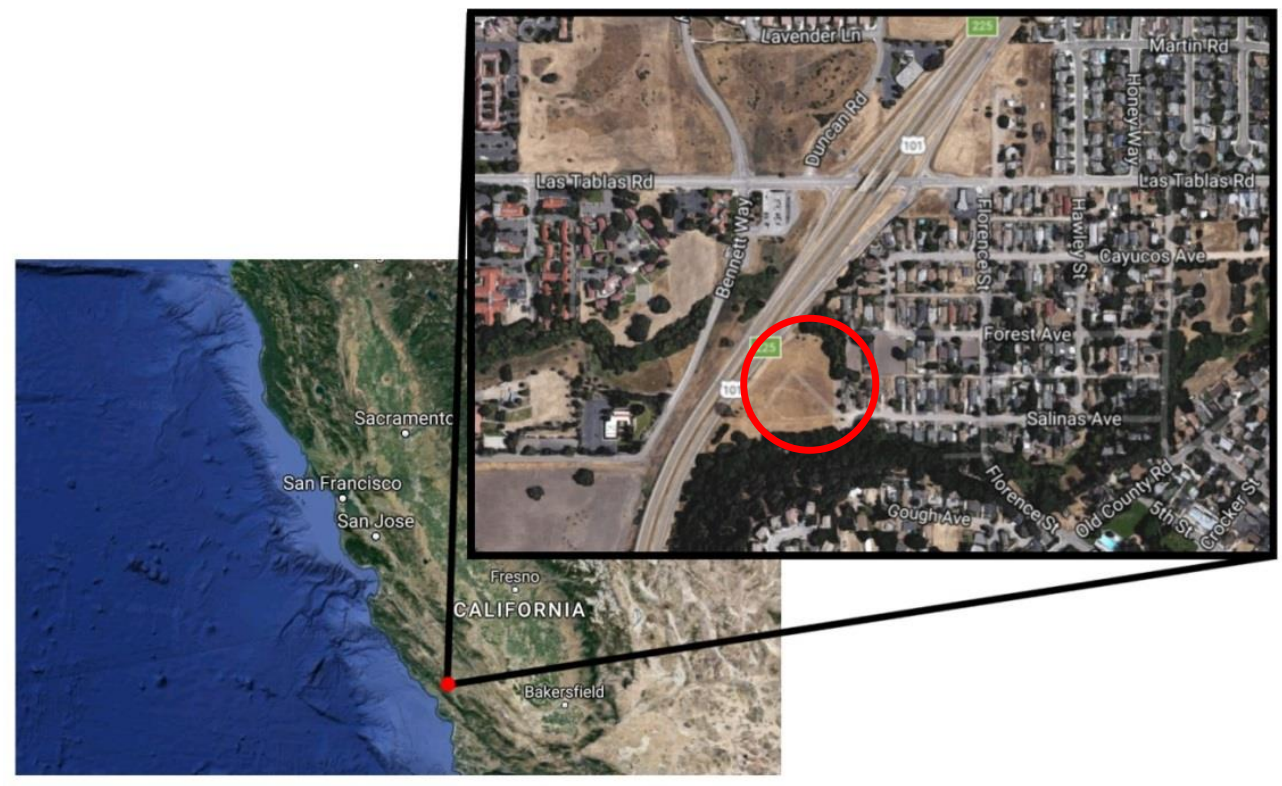

Figure 3.1: Las Tablas Site Map (adapted from Google, 2016) 


\subsubsection{Material Properties}

Banker-Hix (2014) performed the following laboratory tests on the soil:

- ASTM D2487 - Standard Practice for Classification of Soils for Engineering Purposes

- ASTM D4318 - Standard Test Methods for Liquid Limit, Plastic Limit, and Plasticity Index of Soils

- ASTM D4829 - Standard Test Method for Expansion Index of Soils

- ASTM D422 - Standard Test Method for Particle Size Analysis of Soils In addition, ASTM C128 - Standard Test Method for Density, Relative Density and Absorption of Fine Aggregate was performed on washed material retained on a \#20 sieve.

The test results classified the soil as a Yellowish Brown Lean Clay. No predominant clay mineral could be identified. Soil properties and gradation are displayed in Tables 3.1 and 3.2 as well as Figure 3.2. Appendix B contains more detailed testing data from Banker-Hix (2014).

Table 3.1: Las Tablas Soil Properties (from Banker-Hix, 2014)

\begin{tabular}{|c|c|c|c|c|c|}
\hline \multicolumn{3}{|c|}{ Atterburg Limits } & \multirow{2}{*}{$\begin{array}{c}\text { Expansion } \\
\text { Index } \\
\end{array}$} & \multirow{2}{*}{$\begin{array}{c}\text { Expansion } \\
\text { Potential } \\
\end{array}$} & \multirow{2}{*}{$\begin{array}{c}\text { Ave } \\
\text { Abs (\%) }\end{array}$} \\
\hline LL $(\%)$ & PL $(\%)$ & PI $(\%)$ & & & \\
\hline 44 & 12 & 32 & 32 & Low & 27 \\
\hline
\end{tabular}

Table 3.2: Las Tablas Grain Size (from Banker-Hix, 2014)

\begin{tabular}{|c|c|c|c|}
\hline Clay (\%) & Silt (\%) & Sand (\%) & Gravel (\%) \\
\hline 24.7 & 23.3 & 37.1 & 11.8 \\
\hline
\end{tabular}




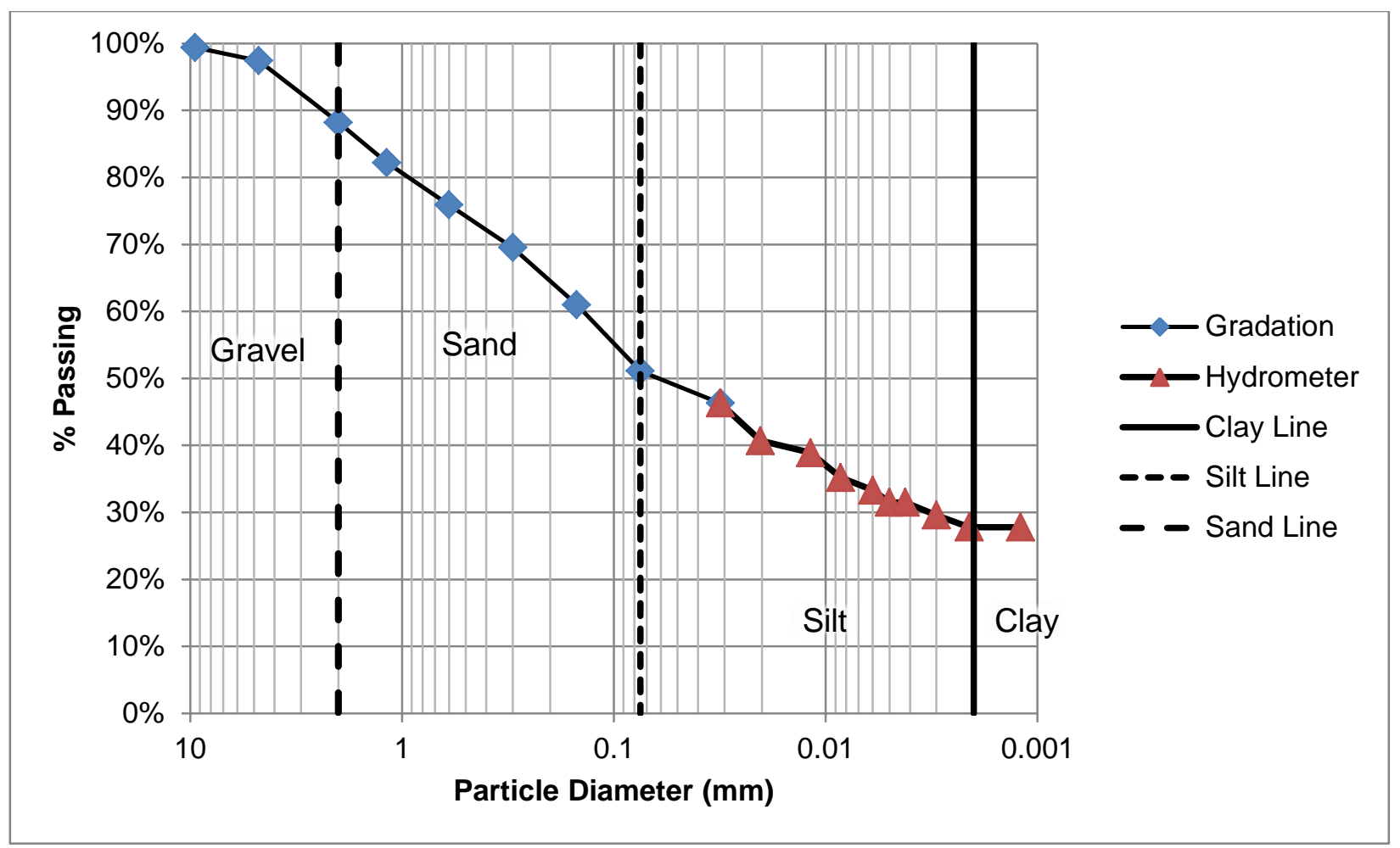

Figure 3.2: Las Tablas Gradation (from Banker-Hix, 2014)

The expansion index tests and absorption tests demonstrated that while the clay in the soil had low expansion potential, the sand and gravel were highly absorptive, drawing significant amounts of water from the clay and causing extensive clay shrinkage during the early Banker-Hix (2014) block pressings.

\subsubsection{Pulverization}

Raw Las Tablas soil contained significant particles larger than one centimeter which were unsuitable in compressed earth blocks. All used soil was therefore pulverized using a Soeng Thai SP3 Soil Pulverizer made by the Center for Vocational Building Technology (CVBT). The pulverizer, shown in Figure 3.3, uses a set of rotating steel blades to break down the soil to pass a \#4 sieve. The soil must be relatively dry so that the finer particles do not clog the sieve; in some cases, soil was air dried outdoors in plastic tubs for a few days before being pulverized, depicted in Figure 3.4. 


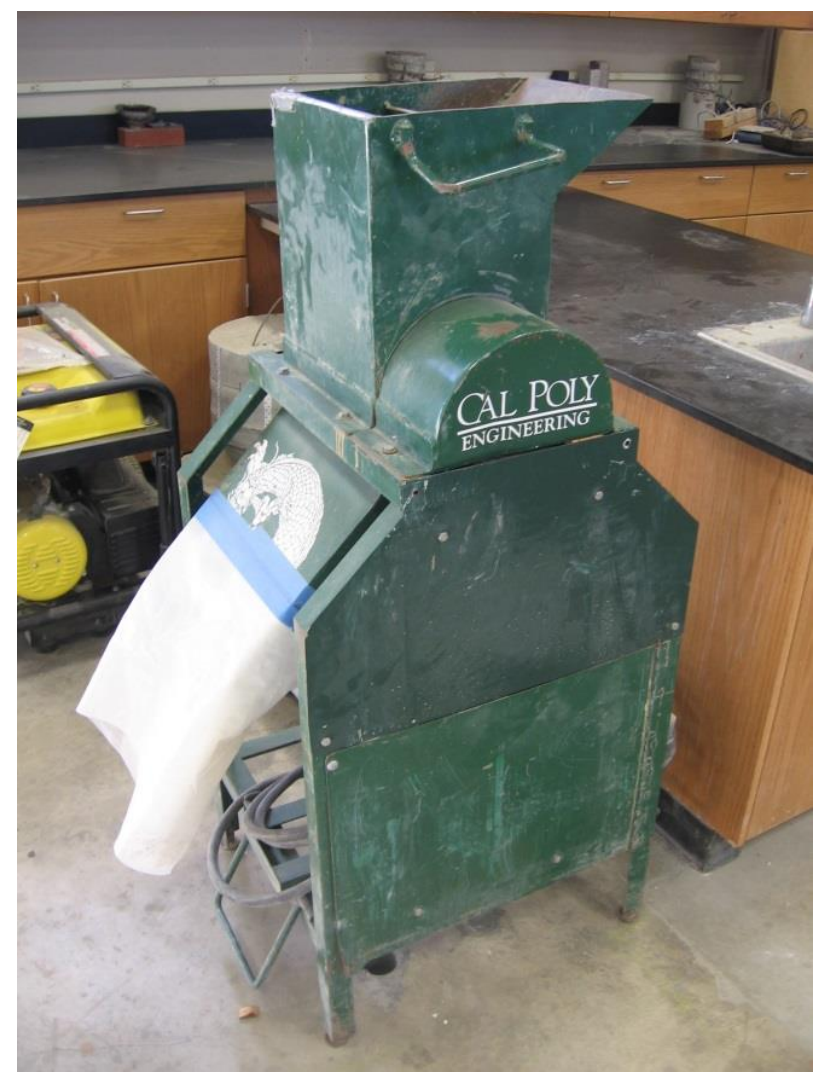

Figure 3.3: Soeng Thai SP3 Soil Pulverizer

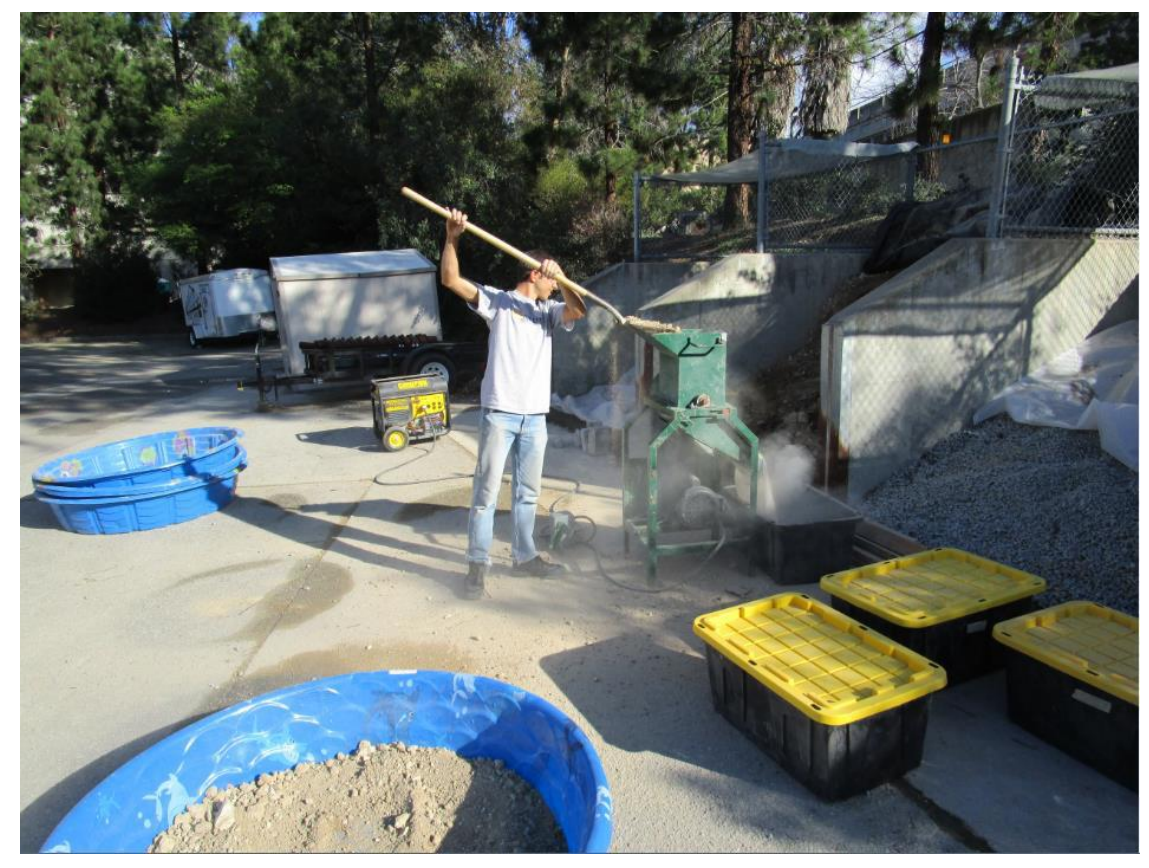

Figure 3.4: Drying and Pulverizing Soil (from Pringle, 2016) 


\subsubsection{Sand}

All sand was ASTM C33 concrete sand, taken from the Cal Poly Civil \& Environmental Engineering Department stockpile. Sand was used in making compressed earth blocks, grout, mortar, and concrete. In some cases, the sand was sieved before use as noted.

\subsubsection{Portland Cement}

All Portland cement was Type II/V Portland cement manufactured by CalPortland. Cement was kept indoors in its original sealed bag before use. Leftover cement was stored in the original bag for future use; the top of the bag was rolled and sometimes weighted with a spare block to reduce moisture infiltration from the air. Compressed earth blocks, grout, mortar, and concrete all required cement.

\subsubsection{Lime}

All lime used in the grout and mortar was Type $\mathrm{S}$ hydrated lime manufactured by Chemstar. As with the Portland cement, leftover lime was stored in the original bag with the top rolled and folded over.

\subsubsection{Gravel}

Pea gravel with a maximum nominal size of $3 / 8 "(9.5 \mathrm{~mm})$ was used as large aggregate in the small batches of concrete. The gravel used for Walls 1 and 3 was predominantly rounded, while Wall 2 used a combination of rounded and angular gravel.

\subsubsection{Water}

All water was potable tap water drawn from the laboratory plumbing systems in buildings 13 (Engineering) and 21 (Engineering West) on the Cal Poly campus. 


\subsection{Compressed Earth Blocks}

Compressed earth blocks consist of soil and sand mixed with cement and pressed into a block that can be dry-stacked without mortar. The two block types used in this research were Rhino blocks and V-Lock blocks.

\subsubsection{CVBT Rhino Blocks}
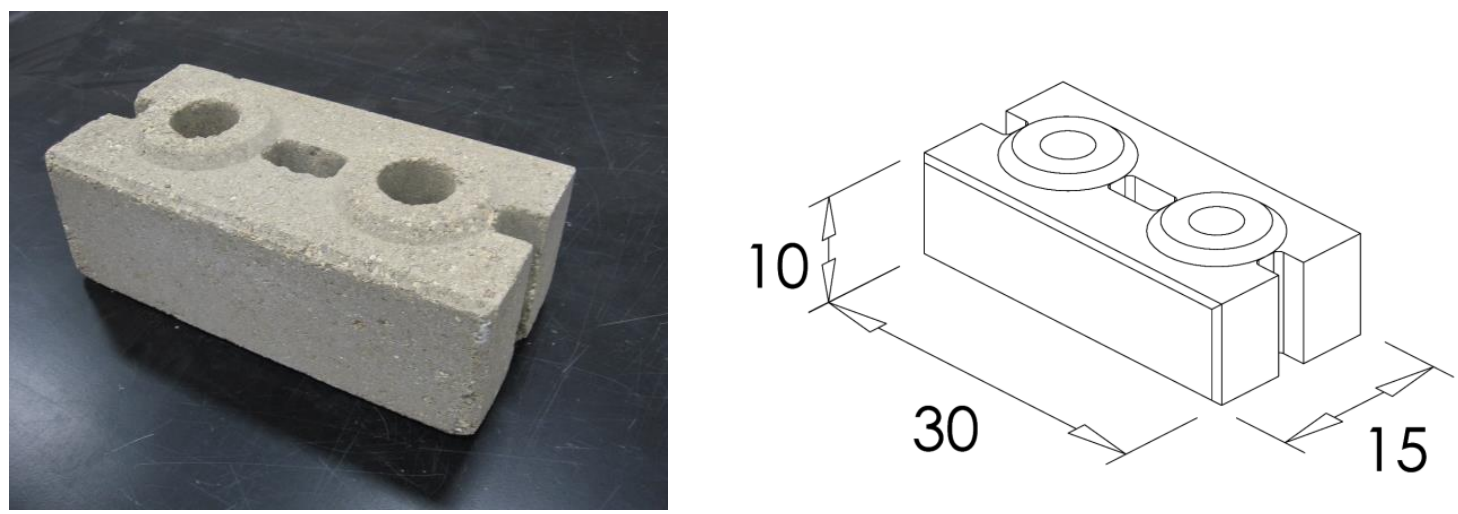

Figure 3.5: Rhino Block, dimensions in cm (right from Wheeler, 2005)

The Rhino block was developed in Thailand by the Asian Institute of Technology in collaboration with the Soil Block Development Company, continuing in the vein of a smaller interlocking block previously developed by the Thailand Institute of Scientific and Technological Research in 1983 (Wheeler, 2005). The Rhino block design is currently in widespread use in Thailand. The Center for Vocational Building Technology (CVBT), which manufactures and promotes both blocks and presses, designed and made the Soeng Thai BP6 manual press shown in Figure 3.6 that was used to make the Rhino blocks for this research. 


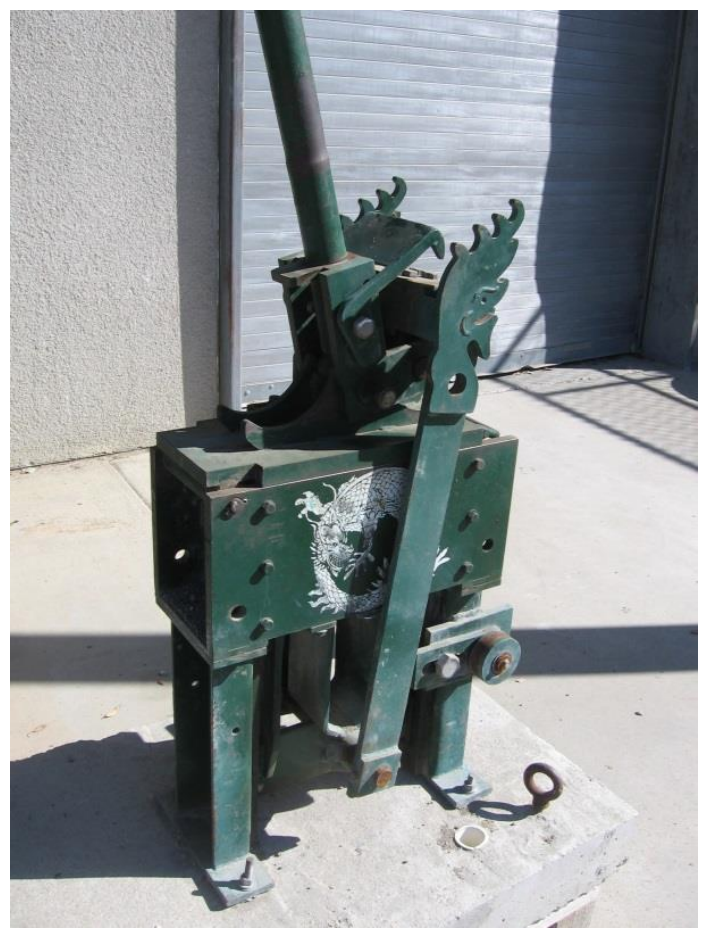

Figure 3.6: Soeng Thai BP6 Block Press

The standard Rhino block shown in Figure 3.5 above features cores for grouting and reinforcement, along with grouted shear keys running vertically along the head joints between blocks. Aside from potential structural value (as evaluated by this research), the head joint shear keys have the added benefit of sealing the joints against air movement, while the layout of the interlocking mechanism similarly inhibits air from moving through the bed joints. The interlocking mechanism uses matching male and female dowels around the grout chambers on the top and bottom of the blocks, respectively.

With the use of inserts, a single BP6 block press can create several different block types, shown in Figure 3.7 along with their typical uses. These include half blocks (to allow the stacking of blocks in a running bond pattern), channel blocks (to allow the placement of transverse reinforcement and electrical conduit), and blocks with the head joint shear keys removed at one or both ends (for cosmetic purposes at corners and pilasters). This research used standard full blocks, half blocks, and channel blocks. To 
test the effects of removing the head joint shear keys for Wall 3, pillar blocks and half corner blocks directly replaced the standard full and half blocks.
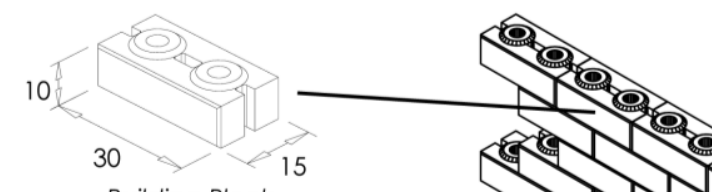

Building Block
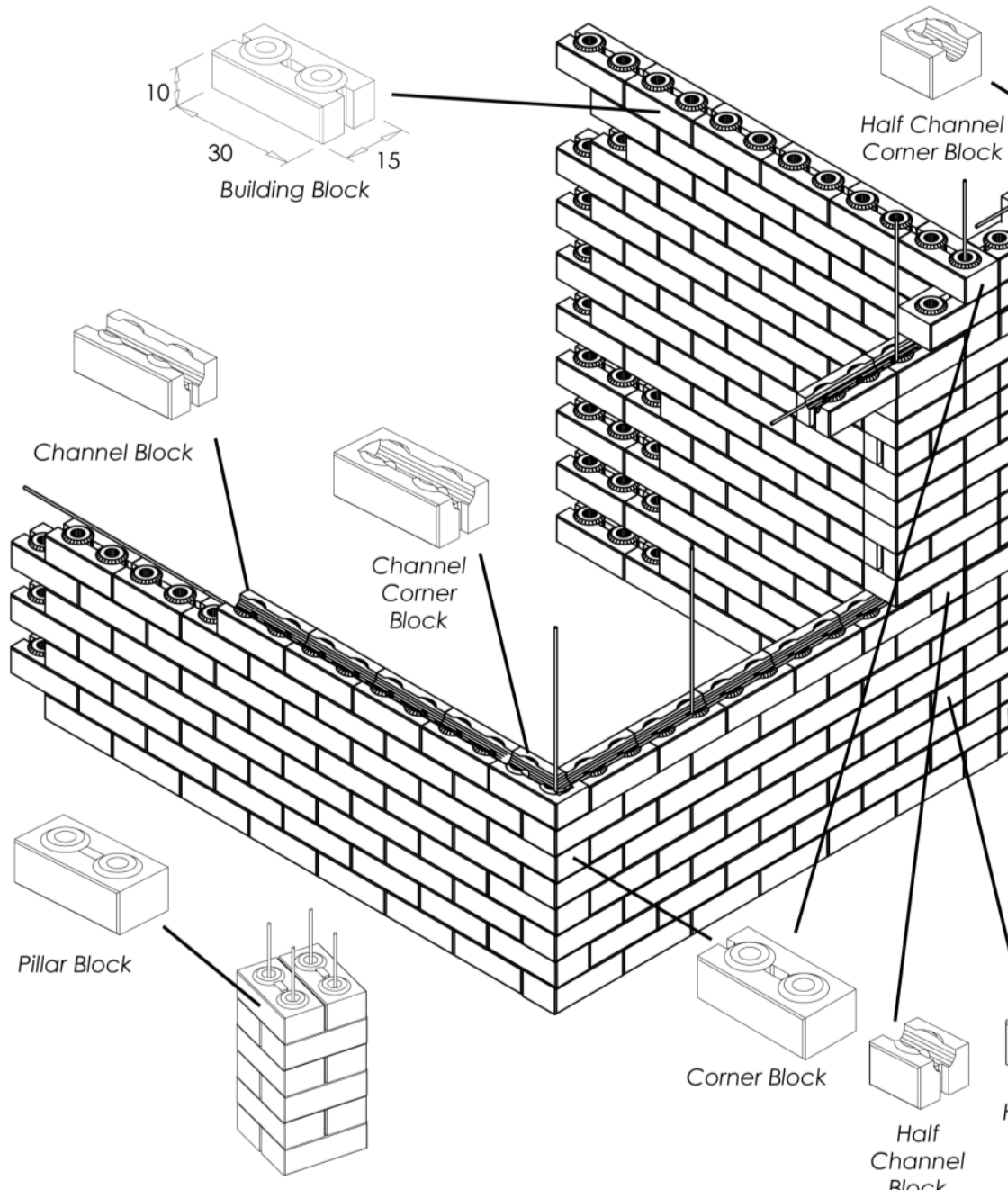
Corner Block
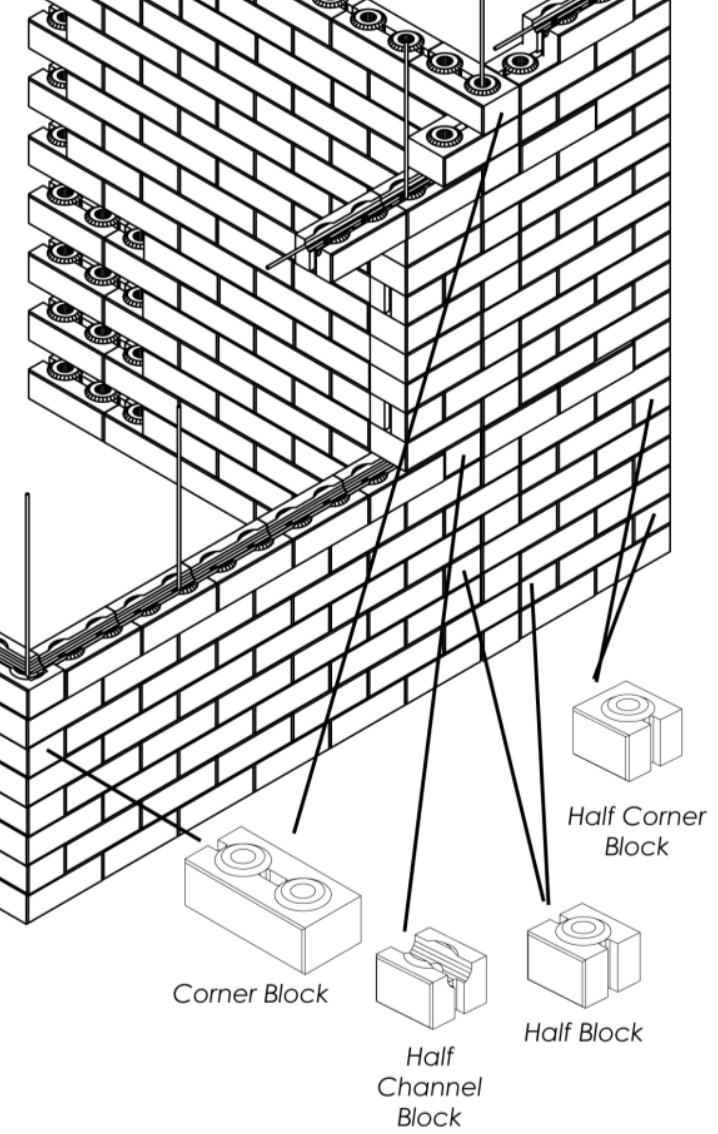

Figure 3.7: Rhino Block Variations and Typical Uses (from Wheeler, 2005)

Because of the age and state of wear of the specific press used here, the Rhino blocks used in this research tended to have one end measurable taller than the other. This was an undesirable imperfection, but no satisfactory solution was found.

\subsubsection{Mix Design}

All Rhino blocks used mix proportions developed by Pringle (2016) using equal stock weights of sand and Las Tablas soil with 9\% Portland cement as a percentage of 
dry ingredients. All sand was passed through a \#4 sieve before batching to remove large particles. The soil/sand proportions were selected by Pringle as a balance between block strength (which decreases with increased soil content) and cohesion immediately after pressing (which increases with soil content and is necessary for conveying blocks from the press to the curing rack). A spreadsheet designed by Pringle calculated the amount of water required to reach optimal water content, determined by a series of Proctor compaction tests outlined in Pringle (2016). This same spreadsheet also determined the approximate amount of ingredients required for an individual block based on the finished block's expected volume. Moisture content tests on the sand and soil provided the necessary data to determine how much water to add; these tests were performed each time fresh sand or soil was drawn from the stockpile and transferred to sealed plastic tubs. The values calculated by the spreadsheet were only used as starting points; actual quantities were adjusted in the field as necessary as described in the following section.

\subsubsection{Pressing Procedure}

Rhino blocks were pressed in batches of ten full blocks or an equivalent number of half or channel blocks, an amount that could be feasibly pressed within an hour of adding water. Pressing blocks too far past the one-hour mark risked excessive hydration of the cement before pressing. The following sections describe the procedure in depth.

\subsection{Mixing Ingredients}

All dry ingredients were mixed in a pile on the concrete slab floor just inside the lab, which provided a relatively smooth, impermeable surface to facilitate mixing, avoid introduction of foreign material, and minimize water loss. The pile's location was chosen to avoid direct sunlight so that it did not excessively dry out during batching. 


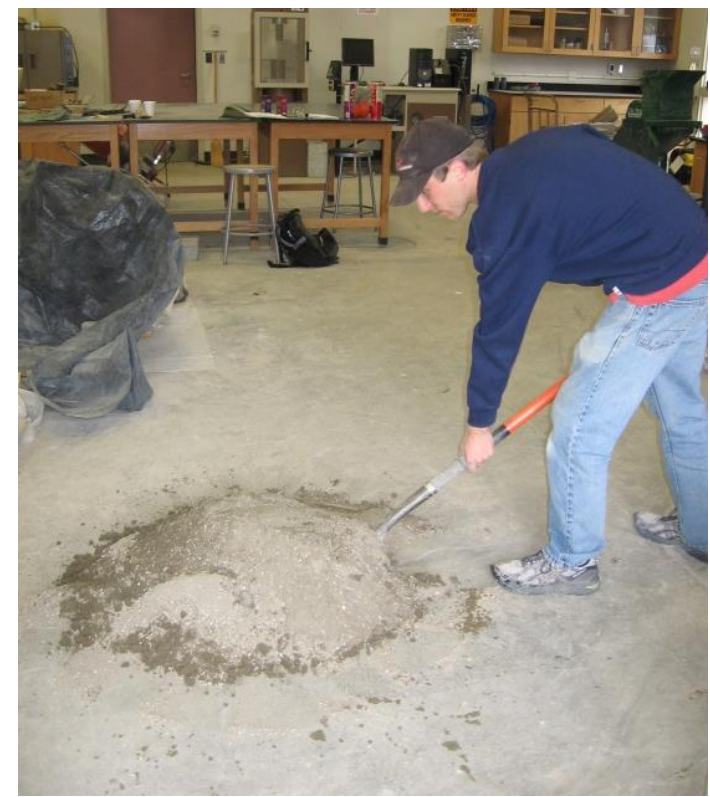

Figure 3.8: Mixing Block Ingredients

The dry ingredients were mixed with a shovel as shown in Figure 3.8. Once the dry ingredients were uniformly mixed, the blade of the shovel was dragged in a spiral pattern out from the center to make a flattened pile with a broad depression. This allowed the water to soak into the pile without running off onto the ground, as can be seen in Figure 3.9.

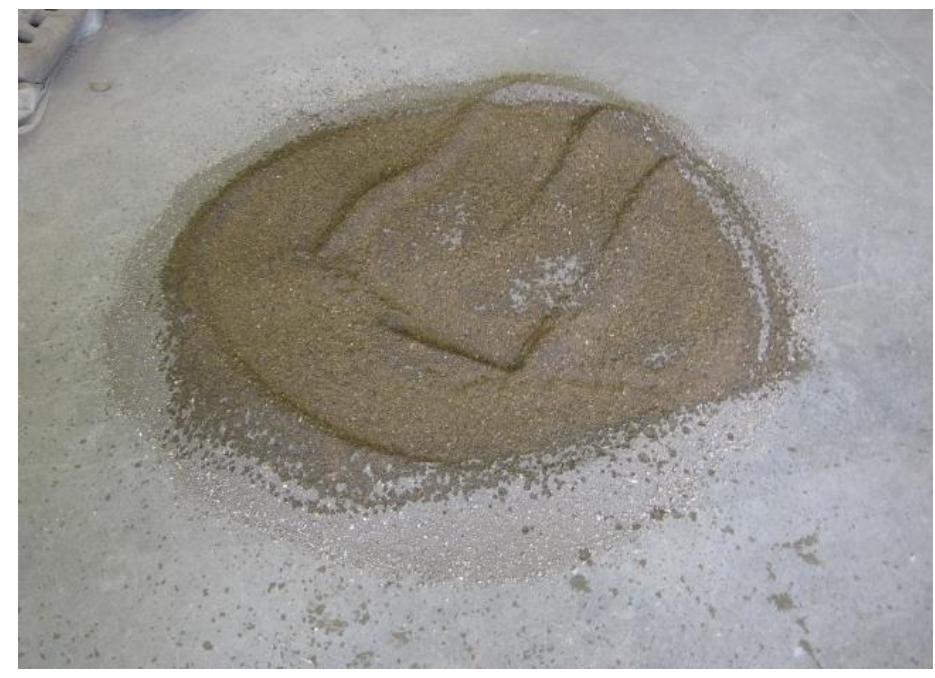

Figure 3.9: Flattened Pile with Added Water 
While the mix design spreadsheet estimates the amount of water to add, the precise amount must be tailored to the batch consistency in the field. After mixing the dry ingredients, approximately one-third of the expected water was added to the pile with a watering can, taking care to avoid eroding the pile or losing excess water on the surrounding area. The pile was allowed to absorb the water before being thoroughly mixed again. Any clumps were deliberately smashed with the shovel. The remaining water was similarly added a third at a time. For the final third, slightly less water was added to avoid overshooting the appropriate water content. At this point, when the resulting mixture resembled moist soil but was noticeably on the dry side, the material's water content was tested with the cigar test, described below.

\subsection{Cigar Test and Final Water Content}

The cigar test is a field test for determining if a compressed earth block batch has an appropriate water content. It involves taking a handful of the mixture and pressing it with the fingers into a roughly cigar-like shape. The sample is then held between two fingers and shaken by twisting the wrist back and forth. If the sample held together when pressed but dryly broke apart when shaken, the water content was close to the target but still on the dry side. At this stage, additional water was mixed into the pile in increments of approximately one-half to one kilogram, and the cigar test was repeated. When the sample passed the cigar test by holding together when shaken, the water content was correct. The total amount was recorded, and pressing began. A mixture with too much water would feel wet (rather than damp) with a cigar test sample that held together wetly when dropped. Little could be done at such a point to remedy the water content; it was therefore better to avoid this by instead aiming for a slightly dry mixture. 


\subsection{Press Preparation}

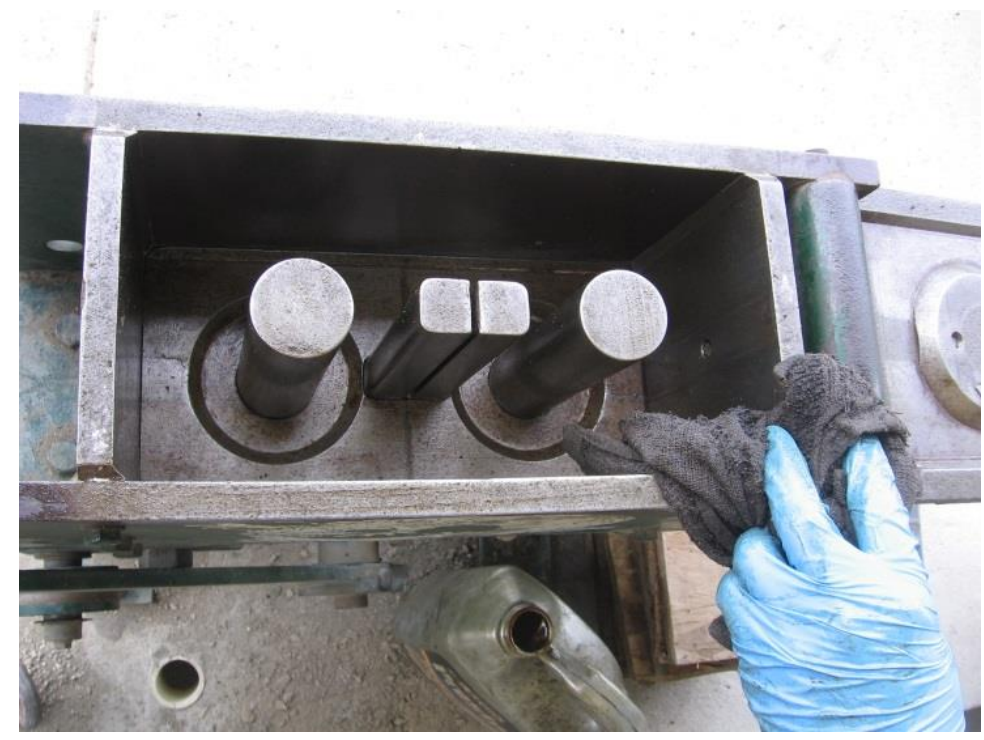

Figure 3.10: Oiling Block Press

The inside of the press was oiled before pressing each block to enable smooth ejection of blocks, necessary in this case because of the press's state of wear. Enough oil was used to thinly coat the inside surfaces without making the final blocks feel significant oily. Similarly, the slides on the underside of the press were oiled before each batch to ensure easy ejection. Used motor oil was utilized because of its relatively high viscosity.

\subsection{Pressing}

Before pressing the full batch of blocks en masse, a tentative quantity of mixed material was weighed out for a single test block. A standard block used approximately seven kilograms of material; other block types required more or less in proportion to their volume. The material was poured into the press, with care taken to distribute it evenly and break up any clumps. This helped ensure that the density of the final block was relatively uniform. The material typically would not fit within the press without a light level of compaction; this was done as minimally and uniformly as possible, again to 
minimize irregularities in density. Loose material was brushed from the flat surfaces so that they could contact the press's lid when closed.

Once the material was placed in the press, the press operator swung the press's lever over to the far side in a smooth motion until it was fully pressed down. The lever should provide some resistance while pressing but not an excessive amount (e.g. the operator should not need to hang from the lever to force it downwards). The operator held the lever down for a few seconds before returning it back to its original position. Once the lid of the press was opened, pressing down on the lever would then eject the block. Figure 3.11 illustrates the pressing action.
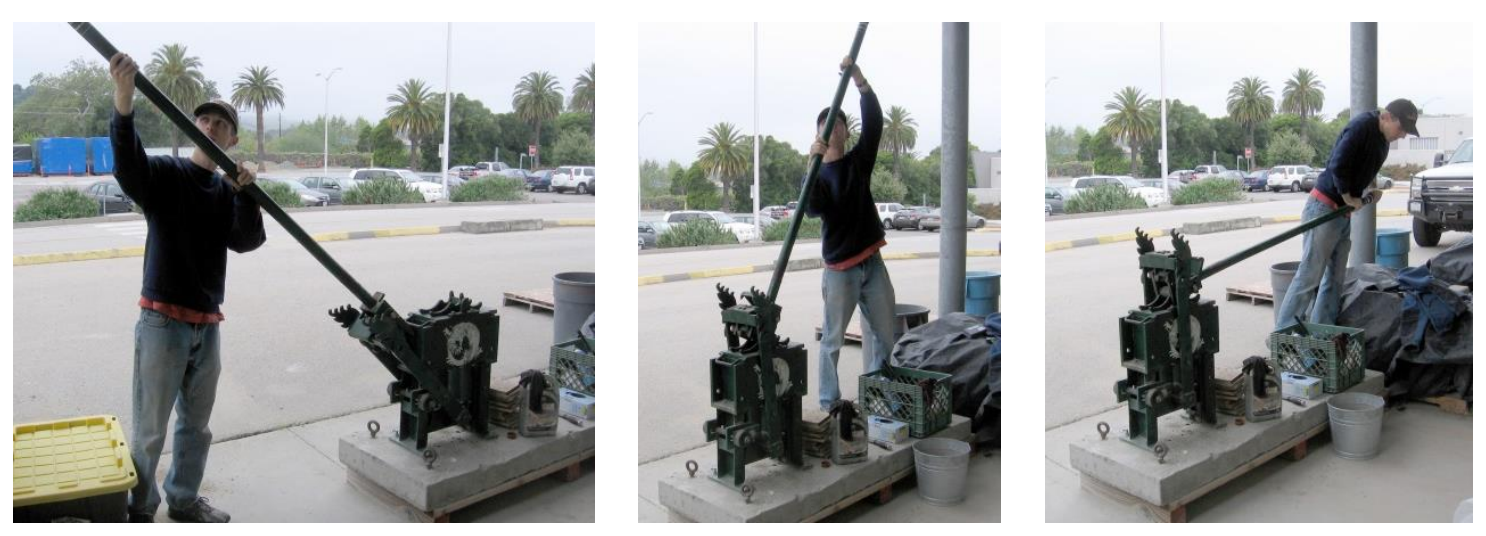

Figure 3.11: BP6 Pressing Action

\subsection{Penetrometer Test and Material Quantity Calibration}

The penetrometer test ensures that each block contains sufficient material. Before ejecting the first block of each batch, a penetrometer was pressed into the surface of the block near the center, as shown in Figure 3.12. The tester would sometimes use his or her fingers to confine the material in the immediate vicinity of the penetrometer to prevent larger-scale damage to the surface of the block. This was also repeated near a corner; the readings should be similar, but because it was difficult to uniformly distribute the soil in the press, the center readings tended to be higher than the corner readings. 
Acceptable readings were $300 \mathrm{psi}(2100 \mathrm{kPa})$ at the center of the block and $250 \mathrm{psi}(1700$ $\mathrm{kPa}$ ) at the corner. Readings below these points indicated that more material per block was necessary; thoroughly crumbling the block back into the material pile allowed it to be reused. High readings above $500 \mathrm{psi}(3400 \mathrm{kPa})$ indicated less material should be used, especially if the press required an unusually high amount of force to operate.

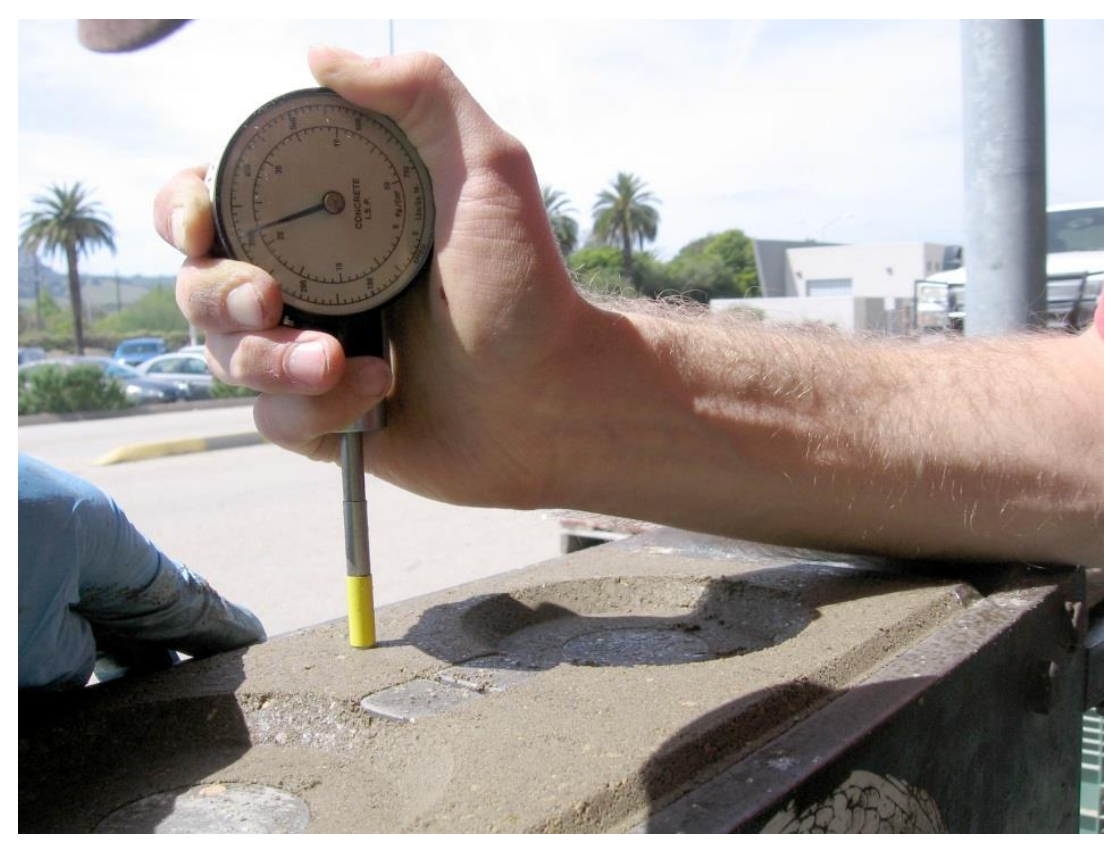

Figure 3.12: Penetrometer Test

Low penetrometer readings indicated that the block needed more material. A block whose penetrometer readings were only slightly below acceptable was typically kept, but subsequent blocks used additional material. If penetrometer readings were exceptionally high and it took an extraordinary amount of effort to press the block, there was too much material; the block may be kept, but future blocks used less material. Often, adding or removing material in approximate increments of 50 grams was sufficient to quickly reach the correct amount. If the penetrometer readings were acceptable but the block consistently broke apart during ejection, the mixture was too dry, and slightly more water was added to the batch. Once the penetrometer readings were within bounds, the 
remainder of the batch was pressed with the same amount. Penetrometer readings typically continued to be taken for the next few blocks to ensure that the measurements were consistently acceptable.

\subsection{Moisture Content Test}

A moisture content sample of the mixed material was taken about halfway through pressing each batch and placed in a sealed bag. The sample was then formally tested for moisture content at the end of the work day. Moisture content test results are recorded with the batch sheets in Appendix C.

\subsection{Curing}

If the penetrometer readings were acceptable, the block was placed on a piece of plywood or similar material, taking care to hold it such that the relatively fragile corners were not significantly damaged. The block and plywood were then transferred together to the curing rack, consisting in this case of dimension lumber supported by preexisting compressed earth blocks. If the block broke at any stage, it was tossed back onto the material pile and thoroughly broken up to reuse the material.

While continuing to make more blocks, the blocks on the rack were periodically misted to prevent them from drying out. The surface should remain moist but not excessively wet. Once pressing was complete for the day, blocks were moistened one last time, and the curing rack was covered with a plastic tarp to maintain some level of humidity. The blocks were then sprayed at least once per day (preferably more) for the first four days after pressing. They could be removed from the curing rack after this point, although they were often left on longer but not sprayed. While a true curing room with continuous misters and temperature control would be more effective at maintaining 
curing conditions, the high humidity may cause clay expansion issues and adversely affect the integrity of the block.

\subsection{Special Techniques for Other Block Types}

Some block types required additional technique after ejection to avoid breaking the fresh block. Half blocks used a divider plate to make two half blocks out of a single pressing. This naturally required the plate to be removed from the fragile, newly-pressed blocks for use in the next pair. Before transferring the blocks to the plywood, tapping the top of the divider plate with a hammer and chisel or putty knife would help the insert debond from the blocks. One half-block of the pair could then be removed by placing another piece of plywood over the other block, holding the sides of the first block, and rotating it away, pressing the thumbs onto the plywood to provide a pivot point. The insert could then be pulled from the second block with little difficulty.
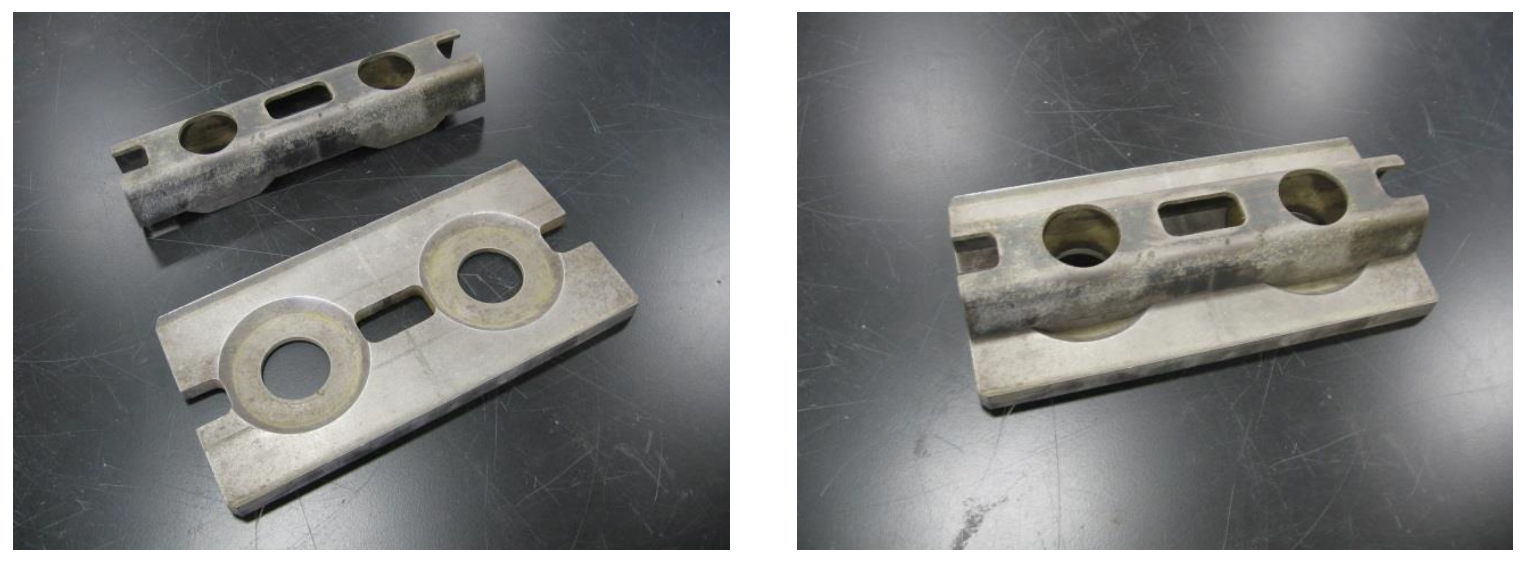

\section{Figure 3.13: Channel Block Insert with Standard Pressing Plate}

Pressing channel blocks required a hollow insert shown in Figure 3.13 which similarly must be carefully removed immediately after pressing each block. Because the blocks are pressed inverted, the channel insert would be beneath the block during and immediately after pressing. To remove the insert after ejection, the plywood would be placed over the upper surface (actually the bottom of the block when used in 
construction). The block/plywood/insert combination would then be flipped over so that the plywood was on the bottom, resulting in the channel insert on top where it could be easily removed. Care was taken to only hold it by the plywood and the rigid channel insert; otherwise the block would rupture violently.

\subsubsection{Vermeer V-Lock Blocks}
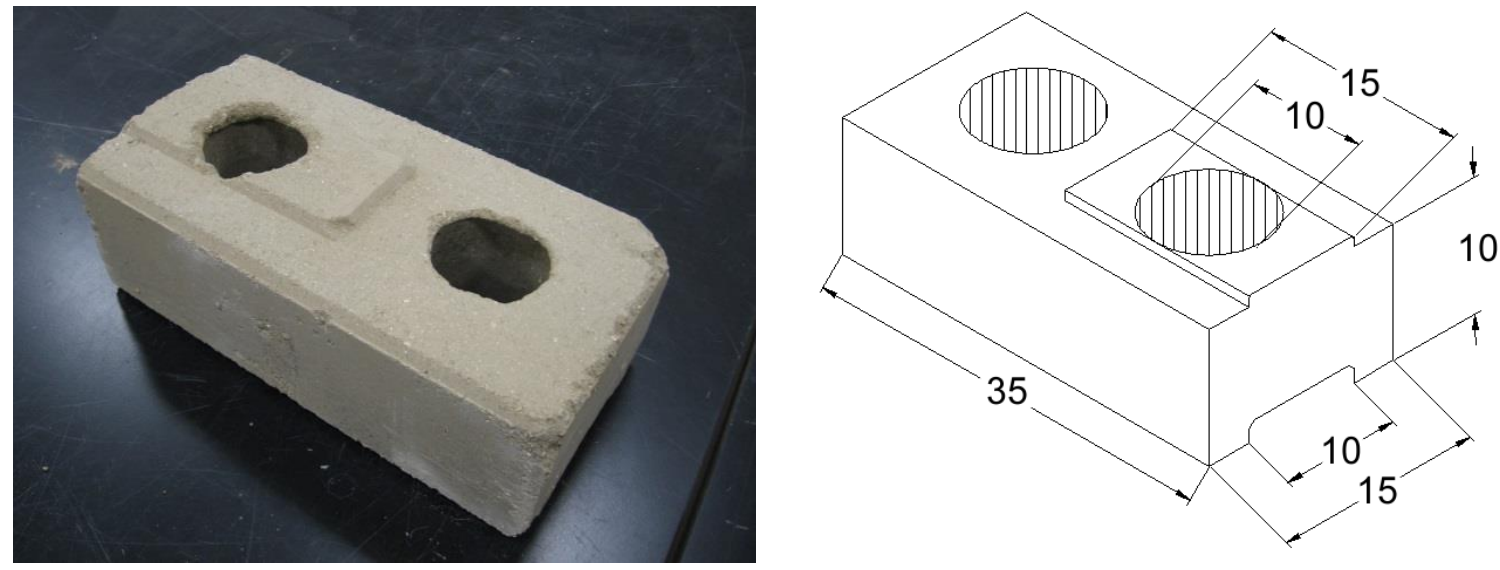

Figure 3.14: V-Lock Block, dimensions in cm (right adapted from Banker-Hix, 2014)

V-Lock blocks and the BP714 hydraulic block press were developed by the Vermeer corporation, entering the market in 2013 (Vermeer, 2013). The V-Lock block is somewhat larger than the Rhino block and has significantly larger grout cores but no head joint shear keys. The hydraulic pressing process is able to achieve higher block strengths than the manually pressed Rhino blocks. The interlocking mechanism consists of a raised rectangular region extending half the length of the top of the block, as can be seen in Figure 3.14. The raised region slots into a channel on the bottom of the block, which is deep enough to accommodate transverse reinforcement. This mechanism provides interlock out-of-plane but not in-plane.

The vast majority of the V-Lock blocks used in this research were previously stockpiled and made from the same Las Tablas soil as the Rhino blocks. However, the 
topmost full course of blocks and most of the half blocks in the V-Lock wall were made from a different soil. The blocks were unmarked and batch records for those blocks were unavailable at the time of this writing; the exact nature of this other soil is therefore unknown, although it was probably either the Prado soil or Mind Body soil used by Banker-Hix (2014). The use of these blocks was deemed not to have a significant impact on the wall's behavior because these blocks were only used for limited regions on the perimeter of the wall. Sample blocks using this other soil were included in the compressive strength tests for the V-Lock blocks recorded in Appendix D, and their results fell in the same range as the rest of the samples, further supporting the assumption that this different soil did not significantly affect full-scale test results.

\subsubsection{Pressing Procedure (adapted from Banker-Hix, 2014)}

No new V-Lock blocks were pressed for this research; all V-Lock blocks were pressed in spring 2014 and stockpiled on the Cal Poly campus. The blocks were stored outside but tightly bound with plastic tarpaulins to minimize moisture damage. The following abbreviated description of the pressing procedure is adapted from Banker-Hix (2014).

\subsubsection{Mixing}

The materials were mixed in a Concrete MD mixer using a "sheep's foot" hydraulic auger, shown in Figure 3.15. Pulverized soil was mixed with the sand and some of the water for approximately five minutes before the cement and additional water were added. Whenever the mixer was stopped, the material was further mixed with a shovel to break up any unmixed material, particularly near the ends of the mixer and the bottom of the auger. 

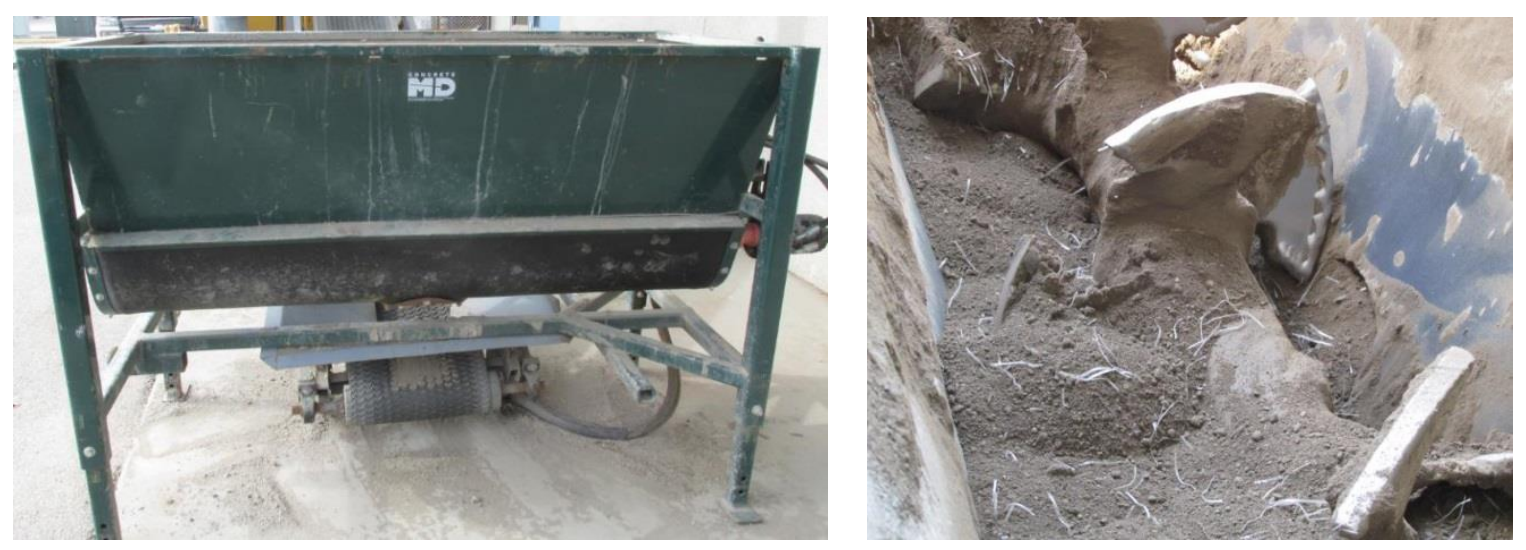

Figure 3.15: Concrete MD Mixer (from Banker-Hix, 2014)

After five more minutes of mixing, moisture content was evaluated using the drop test and a variation of the cigar test. The drop test consists of forming a sample into a ball and dropping it 0.9-1.2 m; if the ball breaks into a few large pieces without significantly disintegrating, it has reached the appropriate water content. The cigar test is described above under Section 3.2.1.2.2 in the Rhino block test procedure, with the altered criteria that at the appropriate moisture content, the cigar should break apart after five or six shakes. Once the appropriate moisture content was reached, improperly mixed sand and soil that collected near the mixer door were removed and put back into the mixer along with additional water. After mixing for one or two more minutes, the soil was transferred to a conveyer belt leading to the block press.

\subsubsection{Pressing}

The V-Lock blocks were pressed with a Vermeer BP714 hydraulic press through the process depicted in Figure 3.16. All actions are hydraulically controlled and operated through a set of control levers. The soil-cement mixture is transferred by conveyer belt from the mixer to a hopper at the top of the press to fall into a volumetric measuring bucket, which slides the material over to the compression chamber. A plate on the same piston as the bucket seals the compression chamber, and the bottom plate rises up to 
compress the block. Two tapered plates then rise from the bottom plate within the block's grout chambers to further compact the block. The measuring bucket retracts to fill with more material from the hopper, and the block is raised up where it could be transferred from the press to the curing rack.

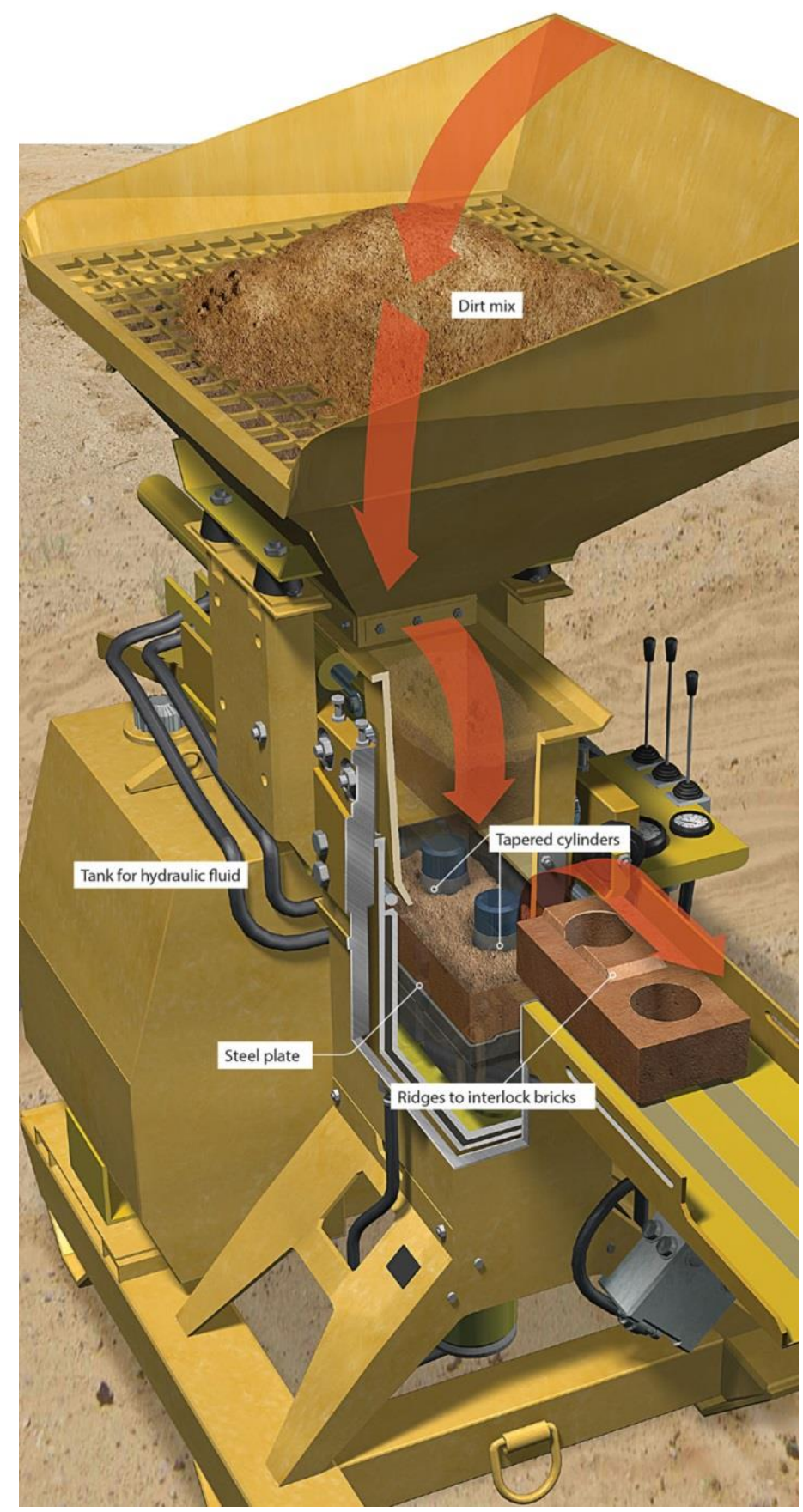

Figure 3.16: V-Lock Pressing Process (Hand, 2013) 
The BP714 features a pressure gauge to measure the pressure on the compression piston and, indirectly, the pressure exerted on the block. When the piston readings fell outside the appropriate range of 1100-2000 psi (7.6-13.8 MPa), the press was adjusted to increase or decrease the amount of soil allowed to fall into the compression chamber. Adjusting the height of the compression chamber also had a similar effect, changing the block volume without altering the amount of material.

\subsubsection{Half Blocks}

Because only full V-Lock blocks were available, half blocks were made by cutting existing full blocks in half with a miter saw fitted with a masonry blade, as shown in Figure 3.17.

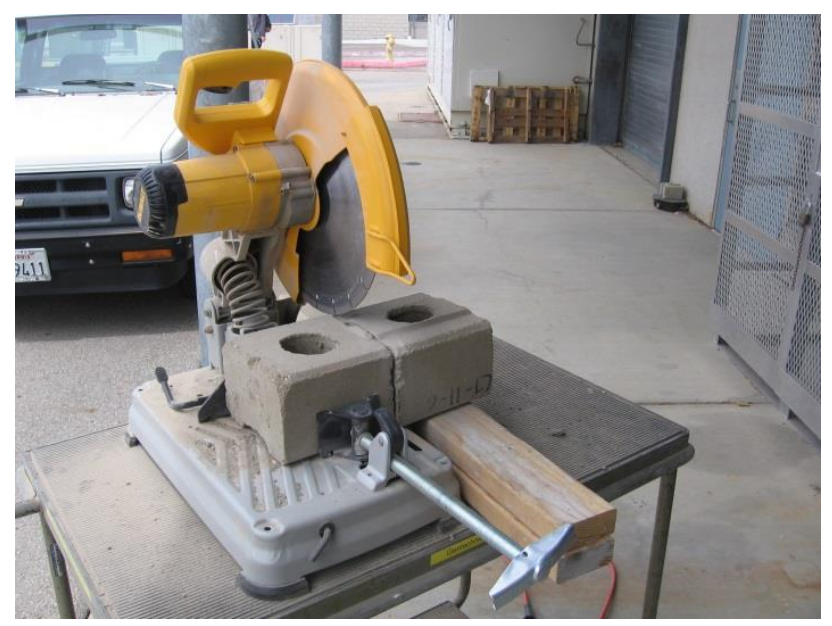

Figure 3.17: Cutting V-Lock Half Blocks

\subsubsection{Compressive Strength}

Two types of samples were tested for compressive strength: single blocks and three-block-high grouted prisms. Both sample types were tested under a loading rate of $40 \mathrm{kPa} / \mathrm{s}$. The results for both sample types are summarized in Table 3.3; Appendix D contains results for individual samples. All reported stress values are based on net area, subtracting voids with unfilled grout cores. V-Lock blocks were consistently stronger 
than the Rhino blocks; this is no doubt because the hydraulic Vermeer BP714 press exerted higher pressure than the manual CVBT BP6 press.

Table 3.3: Compressed Earth Block Compressive Strength

\begin{tabular}{|c|c|c|c|c|c|c|c|}
\hline \multirow{2}{*}{$\begin{array}{c}\text { Wall } \\
\text { (Block } \\
\text { Type })\end{array}$} & \multicolumn{3}{|c|}{ Single Blocks (MPa) } & \multicolumn{3}{c|}{ Prisms (MPa) } & Prism \\
\cline { 2 - 8 } & Mean & $\begin{array}{c}\text { Standard } \\
\text { Deviation }\end{array}$ & $\begin{array}{c}\text { Coefficient } \\
\text { of Variation }\end{array}$ & Mean & $\begin{array}{c}\text { Standard } \\
\text { Deviation }\end{array}$ & $\begin{array}{c}\text { Coefficient } \\
\text { of Variation }\end{array}$ & Block \\
\hline $\begin{array}{c}\text { Wall 1 } \\
\text { (Rhino) }\end{array}$ & 3.95 & 0.571 & $14 \%$ & 1.47 & 0.0901 & $6.1 \%$ & 0.37 \\
\hline $\begin{array}{c}\text { Wall 2 } \\
\text { V-Lock })\end{array}$ & 8.26 & 1.46 & $18 \%$ & 3.32 & 0.143 & $4.3 \%$ & 0.40 \\
\hline $\begin{array}{c}\text { Wall 3 } \\
\text { (Rhino) }\end{array}$ & 4.93 & 0.513 & $10 \%$ & 1.92 & 0.0956 & $5.0 \%$ & 0.39 \\
\hline
\end{tabular}

\subsubsection{Single Blocks}
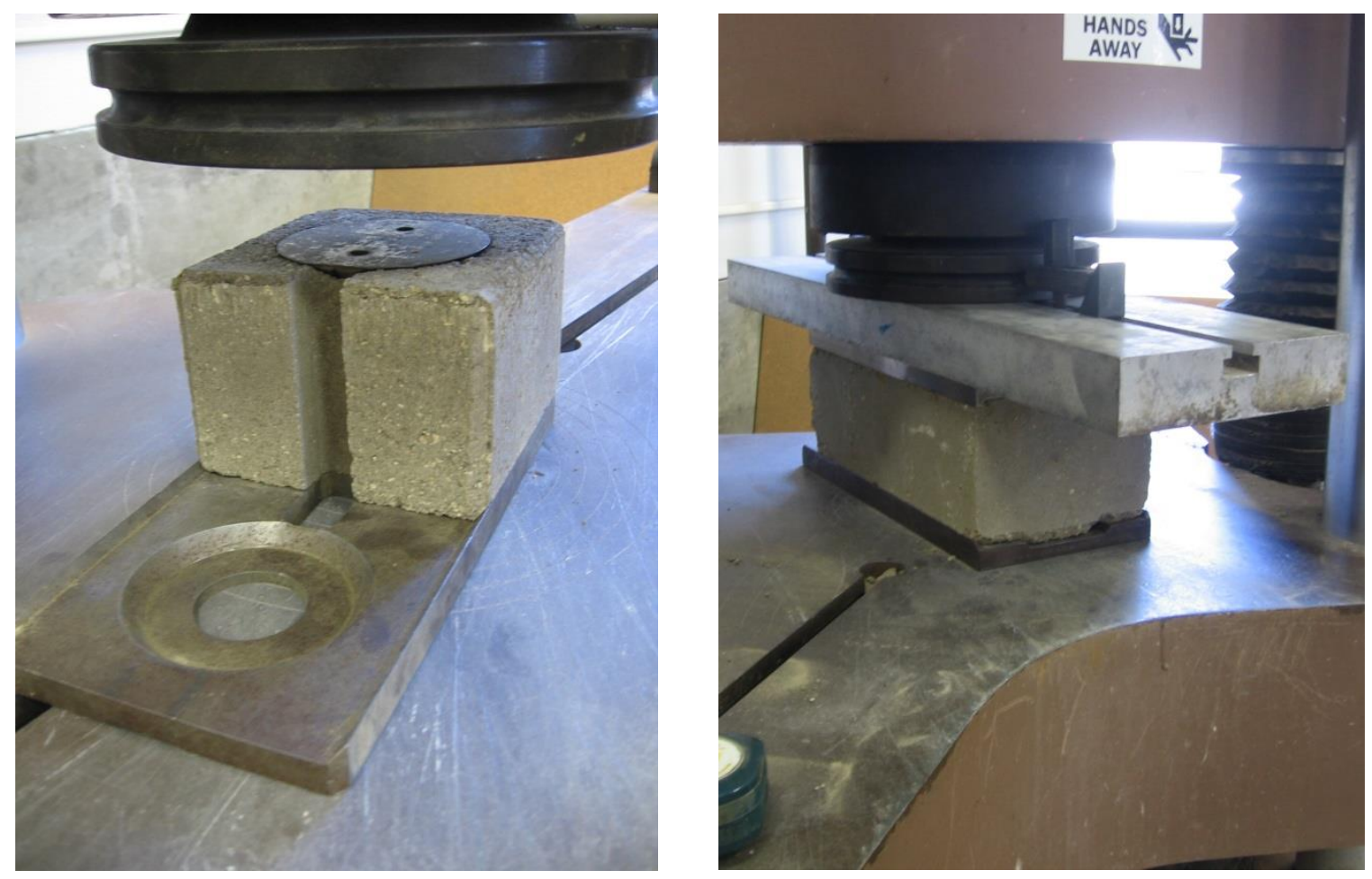

Figure 3.18: Single Rhino (left) and V-Lock (right) Block Tests

Compressive strength tests on individual blocks are analogous to the unit strength test method permitted by the MSJC (2013) code. All single block specimens for the 
Rhino blocks were half blocks. Not only does this reduce the additional resources and effort required to make the total number of blocks, but Pringle (2016) also concluded that tests of half blocks were more consistent than comparable tests of full blocks. No VLock half blocks were available for testing, so all V-Lock tests were performed on full blocks. To provide a conforming contact surface, the blocks were fitted with the plates from their respective presses during testing, as shown in Figure 3.18.

Single compressed earth blocks tested in compression suffer from a testing artifact where the contact plates act to confine the compressed soil cement at the block/plate interface. This artificially increases the block's strength compared to the completely unconfined failure that would take place in a full-scale stack of blocks. It also causes a characteristic conical failure visible in Figure 3.19 that has been widely observed by past research, including Bland (2011) and Pringle (2016). These testing artifacts can be overcome with prism tests.

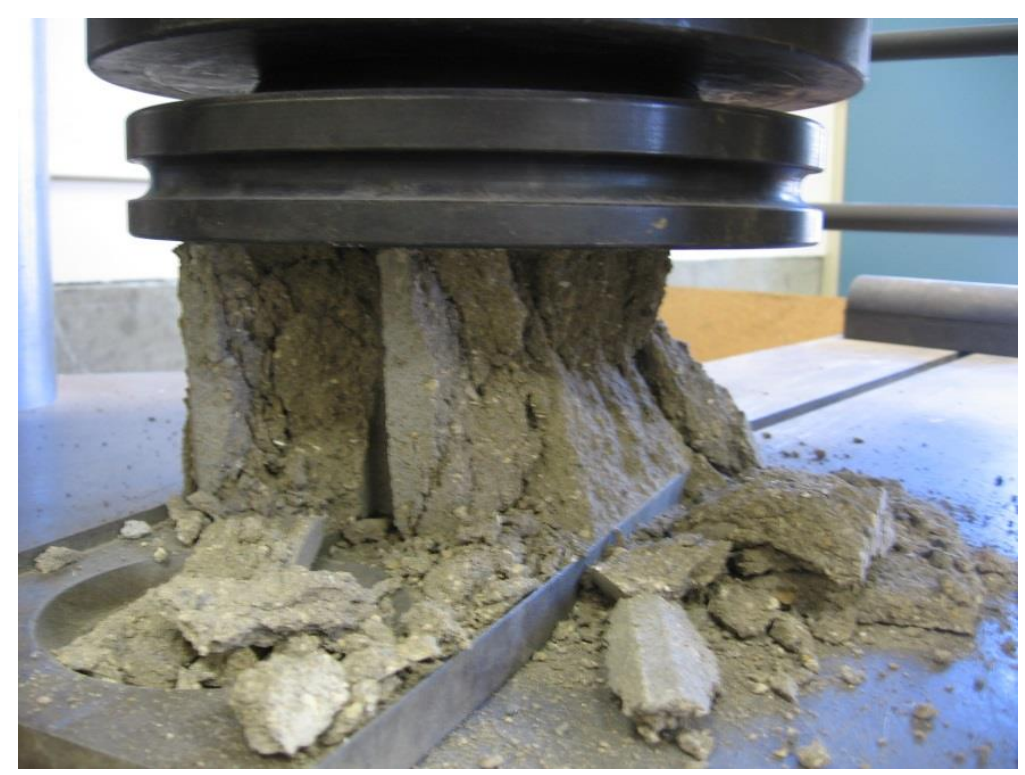

Figure 3.19: Single-Block Conical Failure 


\subsubsection{Prisms}
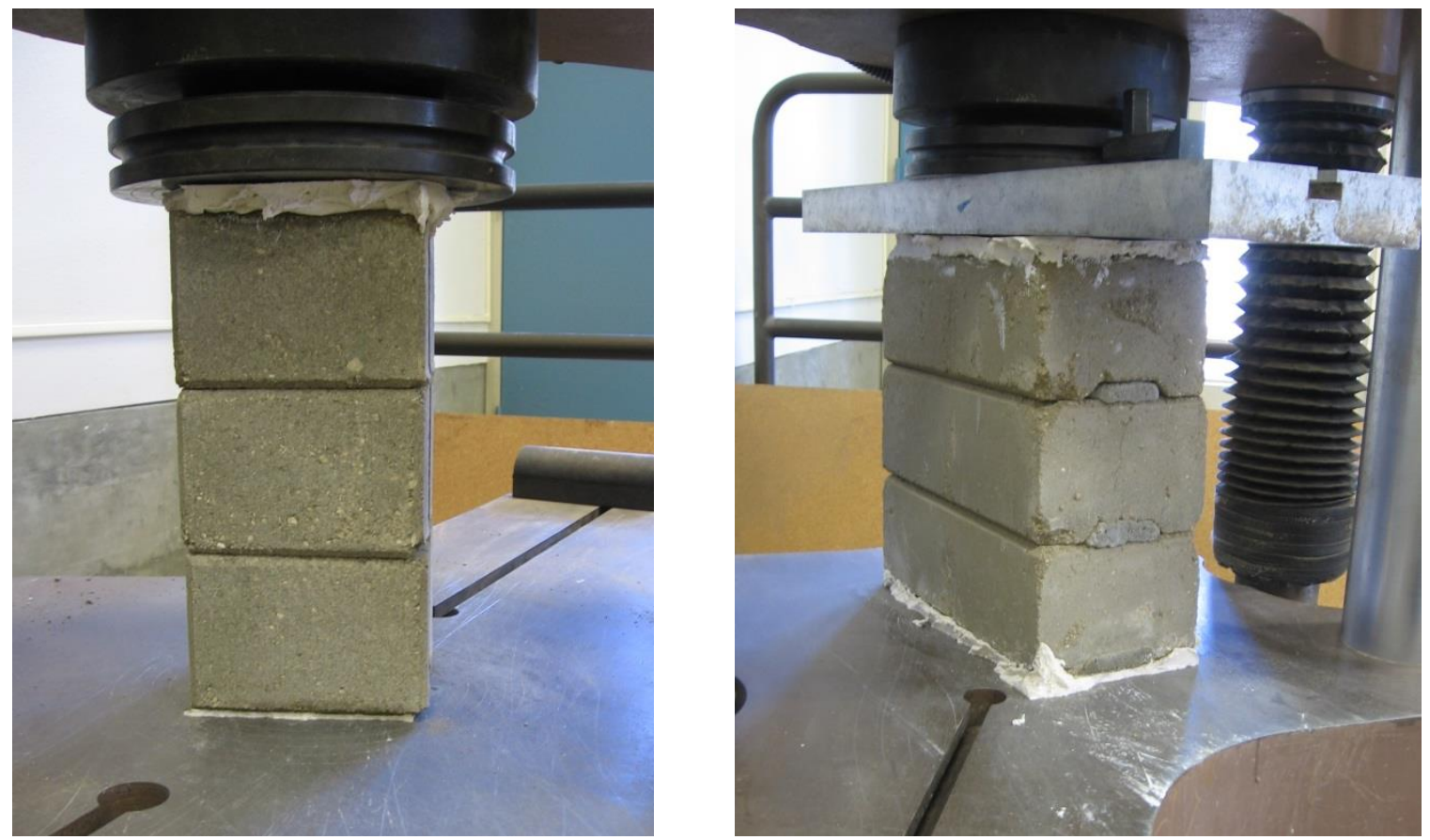

Figure 3.20: Rhino (left) and V-Lock (right) Prisms

Prism samples were created by stacking three blocks and grouting the cores. In conventional masonry design, the prism test is the preferred method for determining masonry strength because it reduces the interacting variables of the blocks, grout, and other factors down to a single representative strength value. With compressed earth blocks, it also reduces the confinement artifacts of the single-block tests and allows an unconfined failure in the center of the tall prism, providing a realistic measure of compressive strength. As with the individual blocks, all prism test results were based on net area, subtracting out the area of ungrouted voids (mainly the ungrouted head joint shear keys in the Rhino blocks).

The prisms used the same block configurations as for the individual block tests (half blocks for the Rhino blocks and full blocks for the V-Lock blocks). The prisms were cured on the laboratory floor next to each wall to maintain similar curing conditions 
as the wall. The head joint shear keys were not grouted for the Rhino block prisms, deviating from the grouting layout for Wall 1. The V-Lock prisms were sprayed with water multiple times before grouting, mimicking the procedure used when grouting Wall 2 (covered in more detail under Section 4.4). The ends of the V-Lock prisms were also strapped with plywood during grouting to prevent grout from leaking from the recessed channels.

For testing, the Rhino block prisms for Wall 1 were fitted with the plates from the block press in an attempt to provide a reasonably conforming surface, with a stack of washers placed in the lower plate's holes to prevent the grout core from punching out. Unlike the individual blocks, however, attempts to remove stray grout at the contact surface resulted in more irregular contact surfaces. Therefore, prisms for Walls 2 and 3 were capped with Hydro-Stone branded gypsum cement, mixed at approximate volumetric proportions of 3:1 cement:water to achieve a toothpaste-like consistency. The cement was allowed to cure for at least 30 minutes before testing.

As can be seen in Table 3.3 above, the ratio of average prism strength to average block strength was approximately 0.4 for both block types, with the V-Lock blocks having a slightly higher ratio. This is lower than the range reported by Bland (2011) of 0.43 to 0.55 but within the range reported by Bales (2009) of 0.37 to 0.43 . Most prism samples failed with extensive vertical cracking that propagated through the grout cores, with the outer block material tending to split away from the cores. This behavior was particularly noticeable in the V-Lock prisms, which tended to have less cracking in the grout with large, relatively intact portions of blocks which fell away from the cores. 

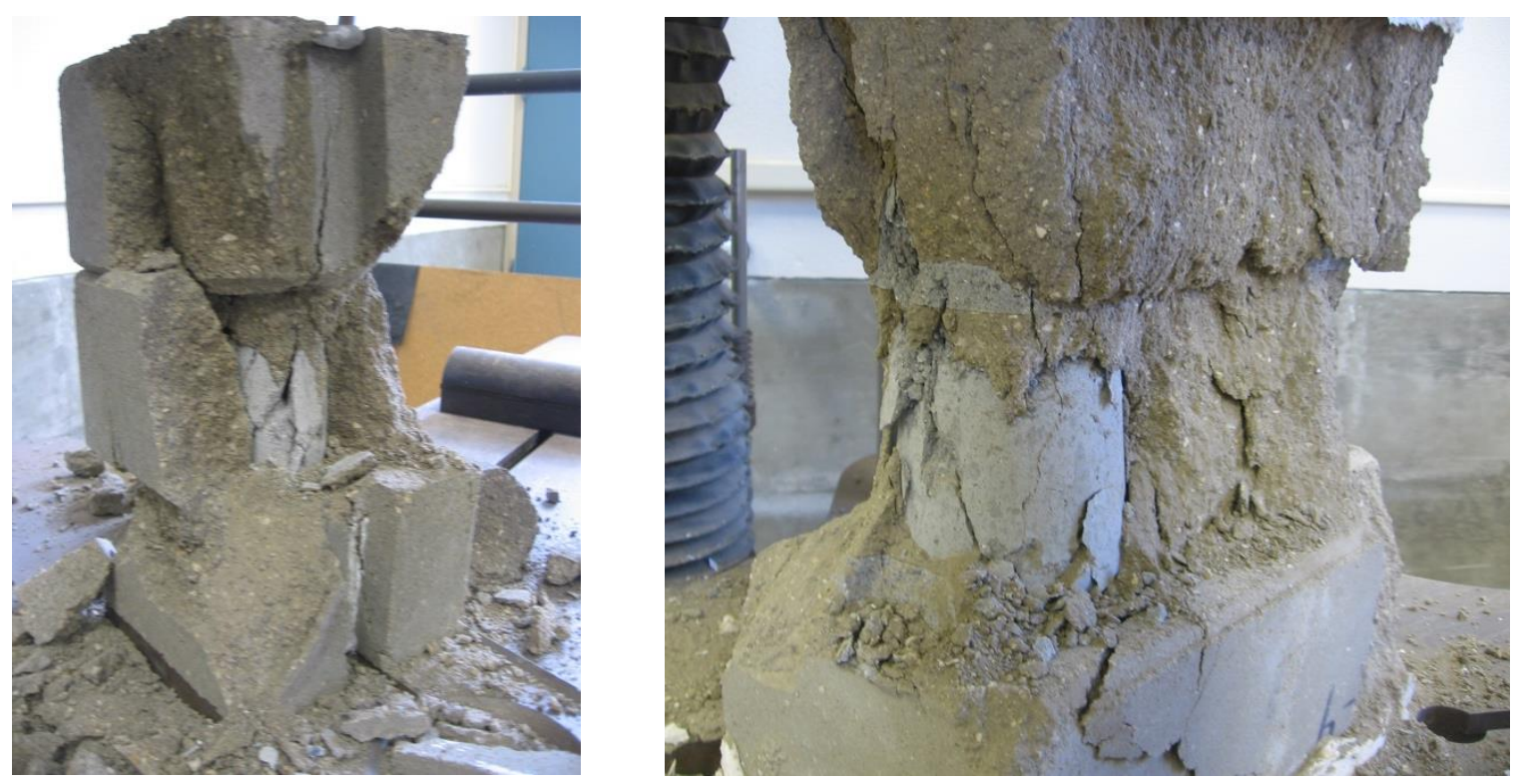

Figure 3.21: Rhino (left) and V-Lock (right) Prism Failures

\subsection{Grout}

The grout used throughout construction and testing utilized mix proportions of 1:0.33:4.9:1.5 Portland cement:lime:sand:water by stock weight. (This was based on trial volumetric proportions of 1:0.67:5.7 cement:lime:sand.) During construction, the compressed earth blocks rapidly absorb water from the grout, causing the grout to stiffen up too fast to consolidate it with rodding. The grout must therefore have a highly fluid consistency and an accordingly high water content to self-consolidate. Water was added based on workability, which was tested using the slump flow method described in the batching procedure below; the listed water proportion is an average value.

The high level of water absorbed by the blocks also has the side-effect of dramatically increasing the grout strength within the walls by reducing the in situ water:cement ratio. Excessively strong grout is undesirable: Bales (2009) observed that if the grout is significantly stronger than the surrounding blocks, they do not behave as a single composite material, and the blocks split in a brittle manner around the interface 
with the grout cores. The amount of sand and water are controlled by the mixture's workability and tendency to bleed; the strength was therefore controlled by replacing some of the Portland cement with hydrated lime, resulting in the mix proportions described above. It is worth mentioning that while the intention was a grout with strength comparable to the blocks, the tested strength using the porous cube method described below was still significantly higher than the block strength.

\subsubsection{Batching Procedure}

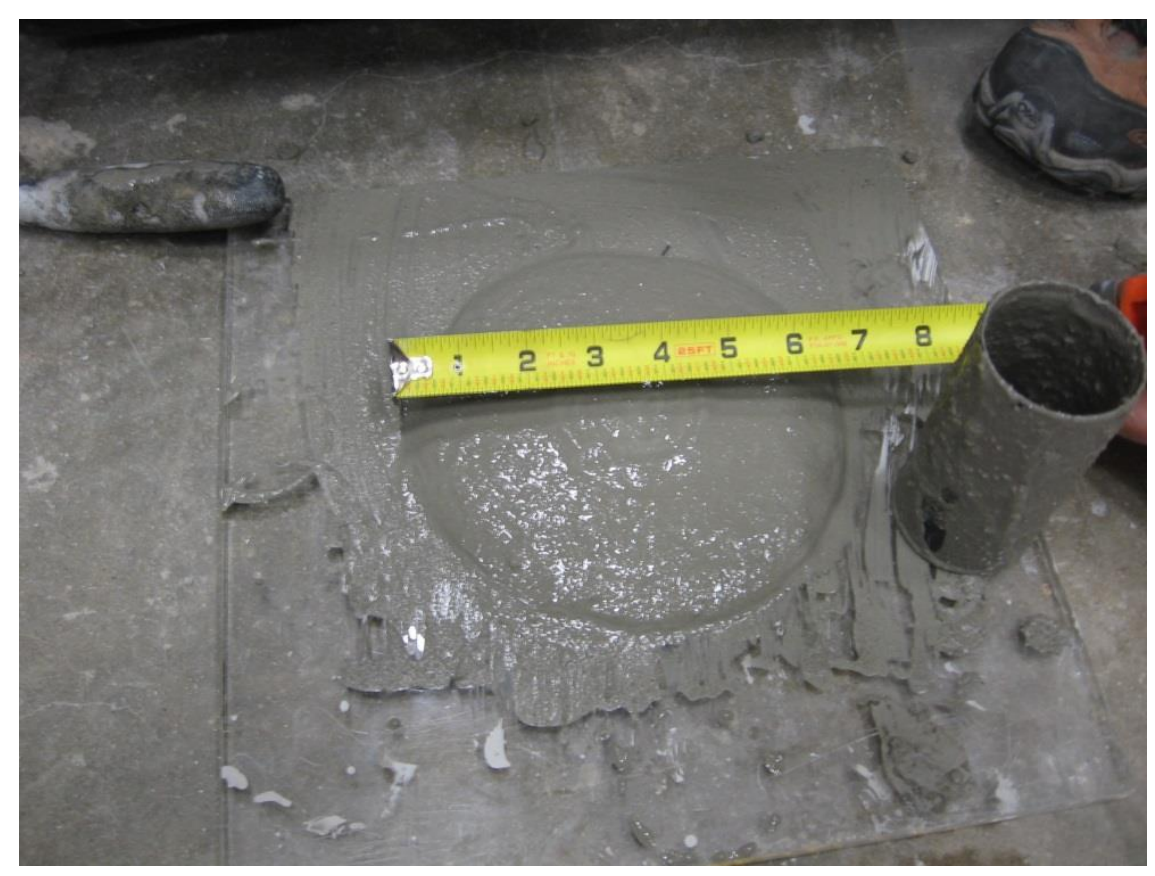

Figure 3.22: Grout Slump Flow Test, Units in Inches

Because a mechanical mixer would cause the sand to settle out, grout was mixed by hand with a metal scoop in a large plastic tub. All dry ingredients were mixed together before incrementally adding water, remixing with each additional increment. When the batch became noticeably fluid (gauged from experience), workability was tested by filling a 100-mm length of 50-mm-diameter cylinder with grout. The cylinder was held in place against a smooth plate; rapidly lifting the cylinder allowed the grout to 
flow out on the plate, similar to the slump flow test. The resulting diameter provided a quantitative measure of workability. If the diameter was too low, the grout was returned to the mixing tub along with additional water, and the process was repeated until reaching a target diameter of $19 \mathrm{~cm}$ (illustrated in inches in Figure 3.22).

\subsubsection{Compressive Strength Tests}

Two main sample types were used to measure the grout compressive strength. For convenience, they are described here as "porous" and "non-porous" cube samples. Non-porous samples were cast in plastic cubes; these do not reflect the in situ water absorption phenomenon and is primarily meant to evaluate variability between batches. Porous samples are cast between blocks to mimic the water absorption that occurs within the walls and therefore capture the actual in situ grout strength. A third sample type, in which cylinders were cast within the grout cores of spare Rhino blocks, was previously used by Bland (2011) for porous samples; it was performed here to compare its performance relative to the porous cube method. All three methods are described in more detail below. Similar to the block prisms, grout samples were covered in plastic wrap and placed on the laboratory floor close to the wall until a day or two prior to wall testing, to maintain similar curing conditions between the walls and grout samples. Tables 3.4 through 3.6 summarize the test results for each wall, while Appendix D contains individual sample results and average values for each batch. Because the grout batches were mixed on different days, sample age is given as a range for each wall. 
Table 3.4: Non-Porous Cube Compressive Strength

\begin{tabular}{|c|c|c|c|c|}
\hline Wall & Mean (MPa) & $\begin{array}{c}\text { Standard } \\
\text { Deviation (MPa) }\end{array}$ & $\begin{array}{c}\text { Coefficient of } \\
\text { Variation }\end{array}$ & $\begin{array}{c}\text { Sample Age } \\
\text { (days) }\end{array}$ \\
\hline 1 & 4.93 & 0.683 & $14 \%$ & $58-65$ \\
\hline 2 & 5.31 & 0.878 & $17 \%$ & $22-24$ \\
\hline 3 & 5.72 & 0.835 & $15 \%$ & $32-33$ \\
\hline
\end{tabular}

Table 3.5: Porous Cube Compressive Strength

\begin{tabular}{|c|c|c|c|c|}
\hline Wall & Mean (MPa) & $\begin{array}{c}\text { Standard } \\
\text { Deviation (MPa) }\end{array}$ & $\begin{array}{c}\text { Coefficient of } \\
\text { Variation }\end{array}$ & $\begin{array}{c}\text { Sample Age } \\
\text { (days) }\end{array}$ \\
\hline 1 & 11.1 & 3.07 & $28 \%$ & $64-71$ \\
\hline 2 & 12.3 & 1.47 & $12 \%$ & $23-25$ \\
\hline 3 & 13.7 & 1.33 & $10 \%$ & $32-33$ \\
\hline
\end{tabular}

Table 3.6: Porous Cylinder Compressive Strength

\begin{tabular}{|c|c|c|c|c|}
\hline Wall & Mean (MPa) & $\begin{array}{c}\text { Standard } \\
\text { Deviation (MPa) }\end{array}$ & $\begin{array}{c}\text { Coefficient of } \\
\text { Variation }\end{array}$ & $\begin{array}{c}\text { Sample Age } \\
\text { (days) }\end{array}$ \\
\hline 1 & 4.05 & 1.19 & $29 \%$ & $65-72$ \\
\hline 2 & 4.32 & 1.03 & $24 \%$ & $23-25$ \\
\hline 3 & 4.79 & 1.68 & $35 \%$ & $44-45$ \\
\hline
\end{tabular}

\subsubsection{Non-Porous Cube Samples}

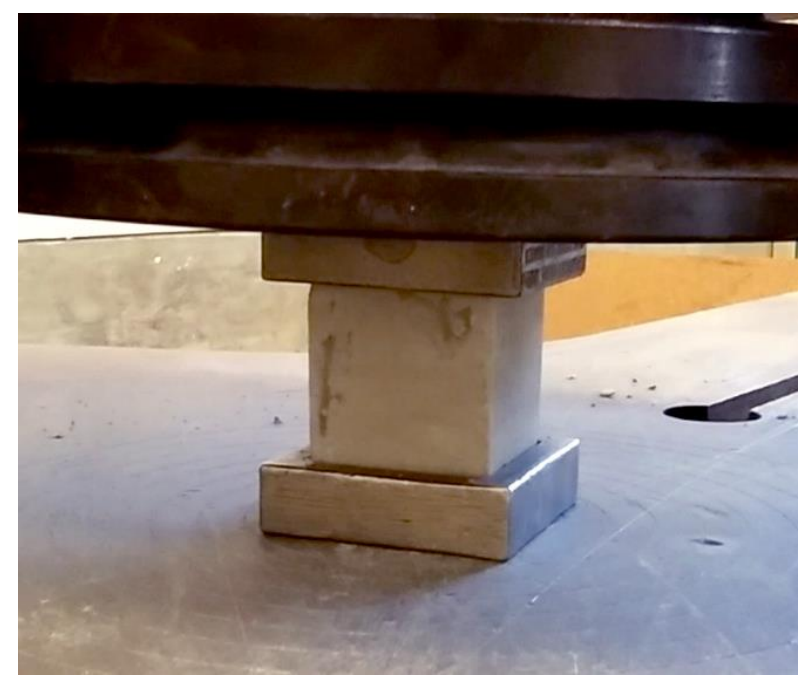

Figure 3.23: Non-Porous Cube Sample 
Non-porous cube samples were cast in 50-mm plastic molds. No water was absorbed by the molds, making this method a poor measure of the walls' in situ grout strength, but the simple nature of the samples makes this a useful tool for quality assurance. Samples were equipped with neoprene caps for compressive testing, as shown in Figure 3.23. After a soft start up to $2.2 \mathrm{kN}$, the compressive testing apparatus loaded samples at a rate of $240 \mathrm{kPa} / \mathrm{s}$ until failure.

\subsubsection{Porous Cube Samples}

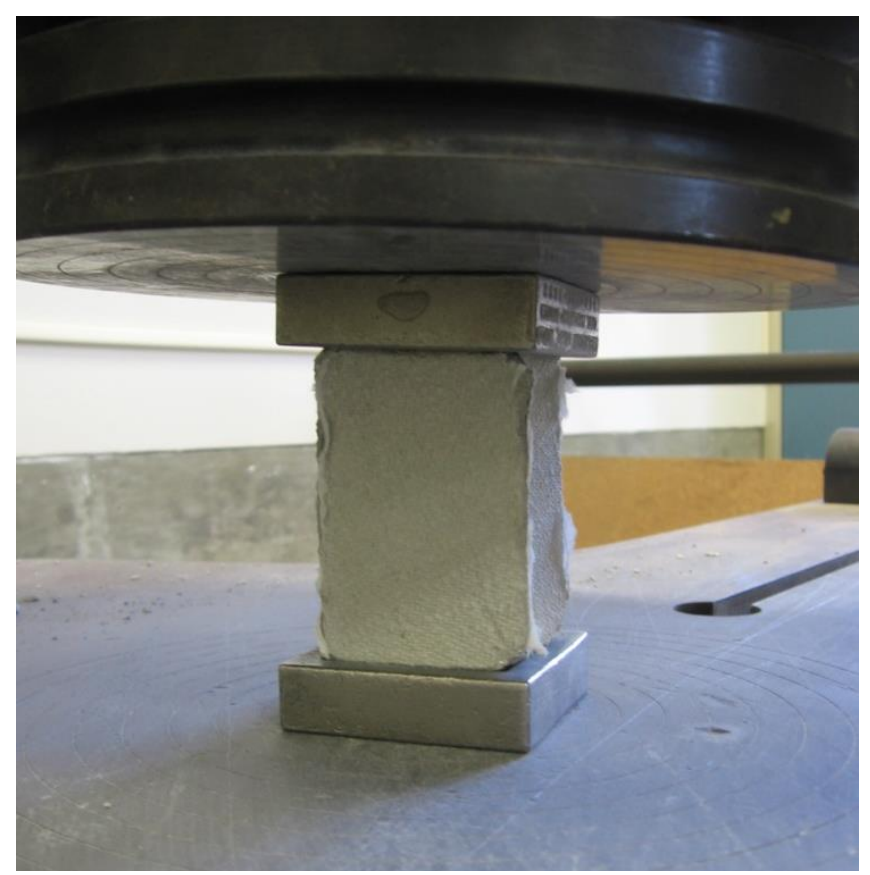

Figure 3.24: Porous "Cube" Sample

To capture the effect of water absorption on grout strength, samples were cast between spare Rhino blocks as shown in Figure 3.25 below, with paper towels placed to allow water absorption while preventing the grout from bonding to the blocks. (The grout did, however, firmly bond to the paper towels, which could not be entirely removed before testing, as can be seen on the outside of the sample in Figure 3.24. This was assumed to have a negligible effect on measured compressive strength.) This follows the 
general principle of ASTM C1019 - Standard Test Method for Sampling and Testing Grout. The samples themselves deviated from the standard in several ways, however, particularly in size: The samples were approximately $50 \mathrm{~mm}$ by $50 \mathrm{~mm}$ like the nonporous cubes with a height of $90 \mathrm{~mm}$, while ASTM C1019 specifies a minimum side length of $76 \mathrm{~mm}$ and a height twice the width. Technically the samples are rectangular prisms rather than cubes, but here they shall be referred to as "cubes" to succinctly distinguish them from the porous cylinders.

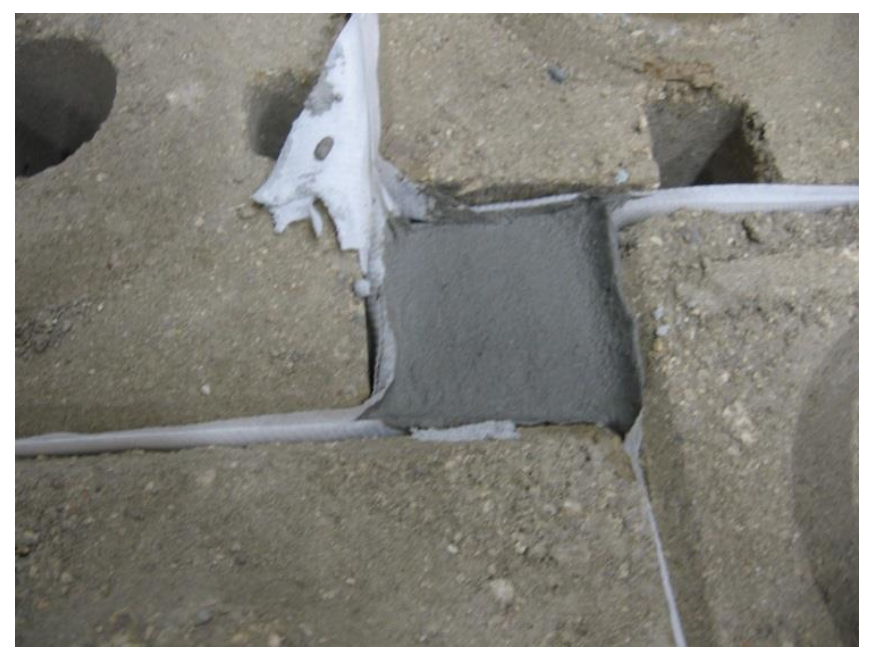

\section{Figure 3.25: Casting a Porous Cube Sample}

As with the non-porous cubes, the porous cubes were capped with neoprene pads for testing. Owing to the course nature of casting samples between blocks, the samples frequently had geometric imperfections that did not fit within the bounds of the neoprene pad and instead would contact the metal portion of the cap. For the samples for Wall 1, these imperfections were coarsely chiseled away, which no doubt explains the unusually high standard deviation for those samples. For subsequent walls, the imperfections were more carefully ground from the sample. Compressive testing followed the same loading protocol as the non-porous samples. 


\subsubsection{Porous Cylinder Samples}

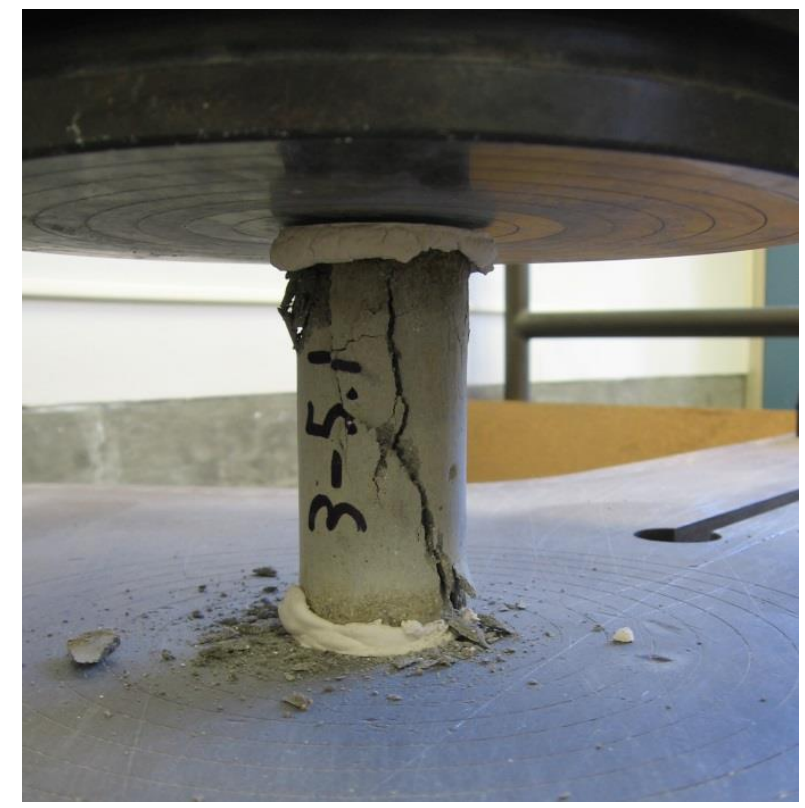

Figure 3.26: Porous Cylinder Sample

For comparison purposes, grout samples were also cast within the grout chambers of spare Rhino blocks, similar to the method used by Bland (2011). Carefully splitting and shaving the compressed soil away from the grout chamber resulted in 43-mmdiameter cylinders. The cylinders were capped with gypsum cement before testing. The samples from Walls 1 and 2 had somewhat irregular caps; this was corrected for the Wall 3 samples. Samples from Walls 1 and 2 were loaded at a rate of $240 \mathrm{kPa} / \mathrm{s}$; the weak nature of the grout resulted in extremely short test durations of approximately 30 seconds. The loading rate for Wall 3 was therefore reduced to $30 \mathrm{kPa} / \mathrm{s}$. The results of the porous cylinder and cube samples are compared in depth in Section 6.4.

\subsection{Mortar}

The mortar used at the base of each wall followed the typical proportions for a Type S mortar. Each mix followed proportions of 1:0.4:8.8 Portland cement:lime:sand, by stock weight. This in turn was based on trial volumetric proportions of 1:0.5:3.5 
cement:lime:sand, within ranges for Type S mortar per ASTM C270 - Standard Specification for Mortar for Unit Masonry. The sand only incorporated material passing a \#8 sieve. Water was added by feel such that the final mortar had a workable consistency similar to wet beach sand at tide level. As with the grout, mortar was mixed by hand. No tests were performed to determine mortar compressive strength.

\subsection{Concrete}

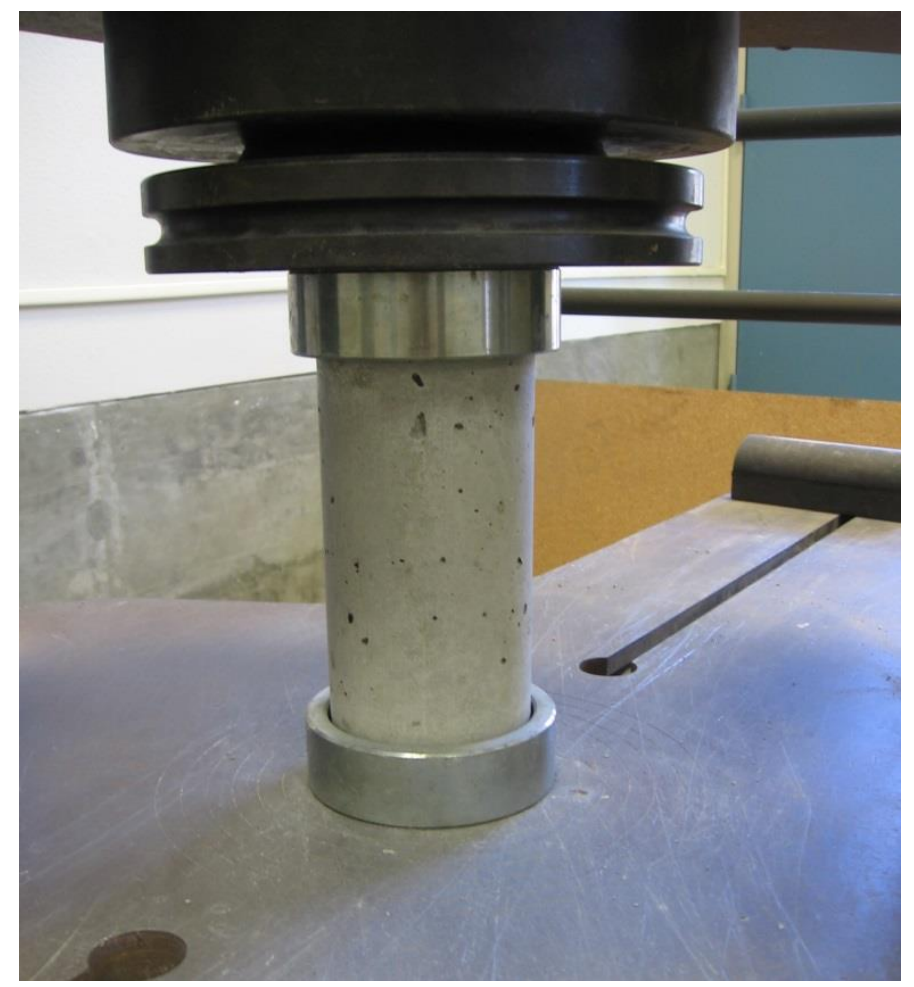

Figure 3.27: Concrete Cylinder Sample

All concrete used proportions of 1:2:1.5:0.6 Portland cement:sand:gravel:water by stock weight. This follows the proportions found in Table 12-16 of the Portland Cement Association's Design and Control of Concrete Mixtures (Kosmatka \& Wilson, 2011). The quantity of added water deviated from the given proportions and was instead added by feel to achieve a workability that would readily flow around reinforcement and into 
the tops of the compressed earth block grout chambers without significant consolidation effort; the proportion of water above is an average value.

Cylinder samples (102 cm diameter by $203 \mathrm{~cm}$ high) were collected and tested in general compliance with ASTM C39. The results are summarized in Table 3.7, while Appendix D contains results for individual samples.

Table 3.7: Concrete Cylinder Compressive Strength

\begin{tabular}{|c|c|c|c|c|}
\hline Wall & Mean (MPa) & $\begin{array}{c}\text { Standard } \\
\text { Deviation (MPa) }\end{array}$ & $\begin{array}{c}\text { Coefficient of } \\
\text { Variation }\end{array}$ & $\begin{array}{c}\text { Sample Age } \\
\text { (days) }\end{array}$ \\
\hline 1 & 38.4 & 3.73 & $9.7 \%$ & 63 \\
\hline 2 & 32.6 & 0.22 & $0.7 \%$ & 19 \\
\hline 3 & 35.3 & 0.37 & $1.1 \%$ & 29 \\
\hline
\end{tabular}

\subsection{Steel}

All tested walls incorporated three distinct types of reinforcing steel in their construction: \#3 deformed reinforcing bar, 6-mm-diameter "pencil rod," and $4 \mathrm{~mm}$ diameter "ladder reinforcement." Samples of each steel type were subjected to tensile testing; Figure 3.28 shows the test setup, while Table 3.8 summarizes the results and Appendix D contains individual sample results. Each variety of steel is briefly described in the following sections along with its application.

Table 3.8: Reinforcing Steel Material Properties

\begin{tabular}{|c|c|c|c|c|c|c|}
\hline \multirow{2}{*}{ Bar Type } & \multicolumn{3}{|c|}{$f_{y}(\mathrm{MPa})$} & \multicolumn{3}{c|}{$f_{u}(\mathrm{MPa})$} \\
\cline { 2 - 7 } & Mean & $\begin{array}{c}\text { Standard } \\
\text { Deviation }\end{array}$ & $\begin{array}{c}\text { Coefficient } \\
\text { of Variation }\end{array}$ & Mean & $\begin{array}{c}\text { Standard } \\
\text { Deviation }\end{array}$ & $\begin{array}{c}\text { Coefficient } \\
\text { of } \\
\text { Variation }\end{array}$ \\
\hline \#3 Deformed & 361 & 8.21 & $2.3 \%$ & $552^{1}$ & N/A $^{1}$ & N/A $^{1}$ \\
\hline Pencil Rod & 445 & 132 & $30 \%$ & 522 & 99.2 & $19 \%$ \\
\hline $\begin{array}{c}\text { Ladder } \\
\text { Reinforcement }\end{array}$ & 447 & 11.6 & $2.6 \%$ & 456 & 8.78 & $1.9 \%$ \\
\hline
\end{tabular}

${ }^{1}$ All \#3 deformed samples except for one slipped from the testing apparatus between yield and rupture. The stated ultimate stress is from a single sample. 


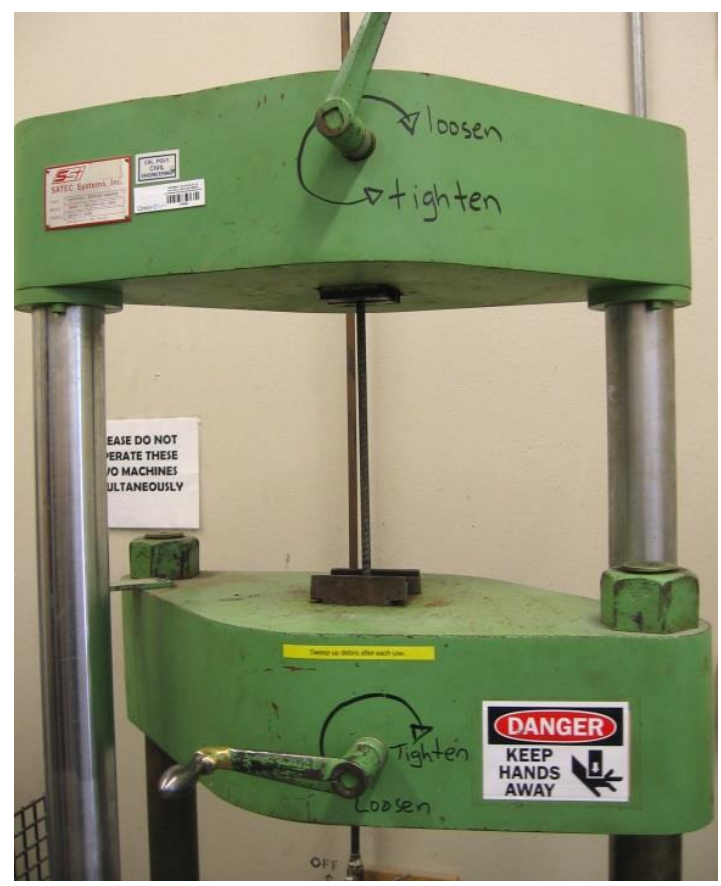

Figure 3.28: Steel Tensile Test Setup

\subsection{1. \#3 Deformed Reinforcing Bar}

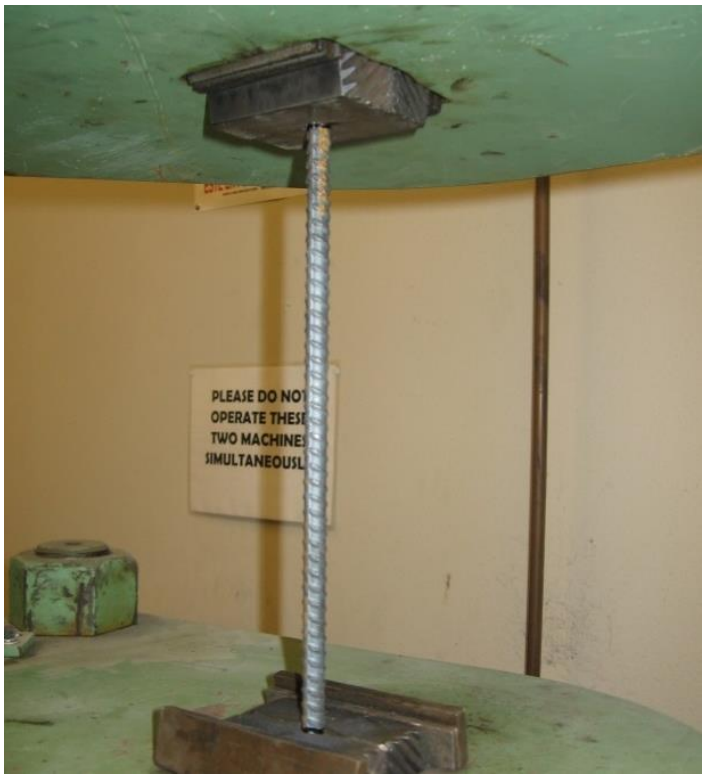

Figure 3.29: \#3 Deformed Bar

All longitudinal reinforcement for the tested walls consisted of deformed \#3 reinforcing bar. The reinforcement consisted of ASTM 615 Grade 40 steel and was purchased from a local masonry construction supplier. 


\subsubsection{Pencil Rod}

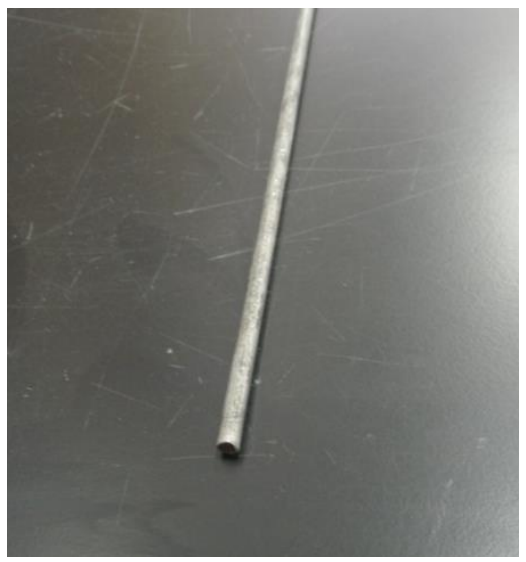

Figure 3.30: Pencil Rod

Smooth 6-mm-diameter steel rod, referred to as "pencil rod," reinforced the concrete beam at the top of each wall. It consisted of ungraded mild steel purchased from a local steel supplier. Testing revealed two distinct types of steel: One which was weaker and highly ductile, and one which was stronger but more brittle. Since the steel strength only mattered inasmuch as it held the bond beam together, this was not deemed important, although it did affect the pencil rod's workability during construction.

\subsubsection{Ladder Reinforcement}

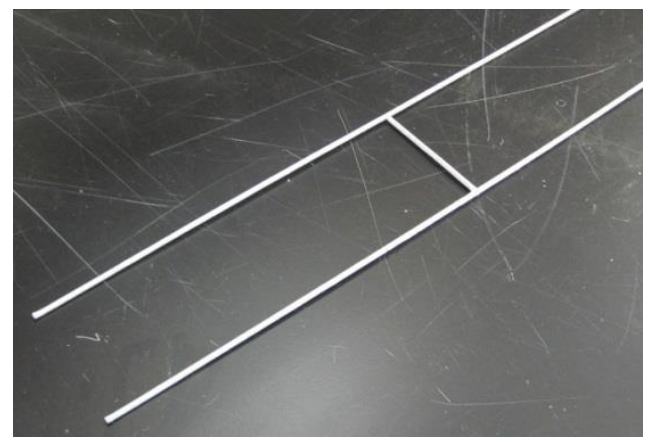

Figure 3.31: Ladder Reinforcement

"Ladder reinforcement" consisted of two 4-mm-diameter steel rods laterally connected at regular intervals for ease of placement. Ladder reinforcement supplemented the pencil rod reinforcement in the concrete beams at the top of each wall. 


\section{WALL CONSTRUCTION}

The following chapter outlines the steps used to construct all the walls used in this research. Despite the differences between the Rhino blocks and the V-Lock blocks, construction of all walls followed the same basic procedure. Differences in method between the two block types are noted where applicable.

\subsection{Vertical Reinforcement Installation}

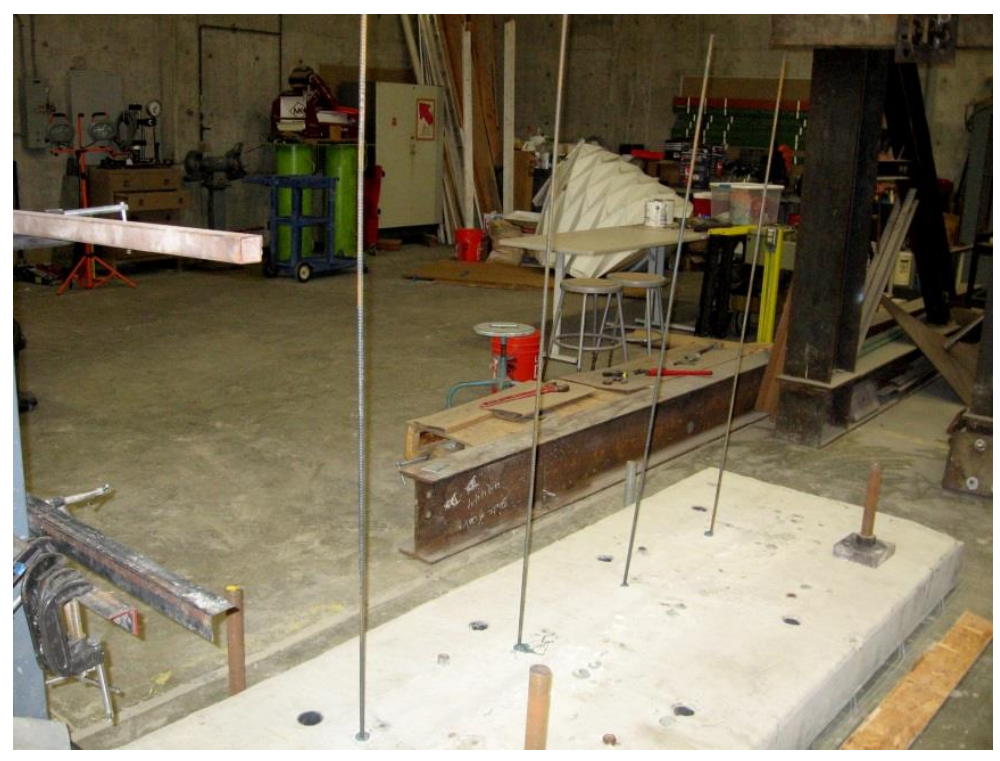

Figure 4.1: Vertical Reinforcement

Each wall was built on a portable, 20 -mm-thick reinforced concrete slab bolted to the laboratory strong floor. Vertical reinforcement for all three walls consisted of four \#3 bars epoxied 190 millimeters (7.5 inches) into the slab with Simpson Strong-Tie Set-XP epoxy, installed in accordance with manufacturer's instructions. Reinforcement was not disturbed for at least 24 hours after placement to allow the epoxy time to cure. After this period, each bar was bent at its base to make it plumb. To facilitate the placement of lower block courses, the reinforcement incorporated a 91-cm lap splice, beginning and ending at the elevations listed in the table below. This length is not sufficient to fully 
develop a Grade 40 \#3 bar, but since rebar yielding would typically occur towards the base of the wall, the length was deemed sufficient. Forensic examination of the splices after testing showed no signs of slip.

Table 4.1: Lap Splice Elevations from Base of Wall

\begin{tabular}{|c|c|c|}
\hline Wall & $\begin{array}{c}\text { Splice Bottom } \\
\text { Elevation }(\mathrm{cm})\end{array}$ & $\begin{array}{c}\text { Splice Top } \\
\text { Elevation }(\mathrm{cm})\end{array}$ \\
\hline 1 & 28 & 119 \\
\hline 2 & 66 & 157 \\
\hline 3 & 66 & 157 \\
\hline
\end{tabular}

\subsection{Base Course}

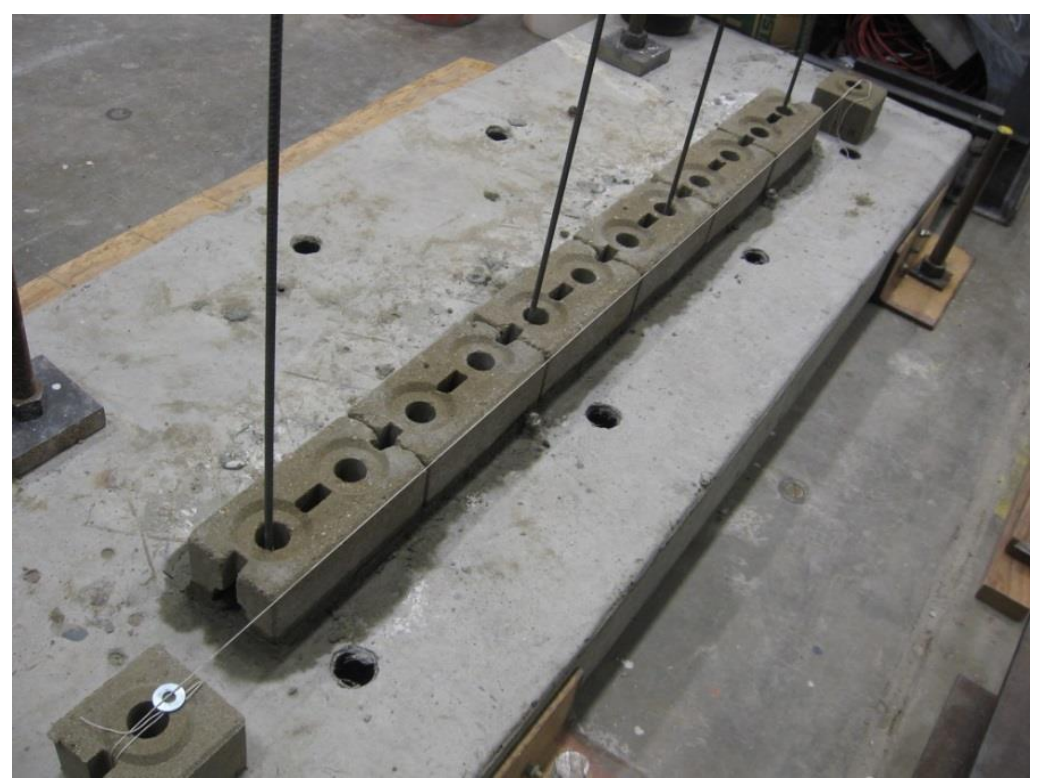

Figure 4.2: Base Course

The base course of each wall consisted of a layer of blocks mortared to the base slab with a Type S mortar, described above in Section 3.4. Before mortaring, the slab was cleaned of residual mortar, epoxy, and debris from prior testing. The foundation had embedded, protruding anchors for transporting the slab which infringed on the edge of the base course; small portions were gouged from the adjacent blocks to accommodate the anchors and properly fit the course, as can be seen in Figure 4.3. 


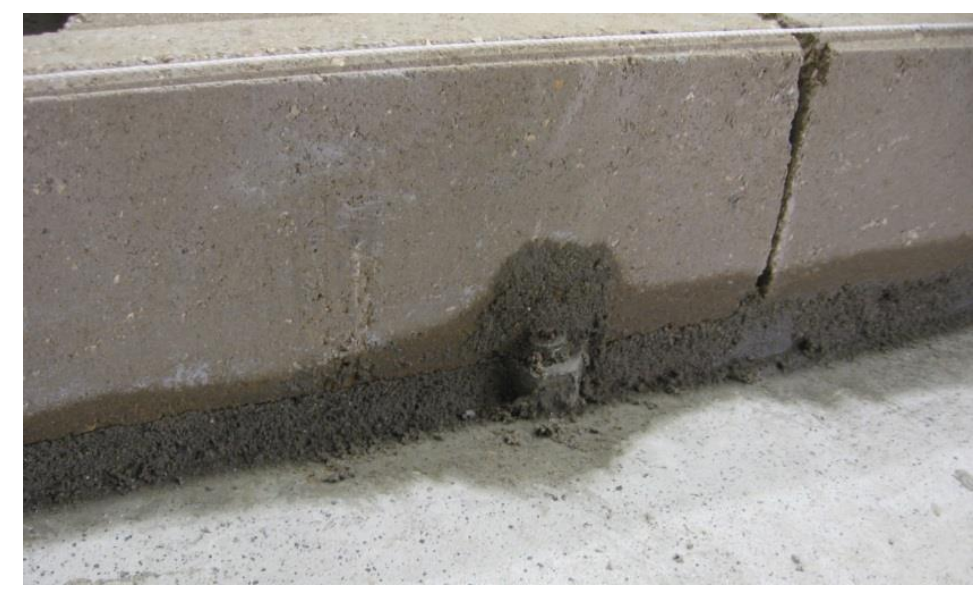

Figure 4.3: Gouged Block Around Anchor

The base course of Wall 2 used the same Vermeer blocks as the rest of the wall, while Walls 1 and 3 used Rhino channel blocks flipped upside-down as in Figure 4.4 with the small raised portions chiseled off. In both cases, this created two narrow contact surfaces on either side of the block, which eased the process of levelling the blocks on the mortar. Using a bubble level in combination with the level string visible in Figures 4.2 and 4.4 ensured the base course was level both in and out of the plane of the wall. The mortar was allowed to harden for at least 24 hours before adding subsequent courses.

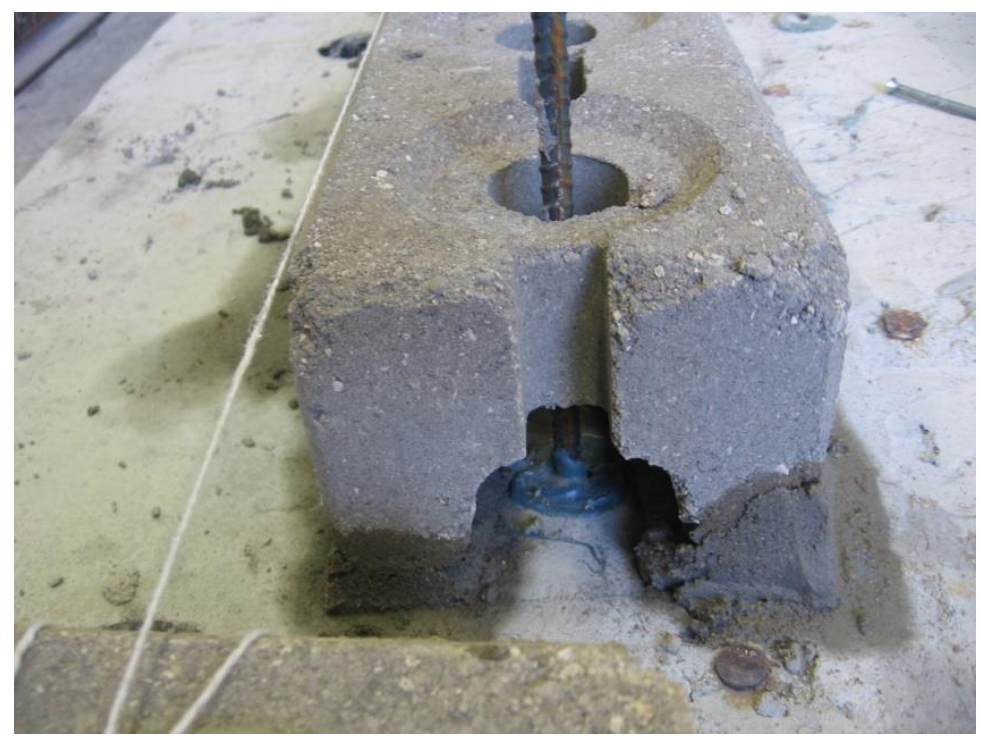

Figure 4.4: Inverted Channel Blocks as Base Course 


\subsection{Subsequent Courses}

Following typical construction technique for these blocks, each subsequent course was dry-stacked over the previous course in a running bond pattern. Brushing the top of the previous course beforehand removed loose particles to provide better contact. Several strategies were used to level the top of each course, often taking advantage of the natural variation in block dimensions. These strategies included:

- rotating blocks 180 degrees (useful in cases where one end of a block was taller than the other)

- exchanging the locations of specific blocks

- purposely selecting over- or undersized blocks to fit a specific situation

- selectively wearing down the tops or bottoms of blocks, either the entire surface (when the block as a whole was too high) or a select region (to accommodate a crown immediately under the block and prevent rocking)

- $\quad$ shimming blocks with nails to raise one end or the other (Figure 4.5)

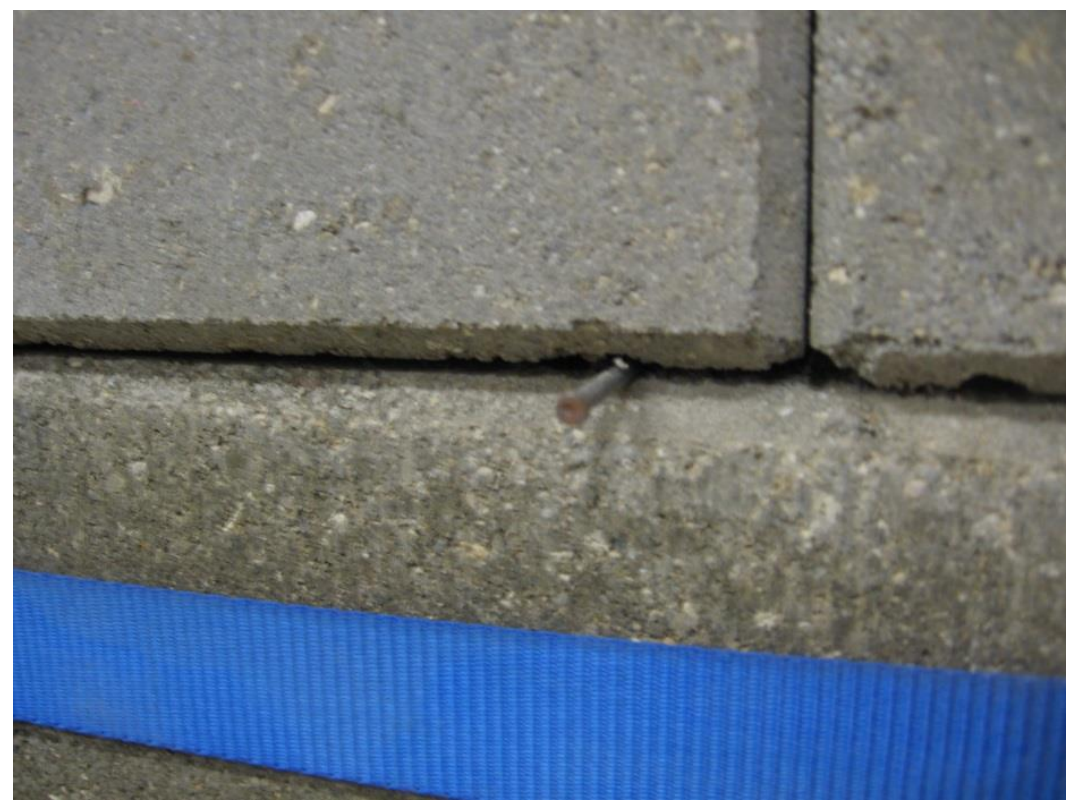

Figure 4.5: Nail Used as a Block Shim 
Achieving a uniformly level top surface for every course was difficult, especially because the Rhino blocks tended to have one end taller than the other (a result of wear in the press, not an innate property of Rhino blocks). In many cases, the first priority was ensuring a smooth transition between blocks to prevent overlying blocks from rocking. If the top of a course could not be made perfectly level, it was at least made level "on average," where the extreme ends of the course formed a level line that the intermediate blocks wavered slightly above and below. Similar variation of the next course could sometimes compensate for it, although the lower course would still remain uneven.

The main tools for judging the uniformity of each course were a mason's line, a 1.2-meter length of aluminum channel, and a bubble level. The mason's line and aluminum channel provided visual references for the variation in the level of a course and facilitated identification of extreme high and low spots, while the bubble level measured if the course was in fact level. The channel and level were also used to determine if the wall's edges were plumb both in and out of plane.

\subsection{Grouting}

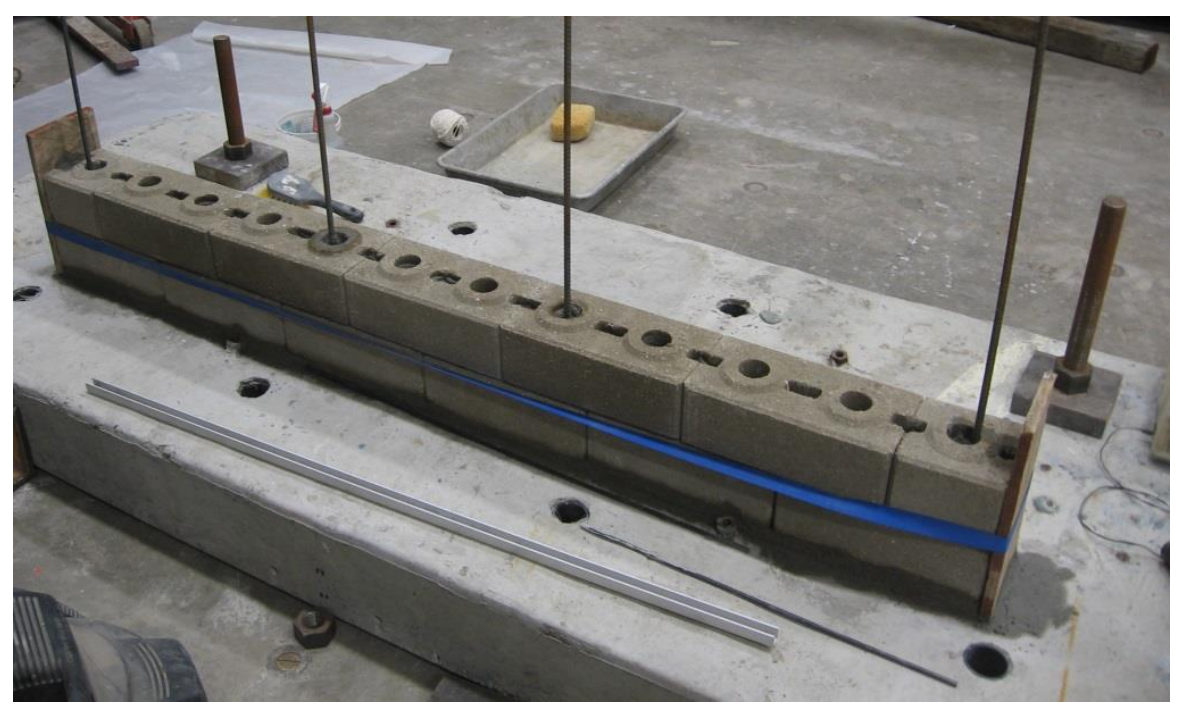

Figure 4.6: Second Course with Grout 
All walls were fully grouted, with grout filling every vertical grout core and the shear keys where present (i.e. Wall 1). Because the grout stiffened quickly on contact with the compressed earth blocks, each grout lift filled no more than four courses of Rhino blocks for Walls 1 and 3. Furthermore, because the upside-down channel blocks in the base course for these walls resulted in no interlock between the first two courses (see Figure 4.4 above), a lift was poured immediately after placing the second course to fill the interlock voids with grout and stabilize the second course. This lift also filled the deep channel of the base course, more firmly bonding it to the foundation. Plywood strips strapped to the ends of the walls during grouting provided formwork for the Rhino blocks' head joint shear keys at the end of the wall and prevented grout from pouring out the ends of the channels of standard V-Lock blocks and Rhino channel blocks.

The V-Lock blocks of Wall 2 were grouted in two-course lifts because it was impractical to mix any more grout at a time. Had this not been an issue, the larger grout cores may have allowed lifts higher than those of the Rhino blocks. Pringle (2016) noted that the Vermeer blocks used in both experiments tended to split longitudinally during grouting, perhaps due to a combination of the expansive properties of the clay in Las Tablas soil (causing the soil immediately surrounding the grout cores to expand) and the relatively higher rigidity of the Vermeer blocks (which would be less able to accommodate the expansion). To compensate for this, the exteriors of the courses were sprayed with water four times immediately before being grouted to reduce the difference in saturation within the blocks. This technique succeeded: Only isolated blocks cracked during grouting. However, this was later found to have possibly affected the final grout strength; see Section 6.2.2 for further discussion. 
Each grout lift ended slightly below the top of the topmost course to provide a shear key and avoid a cold joint exactly at the boundary between courses. This can be seen in Figure 4.7, which also illustrates the amount of shrinkage in the grout due to water absorption after less than 20 minutes; the grout clinging to the insides of the cores corresponds to the original height of the grout pour. Because the grout stiffened so rapidly, care was taken to minimize disturbing the rebar and creating adjacent voids in the stiffened grout. Similarly, rodding to aid consolidation would have counterproductively left voids in the stiffening grout. Consolidation instead relied solely on the grout's fluidity. Any stray grout on the top surfaces of the blocks was removed before placing the next course

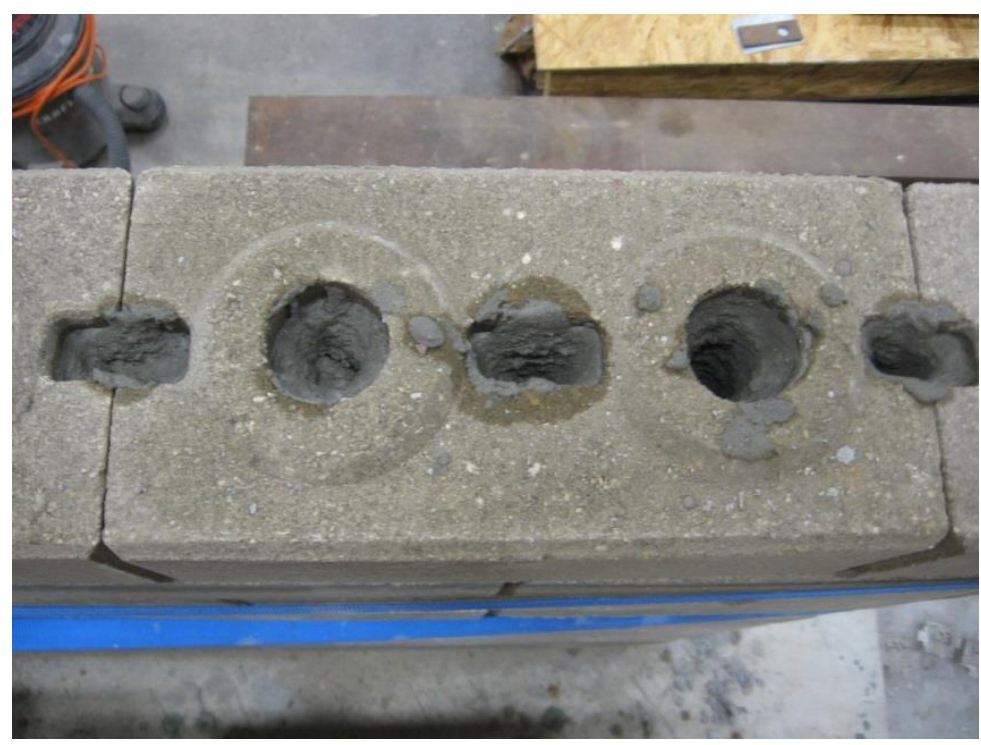

Figure 4.7: Grout Cores and Short-Term Shrinkage

\subsection{Top Course}

The top course of each Rhino block wall consisted of channel blocks to allow the casting of a reinforced concrete bond beam. Because there was no equivalent block type for the V-Lock blocks, the top course was the same as the underlying courses but low enough to allow the casting of a reinforced concrete beam along the top. 


\subsection{Loading Beam Anchors}

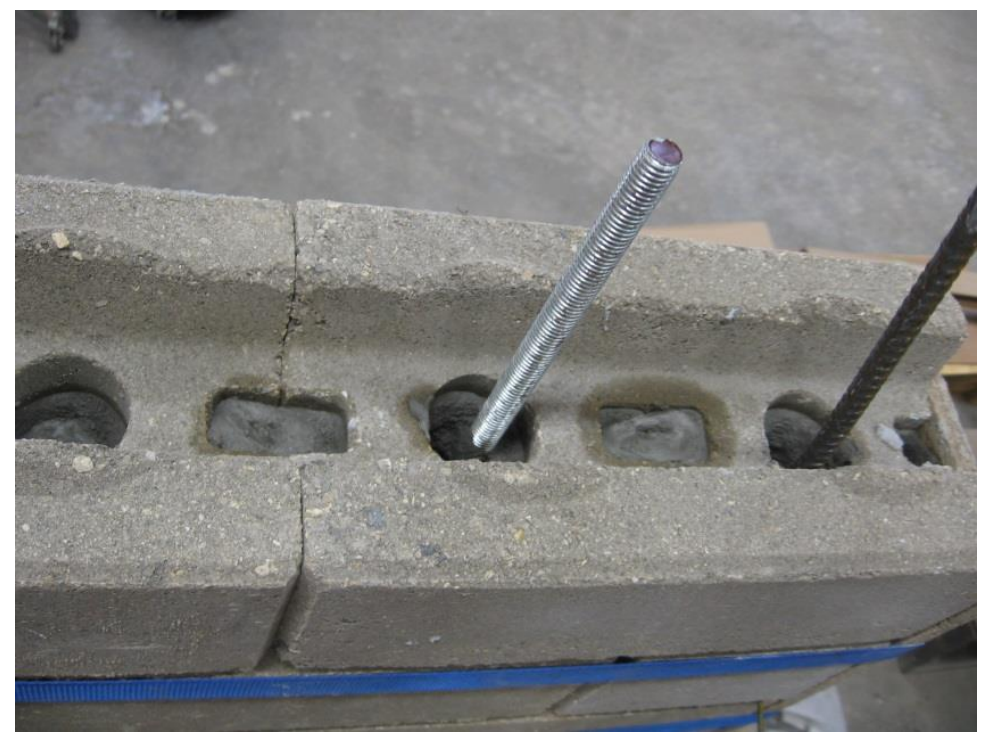

Figure 4.8: Loading Beam Anchor, Post-Grouting

Thirteen-mm-diameter steel threaded rod to anchor the loading beam was installed into the final grout lift of each wall. Five anchors per wall were spaced as evenly and symmetrically along the wall as possible in grout cores not already occupied by vertical reinforcement. Each anchor was embedded into a full grout lift and through the top concrete beam, approximately $330 \mathrm{~mm}$ total. For installation, the anchor was rested on the top of the previous grout lift (usually in a convenient indentation left by shrinkage) and was held in place by hand while the grout lift was poured. The anchor was then released as soon as the grout stiffened enough to hold it upright, typically in less than one minute after pouring. 


\subsection{Reinforced Concrete Beam}

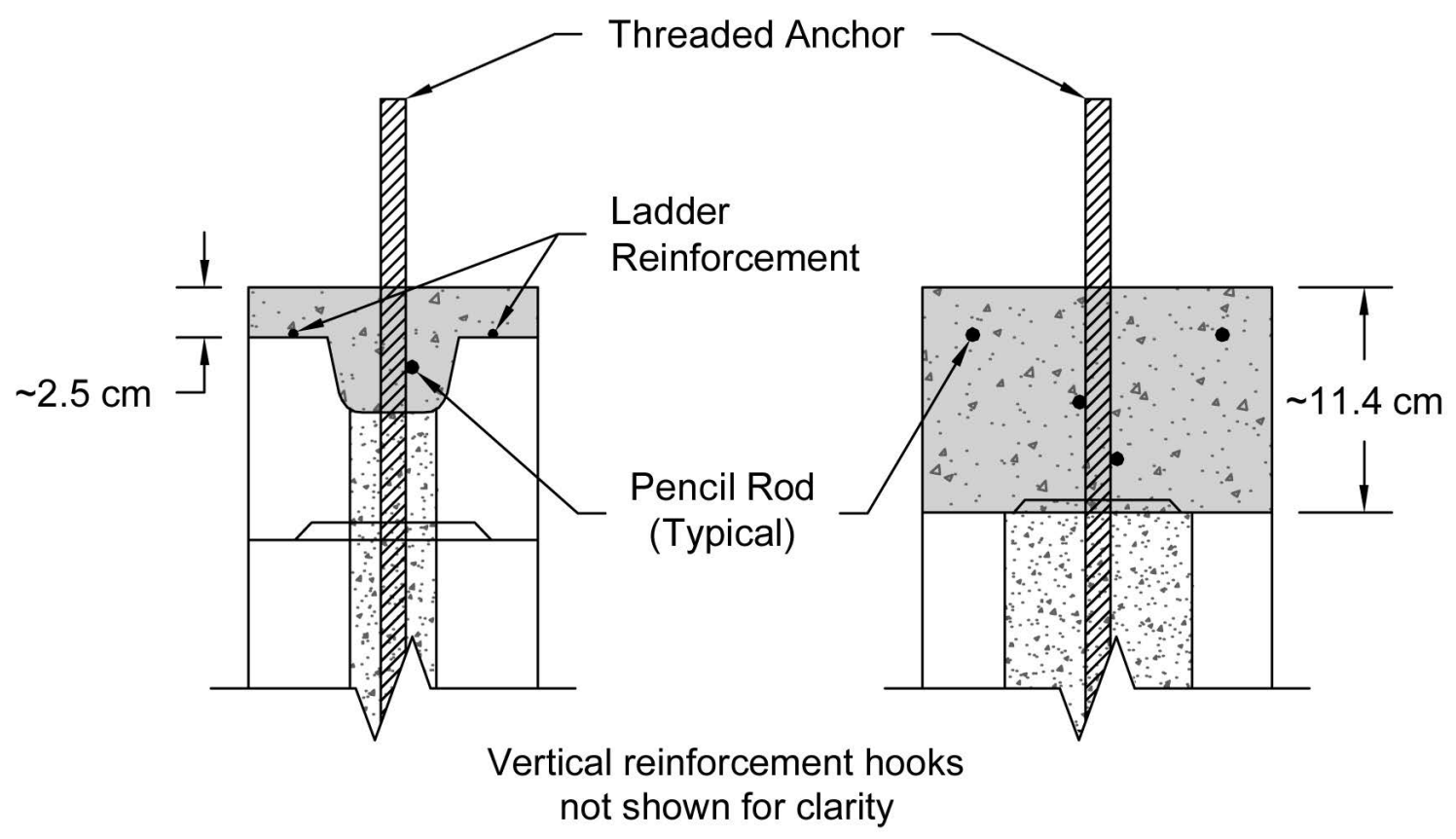

(a) Rhino Block Wall

(b) V-Lock Block Wall

\section{Figure 4.9: Bond Beam Section Detail}

All walls featured a reinforced concrete beam cast along the top to transfer shear from the loading beam along the wall and provide reinforcement continuity around the boundary of the wall. The formwork consisted of lengths of oriented strand board strapped and held to the top course of the wall with ratchet straps and C-clamps. For the Rhino block walls (Walls 1 and 3), the beam took the form of a bond beam cast into a top course of channel blocks and extending far enough above to reach a 1:1 aspect ratio, minus approximately $6 \mathrm{~mm}$ to allow for a layer of gypsum cement between the wall and the steel loading beam. Since there was no channel block equivalent for the V-Lock blocks, the beam for Wall 2 was cast over the top course, occupying a depth greater than a single course of blocks to provide space for the beam's reinforcement, accommodate the hooks of the wall's reinforcement, and again extend high enough to reach a 1:1 aspect 
ratio. The beam's reinforcement used of a combination of pencil rod and ladder reinforcement. Figure 4.9 shows details of the as-built reinforcement for the beam of each wall type.

Hooks at the top of the vertical reinforcement were not bent until at least one day after pouring the final grout lift. The ends of the reinforcement were bent towards the center of the wall either to fit within the channel as much as possible or to be as close to the top course as possible when channel blocks were not present. No attempt was made to match the bend radius to code-based minimums. The actual lengths of the hooks were not measured during construction, but each reinforcing bar was sized to account for a hook approximately $61 \mathrm{~cm}$ long for Wall 1 and $41 \mathrm{~cm}$ long for Walls 2 and 3 . A few centimeters of one of the hooks in Wall 1 were removed via hacksaw because they interfered with another hook pointing towards them. It was not physically possible to bend the hooks far enough such that they remained horizontal when released, so the hooks were tied in place to the threaded anchors.
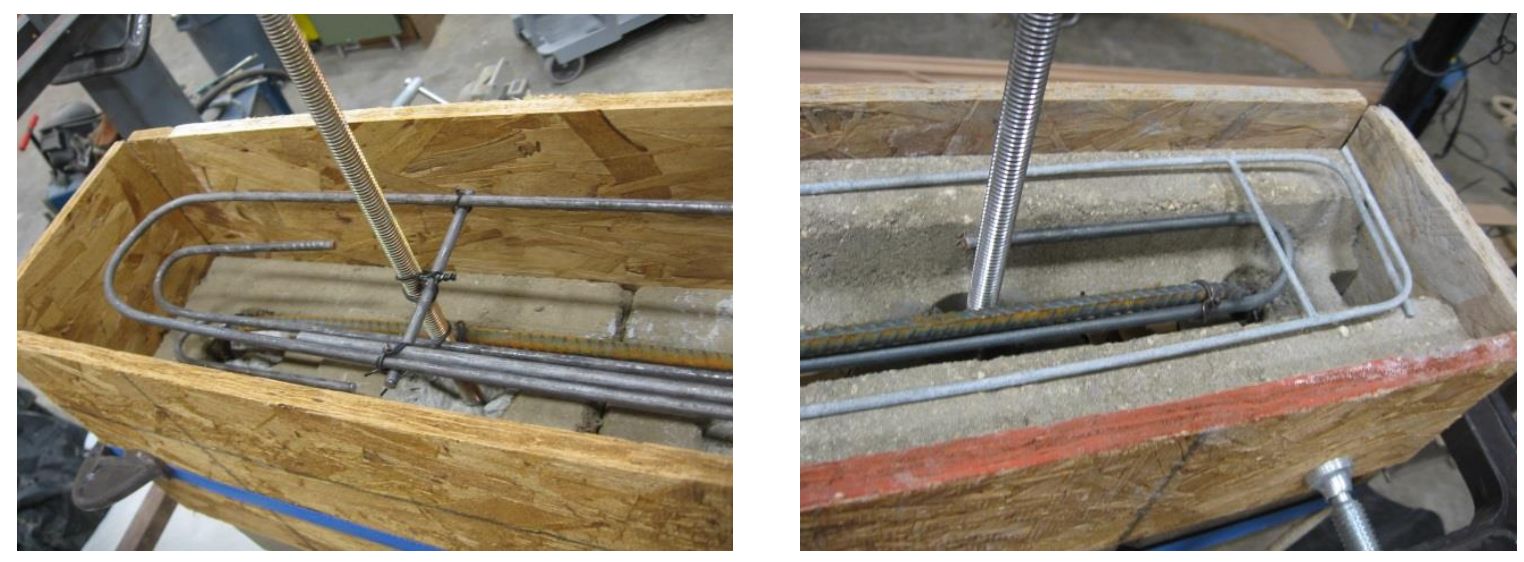

Figure 4.10: Concrete Reinforcement for Walls 2 (left) and 3 (right)

Figure 4.10 shows the beam's reinforcement immediately before casting. Ladder reinforcement terminated in horizontal $90^{\circ}$ hooks. Pencil rod at the center of the beam used $180^{\circ}$ hooks at each end, also possibly tighter than code minimum radii. In Wall 2, 
the pencil rod along the edges of the beam ended in two $90^{\circ}$ bends. Each rod's ends were tied to the other rod's to create a loop around the perimeter of the beam.

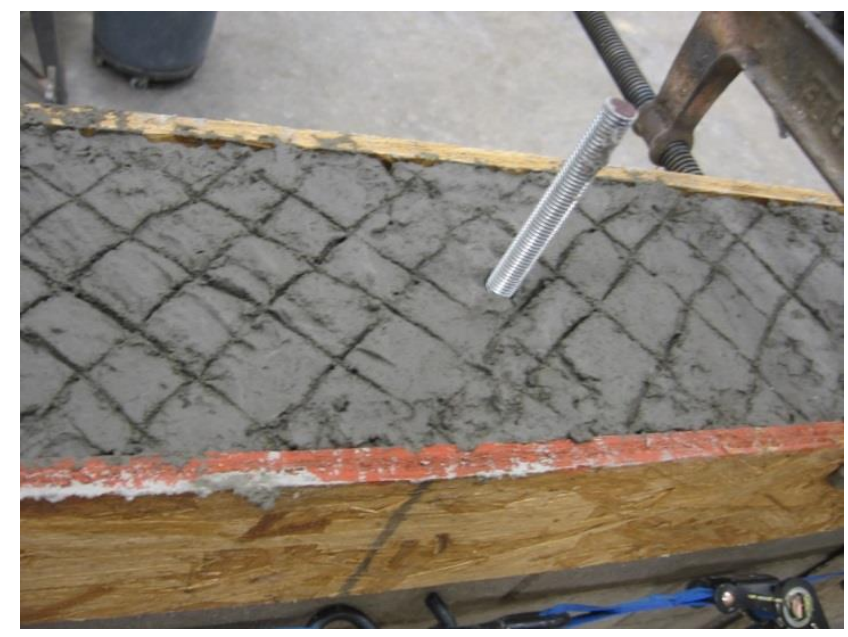

\section{Figure 4.11: Freshy Poured Concrete Beam with Crosshatch Texture}

The concrete was placed and consolidated by hand. After the concrete was placed and troweled level, the sharp edge of the trowel was used to inscribe the crosshatch texture shown in Figure 4.11, roughening the surface to help bond the steel loading beam to the top of the wall.

\subsection{Steel Loading Beam}

A modified steel C10x20 channel section served as the loading beam, connecting directly to the top of the wall and to the hydraulic actuator during testing. The anchor rods fit through holes in the channel, which were drilled when necessary for each wall layout. Steel plates welded to one end created an attachment point for the actuator.

A thin layer of gypsum cement created a conforming surface to support the loading beam. To create this, the oriented strand board formwork originally used for the concrete was moved up approximately $6 \mathrm{~mm}$ so that the top matched the appropriate height for a 1:1 aspect ratio wall. The loading beam was then placed over the wall, resting directly on the formwork. Rope caulk filled the gaps around the plywood to 
minimize leakage. Gypsum cement was mixed with water to reach a very thin, almost watery consistency, and the mixture was poured through preexisting holes in the top of the beam. Ideally, the cement flowed to fill the gap between the loading beam and the top of the wall. Adding enough cement to fill the holes also created shear keys to improve load transfer, shown in Figure 4.12.

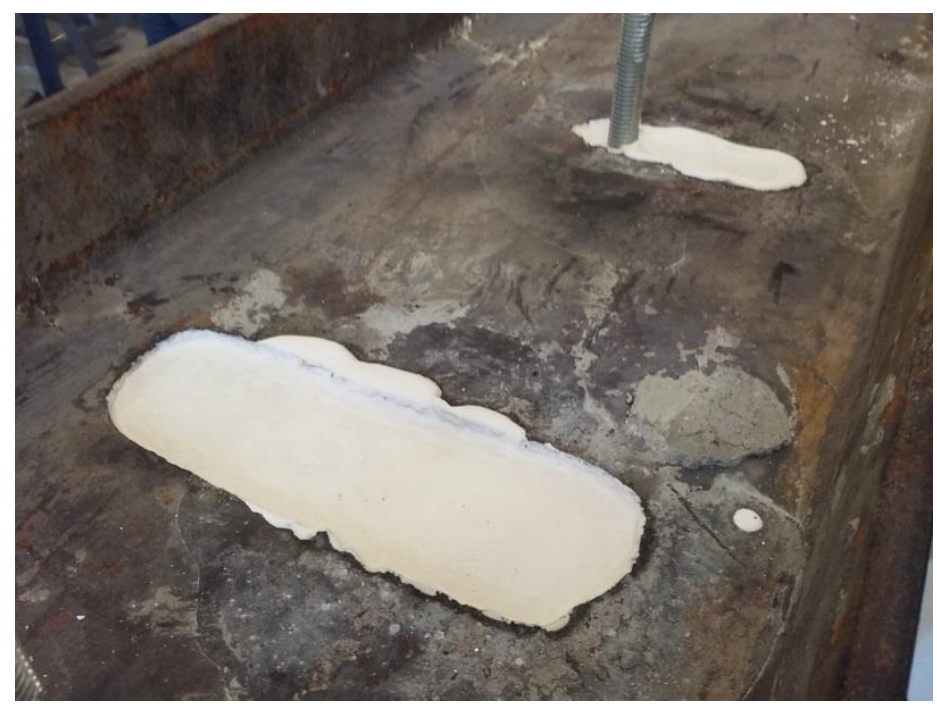

\section{Figure 4.12: Gypsum Cement Shear Keys}

In practice, the effectiveness of this technique highly depended on the viscosity of the gypsum cement mixture. Particularly for the first few batches for Wall 1, the mix was too thick and only flowed within a few inches of each hole as can be seen in Figure 4.13, leaving large regions with no gypsum cement and therefore no contact between the wall and the loading beam. Adding more water to thin the mix helped alleviate the issue, but little could be done for areas where previously poured cement blocked access. Using a much thinner mixture for Wall 2 resulted in few such voids, but the cement leaked through the tiniest holes in the caulk and ran down the face of the wall. An intermediate cement mixture for Wall 3 filled the space reasonably well but still left significant gaps that required remediation. 


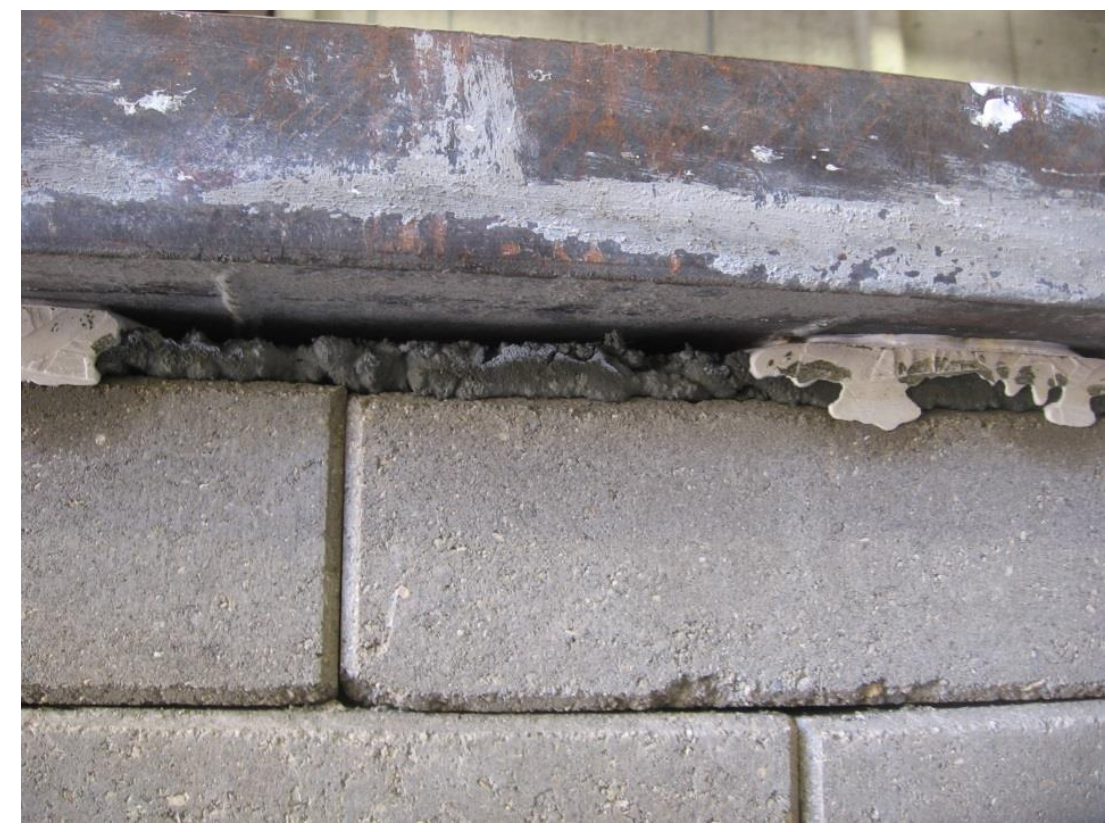

Figure 4.13: Gypsum Cement Gaps, Wall 1
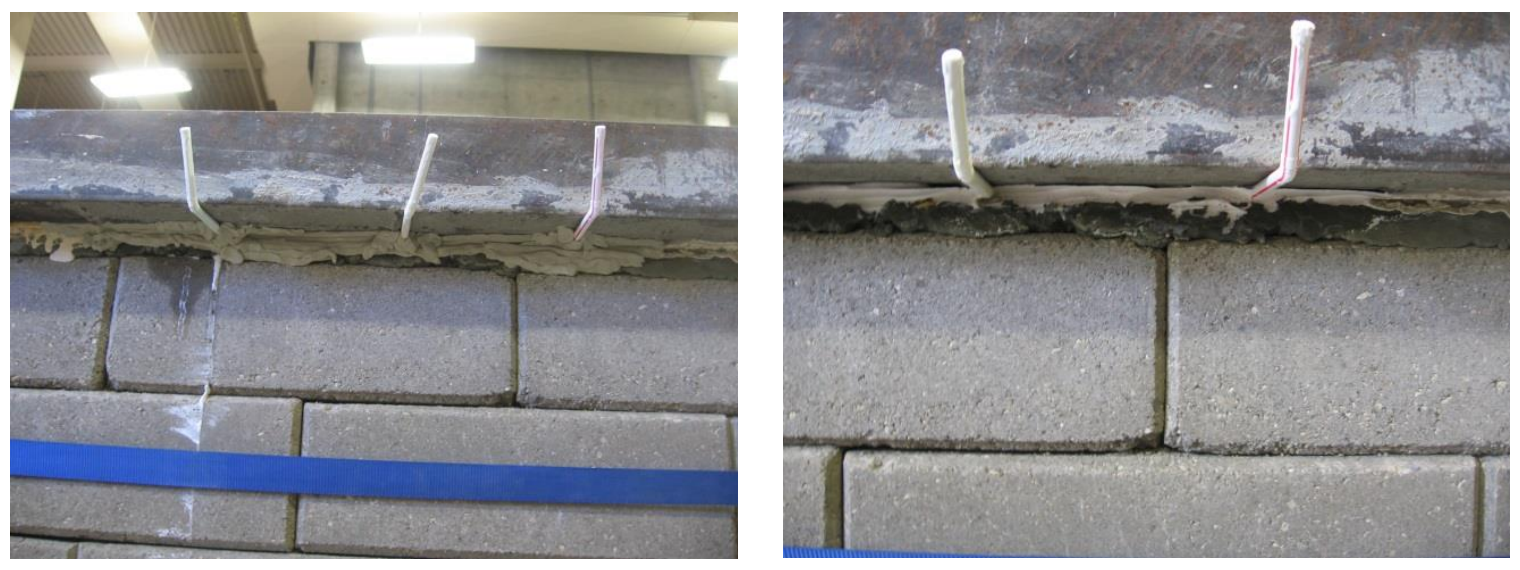

Figure 4.14: Gypsum Cement Remediation, During (left) and After (right)

Remediation consisted of injecting gypsum cement into the voids from the sides of the wall. Rope caulk filled in the gaps along the edges to create improvised formwork, while a rubber bulb syringe was used to inject fresh gypsum cement through plastic drinking straws. This proved effective at filling in the rest of the space under the beam. The primary issue was that insufficiently sealed caulk often resulted in leaks running down the face of the wall. These were scraped off the wall after hardening, sometimes 
resulting in cosmetic damage to the surface of the underlying blocks. After remediation was complete and the gypsum cement hardened, nuts were tightened onto the embedded rods to firmly anchor the beam to the wall. 


\section{WALL TESTING}

This chapter covers material related to testing the three full-size walls in this research. It encompasses the testing setup and procedure, the instrumentation employed during each test, and a description of notable events during each individual test. It also describes the construction history and distinguishing characteristics of each wall.

\subsection{Testing Layout}
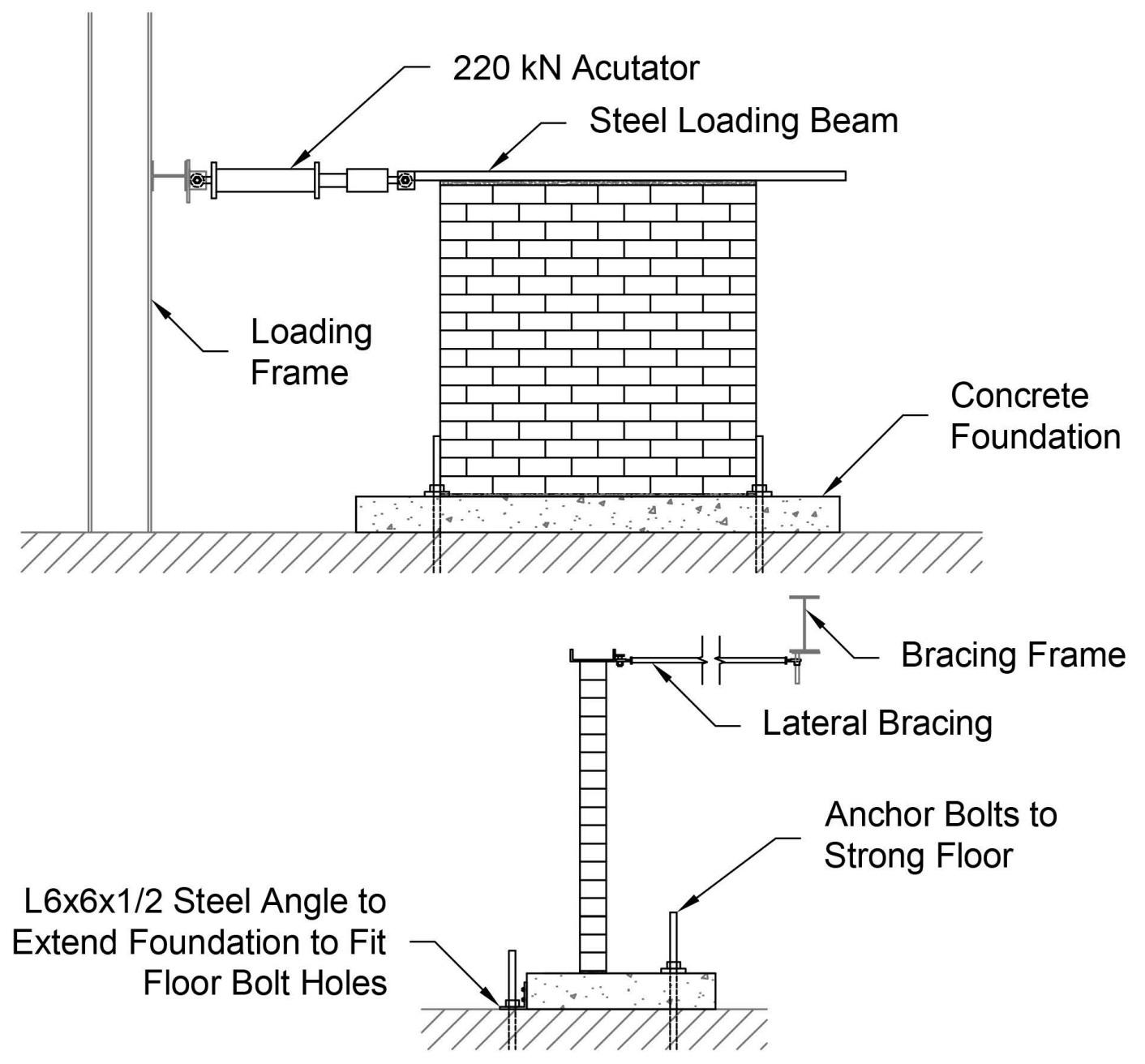

Figure 5.1: Testing Layout

Figure 5.1 depicts the testing layout for all three walls. The following sections cover the details of the testing setup in greater depth. 


\subsubsection{Loading Actuator}

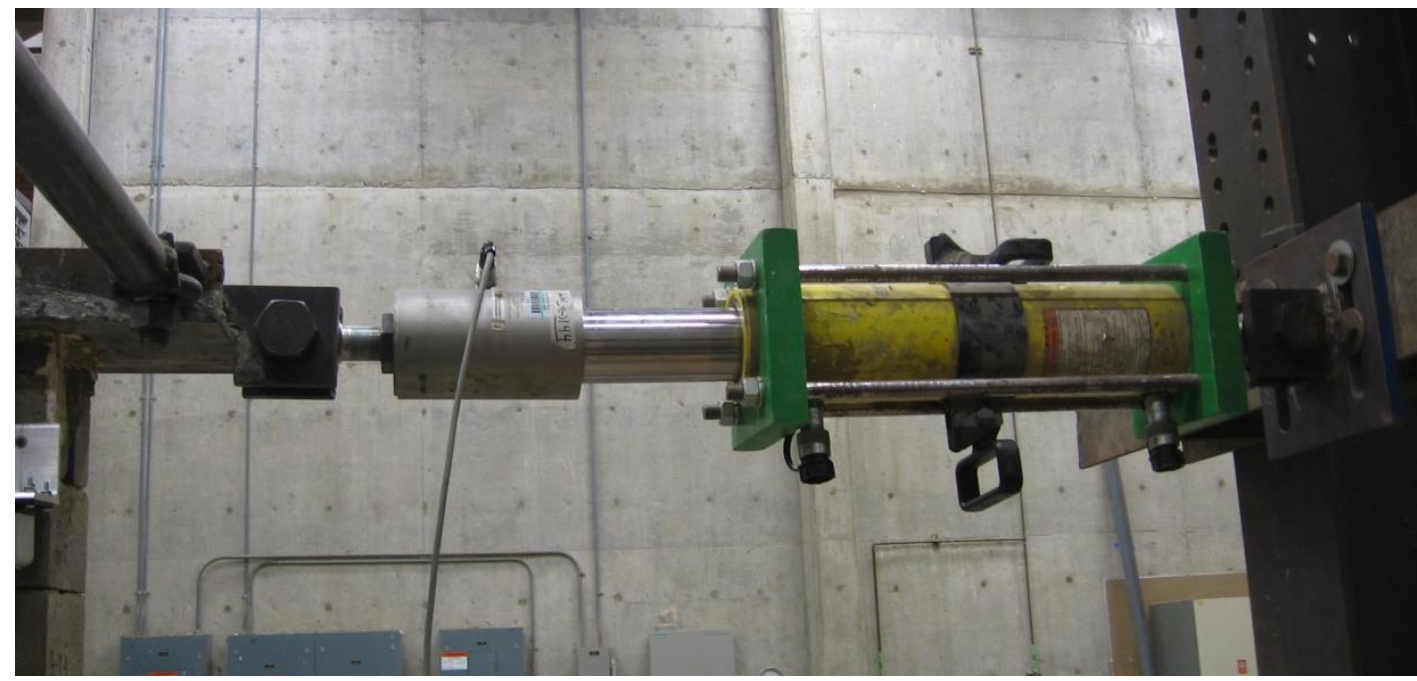

Figure 5.2: Loading Actuator

A $220 \mathrm{kN}$ manually pumped hydraulic actuator applied the in-plane shear force to the top of each wall. The actuator attached to the steel loading beam at the top of the wall and was capable of exerting push and pull forces, allowing bidirectional cyclic loading. A pressure release valve on the pump allowed a degree of control over the rate of unloading. The other end of the actuator was mounted to a relatively rigid steel frame attached to the laboratory floor.

\subsubsection{Out-of-Plane Lateral Bracing}

To restrict the out-of-plane motion of each wall, two steel pipe sections connected one side of the loading beam to a nearby steel bracing frame. Eyelets at each end of the rods allowed them to attach to the beam and frame while still freely rotating. Because these technically rotated in an arc, the walls' motions were arguably not truly in-plane. However, since the in-plane displacements never exceeded $1.1 \%$ of the bracing rods' length, it sufficiently approximated in-plane motion. 


\subsubsection{Instrumentation}

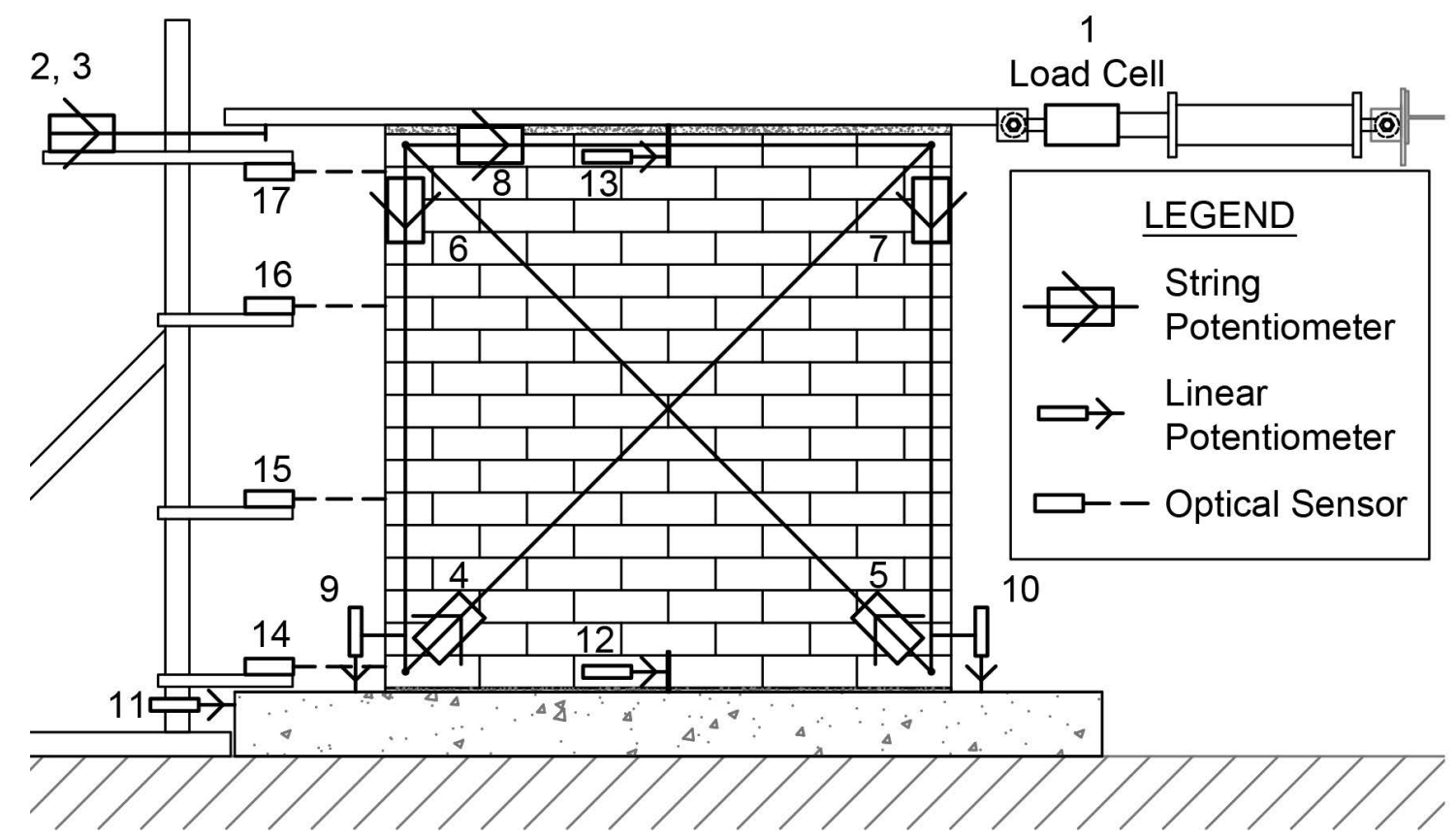

Figure 5.3: Typical Instrumentation

All three walls followed the general instrumentation setup shown in Figure 5.3, with slight variations between walls. Most instruments were mounted either directly to the wall or to a steel reference frame bolted to the laboratory floor. All descriptions of location on the wall are as seen when viewing the face of the wall with mounted instrumentation, the view of Figure 5.3.

\subsubsection{Load}

A load cell mounted in line with the actuator measured the applied load, labeled as instrument 1 in Figure 5.3 and visible in Figure 5.2 above.

\subsubsection{Displacement}

Two string potentiometers measured the displacement of the top of the wall, instruments 2 and 3 in Figure 5.3. The instruments were mounted to the reference frame, while the free ends of the instruments' lines were directly attached to small-diameter 
threaded rod running through the loading beam. The two instruments provided redundant readings: One potentiometer had a 75-mm stroke for more sensitive readings early in testing, and the other had a 635-mm stroke for high displacements when the small-stroke potentiometer was removed to avoid damage.
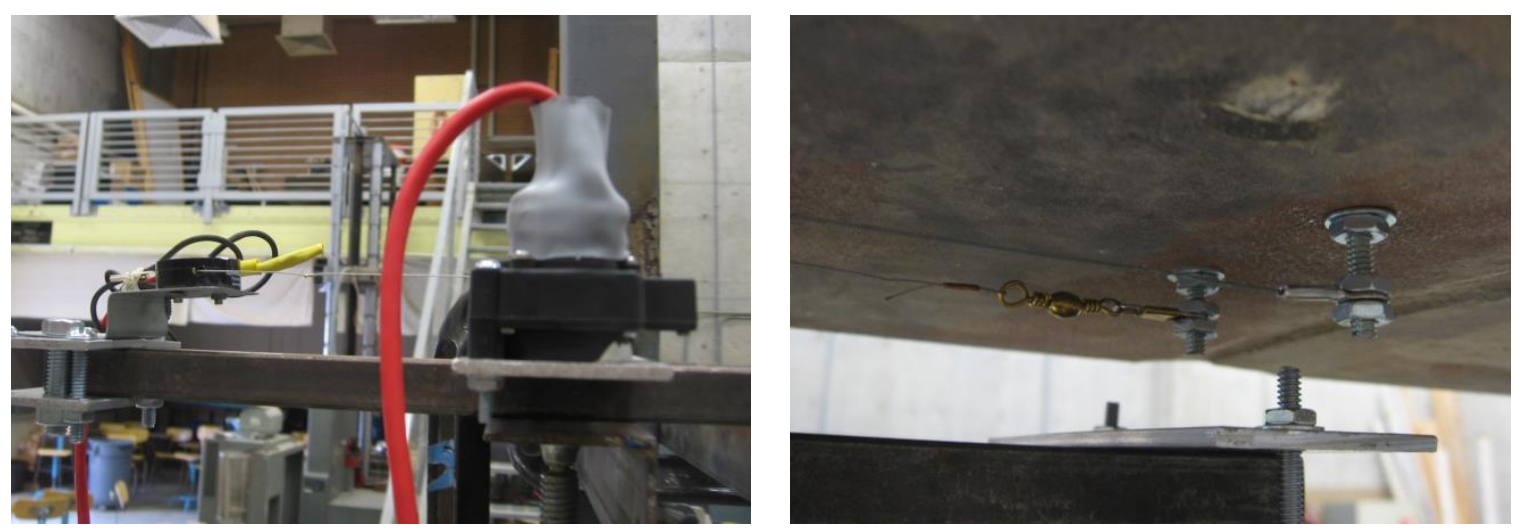

Figure 5.4: Displacement Instruments and Attachments to Loading Beam

\subsubsection{Panel Deformation}

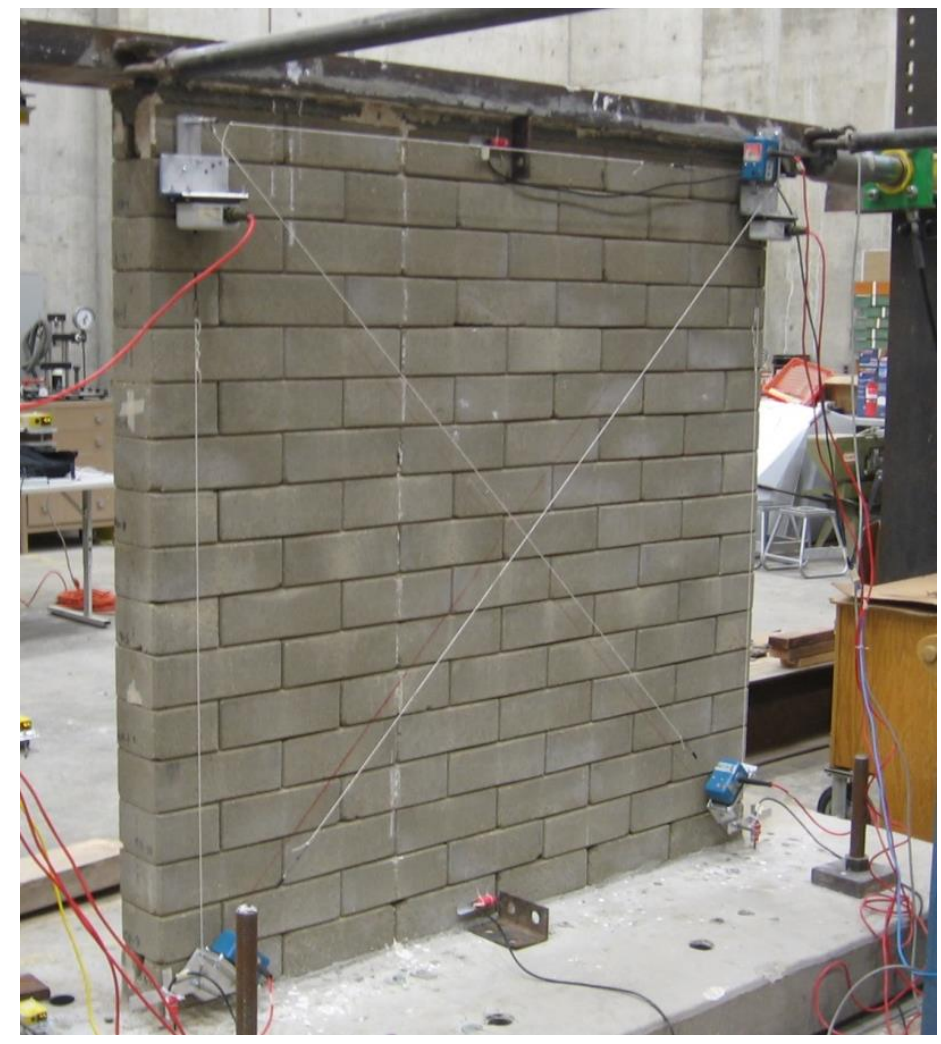

Figure 5.5: Panel Deformation Instruments on Wall 3 


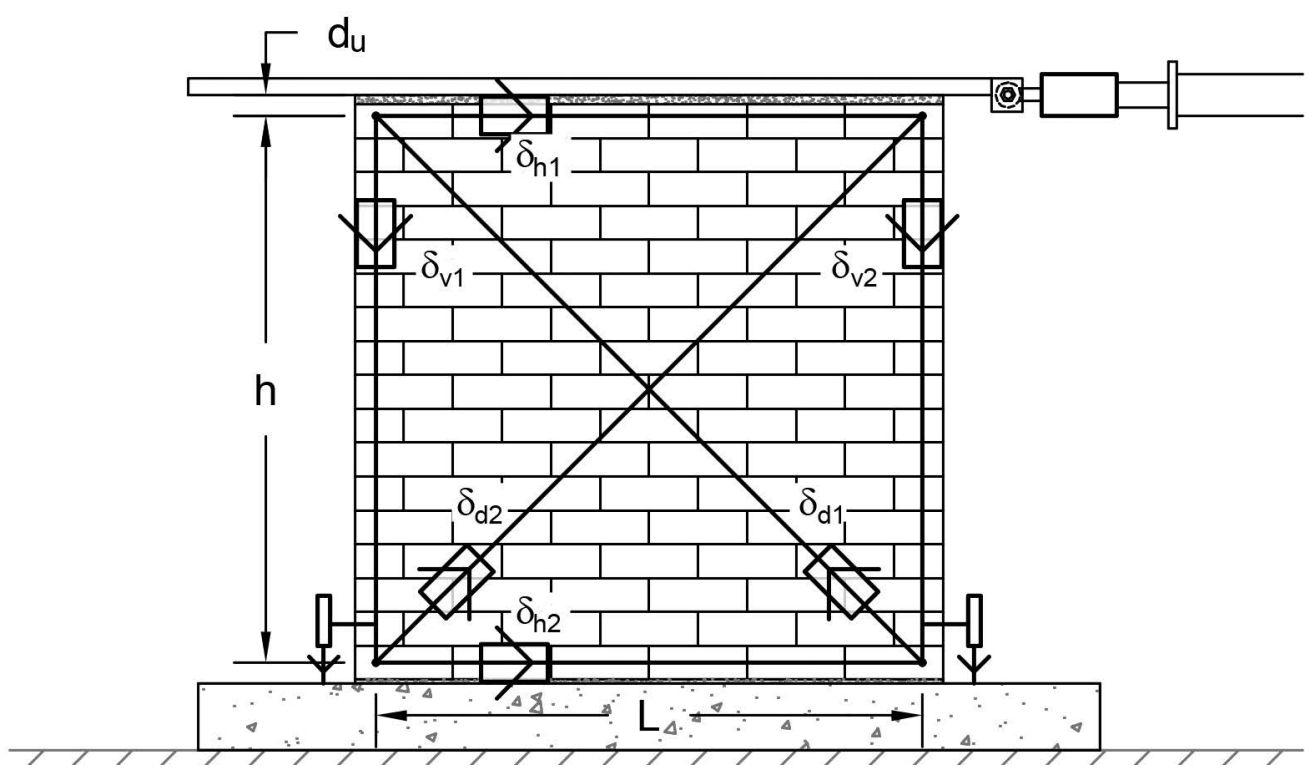

Figure 5.6: Panel Deformation Instrument Schematic (adapted from Voon, 2007)

Five string potentiometers on the face of the wall were intended to measure panel deformation: Two on the diagonals, two on the vertical edges, and one along the top horizontal edge. Figure 5.5 shows the instruments applied to Wall 3; they are also labeled as instruments 4 through 8 on Figure 5.3. The base course was assumed to be inextensible and not instrumented. Equations 5-1 and 5-2 convert these readings into the shear and bending displacement components; Appendix C of Voon (2007) contains the full derivation. Figure 5.6 defines the dimensions and relevant instrument measurements.

$$
\begin{aligned}
& u_{s}=\frac{d}{2 L}\left(\delta_{d 2}-\delta_{d 1}\right)-\frac{h^{2}}{6\left(2 d_{u}+h\right)} \frac{\left(\delta_{v 1}-\delta_{v 2}\right)}{L} \\
& u_{b}^{\prime}=\frac{\left(\delta_{v 1}-\delta_{v 2}\right)}{L}\left(h \frac{d_{u}+\frac{2 h}{3}}{2 d_{u}+h}+d_{u}\right)
\end{aligned}
$$

The string potentiometers were mounted to 10-mm-diameter threaded rod embedded into the wall with two-part epoxy. All were mounted so that the cable of the potentiometer formed a straight line between the two anchors. Cotton string fitted with 
wire hooks extended the potentiometers' reach between anchor points. For Wall 3, one diagonal used braided fishing line instead of cotton string. Because there were five instruments and only four anchor points, the top horizontal instrument shared one of the upper anchors with a vertical instrument when present. The two diagonals anchored at the lower left and right corners shared anchors with the rocking instruments.

Walls 1 and 2 used the same instruments to measure panel deformation; the only difference was that Wall 1 used a 635-mm-stroke string potentiometer for the top horizontal, while Wall 2 used no instrument at all. The instrument in question sustained damage between testing Walls 1 and 2; because no extension was expected on the rigid reinforced concrete beam, the instrument was deemed unnecessary and was not immediately replaced. Both walls used string potentiometers with 510-mm strokes on the diagonals and 250-mm strokes on the verticals. Wall 3 used new 130-mm potentiometers on the verticals, moved one of the 510-mm potentiometers to the top horizontal, and moved both $250-\mathrm{mm}$ potentiometers to the diagonals.

\subsubsection{Rocking}

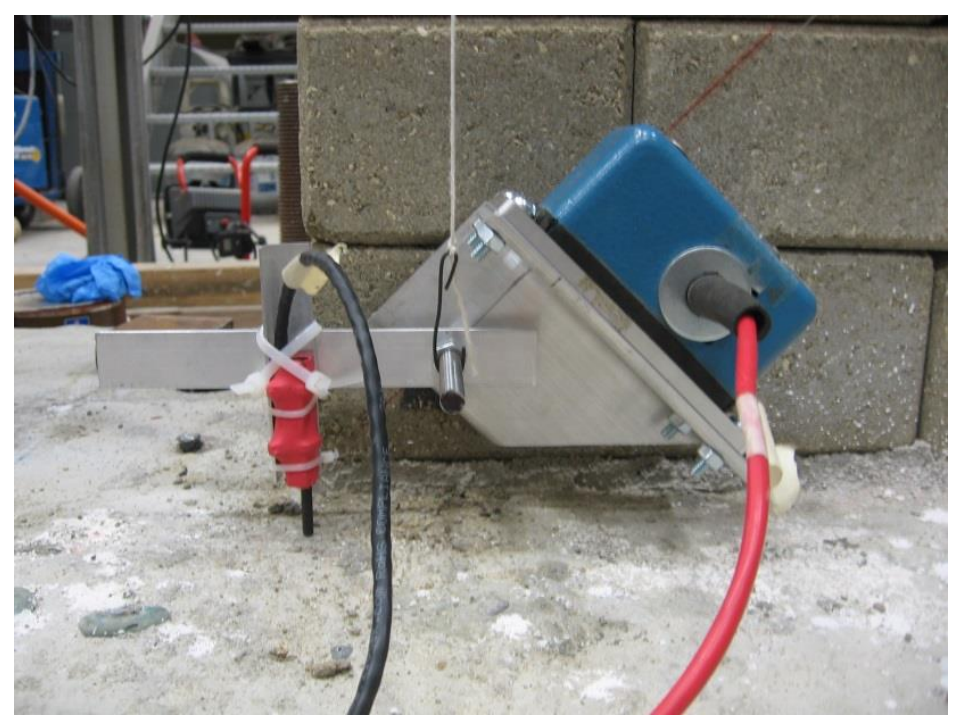

Figure 5.7: Deformation String Potentiometer with Rocking Linear Potentiometer 


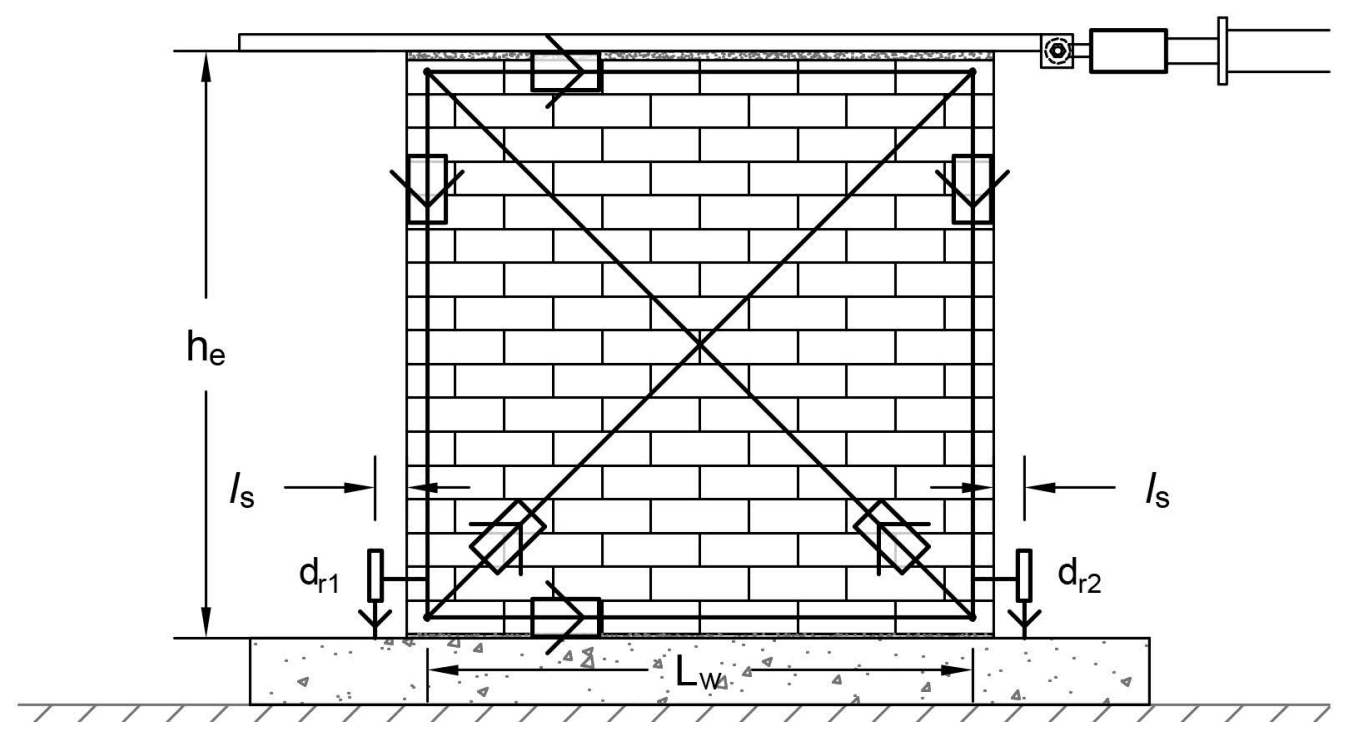

Figure 5.8: Rocking Instrument Schematic (adapted from Voon, 2007)

Two linear potentiometers at either edge of the wall measured rocking, labeled as

9 and 10 on Figure 5.3. Both shared anchors with the lower two string potentiometers on the face of the wall, as shown in Figure 5.7. Equation 5-3 was used to calculate the rocking displacement component of the top of the wall from these measurements. Section 3.5.2 of Voon (2007) contains the derivation for the equation, and Figure 5.8 defines the dimensions and instrument measurements.

$$
U_{r}=\frac{d_{r 1}-d_{r 2}}{L_{w}+2 l_{s}} h_{e}
$$

\subsubsection{Foundation, Wall, and Loading Beam Slip}

Three linear potentiometers measured slip between the loading beam and the wall, the wall and the foundation, and the foundation and the laboratory floor. This allowed the raw displacement measurements recording the displacement of the loading beam relative to the floor (by proxy of the reference frame) to be corrected to reflect the actual wall deformation. The foundation/floor instrument was suspended from the reference frame and pushed against the edge of the concrete foundation. 


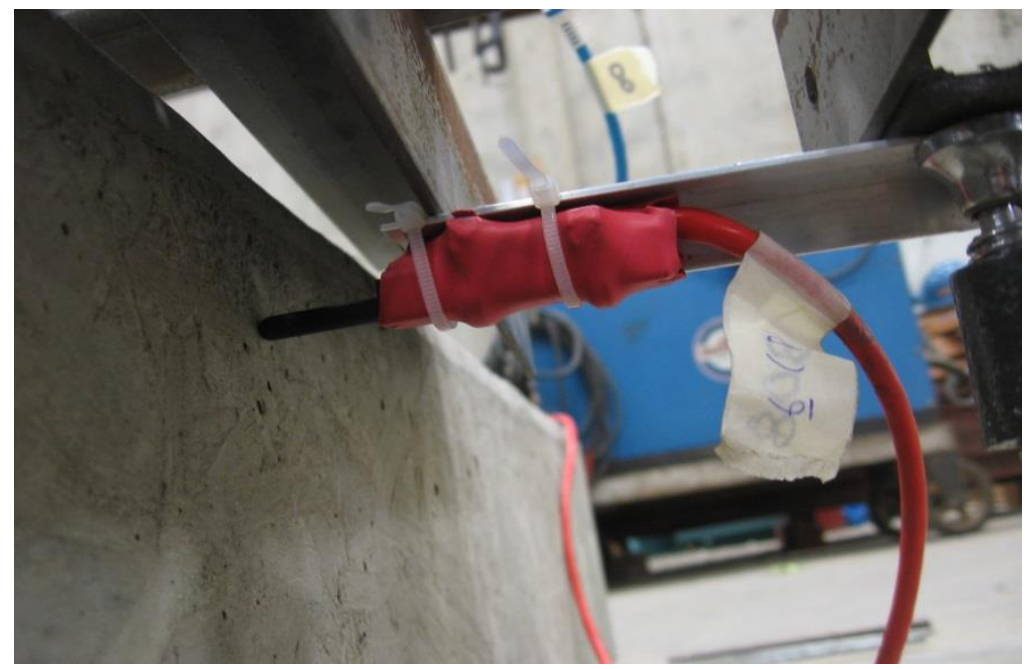

Figure 5.9: Foundation/Floor Slip Instrument

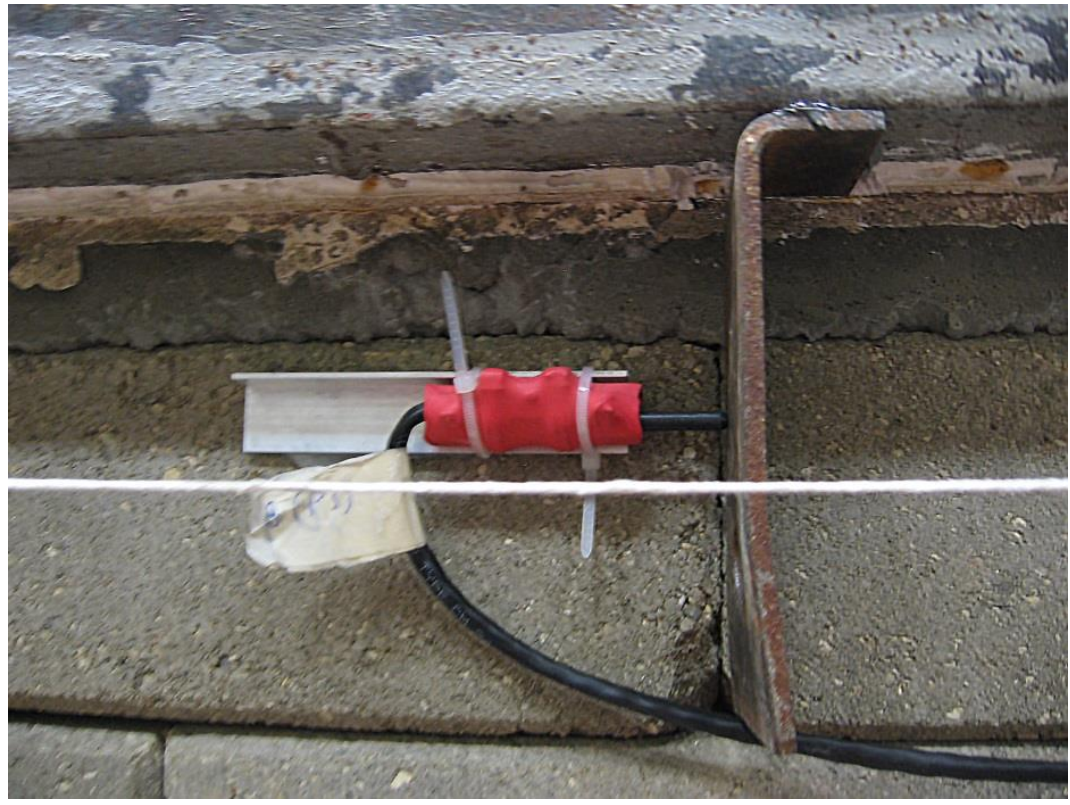

Figure 5.10: Loading Beam/Wall Instrument

In all cases, the wall/foundation and loading beam/wall instruments pushed against steel angle that was glued to either the foundation or the loading beam. For Wall 1, the instruments shared anchors with two of the string potentiometers measuring panel deformation (and, by extension, one of the linear potentiometers measuring rocking). For Walls 2 and 3, these slip instruments were instead hot-glued directly to the face of the 
wall at approximately the midpoint, which eliminated potential error due to motion of the connected instruments or damage to the anchorage.

\subsubsection{Wall Edge Deflection}
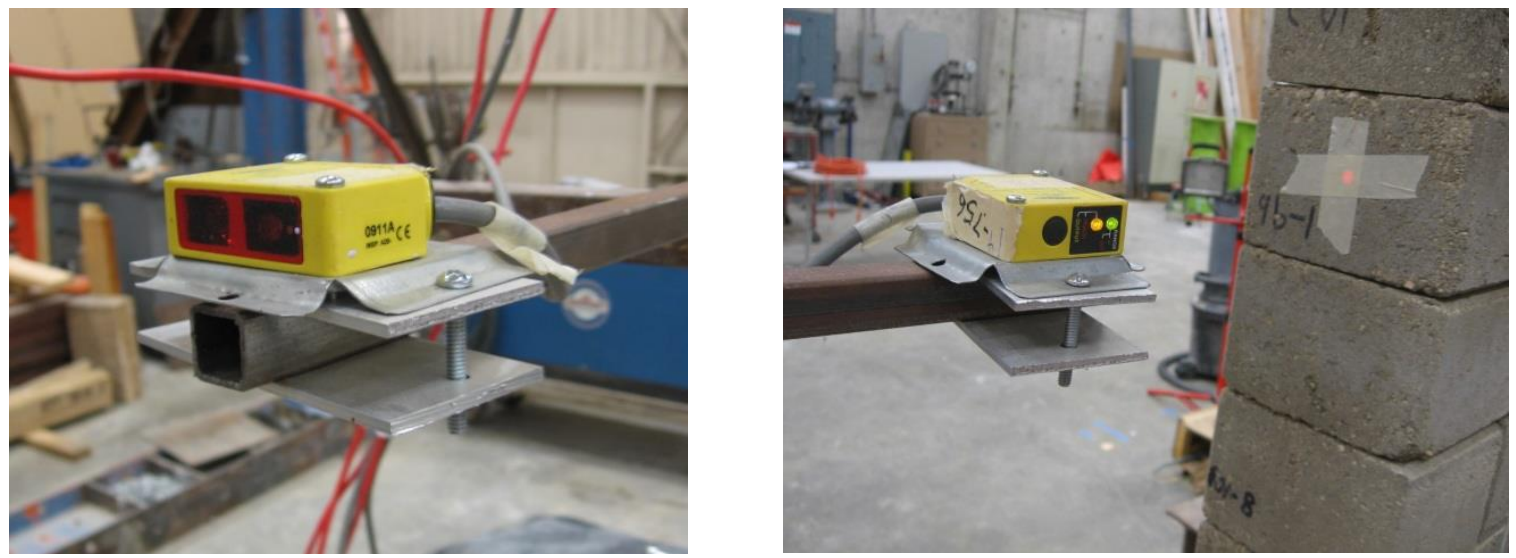

Figure 5.11: Non-Contact Optical Sensors

Four non-contact optical sensors measured the in-plane wall deflection at approximately the base, one-third height, two-thirds height, and top of the wall, labeled as 14 through 17 on Figure 5.3. All four sensors could measure distances within a range of approximately $100 \mathrm{~mm}$ to $300 \mathrm{~mm}$ from the instrument, effectively resulting in a 200mm stroke. These instruments were mounted to the reference frame, while masking tape was applied to the edge of the wall to provide a smooth target for each sensor

\subsubsection{Displacement Tracking Photography}

An SLR digital camera controlled by a laptop computer photographed all walls continuously during testing. The camera captured images of the face of the wall opposite the instrumentation at an approximate rate of one image per five seconds. Aside from providing a visual record of testing, this also allowed later analysis of the wall with displacement tracking software to help capture wall deformation and identify crack formation. To improve the performance of the processing algorithm, the face of the wall 
was coated in paint speckles. For Walls 1 and 2, these speckles were applied with a dark texture spray paint, while Wall 3 used larger splatters of latex paint and decking stain. 0 describes the image processing technique in more depth.
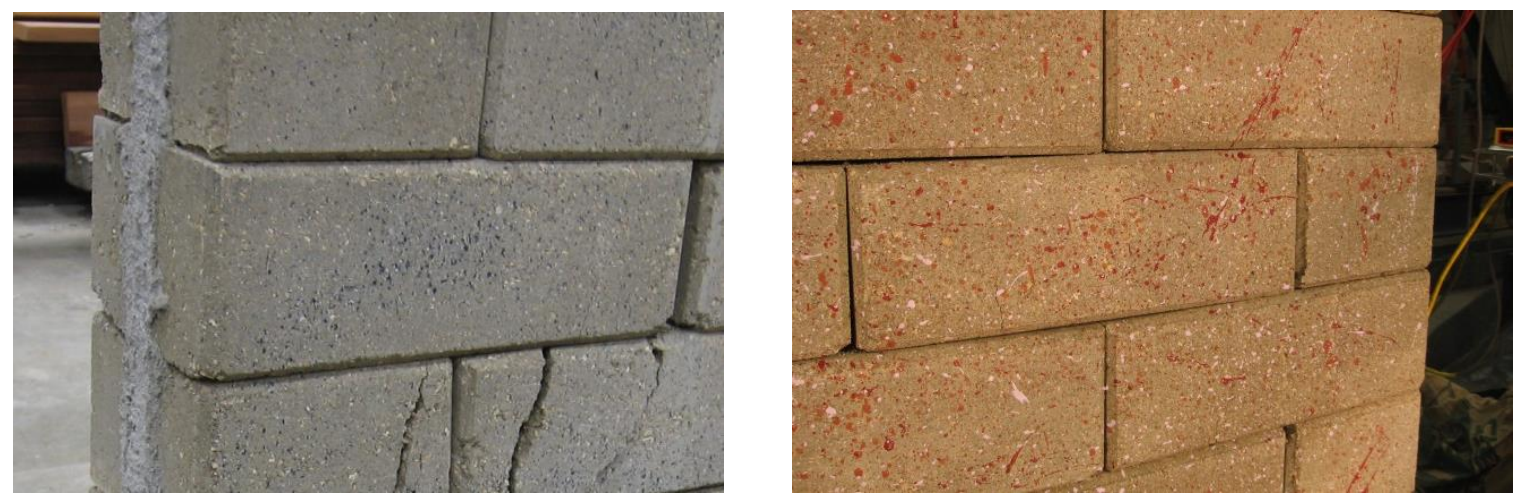

Figure 5.12: Paint Speckles on Walls 1 (left) and 3 (right)

\subsubsection{Deformation Components}

The photographic displacement analysis was also used as a backup for the panel deformation analysis by extracting the select data points shown in Figure 5.13. Calculating the changes in distance between the points over the course of the test mimicked the expected instrumentation output and could then be processed with the Voon (2007) equations. The resolution was limited by both the capabilities of the subpixel interpolation and by the level of noise in the output, but it was sufficient to allow a quantitative analysis. The corner points were used to calculate the panel deformation using the Voon (2007) equations, while the difference in horizontal displacement between the central top and bottom points provided a direct measurement of the total displacement. 


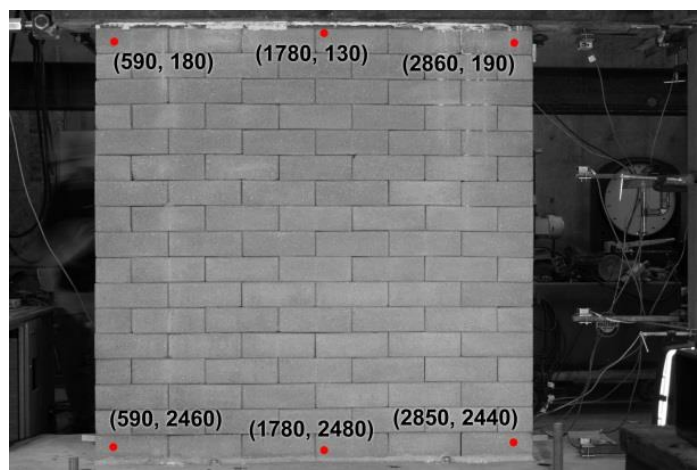

(a) Wall 1

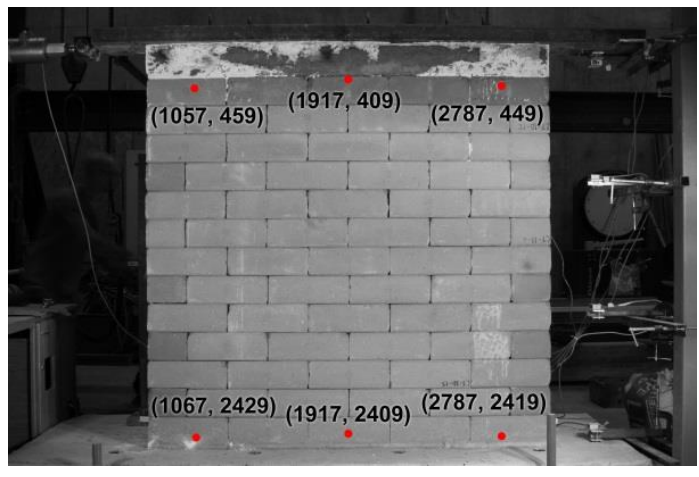

(b) Wall 2

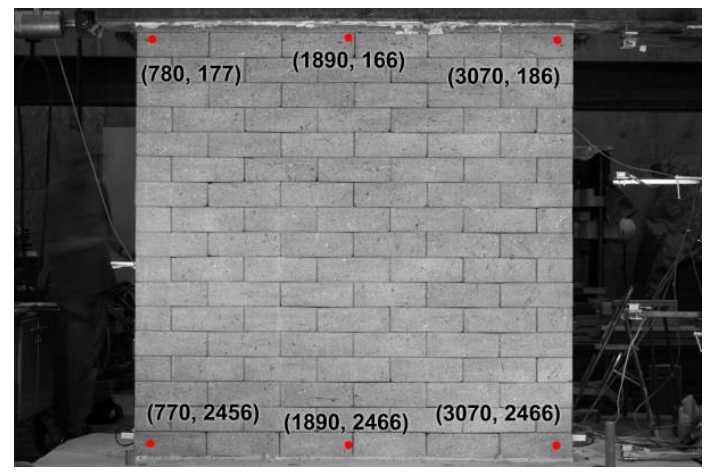

(c) Wall 3

\section{Figure 5.13: Image Analysis Points Used for Panel Deformation (Units in Pixels)}

For Walls 1 and 3, the points approximately coincided with the corresponding mounting points of the physical instruments. The sums of the components closely matched the measured total displacement from both the main physical displacement instruments, validating the results. For Wall 2, the analyzed region for motion tracking did not include the reinforced concrete beam along the top, so it does not strictly match the instrumentation. The analyzed points are also spaced farther from the edge for two reasons:

- The sum of the components calculated using these points matched the transducermeasured displacement closer than the sum calculated using points closer to the edges. 
- The image analysis, which performs poorly with points nearby cracking, maintained valid results for more of the test with these points than with points closer to the edges.

\subsubsection{Loading Protocol}

All tests used the displacement-based loading protocol listed in Table 5.1 and plotted in Figure 5.14 below. The protocol was originally taken from Voon (2007) and was also used by Bland (2011) and Stirling (2011). As outlined in Voon (2007), the two primary reasons behind this particular protocol are:

- Minimizing reliance on instrument readings by only depending on the reported displacement of the loading beam

- Starting with relatively small displacements to avoid a brittle failure too early in testing

Another primary reason in this case was to allow more direct comparisons with the results of Bland (2011). Any deviations from the loading protocol are discussed with the testing results for each individual wall. Although Wall 2 was a slightly different height than Walls 1 and 3 (owing to the different dimensions of the V-Lock blocks and the desire for a 1:1 aspect ratio), their heights were similar enough that the drift values are identical within the significant figures reported in Table 5.1.

During testing, displacements were based on direct measurements from the loading beam displacement, without necessarily correcting for slip. Positive was defined as the direction of the pull stroke of a cycle. Because of the manual actuator operation, loading was not able to follow a specific rate, although it was slow enough to qualify as pseudo-static. 
Table 5.1: Imposed Displacement History

\begin{tabular}{|c|c|c|c|}
\hline Cycles & $\begin{array}{c}\text { Displacement } \\
(\mathrm{mm})\end{array}$ & $\begin{array}{c}\text { Displacement } \\
\text { (in) }\end{array}$ & Drift (\%) \\
\hline $1-2$ & 0.5 & 0.020 & $0.028 \%$ \\
\hline $3-4$ & 1 & 0.039 & $0.056 \%$ \\
\hline $5-6$ & 2 & 0.079 & $0.11 \%$ \\
\hline $7-8$ & 4 & 0.16 & $0.22 \%$ \\
\hline $9-10$ & 6 & 0.24 & $0.34 \%$ \\
\hline $11-12$ & 8 & 0.31 & $0.45 \%$ \\
\hline $13-14$ & 10 & 0.39 & $0.56 \%$ \\
\hline $15-16$ & 12 & 0.47 & $0.67 \%$ \\
\hline $17-18$ & 14 & 0.55 & $0.78 \%$ \\
\hline $19-20$ & 16 & 0.63 & $0.89 \%$ \\
\hline $21-22$ & 20 & 0.79 & $1.1 \%$ \\
\hline $23-24$ & 24 & 0.94 & $1.3 \%$ \\
\hline $25-26$ & 28 & 1.1 & $1.6 \%$ \\
\hline $27-28$ & 32 & 1.3 & $1.8 \%$ \\
\hline $29-30$ & 36 & 1.4 & $2.0 \%$ \\
\hline $31-32$ & 40 & 1.6 & $2.2 \%$ \\
\hline
\end{tabular}

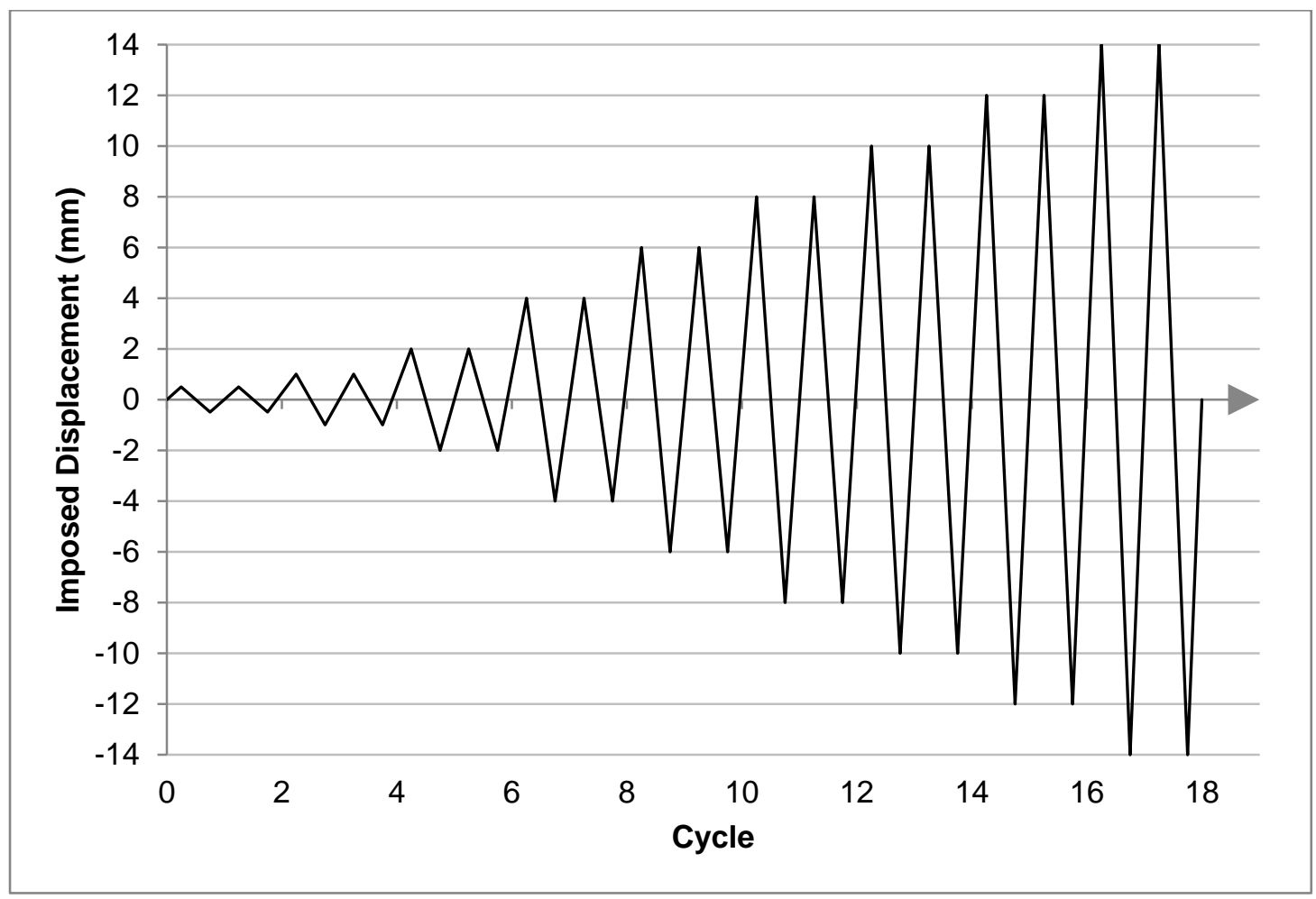

Figure 5.14: Partial Imposed Displacement History (adapted from Voon, 2007) 
After each pair of cycles with matching amplitude, the wall was returned to zero displacement and inspected for visible damage before proceeding. Testing terminated after either meeting one of the following two conditions:

- Peak load of a cycle degraded to at least $80 \%$ of overall peak

- The wall was damaged to the point of becoming potentially unstable

\subsection{Individual Wall Details and Testing}

Table 5.2: Tested Wall Dimensions and Primary Experimental Factors

\begin{tabular}{|c|c|c|c|c|}
\hline Wall & Width $(\mathrm{cm})$ & Height $(\mathrm{cm})$ & Block Type & $\begin{array}{c}\text { Head Joint } \\
\text { Shear Keys }\end{array}$ \\
\hline 1 & 179 & 179 & Rhino & Present \\
\hline 2 & 178 & 178 & V-Lock & Absent \\
\hline 3 & 179 & 179 & Rhino & Absent \\
\hline
\end{tabular}

The following sections outline the construction and testing details specific to each wall. Particular attention is given to irregularities and deviations from the procedures outlined above in Chapter 4 and the preceding portions of Chapter 5. Table 5.2 above provides a quick reference to the main experimental factors of each wall, and Table 5.3 summarizes the numeric test results from each wall. The ultimate deflection reported in Table 5.3 corresponds to the failure criterion of $0.8 V_{\max }$ and was interpolated from the experimental backbone curves covered in Section 6.1.1.

Table 5.3: Test Results

\begin{tabular}{|c|c|c|c|c|c|c|}
\hline Wall & $f_{m}^{\prime}(\mathrm{MPa})$ & $\begin{array}{c}A_{n} \\
\left(\mathrm{~mm}^{2}\right)\end{array}$ & $\begin{array}{c}\text { Loading } \\
\text { Direction }\end{array}$ & $V_{\max }(\mathrm{kN})$ & $\begin{array}{c}\delta_{V \max } \\
(\mathrm{mm} / \% \text { drift })\end{array}$ & $\begin{array}{c}\delta_{u} \\
(\mathrm{~mm} / \% \text { drift })\end{array}$ \\
\hline \multirow{2}{*}{1} & \multirow{2}{*}{1.47} & $2.68 \times 10^{5}$ & Pull (+) & 37.9 & $7.43 / 0.42 \%$ & $9.1 / 0.51 \%$ \\
& Push (-) & 36.9 & $5.64 / 0.32 \%$ & $7.7 / 0.43 \%$ \\
\hline \multirow{2}{*}{2} & \multirow{2}{*}{3.32} & \multirow{2}{*}{$3.15 \times 10^{5}$} & Pull (+) & 39.3 & $5.42 / 0.30 \%$ & $15.6 / 0.88 \%$ \\
& \multirow{2}{*}{3} & \multirow{2}{*}{$2.62 \times 10^{5}$} & Push (-) & 37.2 & $16.07 / 0.90 \%$ & $18.6 / 1.04 \%$ \\
\hline
\end{tabular}




\subsubsection{Wall 1}

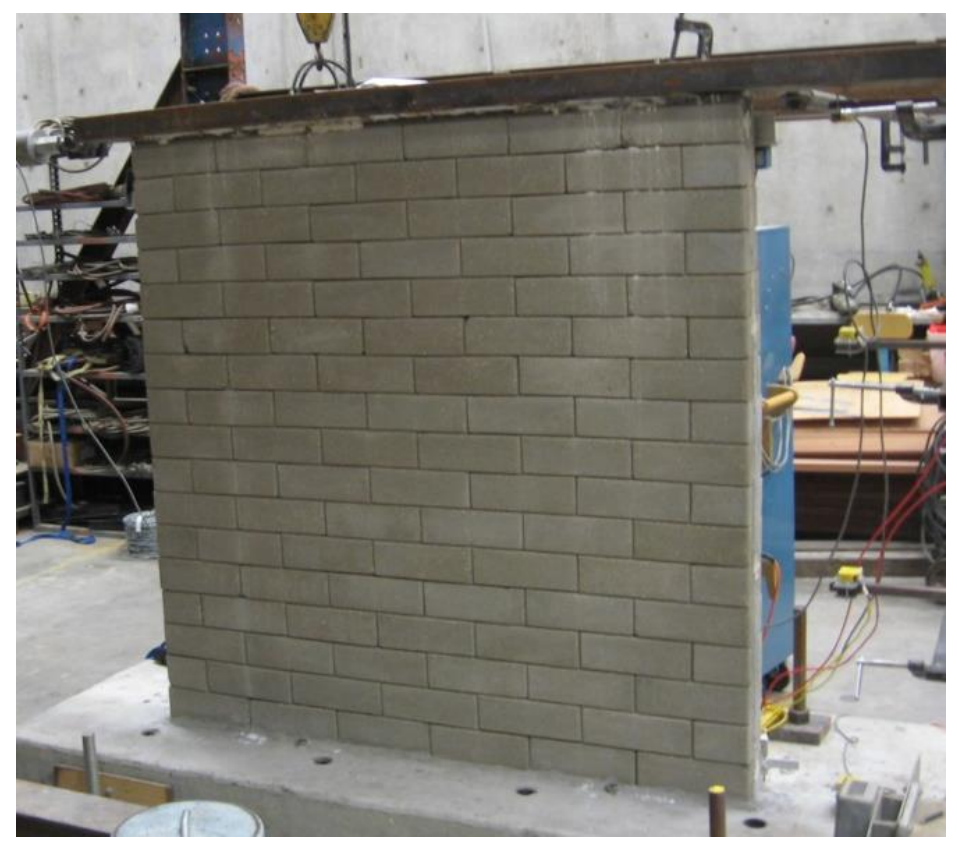

Figure 5.15: Wall 1 Before Testing

Table 5.4 summarizes the construction and testing timeline for Wall 1.

Construction began on February 18, 2016, and testing occurred on April 24, 2016, 54 days after pouring the final grout lift.

Table 5.4: Wall 1 Construction Timeline

\begin{tabular}{|l|l|}
\hline Date & Event \\
\hline February 18, 2016 & Epoxied rebar into foundation \\
\hline February 22, 2016 & Mortared base course \\
\hline February 23, 2016 & Placed course 2, grouted lift 1 \\
\hline February 25, 2016 & Placed courses 3-10, grouted lifts 2-3 \\
\hline February 26, 2016 & Placed courses 11-17, grouted lift 4 \\
\hline March 1, 2016 & Grouted lift 5 \\
\hline March 3,2016 & Placed bond beam reinforcement and concrete \\
\hline April 1,2016 & Poured gypsum cement for loading beam \\
\hline April 5-12, 2016 & Remediated voids in gypsum cement \\
\hline April 24, 2016 & Tested wall \\
\hline
\end{tabular}


The following attributes characterized Wall 1:

- Built with Rhino blocks

- Incorporated grouted shear keys, per standard Rhino block use

- Fully grouted

- $1: 1$ aspect ratio

- Four \#3 bars for flexural reinforcement

- No shear reinforcement

- Negligible applied normal force

\subsubsection{Construction Notes}

- The vertical reinforcing of Wall 1 was spaced slightly too far apart, causing the extreme rebar at either end to be in contact with the edges of the grout cores.

- While clamping the formwork for the concrete bond beam, the C-clamp on the end closest to the loading frame was overtightened, breaking one side of the channel block. Since the block could not be replaced without damaging the intersecting grout cores, the damaged section was removed and allowed to fill with concrete, shown in Figure 5.16.
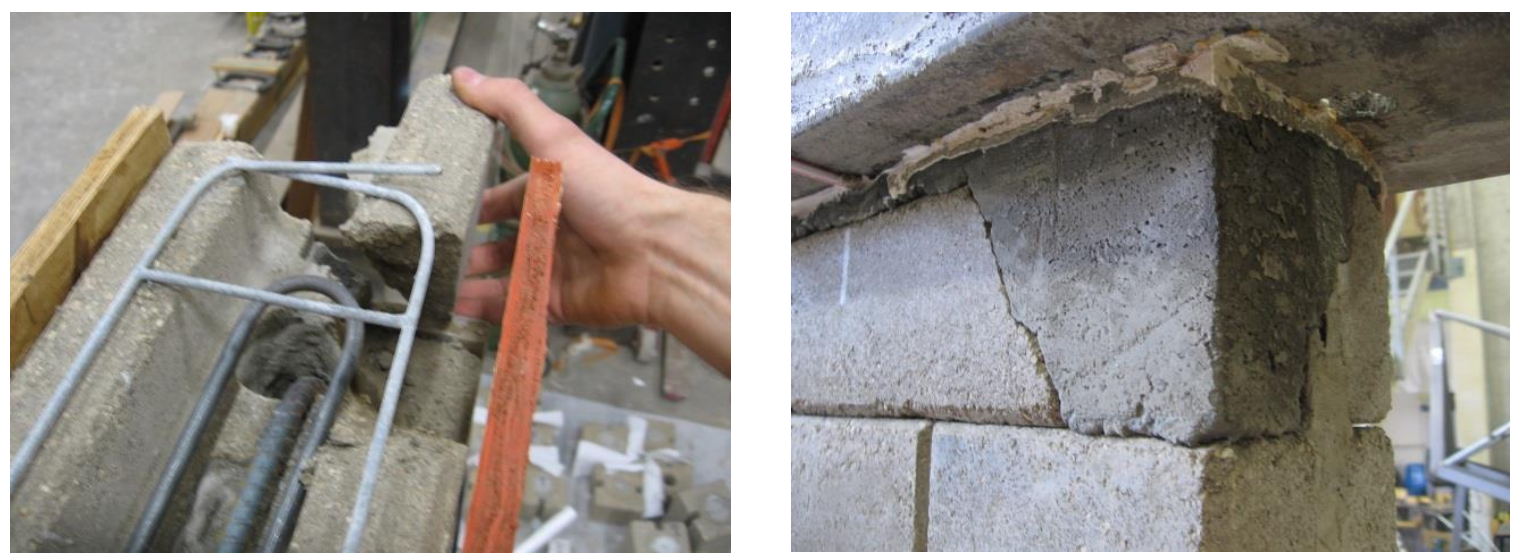

Figure 5.16: Channel Block Damage and Concrete Fill 
- Initial application of the gypsum cement under the loading beam left significant voids, requiring extensive remediation as described above in Section 4.8.

\subsubsection{Testing}

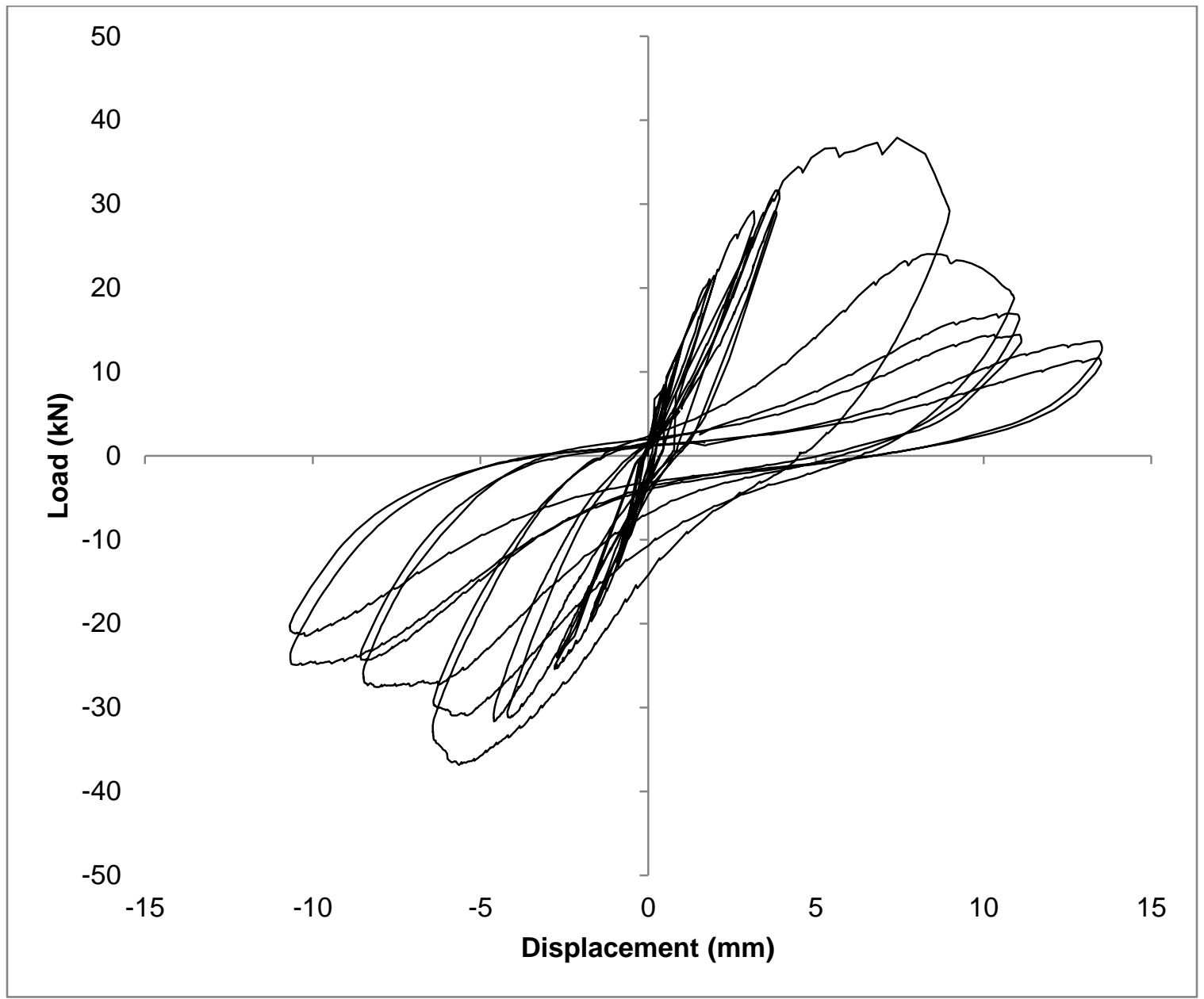

Figure 5.17: Wall 1 Force-Displacement Plot

Wall 1 was tested on April 24, 2016. Testing was carried through cycle 16 to a maximum nominal displacement of $12 \mathrm{~mm}$, at which point the strength had significantly degraded. Cracking noticeable to the naked eye first appeared during the 8-mm cycles. The wall reached peak loads of $37.9 \mathrm{kN}$ in the pull direction and $36.9 \mathrm{kN}$ in the push direction of cycle 11, the first 8-mm cycle. The wall experienced a shear failure mode, as demonstrated by the characteristic X-shaped cracking pattern. Forensic investigation of 
the wall revealed that the cracking pattern propagated through the grout cores as well as the blocks. After the first cycle, the wall required an applied load to pull it into a zero displacement condition, suggesting that some inelastic deformation occurred as early as this first cycle.

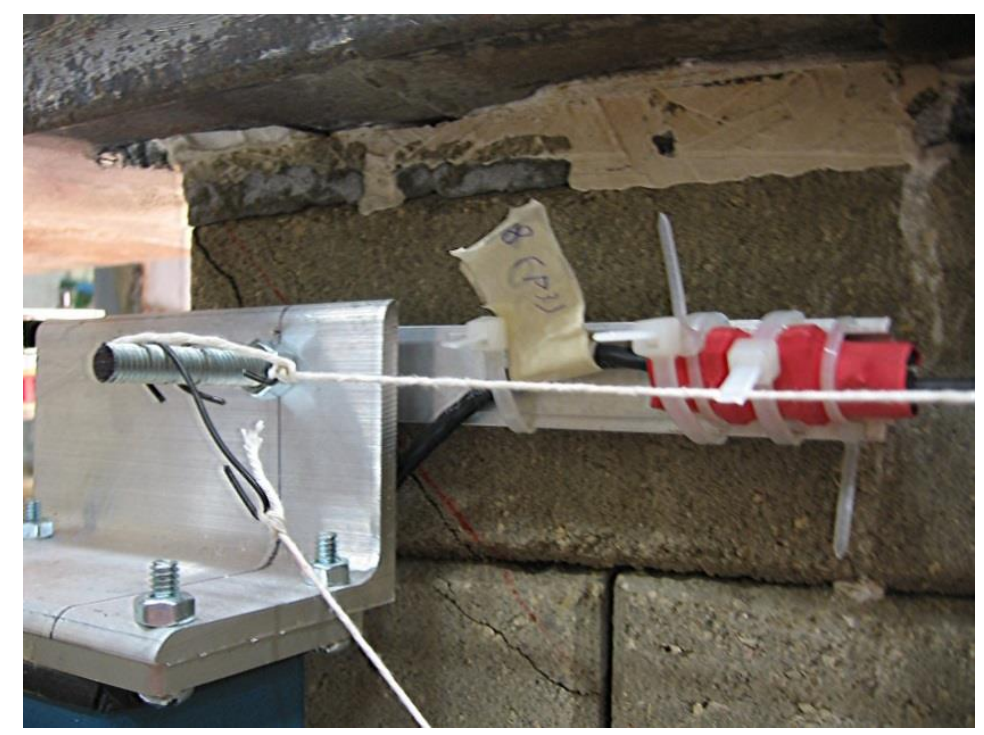

Figure 5.18: Diagonal Cracking Through Instrument Anchor

The diagonal cracking of the wall propagated through the anchorage of instruments 4 and 8 . Instrument 8 recorded an apparent slip between the loading beam and the wall; because there was no visual evidence of loss of contact between beam and wall, this was disregarded and attributed to the damage around the anchor. To avoid damaging the instrumentation, all instruments on the face of the wall were removed prior to cycle 15 (the first 12-mm cycle).

During testing, slip developed between the concrete foundation and the testing lab floor. This resulted in the wall experiencing deformations less than the nominal amplitude specified by the loading protocol for cycles 7 through $10(4 \mathrm{~mm}$ and $6 \mathrm{~mm}$ nominal amplitudes). During these cycles, the slip reached a maximum of $1.9 \mathrm{~mm}$ on the pull cycles and $1.5 \mathrm{~mm}$ on the push cycles After cycle 10, the bolts connecting the 
foundation to the floor were tightened, which significantly reduced the intra-cycle slip for cycles 11 and 12 (8-mm nominal amplitudes). The bolts were tightened again after cycle 12, which further reduced the slip. For cycle 11 onwards, the slip effectively created a permanent offset of approximately $1.3 \mathrm{~mm}$ in the push direction which acted to increase the actual wall deformation on the pull cycles and decrease the deformation on the push cycles. In addition, operator error resulted in the pull stroke of cycle 12 (the second 8$\mathrm{mm}$ cycle) reaching a maximum nominal displacement of $10 \mathrm{~mm}$.

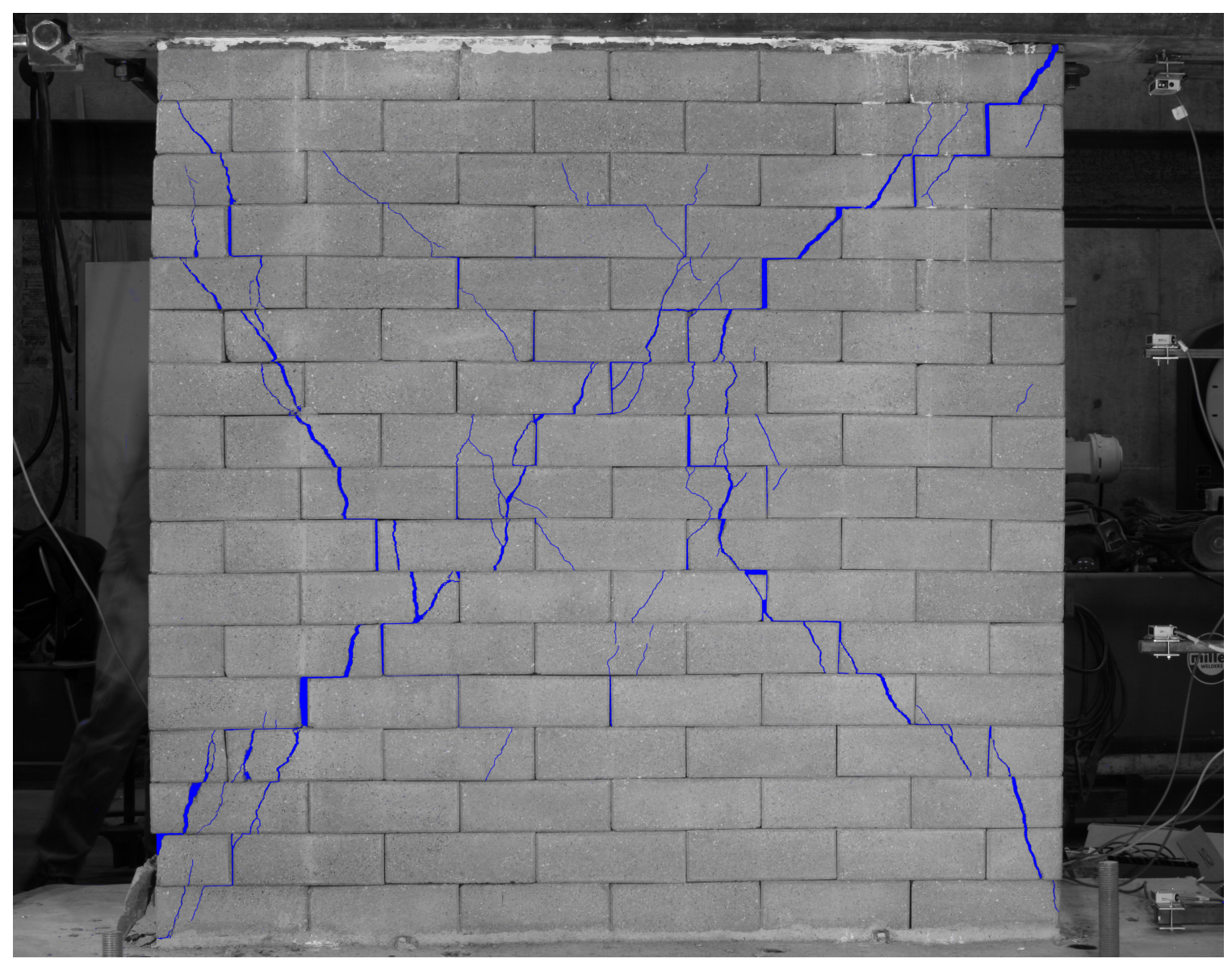

Figure 5.19: Wall 1 Final Cracking 


\subsubsection{Wall 2}

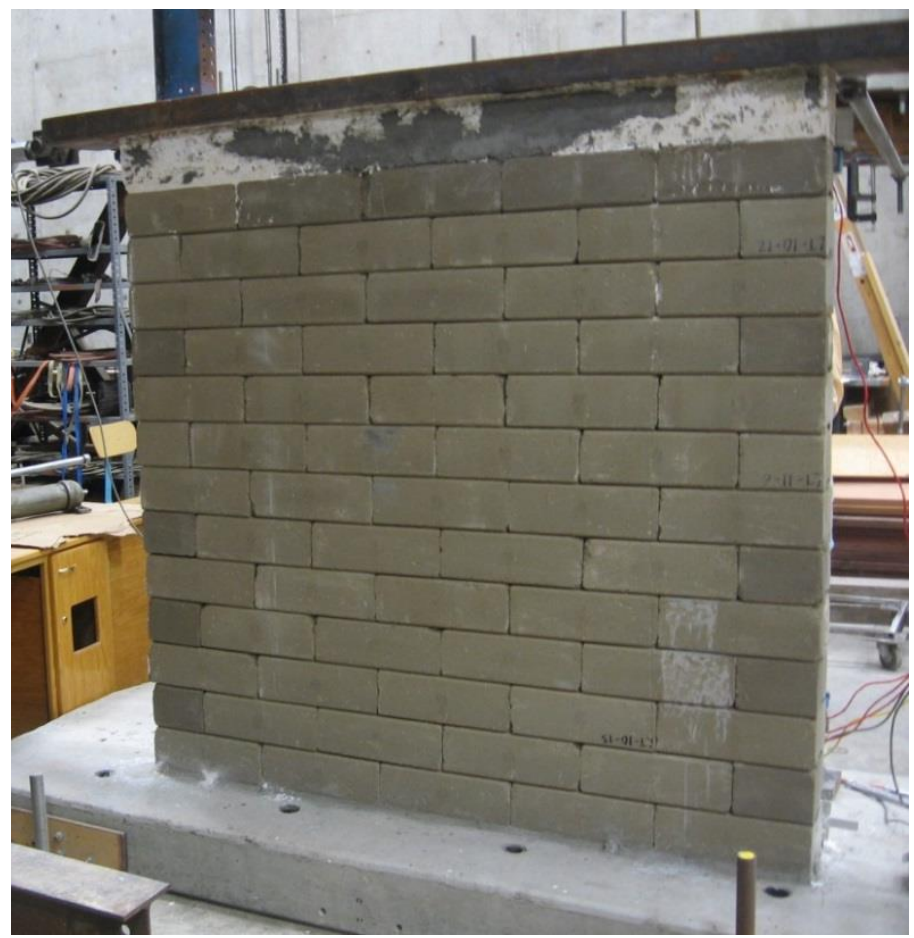

Figure 5.20: Wall 2 Before Testing

Table 5.5 summarizes the construction and testing timeline for Wall 2.

Construction began on April 30, 2016. Testing occurred on May 27, 2016, slightly less than 21 days after pouring the final grout lift at midnight leading into May 7 .

Table 5.5: Wall 2 Construction Timeline

\begin{tabular}{|l|l|}
\hline Date & Event \\
\hline April 30, 2016 & Epoxied rebar into foundation \\
\hline May 2, 2016 & Mortared base course \\
\hline May 5, 2016 & Placed course 2-6, grouted lifts 1-3 \\
\hline May 6, 2016 & Placed courses 7-13, grouted lifts 4-7 \\
\hline May 9, 2016 & Placed top beam reinforcement \\
\hline May 10,2016 & Placed top beam concrete \\
\hline May 19,2016 & Poured gypsum cement for loading beam \\
\hline May 27, 2016 & Tested wall \\
\hline
\end{tabular}


The following attributes characterized Wall 2:

- Built with V-Lock blocks

- Lacking grouted shear keys, per standard V-Lock block design

- Fully grouted

- $1: 1$ aspect ratio

- Four \#3 bars for flexural reinforcement

- No shear reinforcement

- Negligible applied normal force

\subsubsection{Construction Notes}

- The hole drilled for the third bar away from the loading frame hit rebar in the slab approximately $50 \mathrm{~mm}$ deep and could not proceed further. Rather than use this shallow hole, a new full-depth hole was offset a few centimeters closer to the loading frame. Dry packing the shallow hole with a sand/cement/water mixture attempted to recover some of the strength and stiffness in the area. The large grout holes of Wall 2's V-Lock blocks allowed this relocation without altering the position of the blocks.

- All blocks in the top course and most of the wall's half blocks were composed of a different soil than the blocks in the rest of the wall as described in Section 3.2.2. The tested compressive strengths of similar blocks did not differ significantly from those of the Las Tablas soil blocks used in the rest of the wall. 


\subsubsection{Testing}

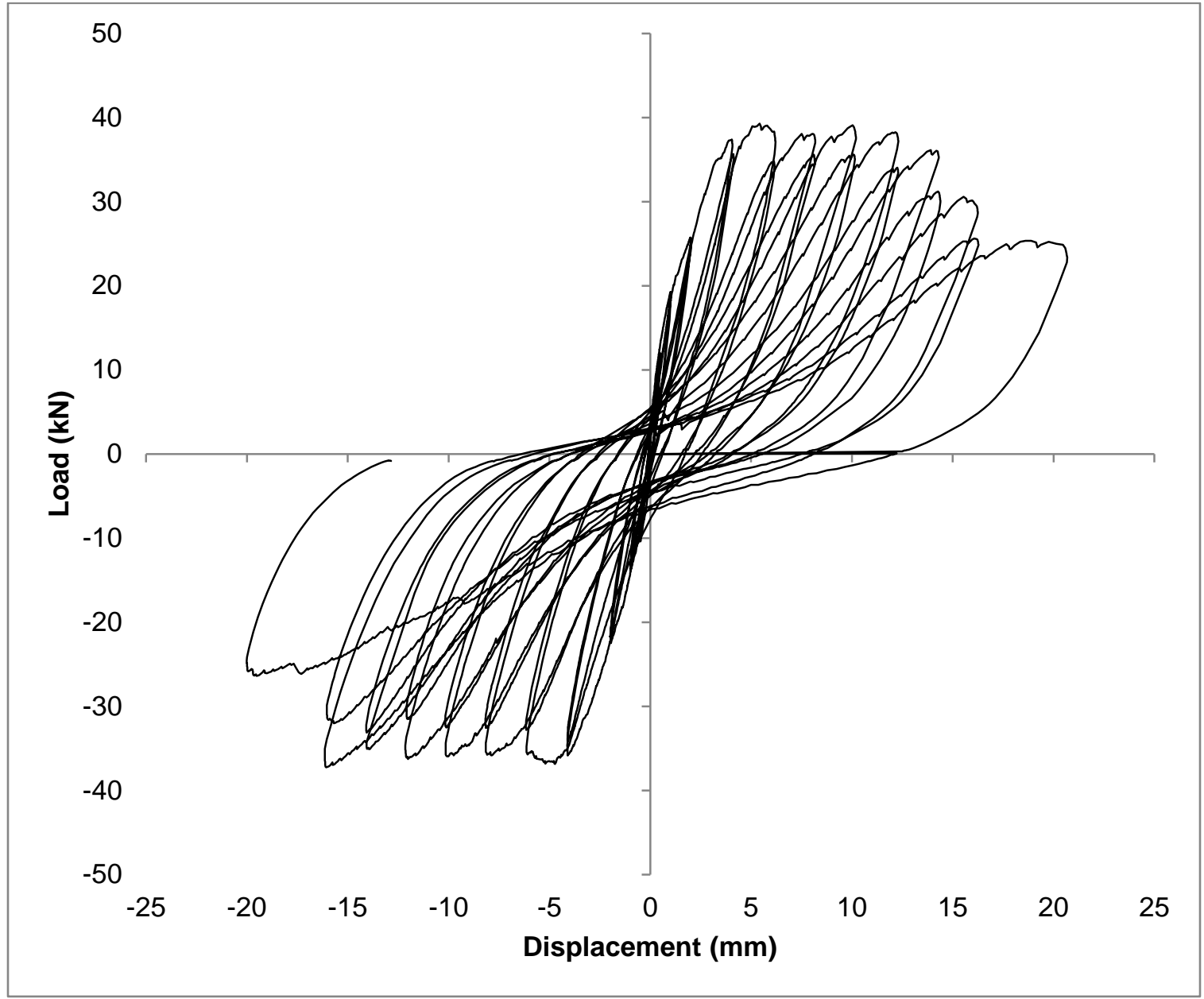

Figure 5.21: Wall 2 Force-Displacement Plot

Wall 2 was tested on May 27, 2016. Testing proceeded through cycle 21 to a maximum amplitude of $20 \mathrm{~mm}$. The load initially peaked at $39.3 \mathrm{kN}$ in the pull direction and $36.9 \mathrm{kN}$ in the push direction of cycle 9 (the first $6 \mathrm{~mm}$ cycle), which corresponds with the first visible signs of cracking. The load then plateaued for the next several cycles, with the push direction reaching a second peak of $37.2 \mathrm{kN}$ during cycle 19 (the first $16 \mathrm{~mm}$ cycle). Testing terminated at cycle 21 because of stability concerns, visible crushing at the toe, and sufficient load degradation. The wall was not returned to zero displacement, but testing instead ended after returning the wall to a position of zero load. 

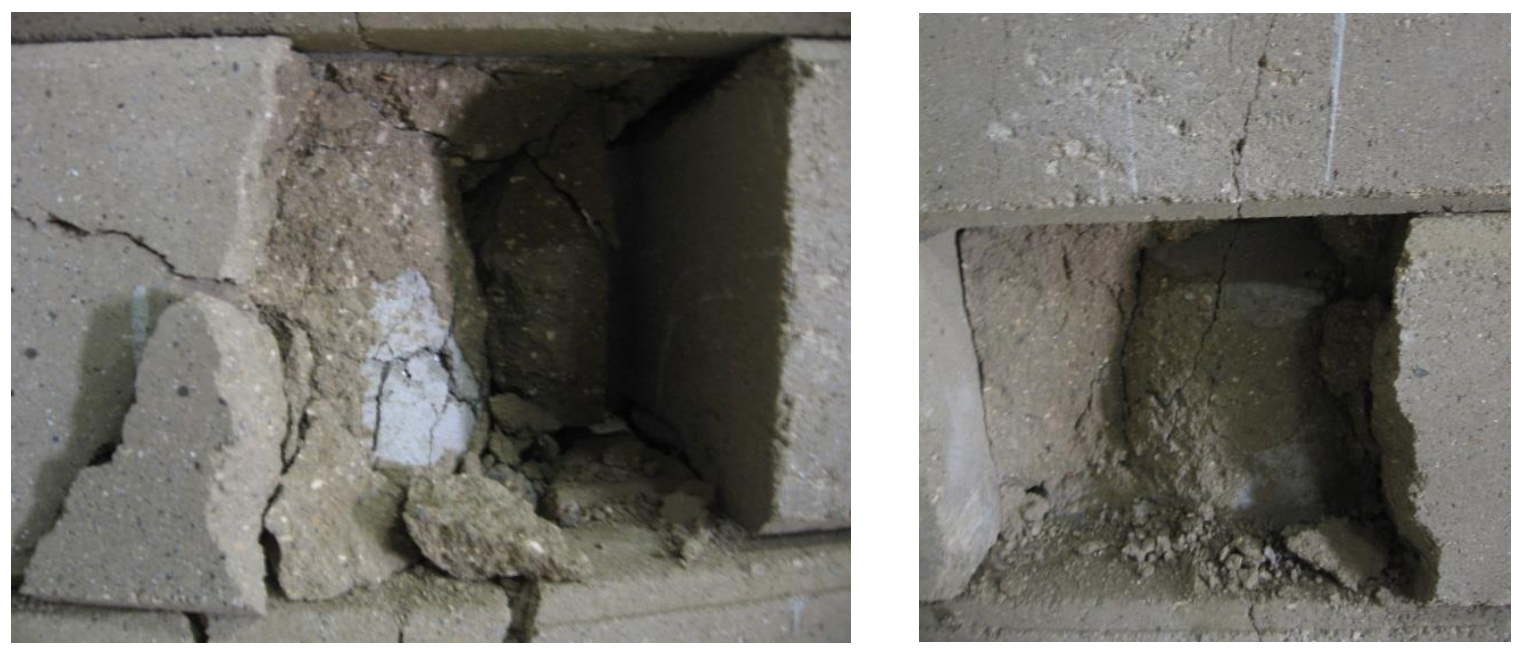

Figure 5.22: Wall 2 Cracking Through Grout Cores

Wall 2 exhibited the X-shaped cracking indicative of a shear failure, although the cracking was not as cleanly diagonal as the cracks on Wall 1. These cracks were first observed during the $6 \mathrm{~mm}$ displacement cycles, corresponding to the initial load peak. Forensic investigation showed that cracking propagated through the grout cores as well as the blocks. It also revealed significant deformation of the rebar at the top corners of the wall so that the upper, untied region of the lap splice separated, as shown in Figure 5.23. This may have contributed to the damage at the top of the wall by acting to split the blocks and grout cores. There were, however, no signs of slip in the regions of the lap splices still embedded in grout, so they still fulfilled their role in flexure.

The instruments on the lower corner nearest the loading frame came loose during testing, apparently during the push stroke of cycle 9 (the first $6 \mathrm{~mm}$ cycle), altering the results of the connected transducers. Falling debris struck the panel deformation instruments during the push stroke of cycle 13 (the first $10 \mathrm{~mm}$ cycle). All instruments on the face of the wall were removed at the end of cycle 14, the second 10-mm cycle. 


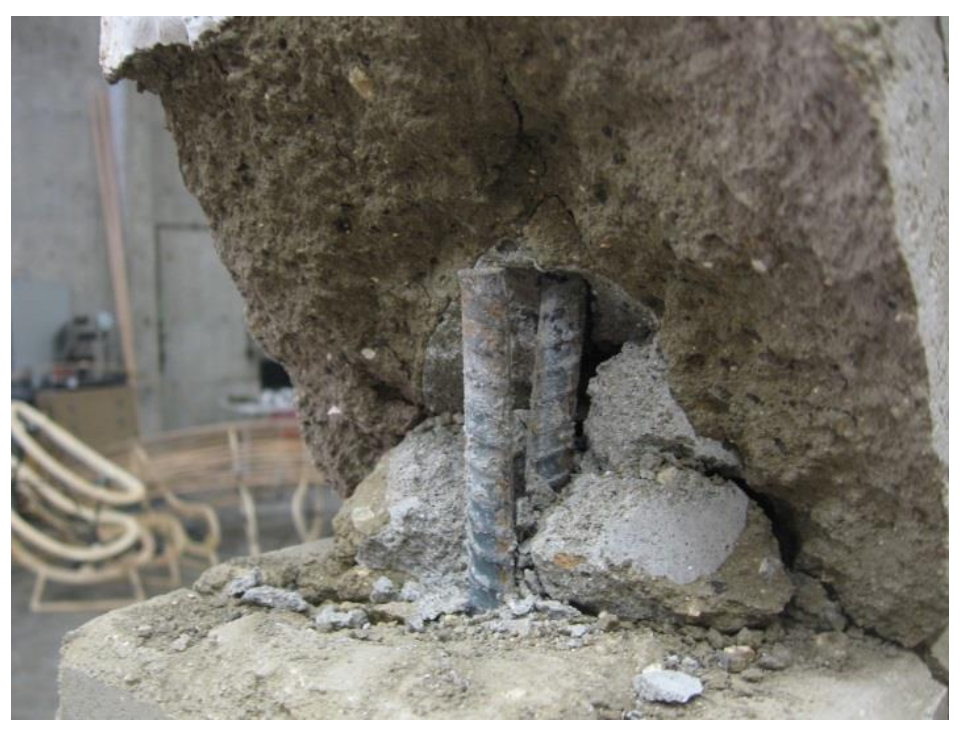

Figure 5.23: Wall 2 Split Upper Lap Splice

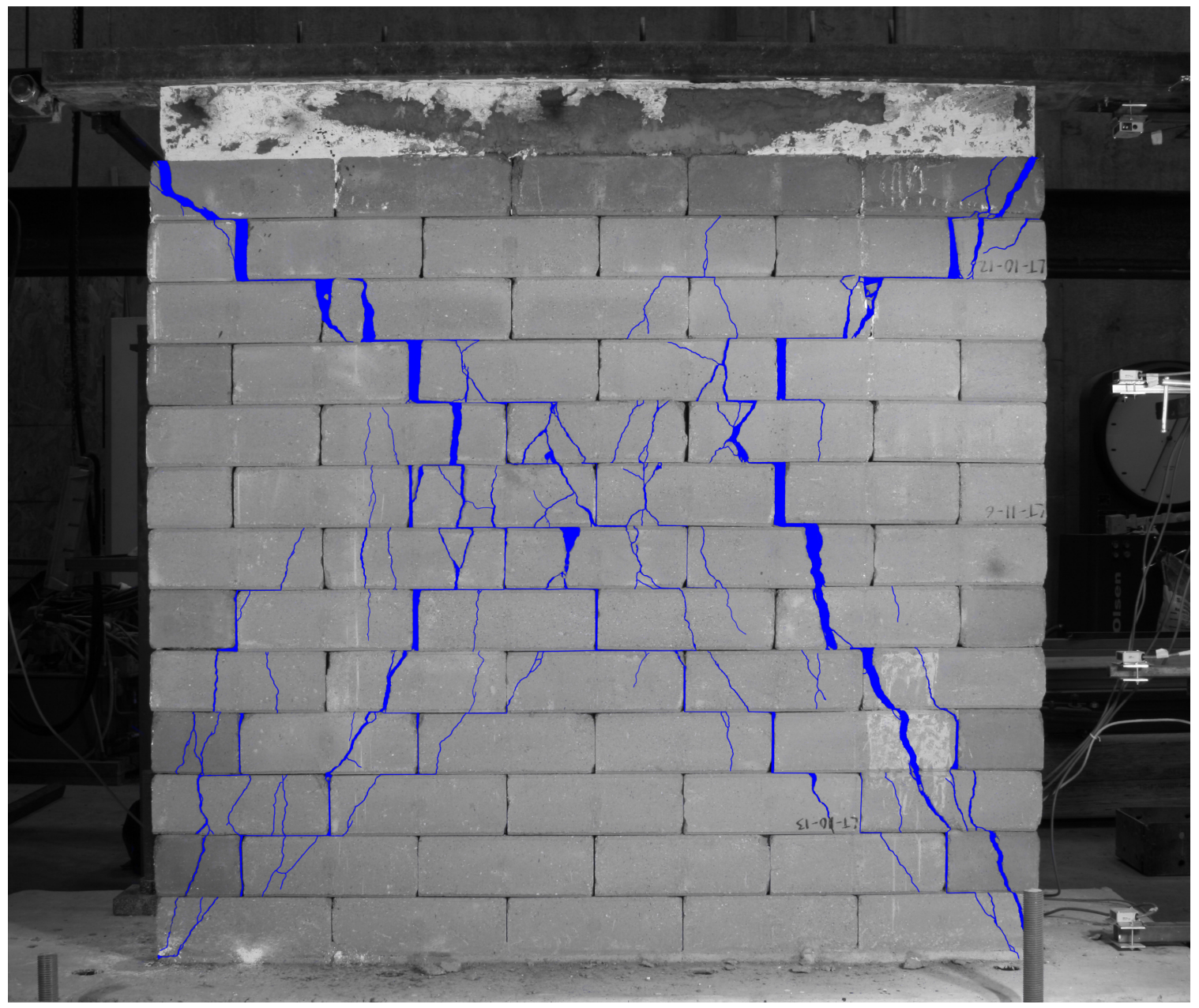

Figure 5.24: Wall 2 Final Cracking 


\subsubsection{Wall 3}

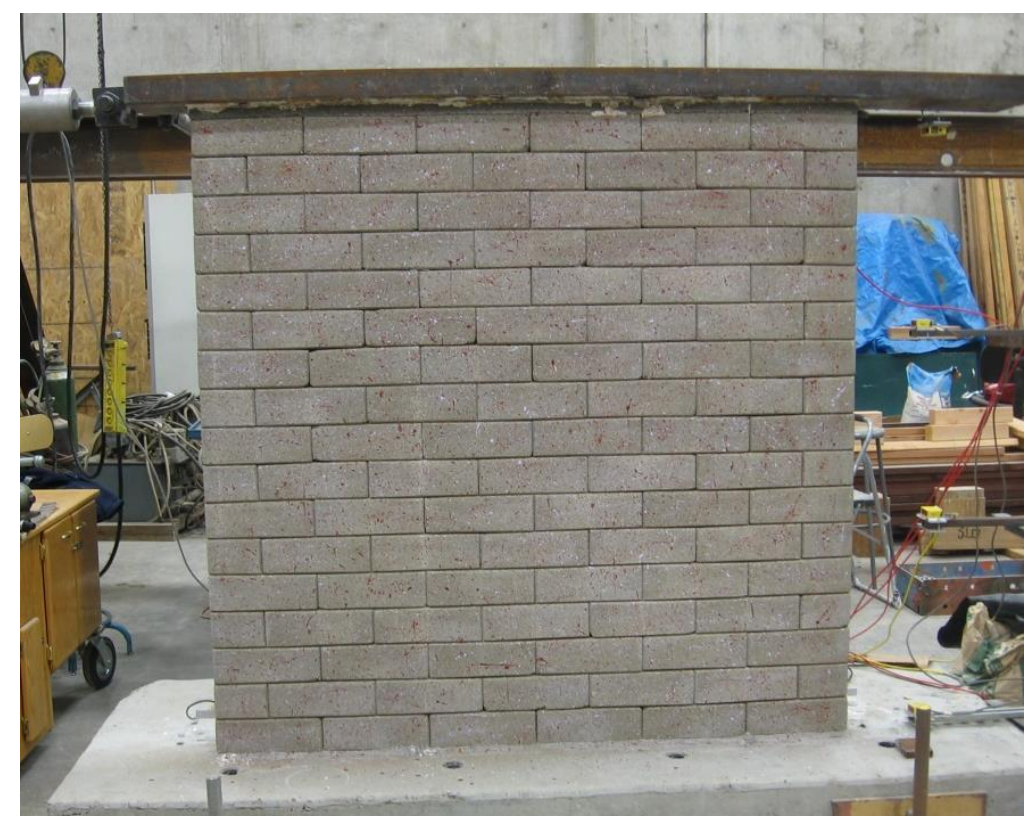

Figure 5.25: Wall 3 Before Testing

Table 5.6 summarizes the construction and testing timeline for Wall 3.

Construction began on June 4, 2016. Testing occurred on July 7, 2016, 28 days after pouring the final grout lift.

Table 5.6: Wall 3 Construction Timeline

\begin{tabular}{|l|l|}
\hline Date & Event \\
\hline June 4,2016 & Epoxied rebar into foundation \\
\hline June 6, 2016 & Mortared base course \\
\hline June 7, 2016 & Placed course 2, grouted lift 1 \\
\hline June 8, 2016 & Placed courses 3-10, grouted lifts 2-3 \\
\hline June 9, 2016 & Placed courses 11-17, grouted lift 4-5 \\
\hline June 12,2016 & Placed bond beam reinforcement and concrete \\
\hline June 22,2016 & Poured gypsum cement for loading beam \\
\hline June 24,2016 & Remediated voids in gypsum cement \\
\hline July 7, 2016 & Tested wall \\
\hline
\end{tabular}


The following attributes characterized Wall 3:

- Built with Rhino blocks

- Lacking grouted shear keys, deviating from standard Rhino block use

- Fully grouted

- $1: 1$ aspect ratio

- Four \#3 bars for flexural reinforcement

- No shear reinforcement

- Negligible applied normal force

\subsubsection{Construction Notes}

- As with Wall 2, the hole for the third bar away from the loading frame encountered rebar approximately $50 \mathrm{~mm}$ deep in the slab. Rather than use this shallow hole, a replacement full-depth hole was drilled a few centimeters closer to the loading frame. The shallow hole was dry-packed with a sand/cement/water mixture to recover some of the strength and stiffness in the area. The wall needed to be shifted slightly closer to the loading frame to accommodate all of the vertical reinforcement. As a result, all reinforcing bars were close to an edge of their respective grout cores.

- It was not possible to press channel blocks without the edge shear keys. This resulted in a vertical void between courses at every interface between a course of channel blocks and a course of regular blocks, as depicted in Figure 5.26. Scraps of the cement bag were used to obstruct the ends of the voids, to prevent grout or concrete from flowing up or down and inadvertently creating shear keys. 


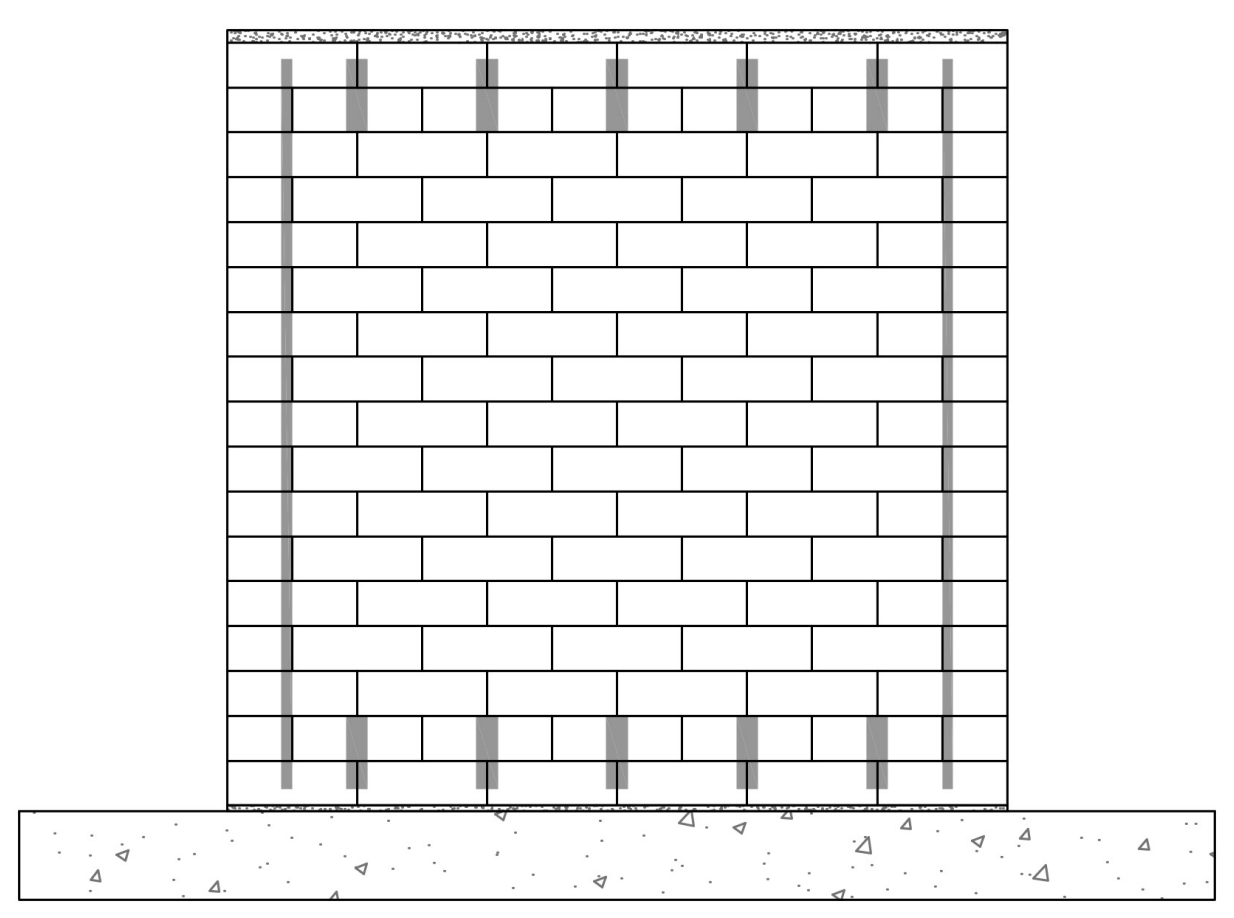

Figure 5.26: Wall 3 Continouous Voids Between Courses

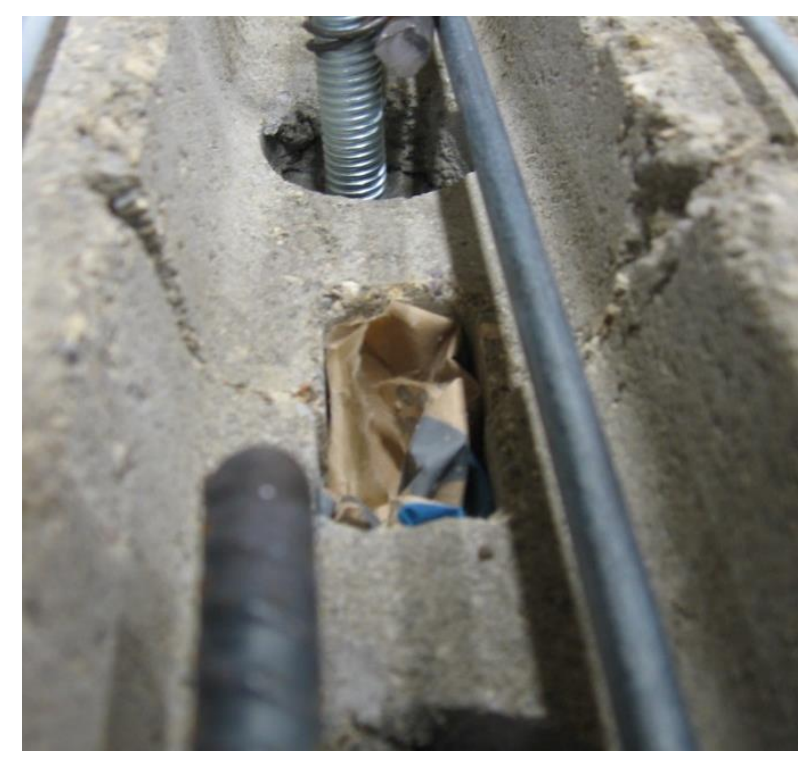

Figure 5.27: Cement Bag Scraps Used as Filler

- Similarly, because it was not possible to remove the center element from the press, all blocks had a vertical empty cavity through the center. In the case of the half blocks, this manifested itself as a shear key along one edge only. For cosmetic reasons, it was decided to turn the half blocks such that the smooth edge 
was visible from the outside even though this disrupted the pattern of voids in the course. This also created a continuous void running the height of the wall at the edge of these half blocks, shown above in Figure 5.26. Again, to prevent concrete for the bond beam from running down the void, the top of the hole was filled with scraps of cement bag.

\subsubsection{Testing}

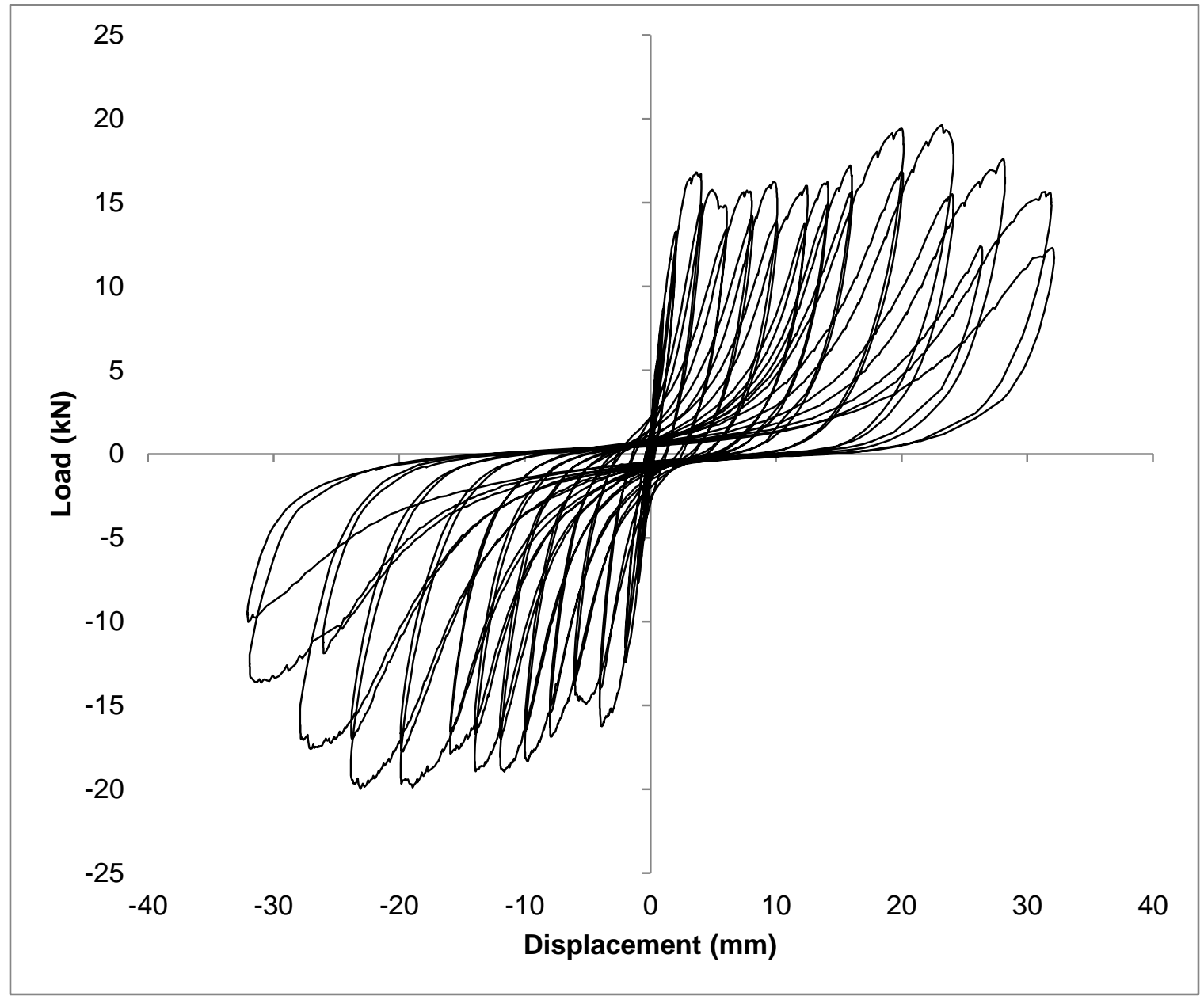

Figure 5.28: Wall 3 Force-Displacement Plot

Wall 3 was tested on July 7, 2016. Testing went through cycle 28 to a maximum amplitude of $32 \mathrm{~mm}$. The load initially peaked during cycle 7 (the first 4-mm cycle) at $16.8 \mathrm{kN}$ in the pull direction and $16.2 \mathrm{kN}$ in the push direction. The peak load 
subsequently dropped for the next few amplitude sets before rising again, ultimately peaking again during cycle 23 (the first $24-\mathrm{mm}$ cycle) at $19.6 \mathrm{kN}$ in the pull direction and $20.0 \mathrm{kN}$ in the push direction. Testing ended after cycle 32 over concerns of significant material spalling and instability and because the peak load finally degraded

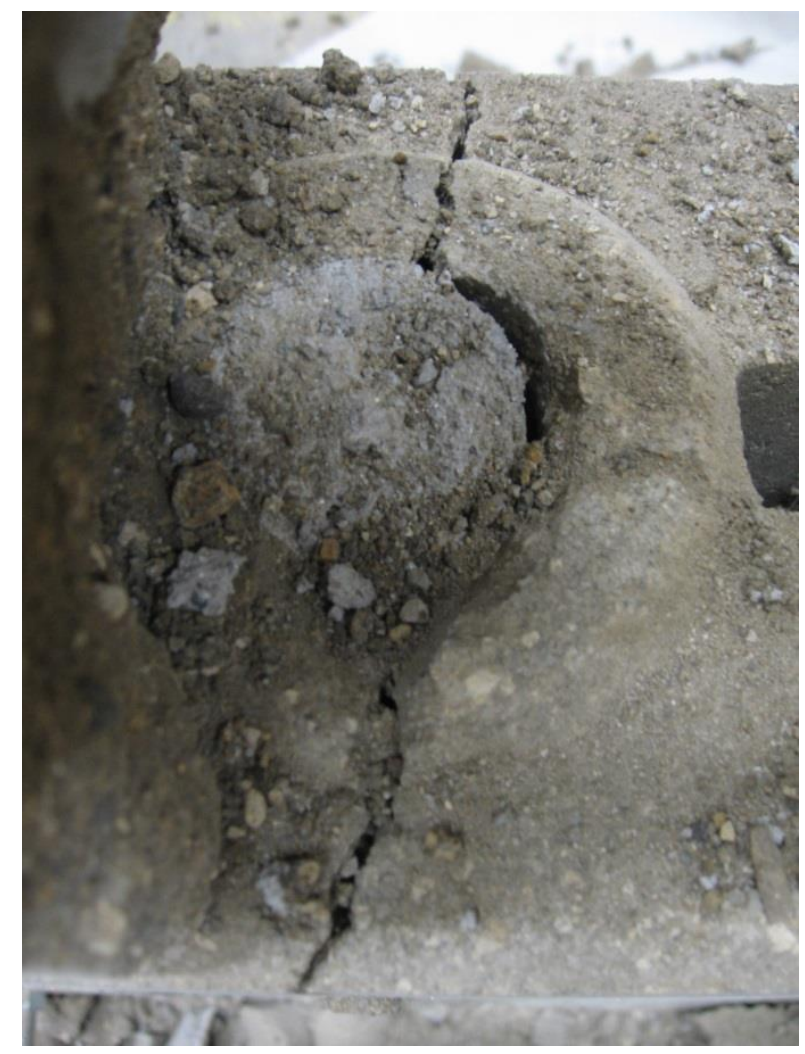

Figure 5.29: Wall 3 Block Cracking Around Core

Cracking followed a generally X-shaped pattern that would be expected from cyclic shear failure, but the majority of the cracks were vertical or nearly vertical on the blocks and corresponded to the approximate location of the grout cores. Many of these cracks did not extend through the grout cores; one such case is depicted in Figure 5.29, where the block cracked around the core and cleanly de-bonded from it on one side. Cracking was first observed after the $4 \mathrm{~mm}$ displacement cycles, coinciding with the initial peak of the load. As with Wall 2, forensic investigation of the wall showed high 
deformation in the reinforcement in the upper corners as shown in Figure 5.30, with separation in the top untied portion of the lap splice. This again may have contributed to the extensive damage to the blocks and grout cores in those corners, which in turn allowed the reinforcement above to further deform. As before, though, the lap splice showed no signs of vertical slip.

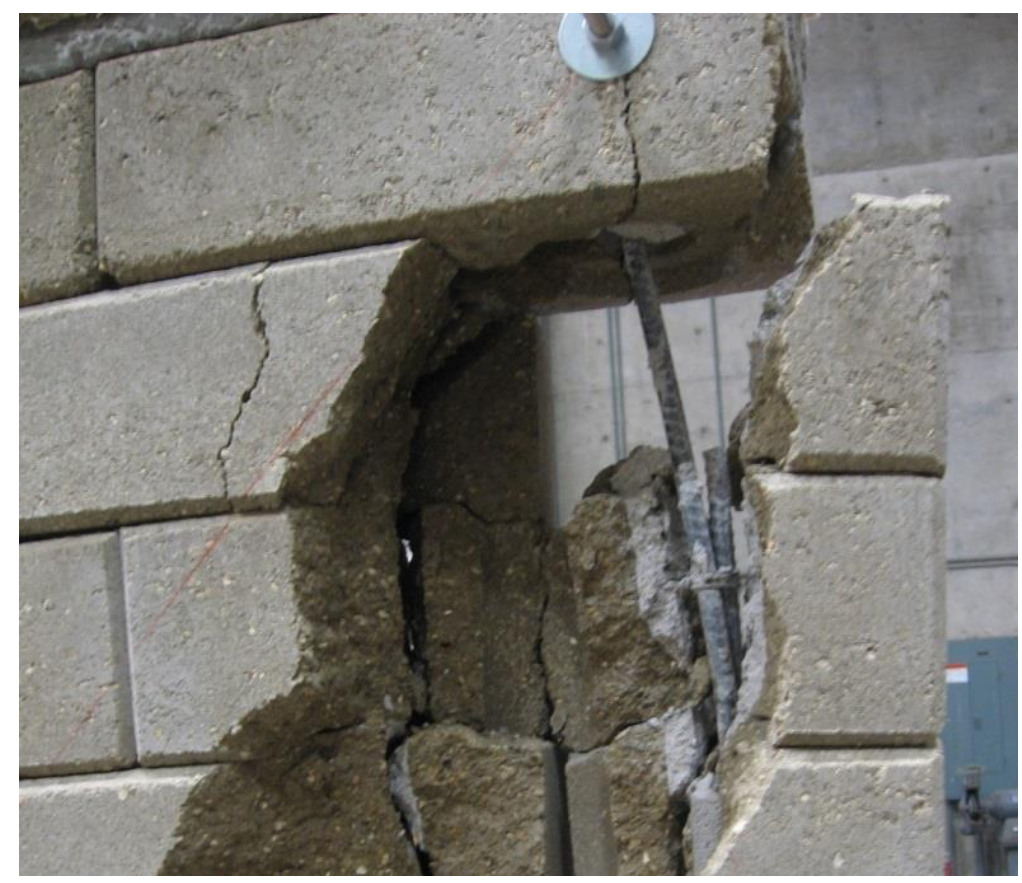

\section{Figure 5.30: Wall 3 Lap Splice Splitting and Reinforcement Deformation}

All instrumentation on the face of the wall was removed after cycle 22 (the second $20 \mathrm{~mm}$ cycle). After cycle 24 (the second $24 \mathrm{~mm}$ cycle), the optical sensors were also removed due to concerns over the possibility of debris falling from the upper corner and striking the instruments. Lastly, the small-stroke string potentiometer was disconnected after cycle 26 (the second $28 \mathrm{~mm}$ cycle) to avoid exceeding its stroke. All subsequent readings for the $32 \mathrm{~mm}$ cycles relied on the redundant, large-stroke transducer. 


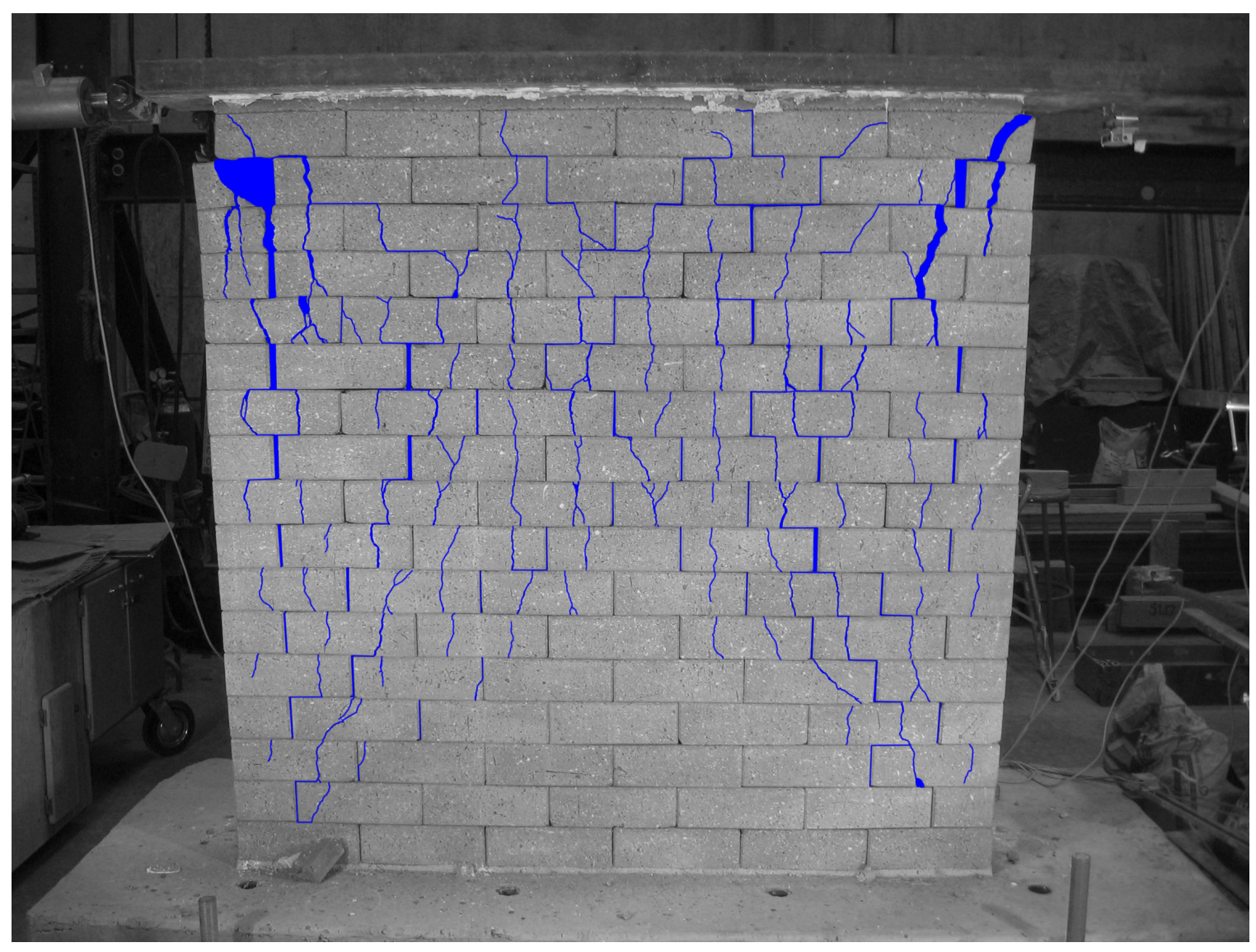

Figure 5.31: Wall 3 Final Cracking 


\section{RESULTS AND ANALYSIS}

This chapter discusses the primary test results in depth. Force-displacement data, image-based displacement data, and visual observations are used to analyze each wall's failure mode. Strength and stiffness are compared to the design equations of MSJC (2013) and Bland (2011), and new modifications to the MSJC equations are proposed. Partial grouting data from Bland (2011) and diagonal panel tests from Pringle (2016) are also compared to this study's results.

\subsection{General Shear Behavior}

The following sections analyze the experimental backbone curves, displacement components, and displacement data to compare the shear behavior of the tested walls.

\subsubsection{Backbone Curves}

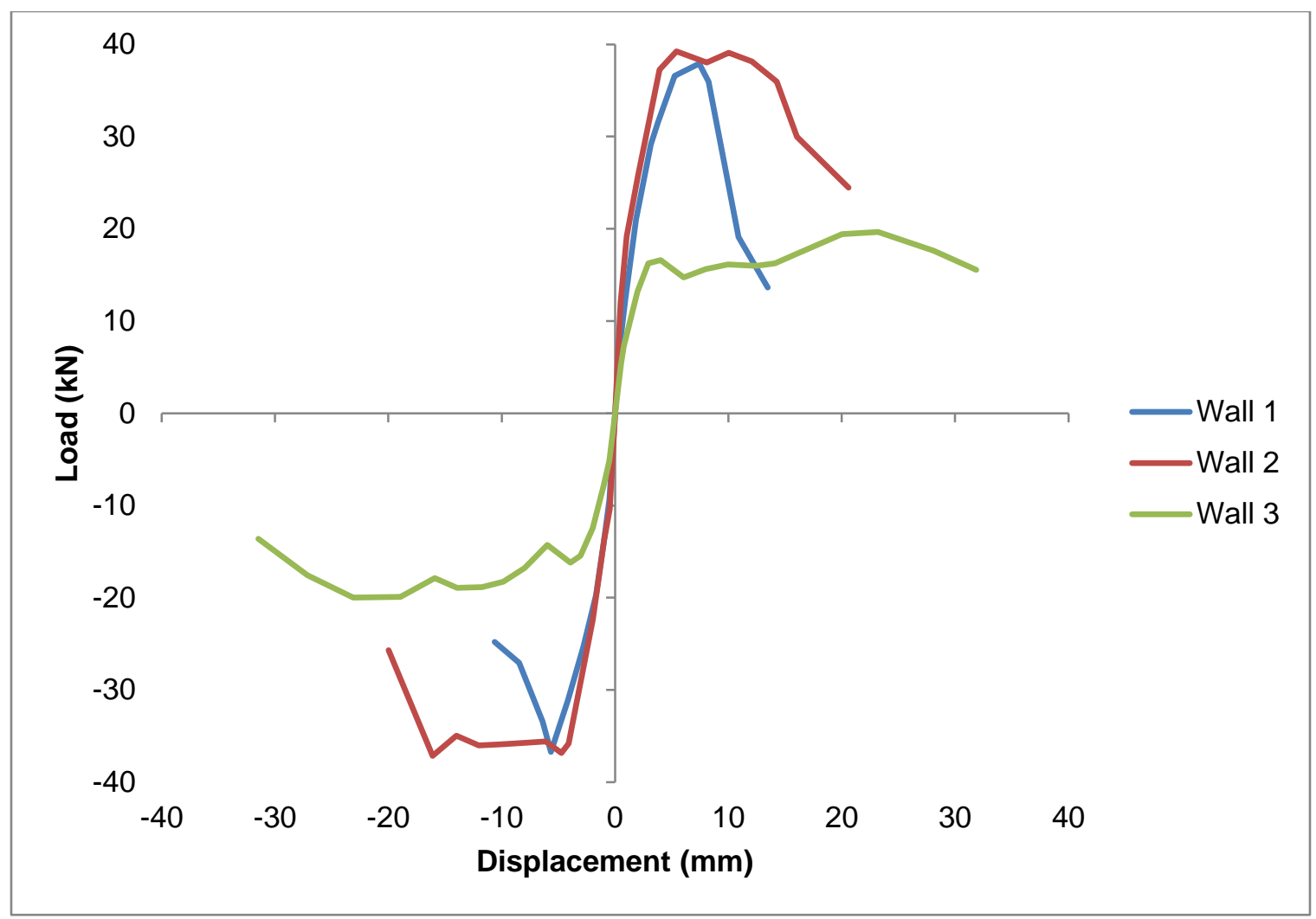

Figure 6.1: Backbone Curves for All Tested Walls 
Figure 6.1 shows backbone curves for all three walls, generated following the general principles of ASCE-41 Supplement 1 Section 2.8.3. Quantitative discussions of strength and stiffness may be found in subsequent sections. Wall 1, consisting of Rhino blocks with grouted head joint shear keys, behaves the closest to the typical brittle shear failure of conventional masonry, with the peak load quickly followed by a dramatic drop in strength. In contrast, Walls 2 and 3 instead reach an initial peak followed by a minor drop in strength and an extended plateau. The push direction of Wall 2 later experienced an $0.8 \%$ higher peak followed by a significant drop in strength, while both the pull and push directions of Wall 3 respectively experienced 17\% and 23\% higher peaks followed by more gradual declines in strength. Such ductility is unusual for an unreinforced shear failure. The partially grouted wall tested in Bland (2011) exhibited the expected postcracking sudden drop in strength; therefore, the plateau appears to be a characteristic of shear failure involving blocks without head joint shear keys.

The residual strength is most likely due to doweling, frictional sliding, and aggregate interlock, with the final strength drop coming after sufficient deterioration. In the case of Wall 3, the significant post-cracking strength gain may be a sign that the Rhino blocks' interlocking system engaged after sufficient displacement. While these same factors probably also determine the residual strength of walls with shear keys, the shear keys may increase the wall's initial strength over the frictional resistance by a greater margin than the grout cores acting alone. Testing of Wall 1 was halted at the more abrupt strength drop before any similar behavior could be observed. 


\subsubsection{Deformation Components}

Equations 5-1 and 5-2 in Section 5.1.3.3 and derived in Voon (2007) enabled the instrument readings on the face of each wall to be converted to the shear, bending, and rocking components of each wall's total displacement. Issues with the physical instruments mounted to the face of the wall resulted in inaccurate values, demonstrated by the fact that the components' sum did not closely match the direct readings of overall displacement. Therefore, the component analysis was instead performed by extracting select points from the photographic displacement analysis as described above in Section 5.1.4.1 and shown in Figure 5.13. Figures 6.2 through 6.4 display the displacement components matching the backbone curve of Figure 6.1 with respect to total displacement. For Walls 1 and 3 (Figures 6.2 and 6.4, respectively), the plotted total displacement is the difference in horizontal displacement between the central top and bottom points, effectively directly measuring the wall displacement via the motion tracking. For Wall 2 (Figure 6.3), the total displacement is instead the sum of the individual components. This is because the sum matched the transducer-measured displacement better than did the difference between the central points. This is probably because the transducer measures the displacement of the entire wall including the concrete beam; the central points only measure the relative displacement of the section excluding the beam, while the Voon (2007) formulas incorporate terms to extend the panel's flexural component up to the full height of the wall. 


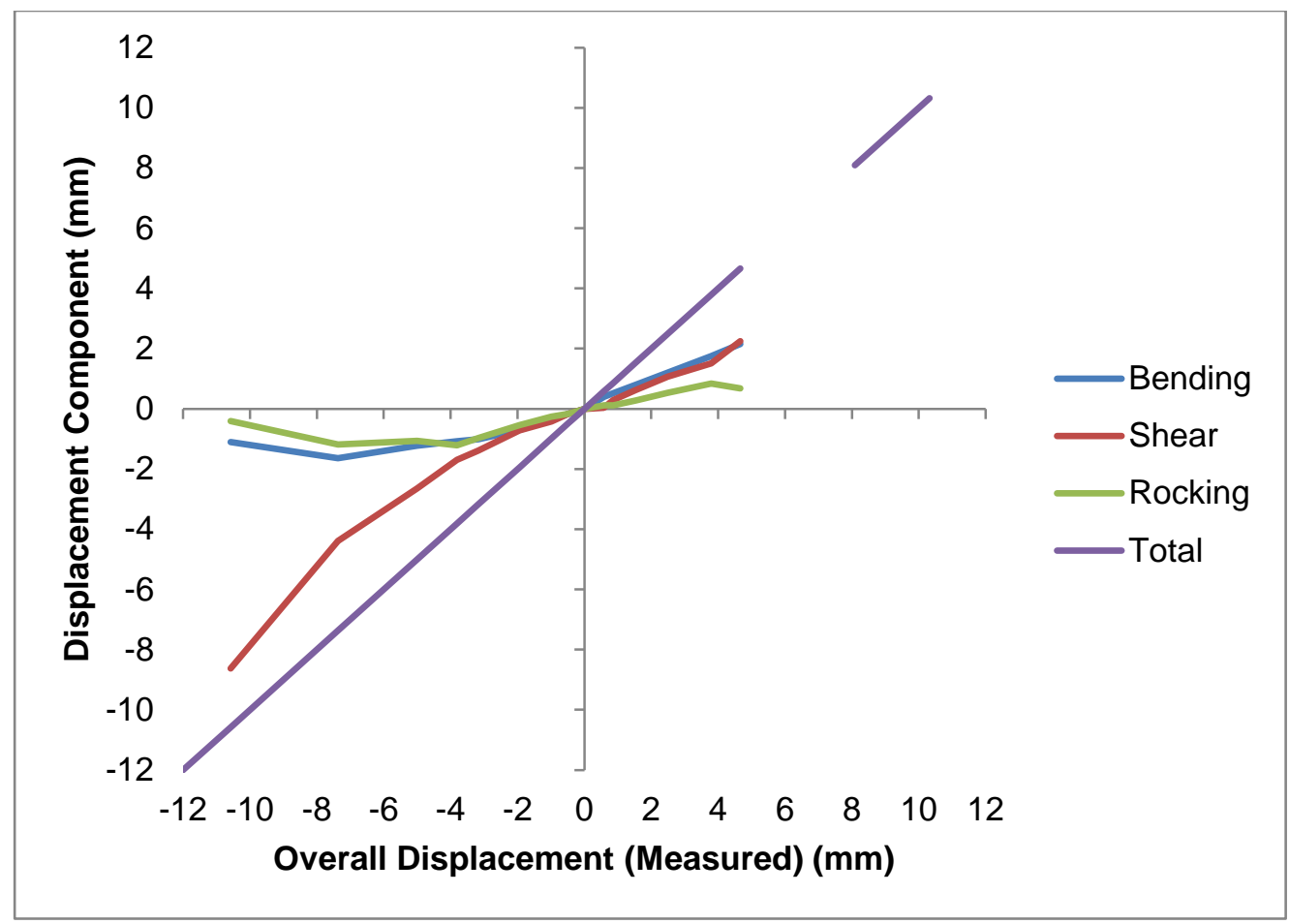

Figure 6.2: Wall 1 Components with Respect to Measured Displacement

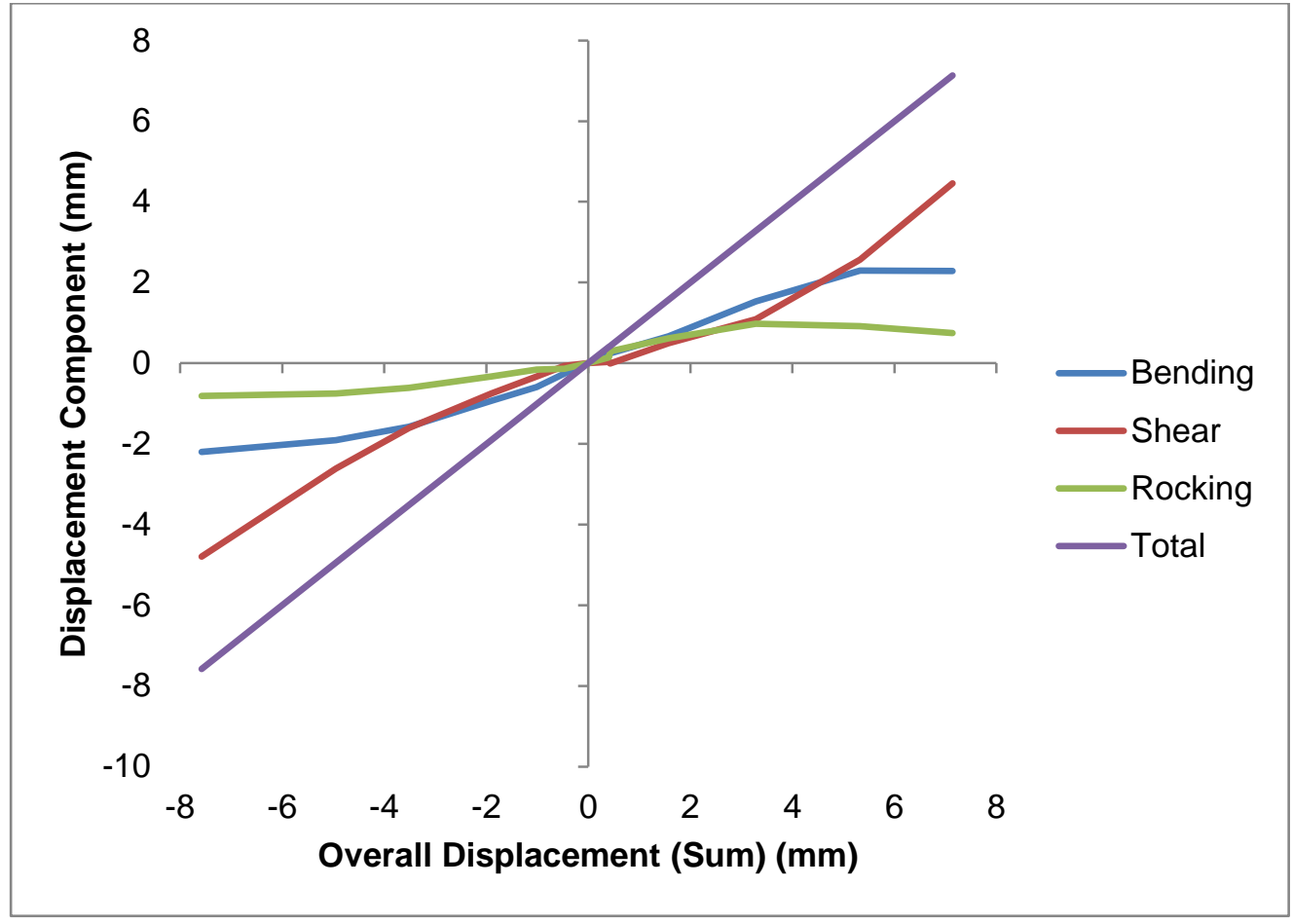

Figure 6.3: Wall 2 Components with Respect to Sum 


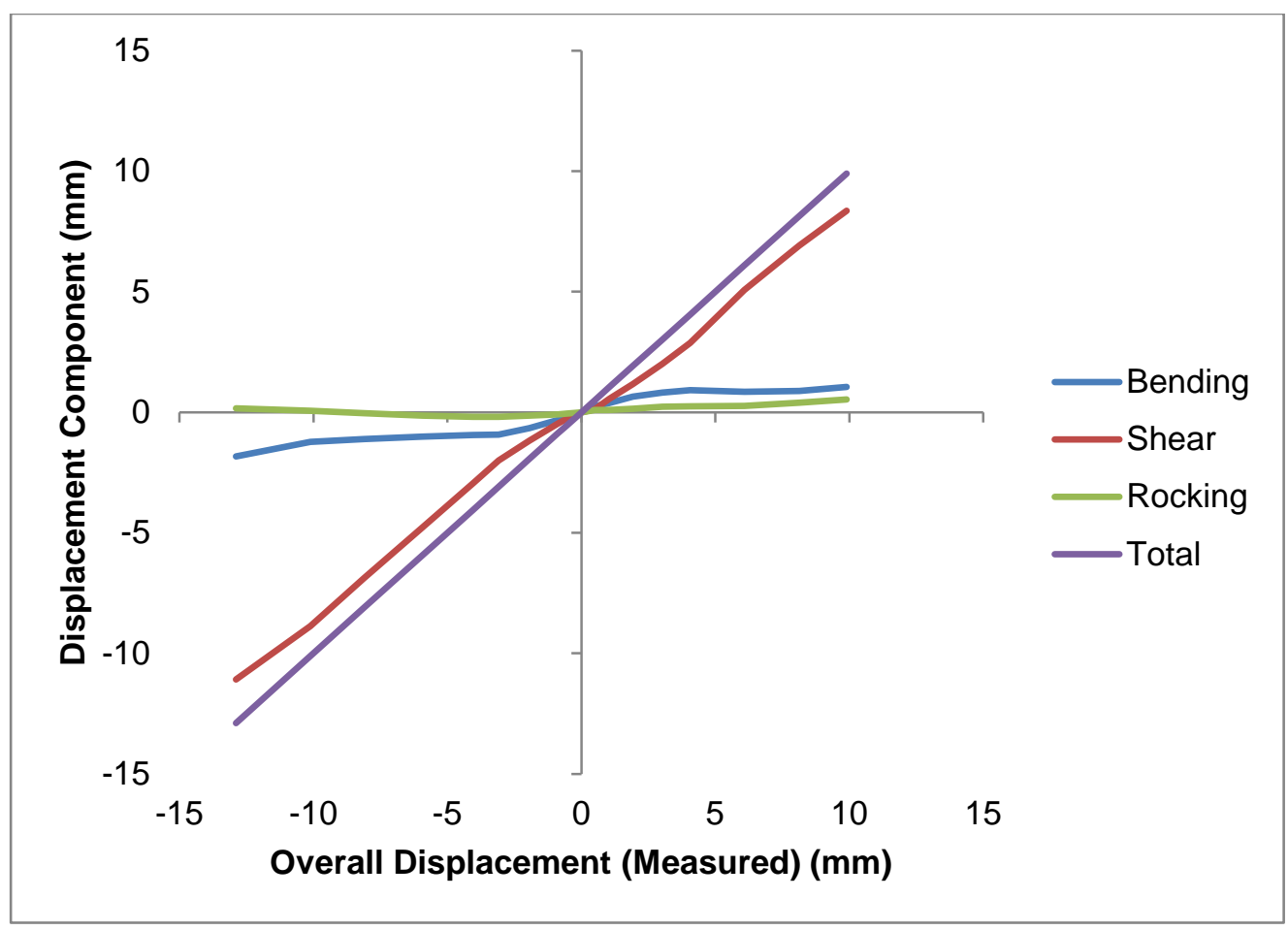

Figure 6.4: Wall 3 Components with Respect to Measured Displacement

On all three walls, the flexural component is nearly equal to or slightly greater than the shear component early in the test, but the shear component ultimately overtakes the flexural component and dominates the response. This is consistent with the shearfailure behavior of the fully grouted wall from Bland (2011). It confirms that, in spite of the unexpected ductility, Walls 2 and 3 did in fact fail in shear. The shear component dramatically increases after the shear cracking decreases the shear stiffness, while the bending component levels off along with the applied load at higher displacements.

\subsubsection{Photographic Displacement Analysis}

All three walls were continuously photographed during testing, and the resulting images were processed with displacement analysis software as described in Section 5.1.4 and 0 . The following sections examine displacement contour plots at selected points during testing to assess the behavior of the wall before and during failure. For simplicity, 
only the pull direction is examined for each wall. The plots display horizontal motion $(u)$ on the left side of each page and vertical motion $(v)$ on the right. Positive values of $u$ represent displacements away from the loading frame, which is opposite the sign convention used elsewhere in this thesis. Positive values of $v$ represent upward displacements. All units are in millimeters.

\subsubsection{Wall 1}

Figure 6.5 matches the selected displacement plots to their locations on the experimental force-displacement plot. Images 451 and 454 on Cycle 11 were specifically selected to illustrate the state of the wall immediately before and after peak load.

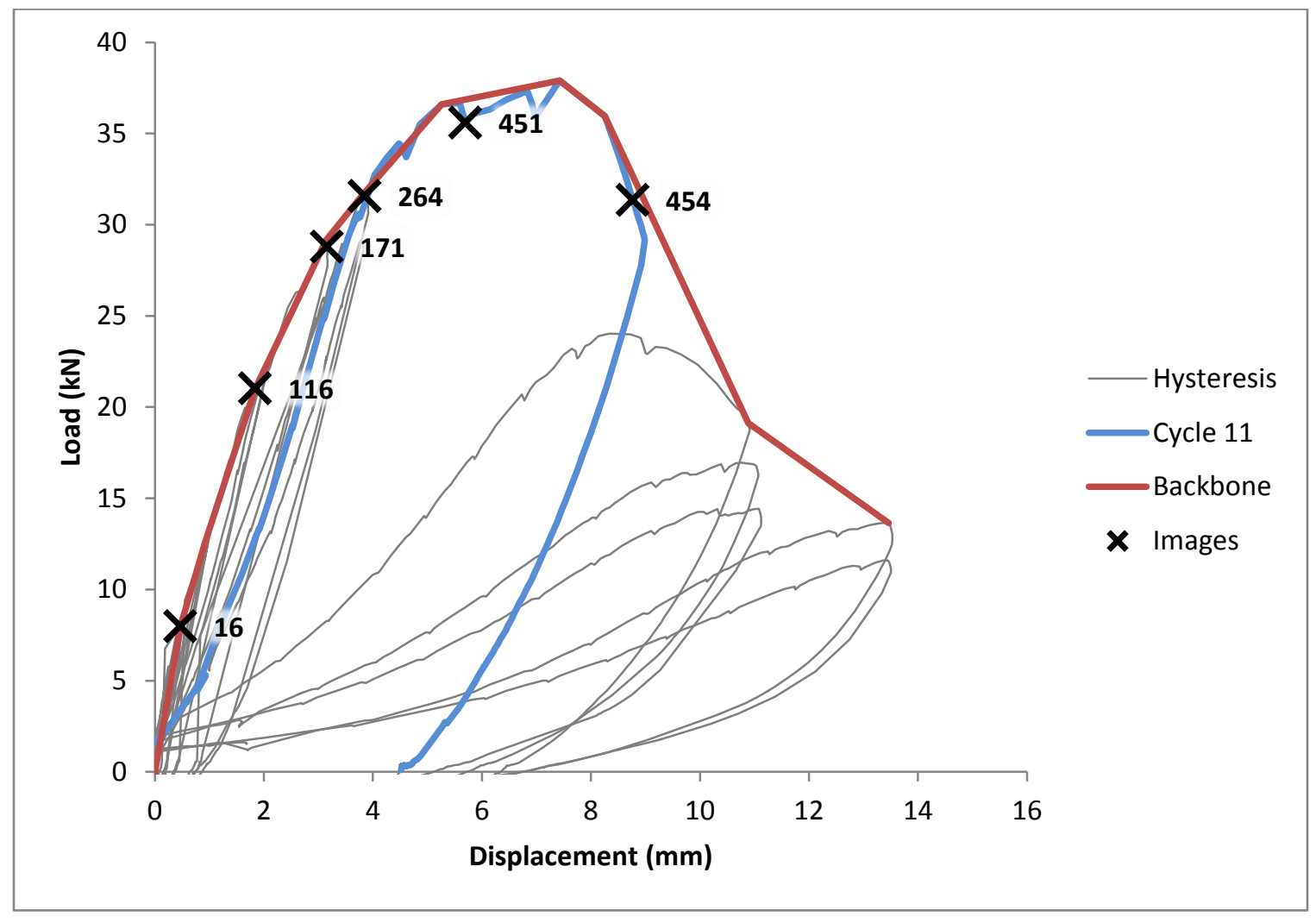

Figure 6.5: Selected Images for Wall 1 Displacement Analysis 

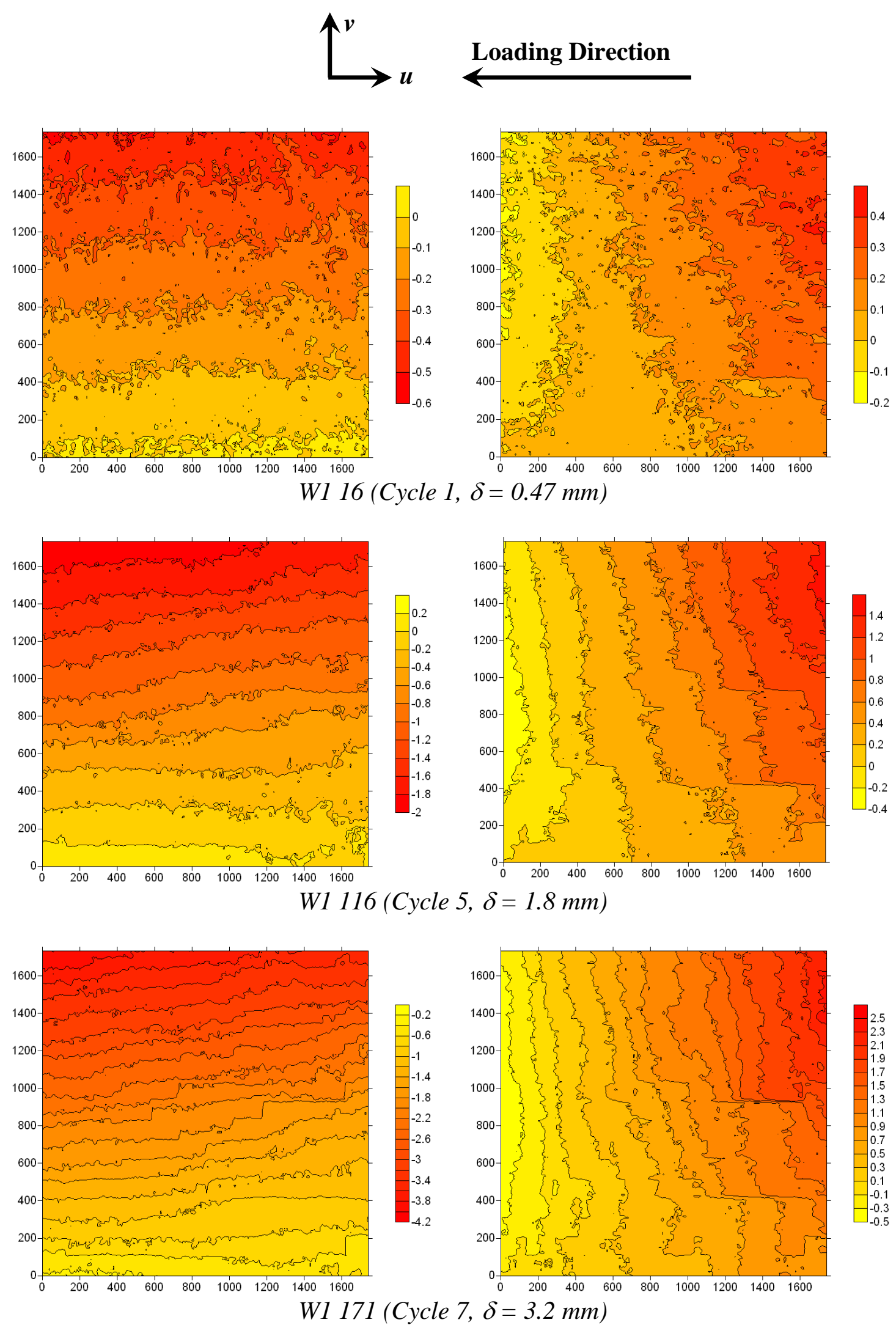

Figure 6.6: Wall $1 u$ (left) and $v$ (right) Displacement Contours 16, 116, and 171 


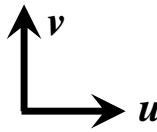

\section{Loading Direction}
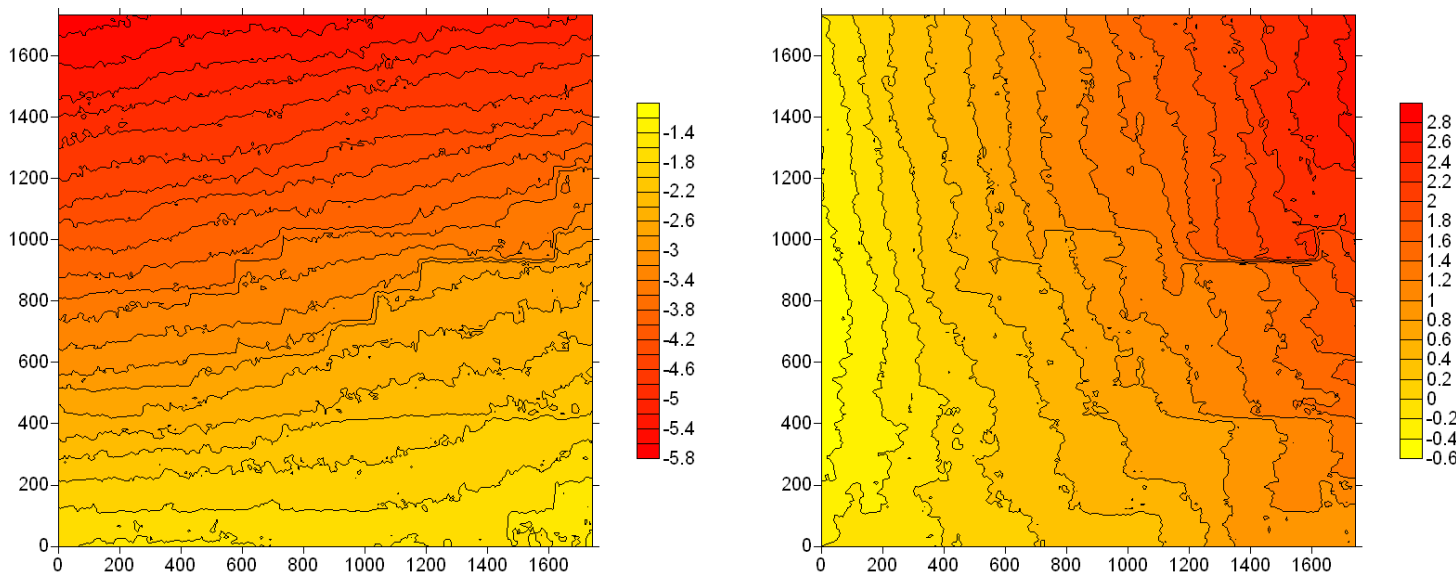

W1 264 (Cycle 9, $\delta=3.9 \mathrm{~mm}$ )
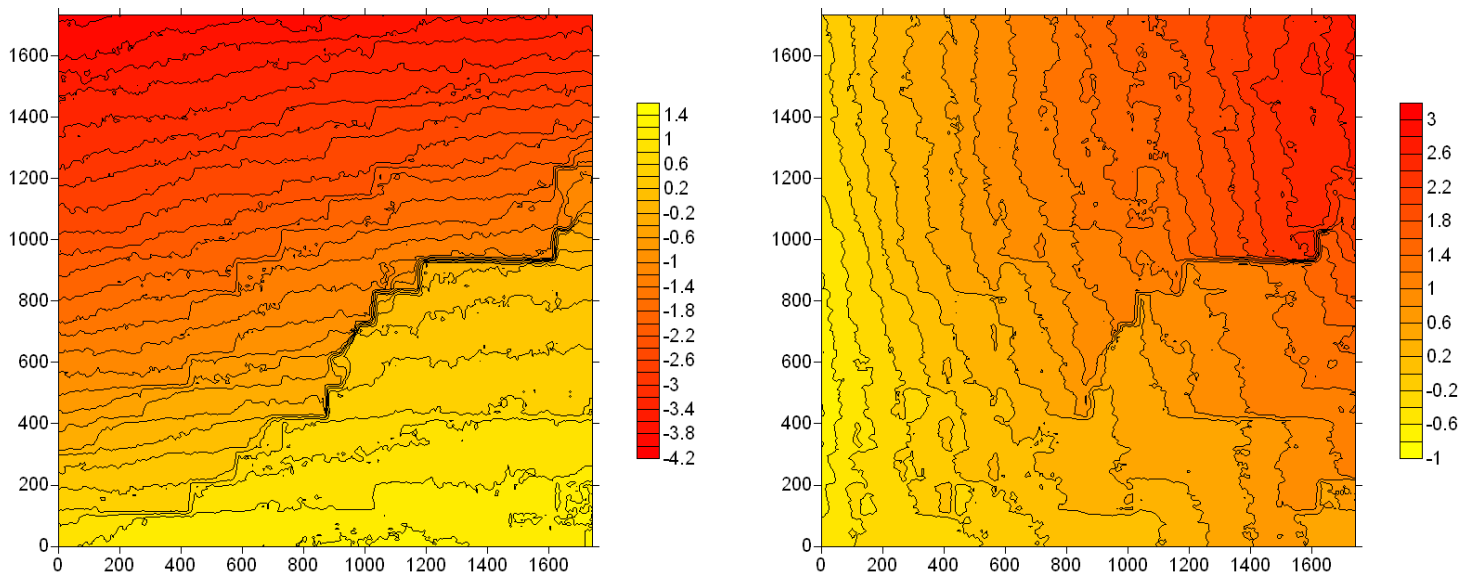

W1 451 (Cycle 11, $\delta=5.7 \mathrm{~mm})$
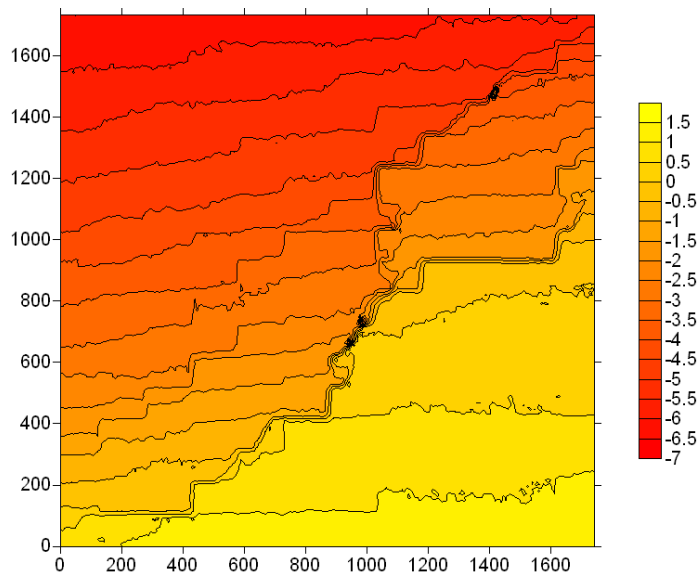

W1 454 (Cycle 11, $\delta=8.8 \mathrm{~mm}$ )

Figure 6.7: Wall $1 u$ (left) and $v$ (right) Displacement Contours 264, 451, and 454 
The $v$ plot for Image 16 shows flexural tension cracking even at this small level of displacement, as demonstrated by the horizontal contour line approximately $400 \mathrm{~mm}$ above the base on the right-hand side. The rest of this plot is consistent with flexural deformation, showing tensile upward motion on the right and slight compressive downward motion on the left. The $u$ plot shows a relatively uniform gradation of displacements without unusual discontinuities. This condition stays approximately the same for Image 116 except with larger magnitudes and an additional flexural crack at an approximate height of $900 \mathrm{~mm}$. The $u$ plot for Image 171 shows some isolated stairstepping around that same height that follows a few of the block boundaries in that region, suggesting sliding between the blocks in this region. This sliding is more prominent in Image 264, and further stair-stepping has begun to appear slightly above and left of the wall's center. Both sliding boundaries have become more pronounced just before the peak load in Image 451, and the first sliding surface now extends farther down. After the peak, at Image 454, both sliding surfaces are very distinct, and the second surface now clearly extends from the upper right corner to about $350 \mathrm{~mm}$ above the lower left corner. The regions where the surface jumps between block boundaries coincide with visible cracks in the original photographs. The regions above and below the lower contour are clearly moving separately, with a less pronounced distinction over the upper contour. Both surfaces are also clearly visible on the $v$ plot.

Figure 5.19 in Section 5.2.1.2 above shows the final cracking of the wall with the open cracks highlighted for clarity. The open head joints and extensive diagonal block cracking roughly follow the main wall diagonals, similar to a typical unreinforced shear failure in conventional masonry. 


\subsubsection{Wall 2}

Figure 6.8 matches the selected displacement plots to their locations on the experimental force-displacement plot. Images 1018 and 1023 on Cycle 9 were specifically selected to illustrate the state of the wall immediately before and after the peak load.

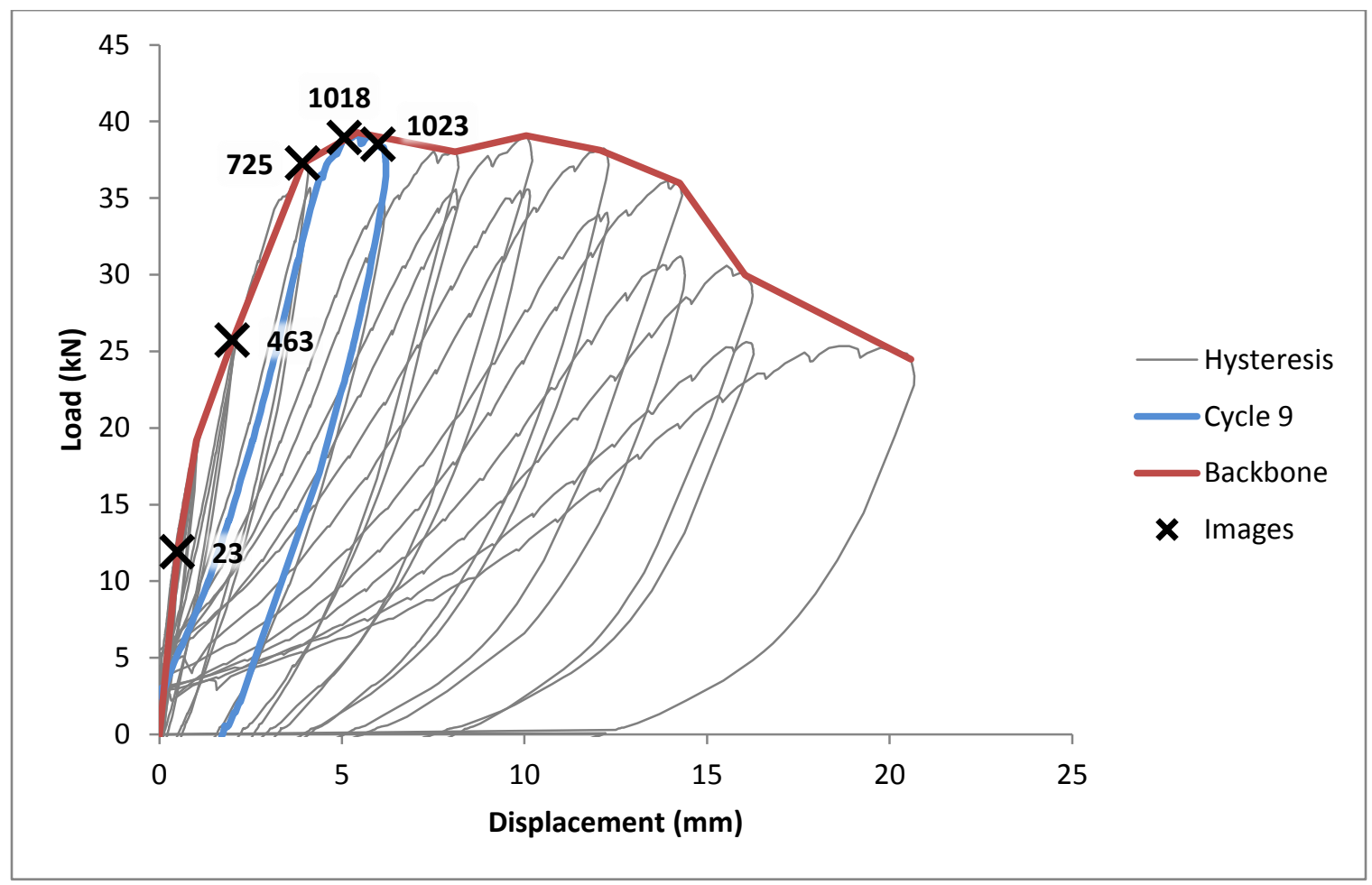

Figure 6.8: Selected Images for Wall 2 Displacement Analysis

Even through the noise in the data, a horizontal flexural tension crack is clearly visible in Image 23 approximately $350 \mathrm{~mm}$ above the base on the right side of the $v$ plot. As with Wall 1, the horizontal displacement increases up the wall with no obvious discontinuities. Image 463's $v$ plot shows a stair-step contour following the block boundaries midway up the right-hand side of the wall. Since this only barely appears on the $u$ plot, the motion is predominantly vertical, so this appears to be a flexural crack with a group of blocks lifting up with the upper half of the wall. 




\section{Loading Direction}
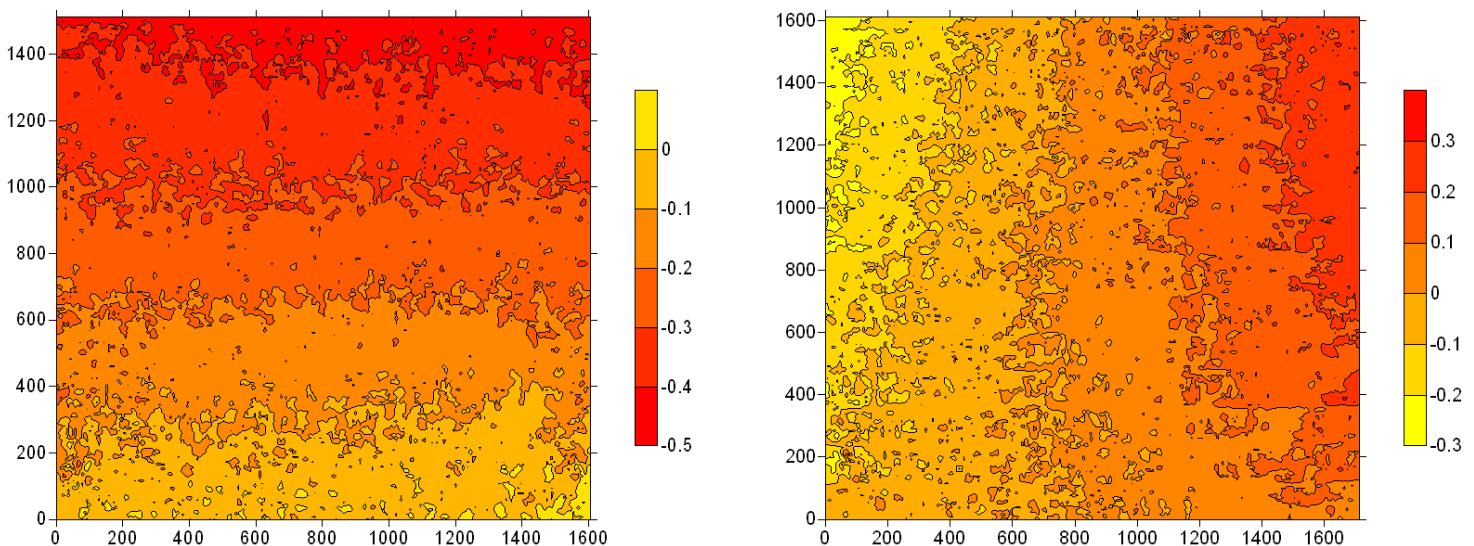

W2 23 (Cycle 1, $\delta=0.49 \mathrm{~mm}$ )
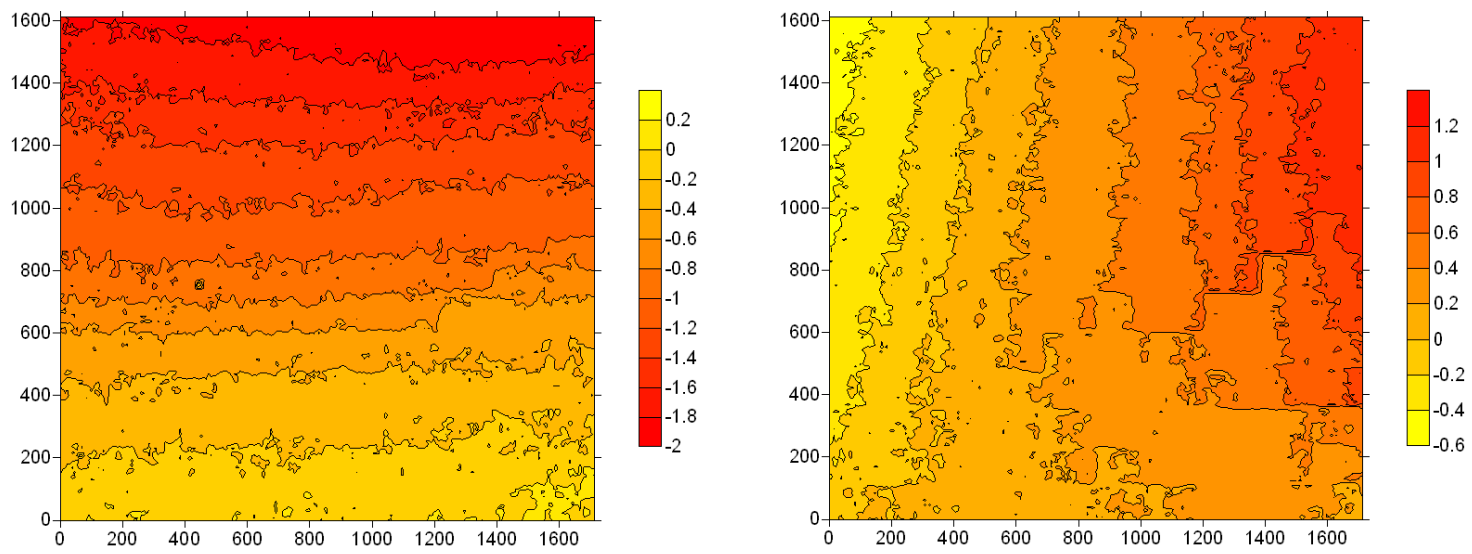

W2 463 (Cycle 5, $\delta=2.0 \mathrm{~mm}$ )
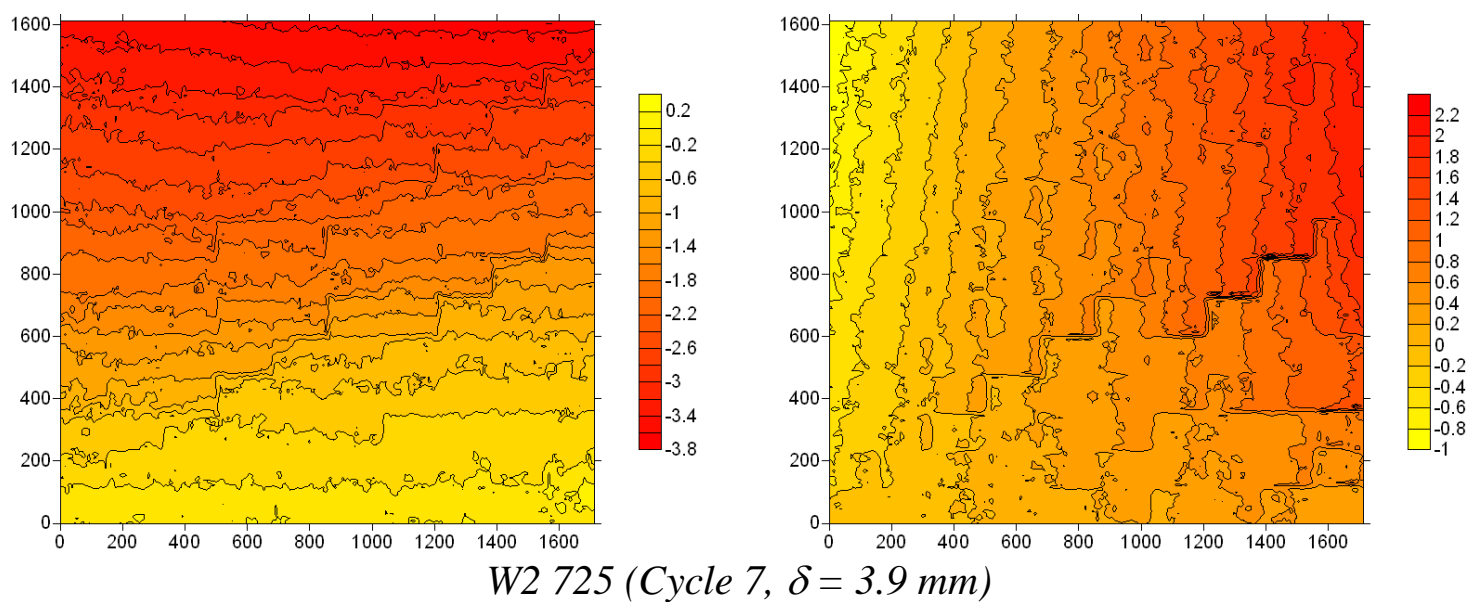

Figure 6.9: Wall $2 u$ (left) and $v$ (right) Displacement Contours 23, 463, and 725 


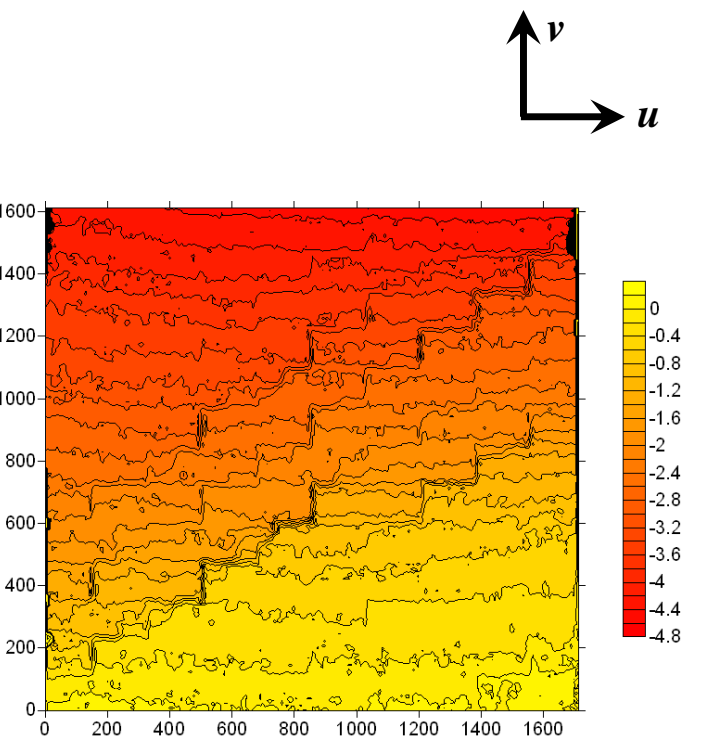

\section{Loading Direction}

W2 $1018($ Cycle $9, \delta=5.1 \mathrm{~mm})$
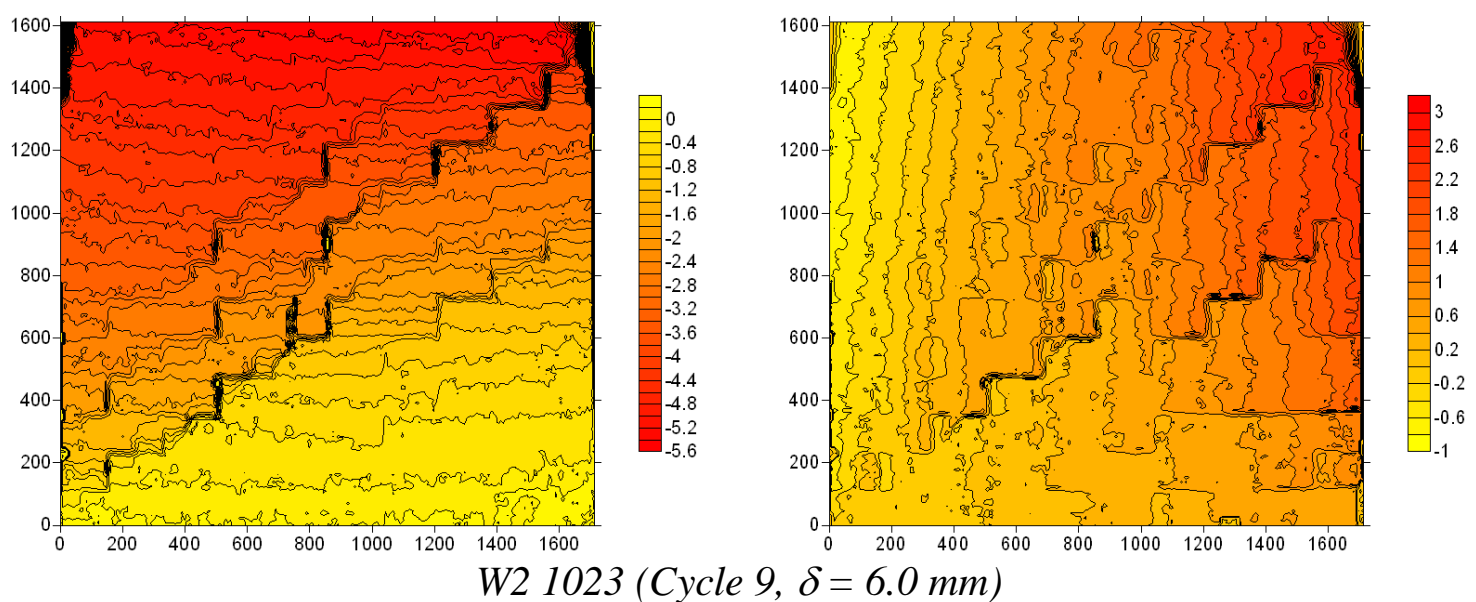

Figure 6.10: Wall $2 u$ (left) and $v$ (right) Displacement Contours 1018 and 1023

Image 725 shows this flexural motion has become more pronounced along with

another flexural crack towards the base. This time, the stair-stepping also appears on the $u$ plot along with similar patterns closer to the center of the wall, suggesting sliding has begun. Image 1018, just before the peak load, shows more stair-stepping along the central diagonal on both the $u$ and $v$ plots, while Image 1023 just after the peak shows that these have become better defined. As with Wall 1, the peak load is accompanied by the formation of well-defined horizontal movement along the main diagonal. 
Figure 5.24 in Section 5.2.2.2 above shows the final cracking of the wall with the open cracks highlighted for clarity. As with Wall 1, the diagonal block cracking and open head joints follow the main wall diagonal, although the cracking is not as clean as it was in Wall 1.

\subsubsection{Wall 3}

Figure 6.11 matches the selected displacement plots to their locations on the experimental force-displacement plots. Images 294 and 298 on Cycle 7 were specifically selected to illustrate the state of the wall immediately before and after the peak load, while Images 428 and 431 were selected to capture the wall immediately before and after formation of the main diagonal cracking, which did not coincide with the peak load in this test.

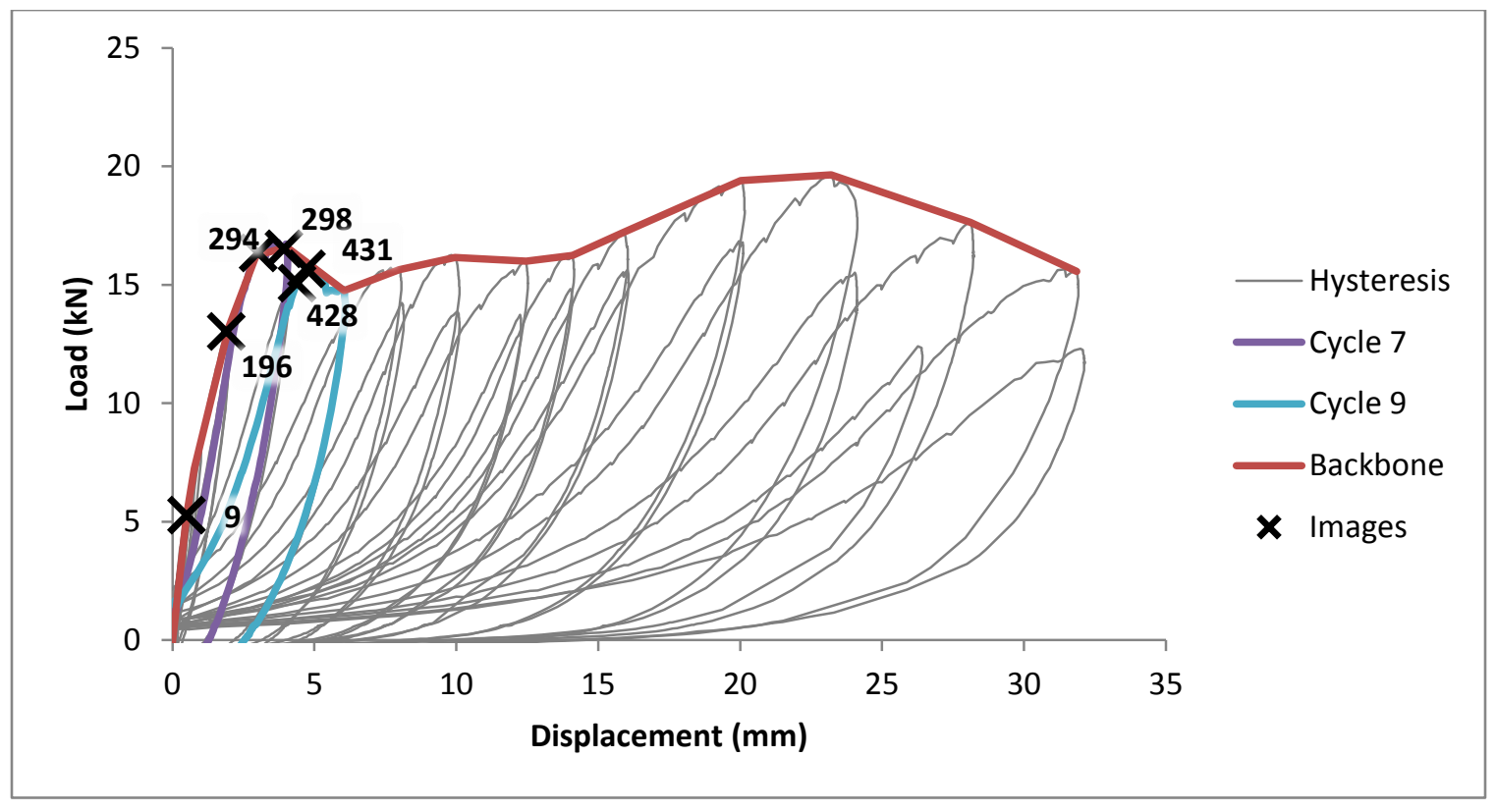

Figure 6.11: Selected Images for Wall 3 Displacement Analysis 


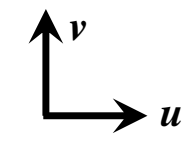

\section{Direction of Loading}
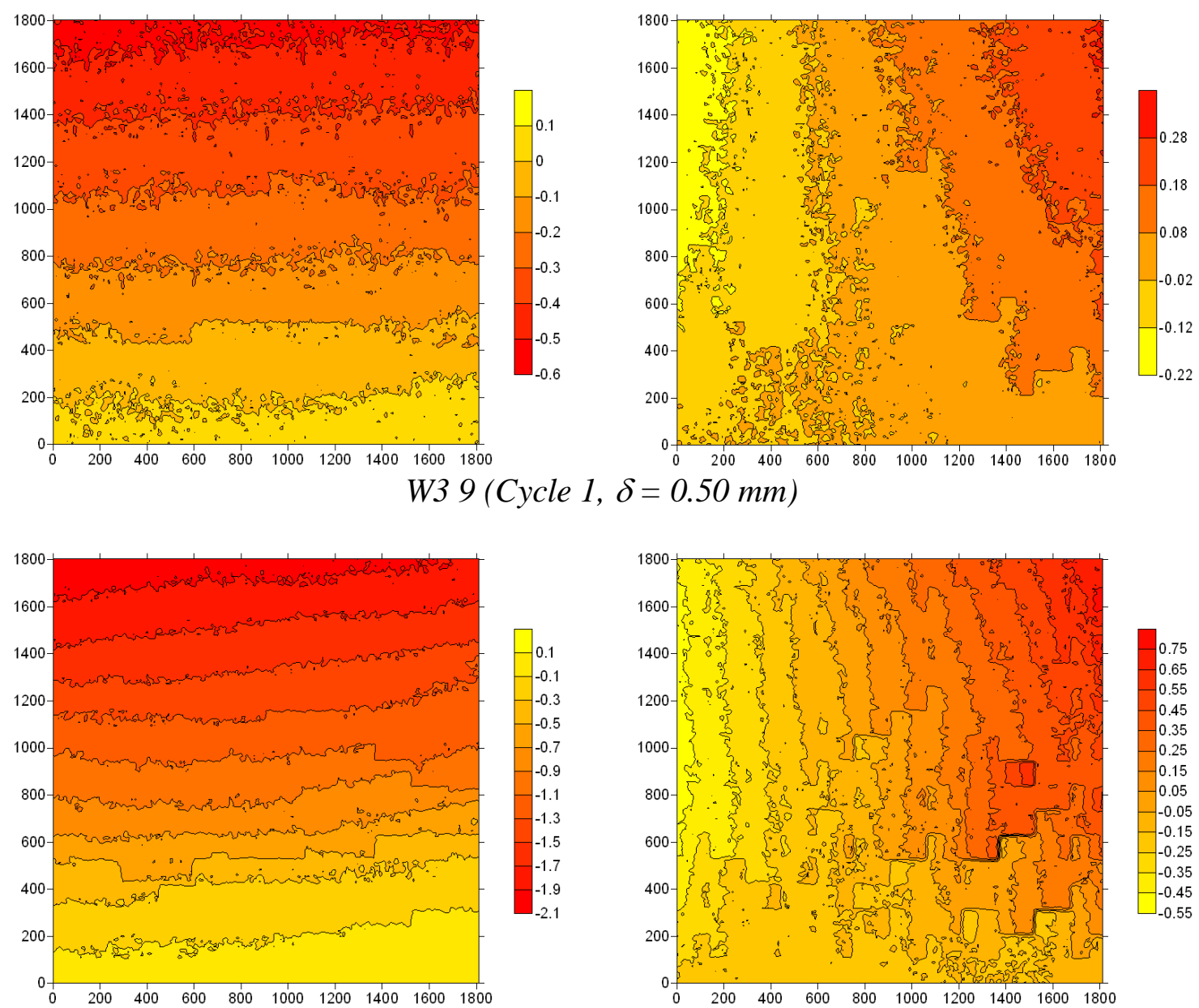

W3 196 (Cycle 5, $\delta=1.9 \mathrm{~mm})$
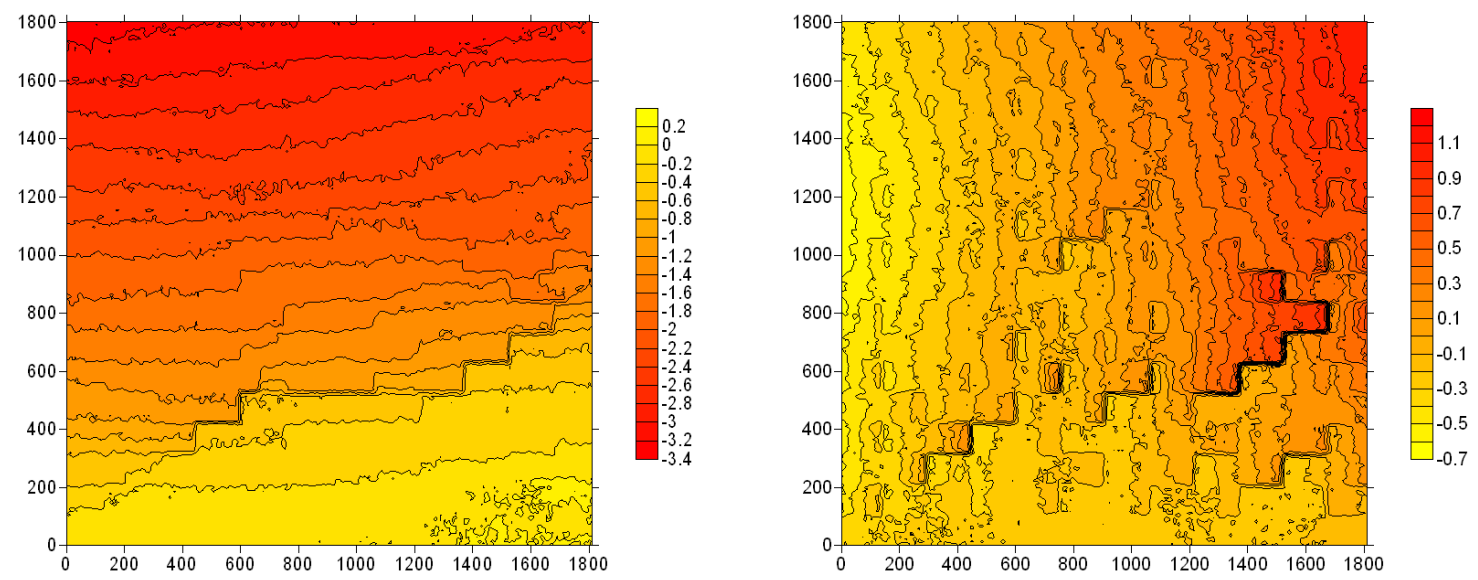

W3 294 (Cycle 7, $\delta=3.0 \mathrm{~mm}$ )

Figure 6.12: Wall $3 u$ (left) and $v$ (right) Displacement Contours 9, 196, and 294 


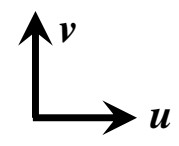

\section{Direction of Loading}
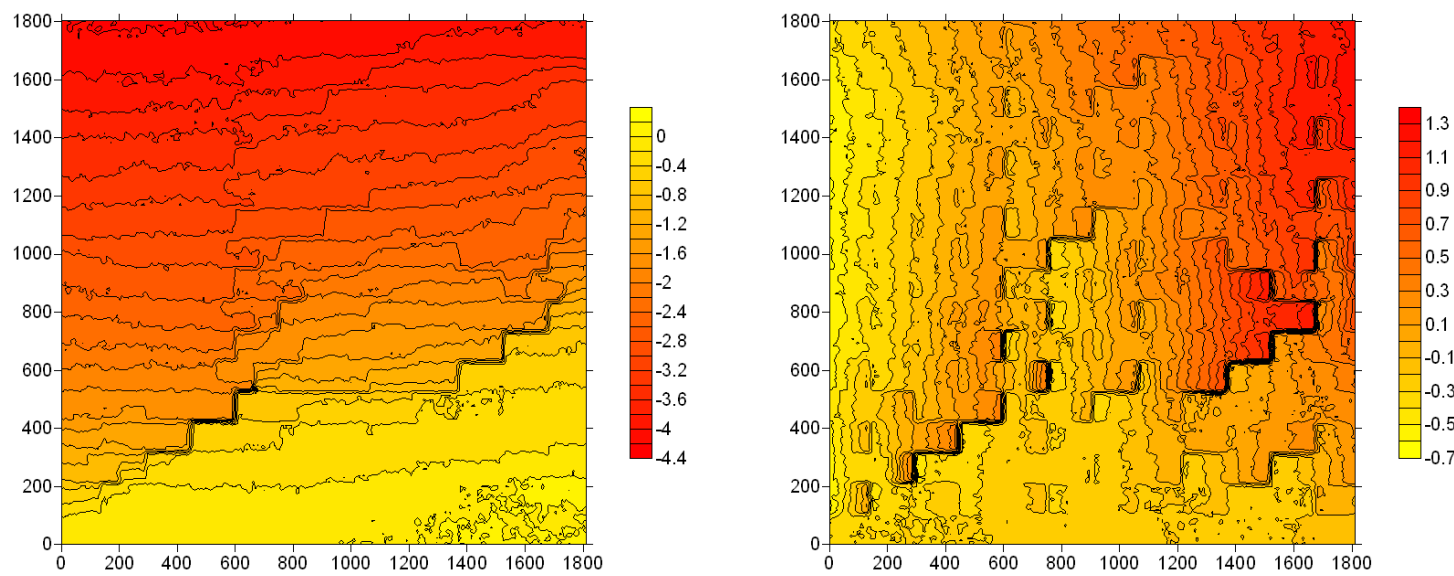

W3 298 (Cycle 7, $\delta=3.9 \mathrm{~mm}$ )
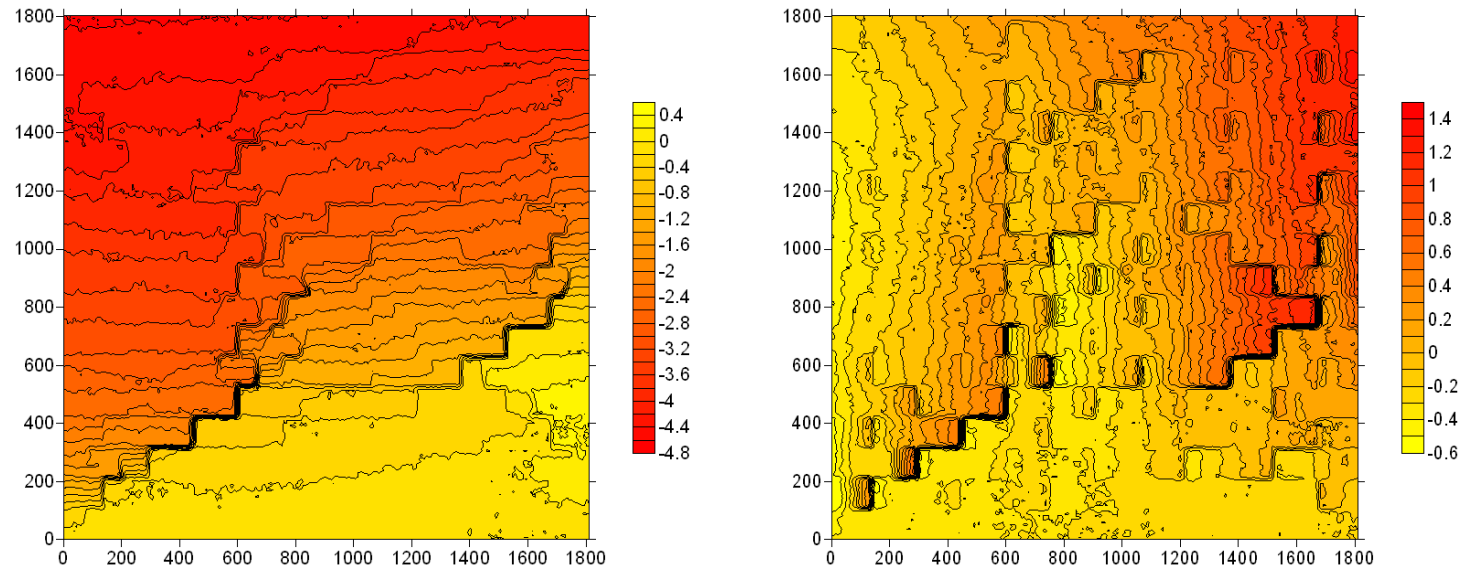

W3 428 (Cycle 9, $\delta=4.4 \mathrm{~mm}$ )
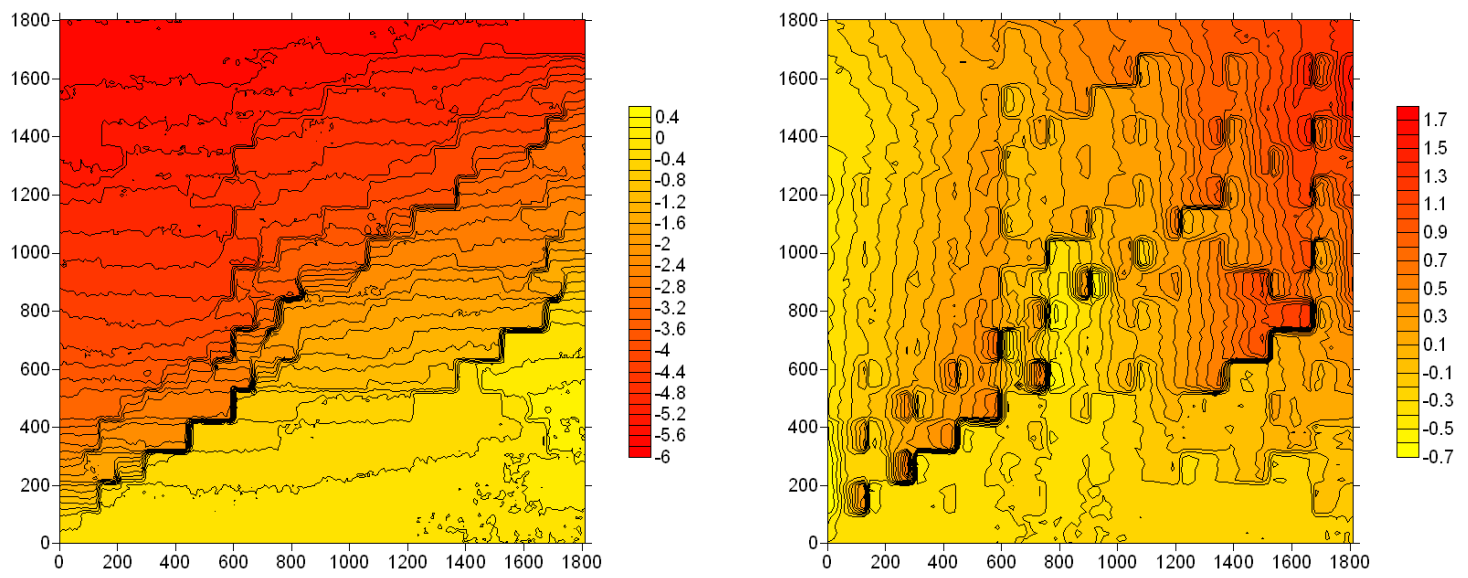

W3 431 (Cycle 9, $\delta=4.7 \mathrm{~mm}$ )

Figure 6.13: Wall $3 u$ (left) and $v$ (right) Displacement Contours 298, 428, and 431 
Unlike the previous walls' early stages of testing, the $u$ displacements for Image 9 of Wall 3 already show a couple of contours that briefly follow block boundaries, most notably between 400 and $500 \mathrm{~mm}$ high on the left side of the plot. This suggests that there is already some level of sliding between blocks even at this low level of displacement. Some of the contours on the right side of the $v$ plot for Image 9 show a poorly-defined stair-step pattern that is not reflected in the $u$ plot. Curiously, it only somewhat follows the block boundaries; Figure 6.14, which superimposes this contour plot over the original image, reveals that some of the vertical contour lines fall mid-block. A probable explanation is that the blocks at this location are independently rotating within the wall, resulting in one end being sufficiently higher or lower than the surrounding blocks to show up in a different contour level.

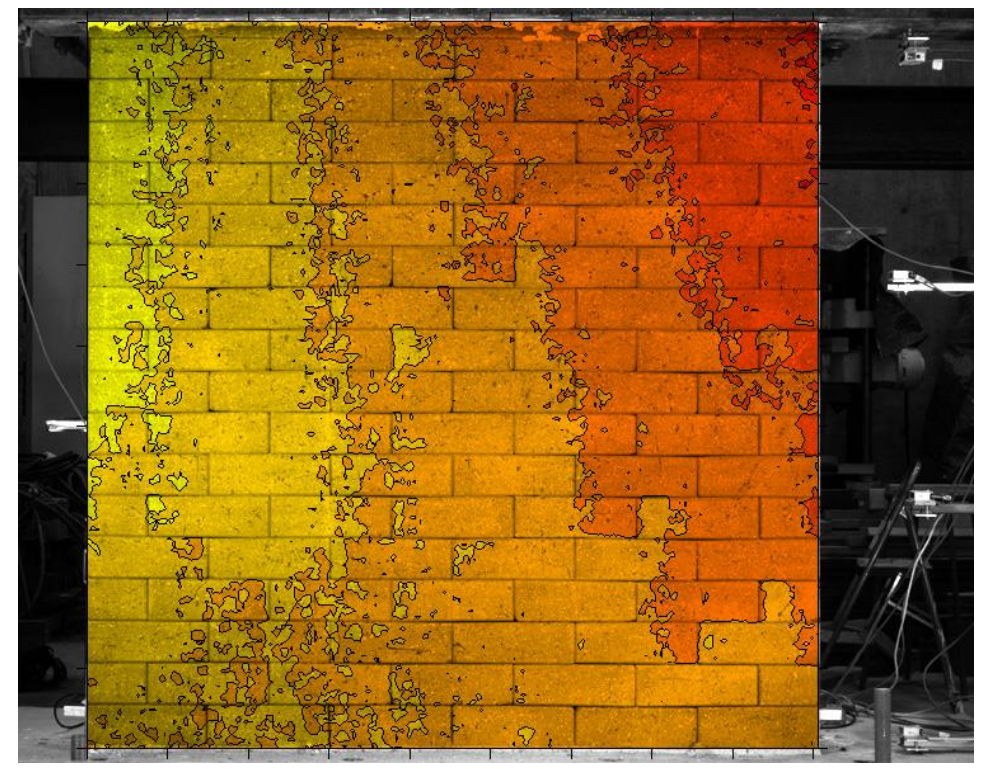

\section{Figure 6.14: Image $9 v$ Contours Superimposed Over Original Image}

The $u$ plot of Image 196 again shows essentially horizontal contours that still occasionally deviate to follow block boundaries, once again demonstrating low-level sliding. The $v$ plot shows continued vague, irregular stair-stepping that is now 
accompanied by two well-defined breaks. These breaks more consistently follow the block boundaries, yet they do not appear in the $u$ plot. Image 294, just before the peak load, shows them more clearly. The lower boundary is likely a flexural tension crack, supported by the fact that the region above it continues to displace upward. In contrast, Image 294 shows that the upper of these partly bounds a region whose right side has moved significantly upward relative to the surrounding wall. This region is most likely rotating independently of the adjacent wall sections, a larger-scale version of the individually rotating blocks visible in Image 9. The $u$ plot shows a well-defined sliding surface extending from this same region across to the left side, also following block boundaries and matching up with similar $v$ contours on the left side.

Image 298, just after the peak load, is made notable by the fact that nothing notable has happened since Image 296; the existing contours are clearer, and a few more block separations at head joints have appeared in the $v$ plot, but apart from that they are essentially the same. Unlike the previous two walls, no clear diagonal tension crack has appeared along with the peak. It finally forms two cycles later, between Images 428 and 431. Note in Figure 6.11 above that the total displacements matching these images are only slightly greater than the maximum displacement of the previous cycles, and Cycle 9's load does in fact drop shortly after Image 431. The likely explanation is that the peak load happened to coincide with the end of a cycle and reversal of load, and while this was not enough load to fully create the shear crack, it and the following cycle reduced the stiffness of the wall such that the crack ultimately formed at a greater displacement but a lower load. Had Cycle 7 continued to that, the crack may have formed at a slightly higher load than was recorded using this loading protocol. The $v$ plots show significant 
displacement discontinuities between numerous head joints, indicating that individual blocks continue to rock significantly.

Figure 5.31 in Section 5.2.3.2 above shows Wall 3's cracks at the end of testing. Very little of the cracking in the blocks is diagonal; instead, it tends to be nearly vertical at the locations of the grout cores within the blocks. It appears that the grout cores have split most of the blocks. The cracking vaguely follows the main wall diagonal, but it is poorly defined at best.

\subsubsection{Common Behavioral Characteristics}

All three walls share common behavioral characteristics, some of which were previously observed in Bland (2011). The initial stages of loading for all three walls showed early flexural cracking. The extremely early formation of these cracks is probably because the dry-stacked bed joints offer no tensile resistance, so cracking only involves overcoming the low tensile strength of the grout cores. The earliest sliding in the walls tended to propagate from these cracks, perhaps because the flexural cracks weakened the grout cores. Extensive sliding and cracking along the main diagonal occurred in all three walls in the vicinity of the peak load, consistent with the diagonal shear cracking that characterizes shear failure in conventional masonry and was previously observed in compressed earth blocks in Bland (2011). While some of this cracking propagated through the blocks, the primary motion appears to be sliding, which is reasonable since the dry-stacked bed joints form natural weak points. This sliding and much of the visible cracking roughly follow the 45-degree plane preferred by shear cracks in conventional masonry. 


\subsubsection{Effect of Head Joint Shear Keys on Behavior}

Walls 2 and 3, which both lacked shear keys, displayed some notable differences in behavior compared to Wall 1. To begin with, the flexural tension cracks were not strictly horizontal in Walls 2 and 3, sometimes jumping between block courses and appearing as stair-stepping in the early $v$ plots that is not reflected in the $u$ plots. This can be seen in Image 463 of Wall 2 and Image 196 of Wall 3. Evidently, the shear keys in Wall 1 prevent relative vertical motion at the head joints and help ensure that the flexural cracks are horizontal.

The ultimate diagonal cracking was visibly cleaner on Wall 1 than either Wall 2 or Wall 3. Wall 1's cracks mainly followed a few clear diagonal paths, similar to an unreinforced shear failure in conventional masonry. Wall 2's cracks are less regular, and Wall 3's are downright chaotic and only vaguely follow the diagonals. The head joint shear keys may aid in transferring shear between individual blocks, allowing the system to behave more like a composite material and partially compensate for the lack of mortar in the joints. Wall 2's cracking has more in common with Wall 1 than Wall 3, which indicates that larger grout cores can also act to improve inter-block shear transfer. However, its cracking is still less regular than Wall 1 despite more grout overall, indicating that the shear keys are more effective at improving shear transfer than increasing the size of the cores.

The individually rotating blocks and regions of Wall 3 are also reasonably explained by the lack of shear keys, which again allows the blocks to move separately at the head joints. Wall 2 does not display this behavior, but its larger and stiffer grout cores may also serve to resist this rotation. This behavior may therefore only become 
apparent in walls with small grout cores, but it nevertheless illustrates another role played by the head joint shear keys.

\subsubsection{Effect of Block Type on Behavior}

Most of the clear behavioral differences between the Rhino and V-Lock block walls are readily attributable to presence of shear keys or size of grout cores, as

previously discussed. The most significant difference between Wall 3 and the other walls is the prominent second loading peak, much more prominent than the second peak of Wall 2. As previously discussed in Section 6.1.1, the second peak may be the interlock mechanism engaging after significant displacement. Wall 1 was not subjected to as high levels of displacement, so it is not known if it would have experienced something similar. The initial peak of Wall 3 behaves similarly to the main failures of Walls 1 and 2, while the second peak represents a different limit state. Interlock mechanism therefore appears to mainly affect post-cracking behavior.

\subsection{Shear Strength}

The following sections compare the experimental strength of the tested walls to code-based design strengths. Equation 9-24 in MSJC (2013), reproduced below, predicts the masonry contribution to shear strength for reinforced masonry, where the units are in pounds and inches.

$$
V_{n m}=\left[4.0-1.75\left(\frac{M_{u}}{V_{u} d_{v}}\right)\right] A_{n v} \sqrt{f_{m}^{\prime}}+0.25 P_{n}
$$

The following sections compare the experimental shear strengths to the strengths predicted by the design equations using different plausible values for $A_{n v}$. The ratio $\left(M_{u} / V_{u} d_{v}\right)$ is taken as 1 , as befits a wall with an aspect ratio of $1: 1$. 
As previously discussed in Section 6.1.6, the initial peak for Wall 3 appears to be a limit state similar to the main failure mode of Walls 1 and 2, while the ultimate peak shows different behavioral characteristics. Because ultimate peak is as much as $23 \%$ greater than the initial peak for Wall 3, both peaks are examined to identify any general trends between the initial peaks of Walls 1, 2, and 3 (representing the same limit state). Although Wall 2 also experienced a second peak in one loading direction, the initial and final peaks were similar enough that distinguishing the two values would serve little purpose.

\subsubsection{Full Net Area}

Table 6.1 compares the maximum applied shear force with the MSJC (2013) inplane flexural $\left(F_{n}\right)$ and shear $\left(V_{n}\right)$ capacities. The shear capacities are based on the entire net cross-sectional area of the wall, and the flexural capacities account for the loading eccentricity from the weight of the actuator.

Table 6.1: Predicted and Experimental In-Plane Capacities, Based on Full Area

\begin{tabular}{|c|c|c|c|c|c|c|c|}
\hline & & & & $\begin{array}{l}\text { Predic } \\
\text { MSJC }\end{array}$ & $\begin{array}{l}\text { ons per } \\
(2013)\end{array}$ & $\begin{array}{r}\text { Experir } \\
\text { Rest }\end{array}$ & $\begin{array}{l}\text { ental } \\
\text { ts }\end{array}$ \\
\hline Wall & $f_{m}^{\prime}(\mathrm{MPa})$ & $A_{n v}\left(\mathrm{~mm}^{2}\right)$ & $\begin{array}{l}\text { Loading } \\
\text { Direction }\end{array}$ & $F_{n}(\mathrm{kN})$ & $V_{n}(\mathrm{kN})$ & $V_{\max }(\mathrm{kN})$ & $V_{\max } / V_{n}$ \\
\hline 1 & 1.17 & $268 \times 10^{5}$ & Pull (+) & 40.9 & 63.2 & 37.9 & 0.60 \\
\hline 1 & 1.47 & $2.00 \times 10$ & Push $(-)$ & 41.5 & 63.2 & 36.9 & 0.58 \\
\hline 2 & 332 & $315 \times 10^{5}$ & Pull (+) & 49.8 & 110 & 39.3 & 0.36 \\
\hline 2 & 0.02 & J.1JAIV & Push $(-)$ & 50.3 & 110 & 37.2 & 0.34 \\
\hline 3, Initial & 103 & $0^{5}$ & Pull (+) & 43.9 & 70.3 & 16.8 & 0.24 \\
\hline Peak & 1.93 & $2.02 \times 10$ & Push (-) & 44.5 & 70.3 & 16.2 & 0.23 \\
\hline 3 , Final & 192 & $262 \times 10^{5}$ & Pull (+) & 43.9 & 70.3 & 19.6 & 0.28 \\
\hline Peak & 1.02 & & Push (-) & 44.5 & 70.3 & 20.0 & 0.28 \\
\hline
\end{tabular}

The ratios of actual to predicted shear capacity show that the empirical MSJC (2013) equation drastically overestimates the walls' shear capacities, as previously 
demonstrated by Bland (2011). Stirling (2011) and Bland (2011) both demonstrated that the ACI assumptions somewhat underestimated flexural capacity of walls such as these; the fact that the experimental peak loads did not exceed the expected flexural capacities further indicates that the ductility observed in Walls 2 and 3 was not a result of yielding in the longitudinal steel.

\subsubsection{Grouted Area}

It is reasonable to suppose that shear strength in dry-stacked walls is primarily derived from the solid grout cores with a lesser frictional contribution from the blocks, as discussed in Bland (2011). Table 6.2 below compares the actual shear capacities to predictions using the grouted area $\left(A_{g}\right.$ in the table) in place of $A_{n v}$ and the porous grout strength $\left(f_{g}^{\prime}\right)$ in place of $f_{m}^{\prime}$ in the shear strength equation.

Table 6.2: Predicted and Experimental In-Plane Capacities, Based on Grouted Area

\begin{tabular}{|c|c|c|c|c|c|c|}
\hline Wall & $f_{g}^{\prime}(\mathrm{MPa})$ & $A_{g}\left(\mathrm{~mm}^{2}\right)$ & $V_{n}(\mathrm{kN})$ & $\begin{array}{l}\text { Loading } \\
\text { Direction }\end{array}$ & $V_{\text {max }}(\mathrm{kN})$ & $V_{\text {max }} / V_{n}$ \\
\hline \multirow{2}{*}{1} & \multirow{2}{*}{11.11} & \multirow{2}{*}{$3.30 \times 10^{4}$} & \multirow{2}{*}{22.7} & Pull (+) & 37.9 & 1.67 \\
\hline & & & & Push (-) & 36.9 & 1.62 \\
\hline \multirow{2}{*}{2} & \multirow{2}{*}{12.26} & \multirow{2}{*}{$7.19 \times 10^{4}$} & \multirow{2}{*}{49} & Pull (+) & 39.3 & 0.80 \\
\hline & & & & Push (-) & 37.2 & 0.75 \\
\hline \multirow{2}{*}{$\begin{array}{c}\text { 3, Initial } \\
\text { Peak }\end{array}$} & \multirow{2}{*}{13.67} & \multirow{2}{*}{$1.86 \times 10^{4}$} & \multirow{2}{*}{15.1} & Pull (+) & 16.8 & 1.12 \\
\hline & & & & Push (-) & 16.2 & 1.08 \\
\hline \multirow{2}{*}{$\begin{array}{c}3 \text {, Final } \\
\text { Peak }\end{array}$} & \multirow{2}{*}{13.67} & \multirow{2}{*}{$1.86 \times 10^{4}$} & \multirow{2}{*}{15.1} & Pull (+) & 19.6 & 1.30 \\
\hline & & & & Push (-) & 20.0 & 1.32 \\
\hline
\end{tabular}

As with the fully and partially grouted walls of Bland (2011), using the strength and area of just the grout conservatively estimates the shear strength of Walls 1 and 3. Surprisingly, however, it still results in an un-conservative prediction for Wall 2. Taken at face value, this would appear to indicate that the wall was somehow weaker than the 
individual grout cores acting alone. It is more likely that the grout strength in the wall did not reach the same strength as the porous grout samples. Two possible reasons are:

- The lower surface-area-to-volume ratio of the cores in the V-Lock blocks compared to the Rhino blocks (a geometric consequence of the larger cores) may have reduced the relative amount of water absorbed by the blocks

- Extensively spraying the exterior of Wall 2 prior to grouting may have prevented the blocks from absorbing as much water during grouting

The latter possibility is supported by the fact that the V-Lock panel tested in Pringle (2016), which was not pre-wetted, was significantly stronger than the standard Rhino panel. Regardless of the cause, Wall 2's performance demonstrates that the porous grout samples may not necessarily accurately represent the strength within the finished wall. Since prisms implicitly account for factors relating to block type or construction technique, prism strength should be the primary basis of material strength for any estimation of shear strength.

\subsubsection{Effective Shear Area}

Bland (2011) proposed the concept of an "effective shear area", found by backsolving for $A_{n v}$ in the MSJC design equation based on the experimental prism strength and maximum lateral load. This would enable use of the code equations by multiplying a correction factor times the full net shear area $\left(A_{n v)}\right.$ to reduce it to the effective net shear area $\left(A_{e}\right)$ for a particular block/grouting configuration. Bland (2011) previously recommended conservative correction factors of 0.4 for fully grouted walls and 0.2 for partially grouted walls. Table 6.3 lists the actual and effective areas for the walls of this experiment along with their ratio. 
Table 6.3: Effective Shear Area

\begin{tabular}{|c|c|c|c|c|c|c|}
\hline Wall & $f_{m}^{\prime}(\mathrm{MPa})$ & $A_{n}\left(\mathrm{~mm}^{2}\right)$ & $\begin{array}{l}\text { Loading } \\
\text { Direction }\end{array}$ & $V_{\max }(\mathrm{kN})$ & $A_{e}\left(\mathrm{~mm}^{2}\right)$ & $A_{e} / A_{n}$ \\
\hline \multirow{2}{*}{1} & \multirow{2}{*}{1.47} & \multirow{2}{*}{$2.68 \times 10^{5}$} & Pull (+) & 37.9 & $1.57 \times 10^{5}$ & 0.59 \\
\hline & & & Push (-) & 36.9 & $1.53 \times 10^{5}$ & 0.57 \\
\hline \multirow{2}{*}{2} & \multirow{2}{*}{3.32} & \multirow{2}{*}{$3.15 \times 10^{5}$} & Pull (+) & 39.3 & $1.08 \times 10^{5}$ & 0.34 \\
\hline & & & Push (-) & 37.2 & $1.02 \times 10^{5}$ & 0.32 \\
\hline \multirow{2}{*}{$\begin{array}{l}\text { 3, Initial } \\
\text { Peak }\end{array}$} & \multirow{2}{*}{1.93} & \multirow{2}{*}{$2.62 \times 10^{5}$} & Pull (+) & 16.8 & $5.63 \times 10^{5}$ & 0.21 \\
\hline & & & Push (-) & 16.2 & $5.41 \times 10^{5}$ & 0.21 \\
\hline \multirow{2}{*}{$\begin{array}{l}\text { 3, Final } \\
\text { Peak }\end{array}$} & \multirow{2}{*}{1.92} & \multirow{2}{*}{$2.62 \times 10^{5}$} & Pull (+) & 19.6 & $6.71 \times 10^{5}$ & 0.26 \\
\hline & & & Push (-) & 20.0 & $6.84 \times 10^{5}$ & 0.26 \\
\hline
\end{tabular}

There is no obvious direct trend for the $A_{e} / A_{n}$ ratio between the tested walls. The ratios for Wall 1 significantly exceeded the ratios found by Bland (2011). Since the walls' strengths were similar, it is likely that this is directly related to the tested masonry compressive strength; the prisms in Bland (2011) tested significantly stronger than those for Wall 1. This may be an artifact of the testing process, since Bland's prisms were partially confined during testing. These correction factors are highly dependent on the prism strength and therefore should only be used when prisms are tested using the exact same method used to determine the factors. Based on the results of this set of tests, a correction factor of 0.5 should conservatively predict the effective area for a fully grouted Rhino wall with head joint shear keys.

Based on the initial peak limit state, a correction factor of 0.3 may be used for the V-Lock blocks, and a factor of 0.2 may be used for Rhino block walls without head joint shear keys. No discernable pattern exists between the three walls, indicating that if effective area correction factors are to be used to modify existing equations, they must be determined individually for any combination of block and grouting pattern. 


\subsubsection{Block Participation Factor}

It is noteworthy that the effective area correction factor for Wall 2 was higher than the factor for Wall 3. This is consistent with the supposition discussed in Bland (2011) that shear strength is primarily developed in the grout cores, with a lesser contribution by the dry-stacked blocks; as shown above, Wall 2 had both a larger grouted area and a higher correction factor than Wall 3, though neither were as high as Wall 1. To reflect this mechanism, a block participation factor $\left(k_{b p}\right)$ is proposed to account for the full contribution of the grout and partial contribution of the blocks.

The assumption behind the block participation factor is that the effective area consists of the full grouted area plus a fraction of the block area. This fraction is the "block participation factor." It may be used to calculate the effective shear area as follows:

$$
\begin{aligned}
& A_{e}=A_{g}+k_{b p} A_{m} \\
& A_{e}=\left(\frac{A_{g}}{A_{n v}}+k_{b p} \frac{A_{m}}{A_{n v}}\right) A_{n v}
\end{aligned}
$$

As discussed above in Section 6.2.2, using grout area alone with grout compressive strength did not conservatively predict shear strength for Wall 2; an effective area calculated with $k_{b p}$ is therefore used in combination with prism strength. Table 6.4 shows the back-calculated block participation factors for the tested walls. 
Table 6.4: Block Participation Factors

\begin{tabular}{|c|c|c|c|c|c|c|c|c|}
\hline Wall & $\begin{array}{c}f_{m}^{\prime} \\
(\mathrm{MPa})\end{array}$ & $\begin{array}{c}A_{n} \\
\left(\mathrm{~mm}^{2}\right)\end{array}$ & $A_{g} / A_{n}$ & $A_{m} / A_{n}$ & $\begin{array}{c}\text { Loading } \\
\text { Direction }\end{array}$ & $\begin{array}{c}V_{\max } \\
(\mathrm{kN})\end{array}$ & $A_{e}\left(\mathrm{~mm}^{2}\right)$ & $k_{b p}$ \\
\hline 1 & 1.47 & $2.68 \times 10^{5}$ & 0.123 & 0.877 & $\begin{array}{c}\text { Pull (+) } \\
\text { Push (-) }\end{array}$ & $\begin{array}{c}37.9 \\
36.9\end{array}$ & $\begin{array}{c}1.57 \times 10^{5} \\
1.53 \times 10^{5}\end{array}$ & $\begin{array}{c}0.53 \\
0.51\end{array}$ \\
\hline 2 & 3.32 & $3.15 \times 10^{5}$ & 0.228 & 0.772 & $\begin{array}{c}\text { Pull (+) } \\
\text { Push (-) }\end{array}$ & $\begin{array}{c}39.3 \\
37.2\end{array}$ & $\begin{array}{c}1.08 \times 10^{5} \\
1.02 \times 10^{5}\end{array}$ & $\begin{array}{c}0.15 \\
0.12\end{array}$ \\
\hline $\begin{array}{c}\text { 3, Initial } \\
\text { Peak }\end{array}$ & 1.93 & $2.62 \times 10^{5}$ & 0.0711 & 0.929 & $\begin{array}{c}\text { Pull (+) } \\
\text { Push (-) }\end{array}$ & $\begin{array}{c}16.8 \\
16.2\end{array}$ & $\begin{array}{c}5.63 \times 10^{4} \\
5.41 \times 10^{4}\end{array}$ & 0.15 \\
\hline $\begin{array}{c}\text { 3, Final } \\
\text { Peak }\end{array}$ & 1.93 & $2.62 \times 10^{5}$ & 0.0711 & 0.929 & $\begin{array}{c}\text { Pull (+) } \\
\text { Push (-) }\end{array}$ & $\begin{array}{c}19.6 \\
20.0\end{array}$ & $\begin{array}{c}6.71 \times 10^{4} \\
6.84 \times 10^{4}\end{array}$ & 0.20 \\
\hline
\end{tabular}

The block participation factor for Wall 1 is significantly higher than the factors for Walls 2 or 3 . This once again confirms that the head joint shear keys play a significant role in wall strength beyond simply increasing the area of grout. More significant, though, is the close similarity in the block participation factors for Wall 2 and the initial peak of Wall 3, which both lacked shear keys. In the pull direction, the factors are identical within two significant figures. This strongly suggests that the block participation factor is more generalizable than a straight ratio between effective and net shear areas. For the initial peak limit state, conservative block participation factors of 0.5 for blocks with head joint shear keys and 0.1 for blocks lacking shear keys may be used.

\subsubsection{Comparison to Partial Grouting}

While this testing program did not include any partially grouted walls, a comparison with the results of Bland (2011) may reveal if partial grouting has a similar effect as removing the head joint shear keys. Table 6.5 lists this testing program's results for Walls 1 and 3 along with the results for the fully and partially grouted walls from Bland (2011). The ratios for maximum shear are relative to the mean strength for the corresponding fully grouted wall. 
Table 6.5: Comparison of Shear Key Removal to Bland (2011) Partial Grouting

\begin{tabular}{|c|c|c|c|c|c|c|c|}
\hline Wall & $A_{n}\left(\mathrm{~mm}^{2}\right)$ & $A_{g}\left(\mathrm{~mm}^{2}\right)$ & $A_{g} / A_{g, F G}$ & $\begin{array}{c}\text { Loading } \\
\text { Direction }\end{array}$ & $\begin{array}{l}V_{\max } \\
(\mathrm{kN})\end{array}$ & $\begin{array}{c}V_{\max } / \\
V_{\max , F G}\end{array}$ & $k_{b p}$ \\
\hline \multirow{2}{*}{1} & \multirow{2}{*}{$2.68 \times 10^{5}$} & \multirow{2}{*}{$3.30 \times 10^{4}$} & \multirow{2}{*}{-} & Pull (+) & 37.9 & - & 0.53 \\
\hline & & & & Push (-) & 36.9 & - & 0.51 \\
\hline \multirow{2}{*}{$\begin{array}{l}\text { 3, Initial } \\
\text { Peak }\end{array}$} & \multirow{2}{*}{$2.62 \times 10^{5}$} & \multirow{2}{*}{$1.86 \times 10^{4}$} & \multirow{2}{*}{0.56} & Pull (+) & 16.8 & 0.45 & 0.15 \\
\hline & & & & Push (-) & 16.2 & 0.43 & 0.15 \\
\hline \multirow{2}{*}{ 3, Final Peak } & \multirow{2}{*}{$2.62 \times 10^{5}$} & \multirow{2}{*}{$1.86 \times 10^{4}$} & \multirow{2}{*}{0.56} & Pull (+) & 19.6 & 0.52 & 0.20 \\
\hline & & & & Push (-) & 20.0 & 0.53 & 0.20 \\
\hline \multirow{2}{*}{$\begin{array}{c}\text { Bland (2011) } \\
\text { FG }\end{array}$} & \multirow{2}{*}{$2.59 \times 10^{5}$} & \multirow{2}{*}{$3.41 \times 10^{4}$} & \multirow[t]{2}{*}{ 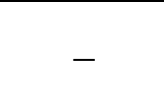 } & Pull (+) & 43.0 & - & 0.17 \\
\hline & & & & Push (-) & 41.8 & - & 0.24 \\
\hline \multirow{2}{*}{$\begin{array}{c}\text { Bland (2011) } \\
\text { PG }\end{array}$} & \multirow{2}{*}{$2.46 \times 10^{5}$} & \multirow{2}{*}{$2.14 \times 10^{4}$} & \multirow{2}{*}{0.63} & Pull (+) & 21.8 & 0.51 & 0.37 \\
\hline & & & & Push (-) & 27.3 & 0.64 & 0.39 \\
\hline
\end{tabular}

(FG = Fully Grouted, PG = Partially Grouted)

For both partial grouting and shear key removal, shear strength decreased at a greater rate than grout area on average. The difference in strength for the push and pull directions of the Bland (2011) partially grouted wall make it difficult to assess and compare the amount of strength reduction. However, dividing the average $V_{\max } / V_{\max }, F G$ ratio by the $A_{g} / A_{g, F G}$ ratio for both cases (effectively normalizing the normalized shear strength by the normalized grout area) results in values of 0.8 for the initial peak of Wall 3 and 0.9 for the Bland (2011) partially grouted wall. This indicates that removing the head joint shear keys reduced shear strength more than partially grouting the wall. Repeating this process for the final peak of Wall 3 results in a ratio of 0.9 , suggesting that the walls ultimately achieve similar relative strengths but do so by different mechanisms.

New block participation factors were also calculated for the Bland (2011) walls using the provided total cross-sectional areas, grouted areas, and back-calculated effective shear areas. The block participation factor for the partially grouted wall is less than that of the fully grouted wall, again demonstrating that partial grouting also reduces the shear strength by more than just the reduction of grouted area. However, the average 
block participation factor for the partially grouted wall was $46 \%$ less than that of the corresponding fully grouted wall, while removing the head joint shear keys reduced the factor by $71 \%$ for the initial peak and $61 \%$ for the final peak. This further indicates that partial grouting maintains relatively more strength than removing the shear keys does.

\subsubsection{Comparison to Diagonal Panel Tests}

Table 6.6: Comparison of Full-Scale Walls to Diagonal Panel Shear Strengths

\begin{tabular}{|c|c|c|c|c|c|}
\hline Wall & $\mathrm{A}_{\mathrm{n}}\left(\mathrm{mm}^{2}\right)$ & $\begin{array}{l}\text { Loading } \\
\text { Direction }\end{array}$ & $\begin{array}{l}\mathrm{V}_{\max } \\
(\mathrm{kN})\end{array}$ & $\begin{array}{c}\text { Average } \\
\text { Stress } \\
(\mathrm{kPa})\end{array}$ & $\begin{array}{c}\text { Average Stress, } \\
\text { Pringle }(2016) \\
(\mathrm{kPa})\end{array}$ \\
\hline \multirow{2}{*}{1} & \multirow{2}{*}{$2.64 \mathrm{E}+05$} & Pull (+) & 37.9 & 143 & \multirow{2}{*}{134} \\
\hline & & Push (-) & 36.9 & 140 & \\
\hline \multirow{2}{*}{2} & \multirow{2}{*}{$3.11 \mathrm{E}+05$} & Pull (+) & 39.3 & 126 & \multirow{2}{*}{181} \\
\hline & & Push (-) & 37.2 & 120 & \\
\hline \multirow{2}{*}{$\begin{array}{l}\text { 3, Initial } \\
\text { Peak }\end{array}$} & \multirow{2}{*}{$2.58 \mathrm{E}+05$} & Pull (+) & 16.8 & 65.2 & \multirow{2}{*}{61.1} \\
\hline & & Push (-) & 16.2 & 63.0 & \\
\hline \multirow{2}{*}{$\begin{array}{l}\text { 3, Final } \\
\text { Peak }\end{array}$} & \multirow{2}{*}{$2.58 \mathrm{E}+05$} & Pull (+) & 19.6 & 76.1 & \multirow{2}{*}{61.1} \\
\hline & & Push (-) & 20.0 & 77.5 & \\
\hline
\end{tabular}

Table 6.6 compares the experimental strengths of the full-scale walls to the results from the diagonal panel tests of Pringle (2016). For Walls 1 and 3, the maximum average shear stresses in the panels were surprisingly close to the full-scale results: The Rhino block panel with head joint shear keys was 5\% less than the average for the full-scale wall's two loading directions, and the panel without shear keys was also 5\% less than the initial peak of Wall 3. Based on this data comparison, it appears that panel tests results may be directly used to estimate the shear strength of Rhino block walls. Wall 2 was significantly different; its corresponding panel was $47 \%$ stronger than the full-scale wall. This may be because of a difference in construction technique: As discussed above in Section 6.2.2, the exterior of Wall 2 was sprayed with water prior to grouting to avoid the 
block splitting observed during the construction of the Pringle (2016) V-Lock panel.

This may have reduced the amount of water absorbed from the grout, making the grout in Wall 2 weaker than either the porous grout sample or the Pringle (2016) panel.

\subsection{In-Plane Stiffness}

In-plane stiffness of a cantilevered masonry shear wall is calculated as a combination of flexural and shear stiffness, calculated as follows (adapted from Brandow et al, 2015):

$$
\begin{aligned}
& K_{m}=\frac{3 E_{m} I}{H^{3}} \\
& K_{v}=\frac{A E_{v}}{1.2 H} \\
& K_{t}=\frac{1}{\frac{1}{K_{m}}+\frac{1}{K_{v}}}
\end{aligned}
$$

MSJC (2013) Section 4.2.2.2 allows the approximations of $E_{v}=0.4 E_{m}, E_{m}=900 f^{\prime}{ }_{m}$ for concrete masonry, and $E_{m}=700 f^{\prime}{ }_{m}$ for clay masonry.

The experimental in-plane stiffness of compressed earth block walls is nonlinear even before permanent deformation occurs, complicating efforts to quantify stiffness. Table 6.7 displays the overall stiffness for each wall calculated using two methods. The initial chord stiffness, intended here to represent the initial stiffness of the wall, was calculated from the data points closest to $\pm 0.025 \mathrm{~mm}$ and $\pm 0.25 \mathrm{~mm}$ displacement in Cycle 1 of each test. The secant stiffness, intended here to represent an average stiffness over the elastic portion of loading, was based on an interpolated point from each backbone curve corresponding to $0.6 V_{\max }$, selected based on the guidelines of Tomazevic (1999). Tomazevic (1999) recommends $0.7 V_{\max }$ for traditional masonry as a point where 
cracks typically begin to form and alter the stiffness; however, it also notes that this experimental point ranges from $0.6 V_{\max }$ to $0.8 V_{\max }$, so this lower value was selected in an attempt to better represent the weaker compressed earth block walls. The photographic displacement analysis above indicates that flexural cracks in fact form as early as the first cycle, well below $0.6 V_{\max }$, but this point is still used here to provide a usable common point of reference.

Table 6.7: Experimental Wall Stiffness

\begin{tabular}{|c|c|c|c|c|}
\hline Wall & $\begin{array}{c}\text { Loading } \\
\text { Direction }\end{array}$ & $\begin{array}{c}\text { Initial Chord } \\
\text { Stiffness } \\
(\mathrm{kN} / \mathrm{mm})\end{array}$ & $\begin{array}{c}\text { Secant Stiffness } \\
(\mathrm{kN} / \mathrm{mm})\end{array}$ & $K_{\text {chord }} / K_{\text {sec }}$ \\
\hline \multirow{2}{*}{1} & Pull (+) & 20.3 & 9.54 & 0.47 \\
& Push (-) & 12.3 & 9.04 & 0.73 \\
\hline \multirow{2}{*}{2} & Pull (+) & 26.8 & 11.4 & 0.43 \\
& Push (-) & 17.9 & 8.97 & 0.50 \\
\hline \multirow{2}{*}{3} & Pull (+) & 12.0 & 5.74 & 0.48 \\
& Push (-) & 7.29 & 5.55 & 0.76 \\
\hline
\end{tabular}

\subsubsection{Initial Stiffness}

Wall 2 was the stiffest of the tested specimens, while Wall 3 was the least stiff. A variety of factors no doubt participate in this: Wall 2 has the advantage of stronger, more rigid blocks with larger grout cores, while Wall 3 is affected by lack of shear keys and overall lower grout area. Stiffness appears generally to increase with grout area, but its effect is difficult to distinguish from other factors such as individual block stiffness and presence/absence of head joint shear keys.

For all three walls, the initial stiffness for the push direction was approximately $60 \%$ of the stiffness in the pull direction. Assuming that the two loading directions were in essentially the same condition before testing began, this demonstrates that a 
loading/unloading cycle in one direction under essentially elastic conditions is still enough to noticeably reduce the stiffness in the other direction. The decrease was remarkably consistent over the three walls; the ratios of the pull-direction stiffness to the push-direction stiffness were $0.61,0.67$, and 0.61 for Walls 1,2 , and 3 , respectively, indicating that similar mechanisms are involved. The fact that the ratios for Walls 1 and 3 were identical within two significant figures also suggests that the exact amount of degradation is mainly related to block type. The fact that the stiffness degrades after relatively low levels of loading makes the initial chord stiffness a poor metric for estimating the actual drift of a wall.

\subsubsection{Secant Stiffness}

The secant stiffness at $0.6 V_{\max }$ was consistently less than the $50 \%$ of the initial chord stiffness in the pull direction, further demonstrating the stiffness' nonlinear nature. The secant stiffness was also more consistent between the push and pull directions, with a ratio between the push and pull directions of $0.95,0.79$, and 0.97 for Walls 1, 2, and 3, respectively. As with the initial chord stiffness, the decrease is probably because damage during the pull stroke diminishes the stiffness of the subsequent push stroke. By this point in the test, however, it appears to have less of an effect, perhaps because more of the damage was already accumulated during earlier cycles. The ratios are again very similar between the two Rhino block walls; the same is true for the ratios between the secant and chord stiffness, as can be seen in Table 6.7. This further suggests that stiffness degradation is mainly a function of block type. 


\subsubsection{Secant Stiffness Components and Elastic/Shear Moduli}

To evaluate the flexural and shear stiffness components separately, the displacement components corresponding to the secant stiffness were interpolated from the curves calculated from the photographic displacement analysis in Figures 6.2 through 6.4 above. Tables 6.8 and 6.9 show the results for the flexural and shear stiffness components, respectively, along with back-calculated values for $E_{m}$ and $E_{v} . E_{m}$ was calculated using both uncracked and cracked moments of inertia that were transformed to account for the reinforcing steel's significantly higher stiffness (assumed to be $200 \mathrm{GPa}$ ). $E_{v}$ was calculated using the full net area. As shown by Figures 6.2 through 6.4, the rocking displacement component was significant enough that the flexural and shear components alone do not add up to the total displacement; therefore, using these values will underestimate total displacement. Brandow et al (2015) acknowledges that effects from foundation distortions may be significant even for conventional masonry, but they are typically neglected in design because of the difficulty of estimating the corresponding stiffness.

\subsubsection{Flexural Stiffness}

Table 6.8: Flexural Stiffness Components

\begin{tabular}{|c|c|c|c|c|c|c|c|}
\hline \multirow[b]{2}{*}{ Wall } & \multirow[b]{2}{*}{$\begin{array}{c}f_{m}^{\prime} \\
(\mathrm{MPa})\end{array}$} & \multirow[b]{2}{*}{$\begin{array}{c}\text { Loading } \\
\text { Direction }\end{array}$} & \multirow[b]{2}{*}{$\begin{array}{l}\text { Flexural } \\
\text { Stiffness } \\
(\mathrm{kN} / \mathrm{mm})\end{array}$} & \multicolumn{2}{|c|}{ Uncracked $I$} & \multicolumn{2}{|c|}{ Cracked I } \\
\hline & & & & $\begin{array}{c}E_{m} \\
(\mathrm{MPa})\end{array}$ & $E_{m} / f_{m}^{\prime}$ & $\begin{array}{c}E_{m} \\
(\mathrm{MPa})\end{array}$ & $E_{m} / f_{m}^{\prime}$ \\
\hline \multirow{2}{*}{1} & \multirow{2}{*}{1.47} & Pull (+) & 30.6 & 525 & 357 & 40800 & 27800 \\
\hline & & Push (-) & 20.7 & 257 & 175 & 1580 & 1080 \\
\hline \multirow{2}{*}{2} & \multirow{2}{*}{3.32} & Pull (+) & 29.1 & 432 & 130 & 24900 & 7500 \\
\hline & & Push (-) & 29.9 & 452 & 136 & 39800 & 12000 \\
\hline \multirow{2}{*}{3} & \multirow{2}{*}{1.93} & Pull (+) & 20.3 & 263 & 136 & 1610 & 837 \\
\hline & & Push (-) & 20.0 & 253 & 131 & 1480 & 766 \\
\hline
\end{tabular}


The flexural stiffness for the push direction of Wall 1 is remarkably similar to both loading directions of Wall 3, while the pull direction's stiffness registers $50 \%$ higher. The pull direction of Wall 1 also differs from most of the other tested walls in that its shear component exceeded its flexural component early in the test; the reverse was true in most other cases, including the push direction of Wall 1. Therefore, it is probable that this high flexural stiffness value is an aberration and that the $20.7 \mathrm{kN} / \mathrm{mm}$ stiffness in the push direction better represents typical behavior.

\subsection{Flexural Modulus, Uncracked Moment of Inertia}

Disregarding Wall 1's apparent stiffness in the pull direction, the average $E_{m}$ was $258 \mathrm{MPa}$ for the Rhino block walls and $442 \mathrm{MPa}$ for the V-Lock wall when calculated with an uncracked moment of inertia. The Rhino block flexural modulus is significantly lower than the elastic moduli directly measured from prism tests by Bland (2011) and Herskedal (2011) of $575 \mathrm{MPa}$ and $350 \mathrm{MPa}$, respectively. This is most likely because the dry-stacked joints decrease the tensile stiffness during flexure, which the uncracked moment of inertia does not take into account.

The ratios of flexural modulus to prism strength show that the MSJC (2013) approximations are unsuitable for characterizing compressed earth blocks when using uncracked moments of inertia. Despite the differences in modulus values, the ratios for Walls 2 and 3 were remarkably similar; it appears that the flexural modulus for compressed earth block walls without shear keys may be reasonably approximated by $E_{m}$ $=133 f^{\prime}{ }_{m}$. Based on the values for the push direction, Wall 1's ratio is higher at $175 f^{\prime} \mathrm{m}$, but the actual values for stiffness and modulus are almost the same as Wall 3. 


\subsection{Flexural Modulus, Cracked Moment of Inertia}

Since the dry-stacked joints have no tensile resistance outside of the grout cores, the flexural modulus was also calculated with a cracked moment of inertia to attempt to better model this behavior. Again disregarding the pull direction of Wall 1, the average $E_{m}$ was $1560 \mathrm{MPa}$ for the Rhino block walls and $32400 \mathrm{MPa}$ for the V-Lock wall. This

Rhino block flexural modulus is multiple times greater than the elastic modulus measured by either Bland (2011) or Herskedal (2011). The value measured by this method is expected to be higher than the actual elastic modulus, since it neglects any actual tensile resistance of the grout cores, but it does not seem reasonable that it would be higher by such a great margin. Furthermore, the average V-Lock flexural modulus here is 21 times that of the Rhino blocks even though the blocks themselves had only twice the compressive strength, which seems questionable. A cracked moment of inertia alone therefore does not appear to adequately model the dry-stacked joints' behavior. That being said, calculating deflection with the actual elastic modulus and a cracked moment of inertia would underestimate the actual flexural stiffness and accordingly overestimate deflection, providing a conservative estimate where deflection is strictly limited.

It is worth noting that the flexural modulus values differ greatly between the two loading directions of each wall even when the stiffness values are very close. For this range, it appears that stiffness is not sensitive to the flexural modulus value when using a cracked moment of inertia. It is also of interest that the Rhino block values correspond to an average of $E_{m}=894 f^{\prime}{ }_{m}$, close to the MSJC (2013) approximation of $E_{m}=900 f^{\prime}{ }_{m}$ for concrete masonry. Given how poorly this corresponds to previously measured elastic modulus values for compressed earth blocks, however, this may just be coincidence. 


\subsubsection{Shear Stiffness}

Table 6.9: Shear Stiffness Components

\begin{tabular}{|c|c|c|c|c|c|}
\hline Wall & $\begin{array}{c}\text { Loading } \\
\text { Direction }\end{array}$ & $\begin{array}{c}\text { Shear Stiffness } \\
(\mathrm{kN} / \mathrm{mm})\end{array}$ & $\begin{array}{c}E_{v} \\
(\mathrm{MPa})\end{array}$ & $\begin{array}{c}E_{v} \text { from } \\
\text { Pringle }(2016) \\
(\mathrm{MPa})\end{array}$ & $E_{v} / E_{m}{ }^{1}$ \\
\hline \multirow{2}{*}{1} & Pull (+) & 28.2 & 226 & 223 & 0.43 \\
& Push (-) & 24.2 & 194 & 223 & 0.75 \\
\hline \multirow{2}{*}{2} & Pull (+) & 39.1 & 266 & 155 & 0.62 \\
& Push (-) & 40.5 & 276 & 155 & 0.61 \\
\hline \multirow{2}{*}{3} & Pull (+) & 11.6 & 95.1 & 76.5 & 0.36 \\
& Push (-) & 11.4 & 93.1 & 76.5 & 0.37 \\
\hline
\end{tabular}

${ }^{1} E_{m}$ determined using an uncracked moment of inertia

Unlike the flexural modulus, the shear modulus values are very different between the three walls. The values follow the same general trends as total stiffness, with Wall 2 having the highest shear modulus and Wall 3 having the lowest; it appears that shear modulus generally increases with grout area, but as with total stiffness, it is difficult to distinguish the effects of other potential factors like the head joint shear keys. The ratios of $E_{v} / E_{m}$, where $E_{m}$ is based on an uncracked moment of inertia, are similarly inconsistent. It does demonstrate, however, that the MSJC (2013) approximation of $E_{v}=$ $0.4 E_{m}$ does not directly apply to compressed earth blocks, although the values for Wall 3 come close. Average modulus values are $210 \mathrm{MPa}$ for Rhino block walls with head joint shear keys, 94.1 MPa for Rhino walls without shear keys, and 271 MPa for Vermeer block walls. Lacking any specific predictive trends, experimental modulus values must be determined individually for each block/grouting combination. 


\subsection{Comparison to Diagonal Panel Tests}

The shear modulus values differ from those determined by the diagonal panel tests of Pringle (2016). Most notably, the Pringle (2016) values for the V-Lock blocks were less than $60 \%$ of the values calculated for Wall 2. Pringle (2016) indicated that the V-Lock blocks had higher strength but a lower shear modulus than Rhino blocks with head joint shear keys, while the full-size wall tests indicate approximately the same strength but a higher shear modulus for these blocks. Again, this may be a result of the practice of wetting the outside of the wall before grouting, which was implemented for Wall 2 after Pringle (2016) reported block longitudinal splitting during grouting. The split blocks may have reduced the panel shear stiffness for Pringle (2016).

The shear moduli for the Rhino blocks also differ between the two test methods, although not as drastically as for the V-Lock blocks. When the head joint shear keys were present, the diagonal panel values were only $6.2 \%$ greater than the average full wall values. Without the shear keys, however, the panel values were $19 \%$ less than the average Wall 3 values. It therefore appears that the shear modulus determined by a compressed earth block panel test does not necessarily correspond to the shear modulus of a full-scale wall.

\subsection{Porous Grout Sample Method}

As described in Section 3.3.2 above, two different porous grout samples were tested: "Cubes" (actually rectangular prisms) cast between blocks, and cylinders cast within the grout cores of spare blocks. The results from cube samples were used as the grout strength for the primary analyses of these full-scale walls and for Pringle (2016), while Bland (2011) exclusively used cylinders. The porous cube samples returned higher 
grout strength values than the cylinders although both were made from the same batches, and the cylinders had a significantly higher intra-batch standard deviation. Tables 3.5 and 3.6 display mean values, while Appendix D contains individual sample results. The purpose of testing both sample types was not only to compare the quality of the results but also to determine a correlation to readily convert from one method's results to the other's. Figure 6.15 plots the cylinder strengths with respect to corresponding mean cube strength for Wall 3. Only samples from Wall 3 are used because the gypsum cement caps for the cylinders from Walls 1 and 2 were of questionable quality.

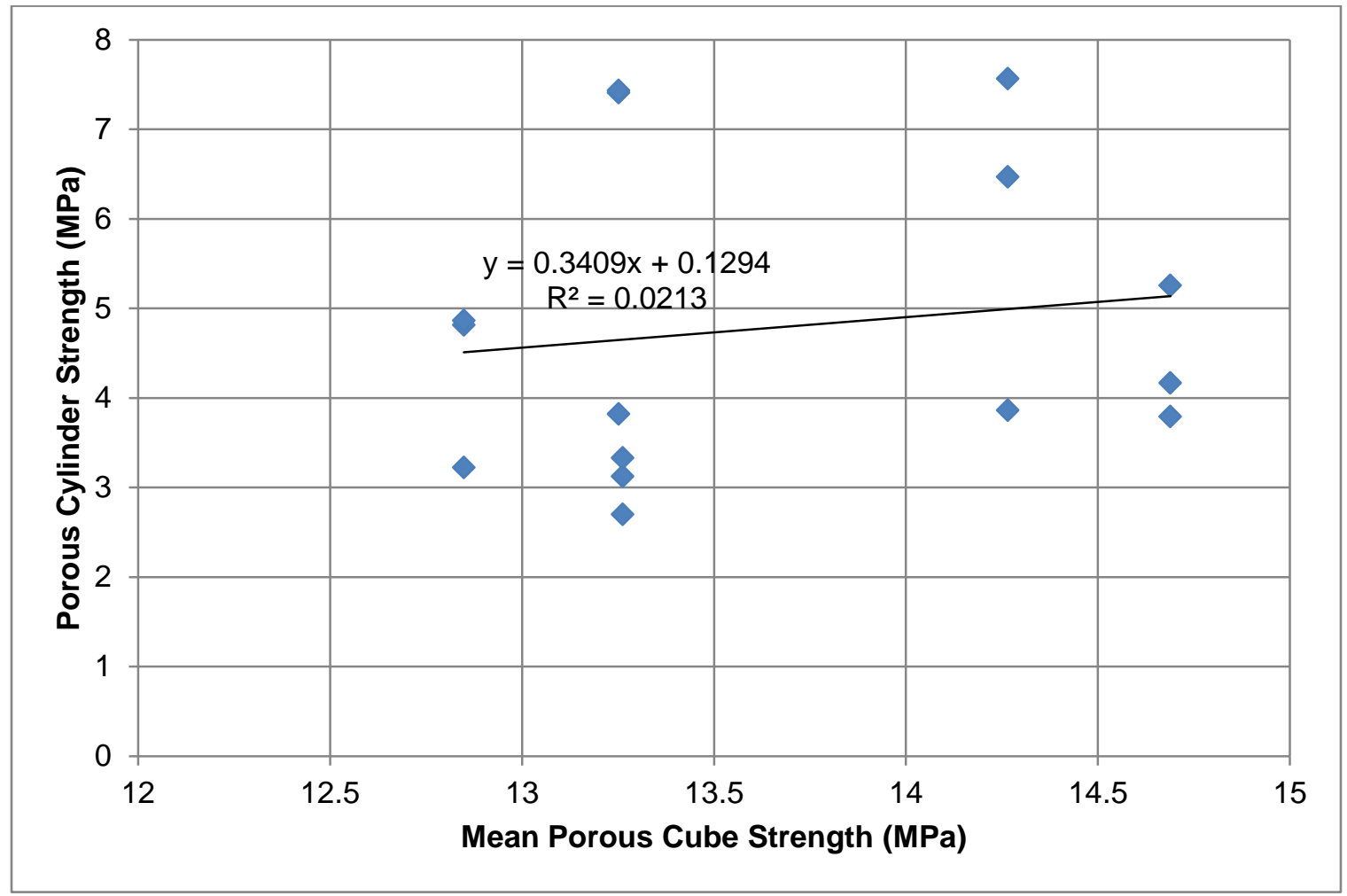

Figure 6.15: Porous Grout Sample Strength Correlation for Wall 3 Samples

The trend line for Figure 6.15 shows only an extremely weak correlation, if any. The two methods are not interchangeable. Because the cube samples were significantly more consistent within batches, it is highly recommended to use them instead of the cylinder method to test grout strength. 


\section{CONCLUSIONS AND FUTURE RESEARCH}

This research evaluated the effects of block type and grouted head joint shear keys on in-plane shear behavior of interlocking compressed earth block walls. Three fully-grouted, full-scale walls were constructed and tested under cyclic in-plane loading. The first wall was constructed from standard Rhino blocks, the second consisted of standard V-Lock blocks, and the third used Rhino blocks made without shear keys. Software-based analysis of continuous photography taken during tests was used to examine the failure modes of each wall and compare behavior. The presence of shear keys was found to play a major role in shear strength, while block type did not significantly influence behavior.

\subsection{Conclusions}

\subsubsection{Materials}

- The V-Block blocks showed consistently higher compressive strengths than Rhino blocks, most likely due to the higher pressure used by the Vermeer BP714 press.

- The ratio of prism strength to block strength was approximately 0.4 for both block types, consistent with previous findings for Rhino blocks.

- No clear correlation exists between the measured compressive strengths of porous cube samples and porous cylinder grout samples. The porous cube sample method is recommended based on its significantly lower variation compared to the cylinder samples. 


\subsubsection{Construction Technique}

- Inverted, grouted channel blocks may be used as a stable, easily constructible base course for walls built from Rhino blocks.

- A $910 \mathrm{~mm}$ lap splice in the vertical reinforcement did not experience slip under the loads reached in this testing. However, the free end of the splice did pry apart the grout cores and blocks at the upper corners of the walls at high displacements.

- Spraying the outside of block courses before grouting proved an effective method to avoid the longitudinal splitting of the Vermeer blocks observed by Pringle (2016) by reducing the differences in moisture content and expansion within the blocks. However, it may have also decreased the wall's grout strength.

\subsubsection{Experimental In-Plane Shear Testing}

- The Rhino block wall with head joint shear keys experienced a significant drop in strength after reaching peak load, while both walls without shear keys experienced an extended plateau after a minor drop from the peak load.

- The Rhino block wall without shear keys experienced a second loading peak, possibly due to the interlocking mechanism engaging at high displacements.

- Flexural cracking along bed joints occurred at low in-plane loads. These cracks tended to form the starting points for diagonal cracks

- The main peak load for all walls was closely accompanied by cracking and sliding along the main wall diagonals, independent of cracking propagating from the flexural cracks. This failure mechanism is similar to that typically observed in conventional masonry shear walls containing little or no horizontal reinforcement. 
- The Rhino block wall without head joint shear keys exhibited rotation of individual blocks and regions within the wall. The head joint shear keys of the standard Rhino blocks and larger grout cores of the V-Lock blocks may have acted to prevent this from happening in the other walls.

- The unaltered shear capacity equations of MSJC (2013) over-predict the shear capacity of interlocking compressed earth block walls. A "block participation factor" may be used to modify the area term of the MSJC (2013) equations, with separate factors for fully grouted walls with and without head joint shear keys. In lieu of this approach, the net area in the MSJC (2013) equations may be directly multiplied times constant factors for each particular block and grouting configuration.

- Using grouted area and porous grout strength values in the MSJC (2013) shear strength equations conservatively under-predicted shear strength for both Rhino block variants but over-predicted capacity for the V-Lock blocks. Therefore, this cannot be recommended as a method for conservatively estimating capacity. Methods based on prism strength are preferred.

- Based on a comparison to Bland (2011), removing the head joint shear keys results in a greater drop in capacity than partial grouting.

- In-plane stiffness generally increases with grouted area, although other factors like block stiffness and head joint shear keys may also play roles.

- The Rhino block flexural modulus back-calculated with an uncracked moment of inertia from a decomposition of the displacement components was lower than that measured from prism tests in previous research, possibly because the tensile 
opening of the dry-stacked bed joints decreases the flexural stiffness.

Recalculating with a cracked moment of inertia resulted in significantly higher values, suggesting that a cracked moment of inertia alone does not adequately approximate the dry-stacked joints

- The MSJC (2013) estimate of shear modulus does not apply to compressed earth blocks. Shear modulus values depend on the specific block and grouting combination.

- Diagonal panel tests provide a good predictor of shear capacity for full-size walls made of Rhino blocks. They do not appear to correspond well to the capacities of the V-Lock wall, although this may be due to differences in construction technique. The shear modulus determined by diagonal panel tests does not necessarily correspond to the shear modulus of a full-scale wall.

\subsection{Recommendations for Future Work}

- Research should be conducted to determine the effect on strength of wetting all or part of the blocks before grouting.

- Testing of different sizes of porous grout samples may help determine whether the surface-area-to-volume ratio of porous cores or formwork affects grout strength.

- The effect of axial load on shear capacity needs evaluation. This and prior research have assumed that the MSJC (2013) equations' axial load component directly carries over to compressed earth blocks, which may not be the case.

- The contribution of horizontal reinforcement in compressed earth block walls and its effect on shear behavior needs to be quantified. This will provide valuable information not only on capacity but also on ductility of a reinforced shear failure. 
It should also determine whether, as with conventional masonry, there is a limit to the amount of transverse steel that may be added before it no longer significantly increases shear strength.

- The effect of aspect ratio on shear strength, flexural modulus, and shear modulus should be assessed.

- Research should be performed to evaluate whether the splitting action of the lap splice against the upper corner blocks and grout cores significantly affects strength or performance.

- Further in-plane shear testing of other compressed earth block types as well as concrete dry-stack masonry blocks should be conducted to determine whether their behavior also can be described by the correction factors presented here.

- Further research should be performed to determine if the size of the head joint shear keys affects strength and behavior apart from just the increase in grouted area. 


\section{REFERENCES}

ASTM International. (2007). Standard test method for particle-size analysis of soils (D422-63[2007]E2). West Conshohocken, PA: ASTM International.

ASTM International. (2010). Standard test methods for liquid limit, plastic limit, and plasticity index of soils (D4318-10E1). West Conshohocken, PA: ASTM International.

ASTM International. (2011). Standard practices for classification of soils for engineering purposes (Unified soil classification system) (D2487-11). West Conshohocken, PA: ASTM International.

ASTM International. (2011). Standard test method for expansion index of soils (D482911). West Conshohocken, PA: ASTM International.

ASTM International. (2012). Standard test method for density, relative density (specific gravity), and absorption of fine aggregate (C128-12). West Conshohocken, PA: ASTM International.

ASTM International. (2014). Standard specification for mortar for unit masonry (C12812). West Conshohocken, PA: ASTM International.

ASTM International. (2016). Standard specification for loadbearing concrete masonry Uuits (C90-16). West Conshohocken, PA: ASTM International.

ASTM International. (2016). Standard test method for compressive strength of cylindrical concrete specimens (C39/C39M-16B). West Conshohocken, PA: ASTM International.

ASTM International. (2016). Standard test method for sampling and testing grout (C1019-16). West Conshohocken, PA: ASTM International. 
Anand, K., \& Ramamurthy, K. (2003). Laboratory-based productivity study on alternative masonry systems. Journal of Construction Engineering and Management, 129(3), 237-242. http://dx.doi.org/10.1061/ (ASCE)0733-9364(2003)129:3(237)

Bales, C., Donahue, C., Fischer, M., Mellbom, A., \& Pearson, T. (2009). Interlocking compressed earth blocks: From soils to structures (Senior project). California Polytechnic State University, San Luis Obispo, California. Retrieved from http://www.cvbt-web.org/uploads/Blocks/ ICEB\%202009\%20Senior\%20Project\%20Report.pdf

Banker-Hix, W. (2014). The effect of clay, cement and fibers on the strength and durability of compressed earth blocks (Masters thesis). California Polytechnic State University, San Luis Obispo, California. https://doi.org/10.15368/ theses.2014.78.

Bland, D. (2011). In-plane cyclic shear performance of interlocking compressed earth block walls (Masters thesis). California Polytechnic State University, San Luis Obispo, California. https://doi.org/10.15368/theses.2011.61

Brammer, D. R. (1995). The lateral force-deflection behaviour of nominally reinforced masonry walls (Masters thesis). University of Auckland, New Zealand.

Brandow, G.E., Ekwueme, C.G., \& Hart, G.C. (2015). 2012 Design of Reinforced Masonry Structures. Citrus Heights, CA: Concrete Masonry Association of California \& Nevada.

Drysdale, R. (2000). Racking tests of Azar dry-stack block ${ }^{\mathrm{TM}}$. Hamilton, Ontario: McMaster University. 
Elvin, A. \& Uzoegbo, H. C. (2011). Response of a full-scale dry-stack masonry structure subject to experimentally applied earthquake loading. Journal of the South African Institution of Civil Engineering, 53(1), 22-32. Retrieved from http://www.saice.org.za/services/journal-issues

Google. (2016). [Satellite maps of Templeton, CA and western United States]. Google Maps. Retrieved from maps.google.com

Hand, K. (2013). Vermeer Block Pressing Process [Image]. Retrieved from http://www.popsci.com/sites/popsci.com/files/styles/large_1x_/public/import/ 2013/images/2013/05/building_blocks_new.jpg?itok=HaU78np0

Herskedal, N. (2012). Investigation of out-of-plane properties of interlocking compressed earth block walls (Masters thesis). California Polytechnic State University, San Luis Obispo, California. https://doi.org/10.15368/theses.2012.235

Hiraishi, H. (1984). Evaluation of Shear and Flexural Deformation of Flexural Type Shear Walls. New Zealand Society for Earthquake Engineering Quarterly Bulletin, 17(2), 135-144.

Jaafar, M. S., Alwathaf, A. H., Thanoon, W.A., Noorzaei, J., \& Abdulkadir, M. R. Behaviour of interlocking mortarless block masonry. Proceedings of the Institution of Civil Engineers: Construction Materials, 159(3), 111-117.

Kosmatka, S. H., \& Wilson, M. L. (2011). Design and Control of Concrete Mixtures (15 $5^{\text {th }}$ ed.). Skoke, IL: Portland Cement Association.

Lee, W. K., Jansen, D. C., Berlin, K. B., \& Cohen, I. E. Flexural cracks in fiberreinforced concrete beams with fiber-reinforced polymer reinforcing bars. ACI Structural Journal, 110(06), 321-329. 
Masonry. (2016). In Encyclopadia Britannica. Retrieved from https://www.britannica.com/technology/masonry

Masonry Standards Joint Committee. (2013). Building code requirements and specification for masonry structures (TMS 402-13/ACI 530-13/ASCE 5-13; TMS 602-13/ACI 530.1-13/ASCE 6-13). Farmington Hills, MI: American Concrete Institute.

Morel, J., Pkla, A., \& Walker, P. (2007). Compressive strength testing of compressed earth blocks. Construction and Building Materials, 21(2), 303-309. http://dx.doi.org/10.1016/j.conbuildmat.2005.08.021

Niroumand, H., Zain, M., Jamil, M., \& Niroumand, S. (2013). Earth architecture from ancient until today. Procedia - Social and Behavioral Sciences, 89, 222-225. http://dx.doi.org/10.1016/j.sbspro.2013.08.838

Nolph, S. M. \& ElGawady, M. A. (2012). Static cyclic response of partially grouted masonry shear walls. Journal of Structural Engineering, 138(7), 864-879. http://dx.doi.org/10.1061/(ASCE)ST.1943-541X.0000529

Ngowi, J. V. (2006). Stability of dry-stack masonry (Ph.D. thesis). University of Witwatersrand, Johannesburg, South Africa. http://hdl.handle.net/10539/1557

Pringle, S. (2016). Diagonal tension testing of interlocking compressed earth block panels (Masters thesis). California Polytechnic State University, San Luis Obispo, California. Retrieved from http://digitalcommons.calpoly.edu/theses/1588

Shing, P. B., Noland, J. L., Klamerus, E., \& Spaeh, H. (1989). Inelastic behavior of concrete masonry shear walls. Journal of Structural Engineering, 115(9), 22042225. http://dx.doi.org/10.1061/(ASCE)0733-9445(1989)115:9(2204). 
Stirling, B. (2011). Flexural behavior of interlocking compressed earth block shear walls subjected to in-plane loading (Masters thesis). California Polytechnic State University, San Luis Obispo, California.

Sturm, T., Ramos, L. F., \& Lourenço, P. B. (2015). Characterization of dry-stack interlocking compressed earth blocks. Materials and Structures, 48(9), 30593074. http://dx.doi.org/10.1617/s11527-014-0379-3

Tomazevic, M. (1999). Earthquake-resistant design of masonry buildings. London: Imperial College Press.

Voon, K.C. (2007). In-plane seismic design of concrete masonry structures (Doctoral thesis). University of Auckland, New Zealand. http://hdl.handle.net/2292/580

Wheeler, G. (2005). Interlocking compressed earth blocks: Volume II. Manual of construction. Center for Vocational Building Technology, Thailand. Retrieved from http://cvbt-web.org/uploads/Pubs/RCnsChpt/CnstChpt.pdf 


\section{APPENDICES}

\section{APPENDIX A. DIGITAL IMAGE ANALYSIS}

The digital image analysis used in this research creates displacement maps by comparing a given target image to a reference image taken at the beginning of testing. The processing algorithm identifies a small, square sub-image within the original reference image and then searches for it within the target image, returning a relative displacement vector with horizontal and vertical components. Figure A.1 illustrates this process, which is performed on a grid of nodes with each node representing the center of a distinct sub-image. The algorithm uses sub-pixel interpolation to determine displacements in increments of less than one pixel. The relative displacements for the entire set of nodes form a displacement map of the target image; Figure A.2 shows a sample contour plot of a processed image's displacement with units in millimeters. Displacements are converted from pixels to real-world units with a photograph taken immediately before testing of a meter stick or yard stick held against the wall.

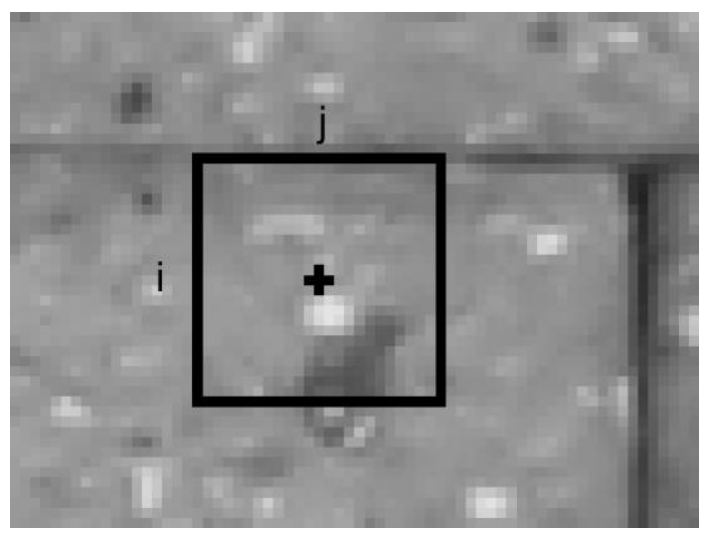

Reference Image

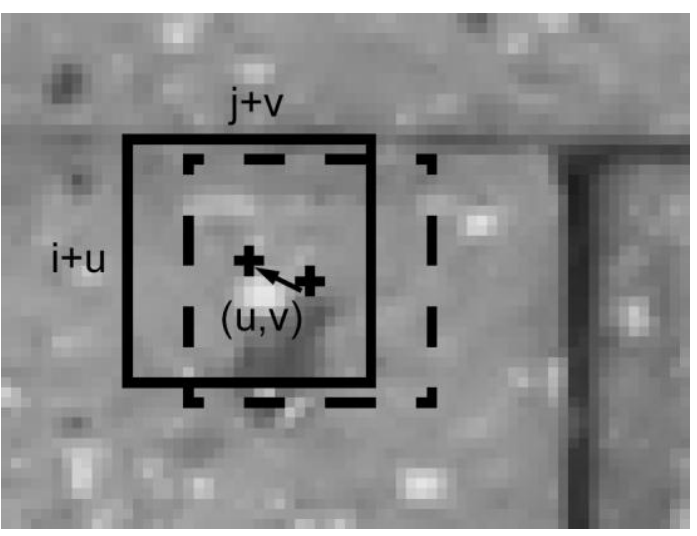

Target Image

Figure A.1: Example Sub-Image Displacement (adapted from Lee, 2010) 

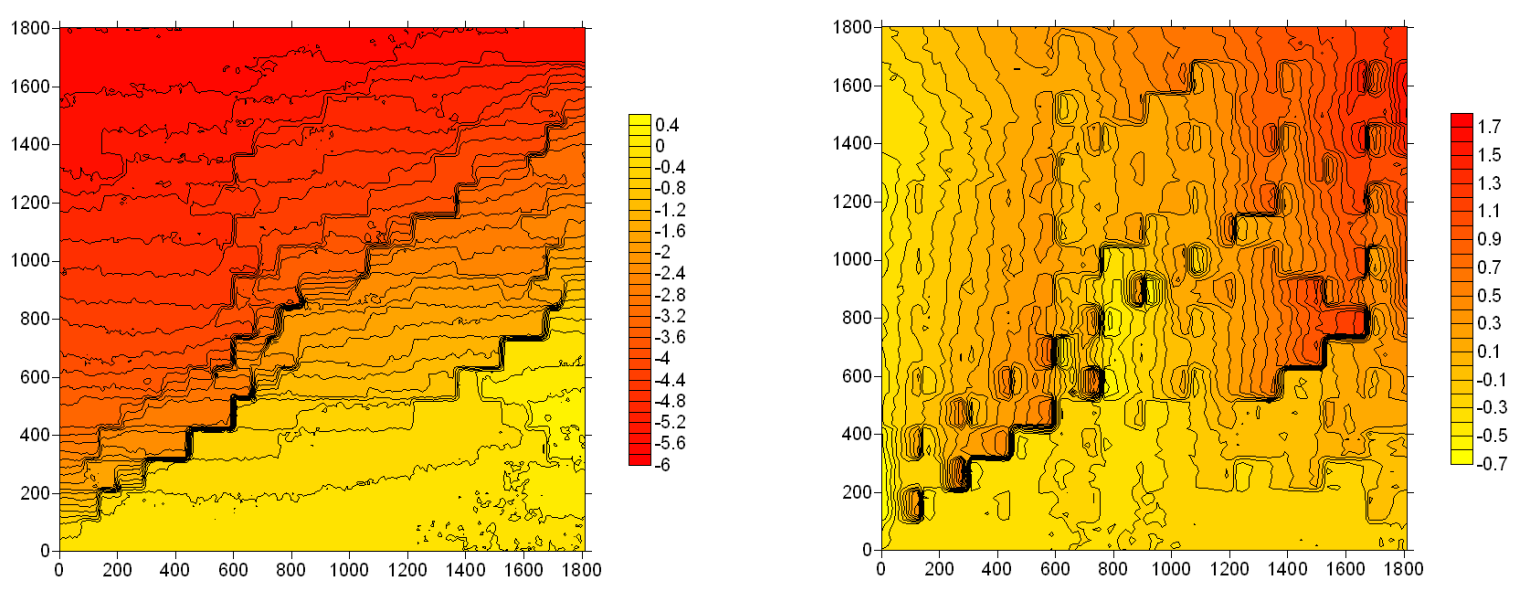

Figure A.2: Wall 3, Image $431 u$ (left) and $v$ (right) Displacement Contours

The processing technique is valuable in its ability to reveal fine cracks and relative displacements that are not readily visible to the naked eye during testing. However, it is limited in that it is easily confused by large open cracks, which interfere with its ability to locate sub-images in the area and cause it to settle for "matches" with distant regions that only vaguely correlate to the correct sub-image. For this reason, the imaging analysis was mainly useful in evaluating pre-failure behavior before the main cracks significantly opened. Good performance also requires unique patterns throughout the analyzed image that the computer can easily recognize without returning false matches; before testing, each wall was speckled with droplets of paint with varying contrast to create these patterns. Despite this, most processed images have some amount of nodes with false matches, even with images that perform relatively well overall. Some of these erroneous points are automatically discarded by the software based on their poor correlation to the original sub-image. Any remaining points that pass under the correlation threshold but are obviously too large (e.g. a small fraction of points that are multiple times greater than the displacements of the rest of the image) are manually removed before plotting. 


\section{APPENDIX B. SAND AND SOIL PROPERTIES}

\section{B.1. Sand Testing Data Sheet (supplied by Hanson Aggregates)}

\section{Sisquoc Washed Concrete Sand}

The Sisquoc Washed Concrete Sand supplied by Hanson Aggregates meets the requirements of the referenced specifications. This aggregate is produced at the Sisquoc, California Plant, SMARA No. 91-42-003. The typical physical properties of the aggregate are summarized below.

\section{1-Sand Concrete}

Procedure

Sieve/Test
3/8" $(9.5 \mathrm{~mm})$
$\# 4(4.75 \mathrm{~mm})$
$\# 8(2.36 \mathrm{~mm})$
$\# 16(1.18 \mathrm{~mm})$
$\# 30(0.6 \mathrm{~mm})$
$\# 50(0.3 \mathrm{~mm})$
$\# 100(0.15 \mathrm{~mm})$
\#200 $(75 \mu \mathrm{m})$
Pan
FM
SE

Average

100

99

88

75

52

22

5

1.9

0.0

2.58

83

67

2.55

$2.0 \%$

Lighter

$95 \% \quad 95 \% \operatorname{Min}$

$2.3 \%$

$0.5 \%$

$0 \%$

None Detected

Innocuous

$0.22 \%$

60 Min
ASTM C33

95-100

80-100

50-85

25-60

5-30

0-10

0-3

2.3-3.1

$>71$

Asbestos, EPA 600/\$-93-116

Alkali Reactivity, C 289

C 1260 Expansion

Specific Gravity, Bulk S.S.D.

Organic Impurities, C 40

Sodium Sulfate Soundess C 88

Clay \& Friables, C 142 


\section{B.2. Las Tablas Soil Testing (from Banker-Hix, 2014)}

\section{DEPARTMENT OF CIVIL AND ENVIRONMENTAL ENGINEERING}

Atterberg Limits Measurements

Test Method: ASTM D43 I8, D2487

\begin{tabular}{|l|l|l|l|}
\hline Project Name & LT Thesis Testing & Project No. & -....- \\
\hline Tested By & WBH & Testing Date & $4 / 12 / 2014$ \\
\hline
\end{tabular}

\begin{tabular}{|l|l|l|l|l|c|}
\hline \multicolumn{7}{|c|}{ SPECIMEN ID AND CLASSIFICATION } \\
\hline Boring No. & $-\cdots--$ & Sample No. & $\cdots--$ & Depth (ft) & $\cdots$ \\
\hline Soil Description & \multicolumn{2}{|l|}{ Lean Clay (CL): Yellowish Brown } \\
\hline
\end{tabular}

\begin{tabular}{|l|l|l|l|}
\hline \multicolumn{4}{|c|}{ LIQUID LIMIT } \\
\hline Target Range of Blows & $40-30$ & $30-25$ & $25-20$ \\
\hline Actual Number of Blows & 34 & 24 & 19 \\
\hline Dish ID & 24 & 208 & 52 \\
\hline Mass of Dish (g) & 30.70 & 30.15 & 31.09 \\
\hline Mass of Moist Soil + Dish (g) & 39.43 & 37.07 & 37.55 \\
\hline Mass of Dry Soil + Dish (g) & 36.84 & 34.97 & 35.53 \\
\hline Water Content & $42.2 \%$ & $43.6 \%$ & $45.5 \%$ \\
\hline
\end{tabular}

\begin{tabular}{|l|l|l|}
\hline \multicolumn{3}{|c|}{ PLASTIC LIMIT } \\
\hline Dish ID & 93 & 226 \\
\hline Mass of Dish (g) & 30.41 & 30.25 \\
\hline Mass of Moist Soil + Dish (g) & 37.46 & 43.14 \\
\hline Mass of Dry Soil + Dish (g) & 36.72 & 41.69 \\
\hline Water Content & $11.7 \%$ & $12.7 \%$ \\
\hline
\end{tabular}

\begin{tabular}{|l|c|}
\hline \multicolumn{2}{|c|}{ SUMMARY } \\
\hline Liquid Limt & 44 \\
\hline Plastic Limit & 12 \\
\hline Plasticity Ind. & 32 \\
\hline
\end{tabular}
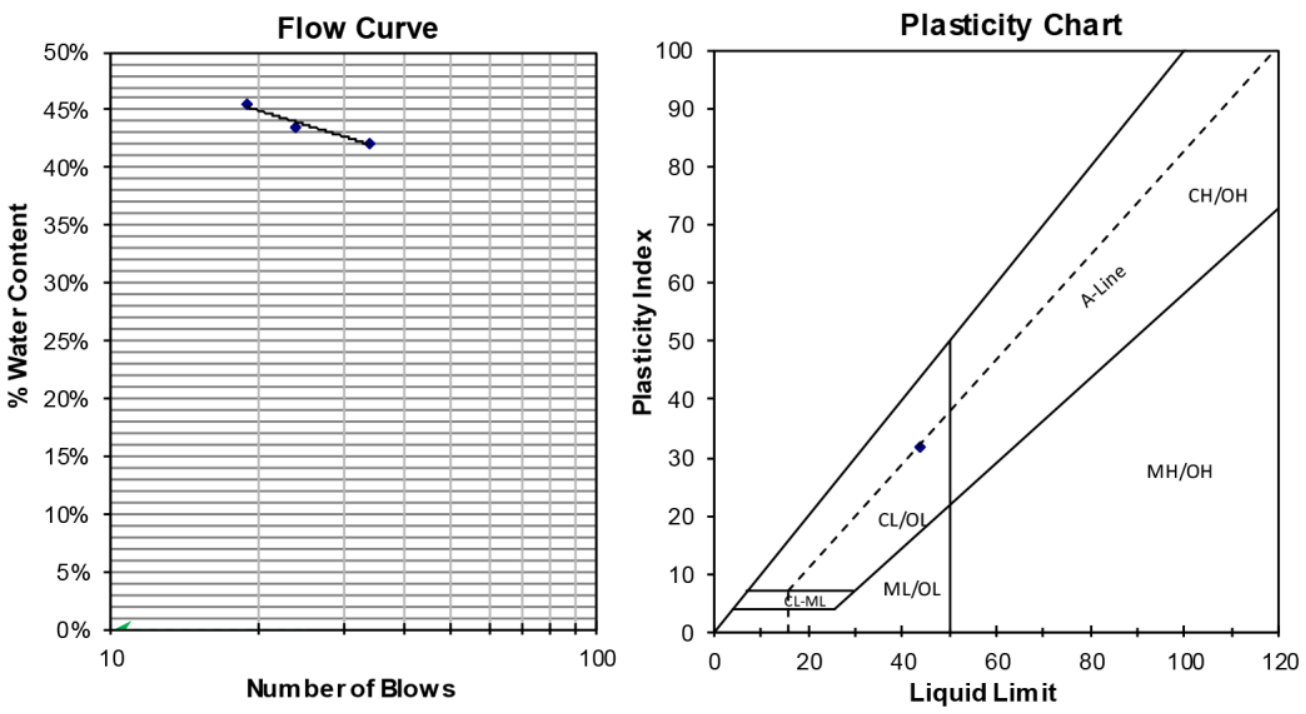


\section{DEPARTMENT OF CIVIL AND ENVIRONMENTAL ENGINEERING}

Hydrometer Analysis

Test Method: ASTM D422, D2487

\begin{tabular}{|l|l|l|l|}
\hline Project Name & \multicolumn{3}{|c|}{ LT Thesis } \\
\hline Tested By & WBH & Testing Date & $4 / 8 / 2014$ \\
\hline Soil Description & & Lean Clay (CL): Yellowish Brown \\
\hline
\end{tabular}

\begin{tabular}{|l|l|l|l|l|l|}
\hline \multicolumn{7}{|c|}{ GRAVEL GRADING } \\
\hline Tray ID & $\mathrm{I}$ & Air-Dry Soil Mass $(\mathrm{g})$ & 266.07 & Corrected Dry Mass $(\mathrm{g})$ & 256.74 \\
\hline
\end{tabular}

\begin{tabular}{|l|c|c|c|c|c|}
\hline Sieve No. & Size, $\mathrm{mm}$ & Mass Retained $(\mathrm{g})$ & Cumulative Retained $(\mathrm{g})$ & \% Retained & $\begin{array}{c}\text { Combineed } \% \\
\text { Passing }\end{array}$ \\
\hline 3 in & 76.2 & 0.00 & 0.00 & $0.0 \%$ & $100.0 \%$ \\
\hline 2 in * & 50.8 & 0.00 & 0.00 & $0.0 \%$ & $100.0 \%$ \\
\hline 1 in * & 25.4 & 0.00 & 0.00 & $0.0 \%$ & $100.0 \%$ \\
\hline $3 / 4$ in * & 19.1 & 0.00 & 0.00 & $0.0 \%$ & $100.0 \%$ \\
\hline $1 / 2$ in * & 12.7 & 0.00 & 0.00 & $0.0 \%$ & $100.0 \%$ \\
\hline $3 / 8$ in * & 9.50 & 1.52 & 1.52 & $0.6 \%$ & $99.4 \%$ \\
\hline No. $4 *$ & 4.75 & 5.27 & 6.79 & $2.6 \%$ & $97.4 \%$ \\
\hline
\end{tabular}

\begin{tabular}{|l|c|l|c|l|l|}
\hline \multicolumn{2}{|c|}{ WATER CONTENT OF MINUS \#4 = } & $3.6 \%$ & \multicolumn{2}{c|}{ \#4 BY \#I 0 GRADING } \\
\hline Dish ID & 2 & Moist Soil + Dish $(\mathrm{g})$ & 54.46 & Mass of Air-Dried Soil (g) & I20.34 \\
\hline Dish Mass $(\mathrm{g})$ & 30.78 & Dry Soil + Dish $(\mathrm{g})$ & 53.63 & Corrected Dry Mass $(\mathrm{g})$ & $\quad / 16 . / 2$ \\
\hline
\end{tabular}

\begin{tabular}{|c|c|c|c|c|c|}
\hline Sieve No. & Size, $\mathrm{mm}$ & Mass Retained $(\mathrm{g})$ & \% Retained & Combined \% Passing & Passing \\
\hline No. 10 & 2.00 & 10.87 & $9.4 \%$ & $90.6 \%$ & $88.2 \%$ \\
\hline \multicolumn{2}{|c|}{ Pan } & 109.46 & Split Minus \#10 for Hydrometer Test (I52H) \\
\hline
\end{tabular}






\begin{tabular}{|l|c|l|c|l|c|}
\hline HYDROSCOPIC WATER CONTENT = & $4.1 \%$ & \multicolumn{2}{c|}{ HYDROMETER } \\
\hline Dish ID & 76 & Moist Soil + Dish (g) & 90.70 & Mass of Air-Dried Soil (g) & 49.13 \\
\hline Dish Mass (g) & 30.58 & Dry Soil + Dish (g) & 88.35 & Corrected Dry Mass (g) & 47.21 \\
\hline
\end{tabular}

\begin{tabular}{|c|c|c|c|c|c|c|}
\hline Time $(\mathrm{min})$ & $\begin{array}{c}\text { Hydro. } \\
\text { Reading }\end{array}$ & Temperature $\left({ }^{\circ} \mathrm{C}\right)$ & $\begin{array}{c}\text { Effective } \\
\text { Depth }\end{array}$ & $\begin{array}{c}\text { Diameter } \\
(\mathrm{mm})\end{array}$ & $\begin{array}{c}\text { Combined } \% \\
\text { Passing }\end{array}$ \\
\hline 2 & 31.0 & 21.0 & 11.2 & 0.0314 & $52.4 \%$ & $46.3 \%$ \\
\hline 5 & 28.0 & 21.0 & 11.7 & 0.0203 & $46.1 \%$ & $40.7 \%$ \\
\hline 15 & 27.0 & 21.0 & 11.9 & 0.0118 & $44.0 \%$ & $38.9 \%$ \\
\hline 30 & 25.0 & 21.0 & 12.2 & 0.0085 & $39.8 \%$ & $35.2 \%$ \\
\hline 60 & 24.0 & 21.0 & 12.4 & 0.0060 & $37.7 \%$ & $33.3 \%$ \\
\hline 90 & 23.0 & 21.0 & 12.5 & 0.0050 & $35.6 \%$ & $31.5 \%$ \\
\hline 120 & 23.0 & 22.0 & 12.5 & 0.0042 & $35.6 \%$ & $31.5 \%$ \\
\hline 240 & 22.0 & 22.0 & 12.7 & 0.0030 & $33.6 \%$ & $29.6 \%$ \\
\hline 480 & 21.0 & 23.0 & 12.9 & 0.0021 & $31.5 \%$ & $27.8 \%$ \\
\hline 1440 & 21.0 & 23.0 & 12.9 & 0.0012 & $31.5 \%$ & $27.8 \%$ \\
\hline
\end{tabular}

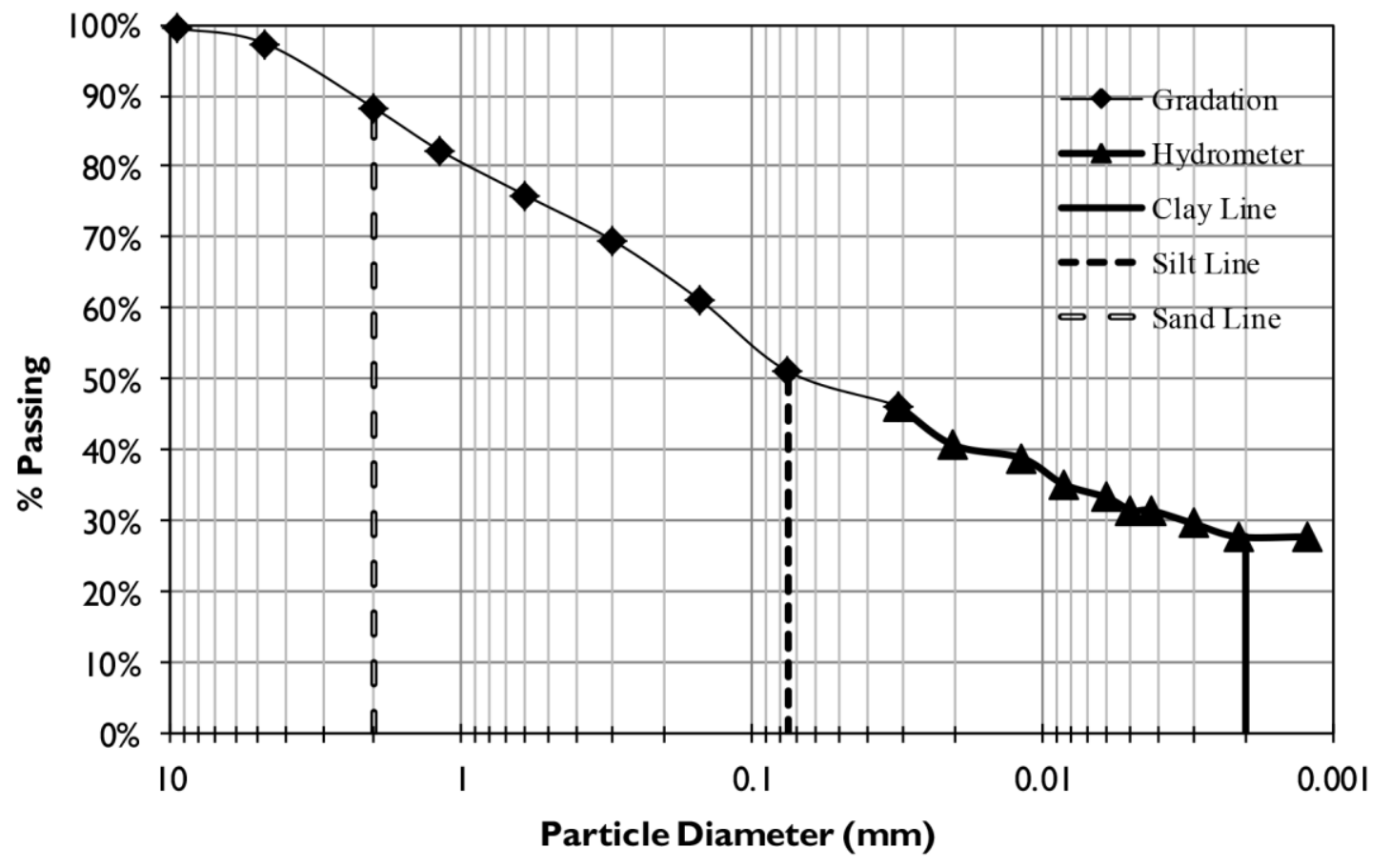


DEPARTMENT OF CIVIL AND ENVIRONMENTAL ENGINEERING

Expansion Index

Test Method: ASTM D4829

\begin{tabular}{|l|l|l|l|}
\hline Project Name & Las Tablas & Project No. & $\ldots . .-$ \\
\hline Tested By & WBH & Testing Date & $4 / 19 / 2014$ \\
\hline
\end{tabular}

\begin{tabular}{|l|l|l|l|l|c|}
\hline \multicolumn{7}{|c|}{ SPECIMEN ID AND CLASSIFICATION } \\
\hline Boring No. & $-\cdots$ & Sample No. & $\cdots---$ & Depth (ft) & $\ldots--\cdot$ \\
\hline Soil Description & Lean Clay $(\mathrm{CL})$ : Yellowish Brown \\
\hline
\end{tabular}

\begin{tabular}{|l|c|}
\hline \multicolumn{2}{|c|}{ Moisture Content } \\
\hline Tare No. & 15 \\
\hline Wet soil + tare, g & 685.65 \\
\hline Dry soil + tare, g & 675.96 \\
\hline Water, g & 9.69 \\
\hline Tare, g & 633.71 \\
\hline Soil, g & 42.25 \\
\hline$\%$ Water & 22.93 \\
\hline
\end{tabular}

\begin{tabular}{|l|c|}
\hline \multicolumn{2}{|c|}{ SPECIMEN MASS } \\
\hline Height, in & 0.99 \\
\hline Diameter, in & 4.01 \\
\hline Ring No. & $201 \mathrm{GM}$ \\
\hline Ring, g & 200.72 \\
\hline Ring + soil, g & 510.80 \\
\hline Wet density, pcf & 94.02 \\
\hline Dry density, pcf & 76.48 \\
\hline
\end{tabular}

\begin{tabular}{|c|c|c|c|}
\hline \multicolumn{4}{|c|}{ EXPANSION READINGS } \\
\hline DATE & TIME & DIAL READING, in. & REMARKS \\
\hline $4 / 13 / 2014$ & $10: 30$ & 0.0309 & 10 min after loading \\
\hline $4 / 14 / 2014$ & $20: 30$ & 0.0616 & FINAL READING \\
\hline
\end{tabular}

\begin{tabular}{|l|c|}
\hline SATURATION: & 51.5 \\
\hline EI MEASURED: & 31 \\
\hline EI at 50\% SAT: & 32 \\
\hline
\end{tabular}

Low Expansion Potential

\begin{tabular}{|l|c|c|}
\hline \multicolumn{3}{|c|}{ Absorption Test (Ret \#20) } \\
\hline Trial & 1 & 2 \\
\hline SSD Sand $(\mathrm{g})$ & 1120.0 & 1104.5 \\
\hline Oven Dry Sand $(\mathrm{g})$ & 894.6 & 855.2 \\
\hline Absorption $(\%)$ & 25.2 & 29.2 \\
\hline
\end{tabular}




\section{APPENDIX C. MATERIAL BATCH SHEETS}

\section{C.1. Rhino Blocks}

Batch Naming Format: "[Wall ID]-[Batch Number] ([Batch on Given Day, Optional])"

Example: Batch 1-4 (1) is the fourth batch of wall one and the first batch made on that day.

CEB Pressing Data Sheet

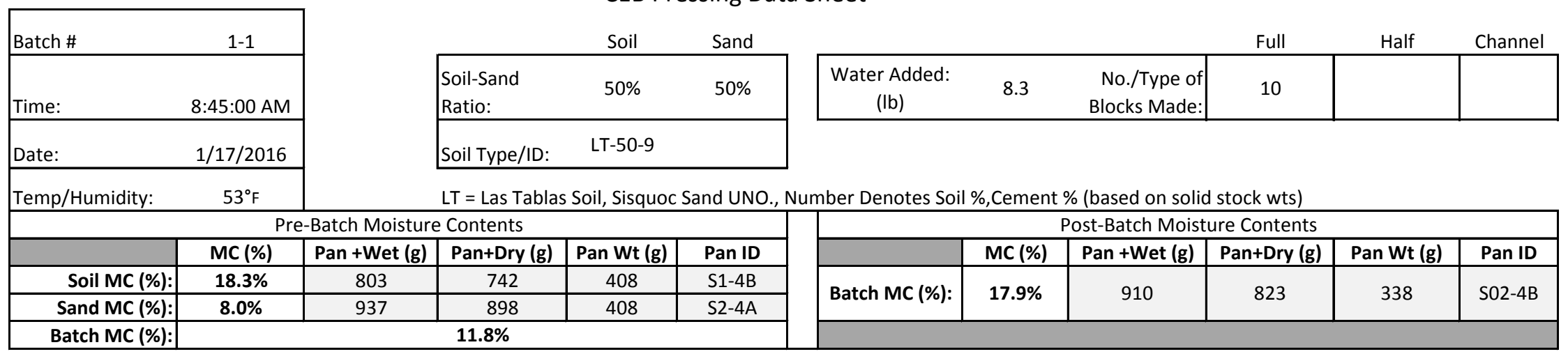

Penetrometer Readings:

\begin{tabular}{|c|c|}
\hline Block ID: & 1 \\
\hline Reading (psi): & $375 \mathrm{C}, 350 \mathrm{E}$ \\
\hline
\end{tabular}

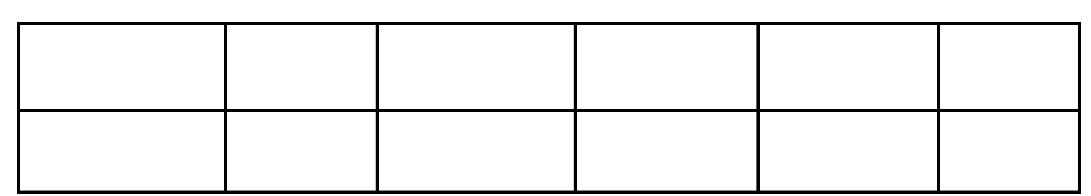

Batching Notes:

$\mathrm{C}=$ Center, $\mathrm{E}=\mathrm{Edge}$

Overshot water quantity

Minor cracking on most blocks

$15.1 \mathrm{lb} /$ charge

\begin{tabular}{|l|c|c|c|c|}
\hline Material & $\begin{array}{c}\text { Measured } \\
\text { MC (\%) }\end{array}$ & $\begin{array}{c}\text { Stock Weight } \\
(\mathrm{lb})\end{array}$ & $\begin{array}{c}\text { OD Weight } \\
(\mathrm{lb})\end{array}$ & \% Total Mix \\
\hline Soil & $18.3 \%$ & 69.4 & 58.7 & $41 \%$ \\
\hline Sand & $8.0 \%$ & 69.4 & 64.3 & $45 \%$ \\
\hline Cement & - & 12.5 & 12.5 & $9 \%$ \\
\hline Water & - & 7.7 & 7.7 & $5 \%$ \\
\hline Total & - & 159.0 & 143.2 & $100 \%$ \\
\hline
\end{tabular}




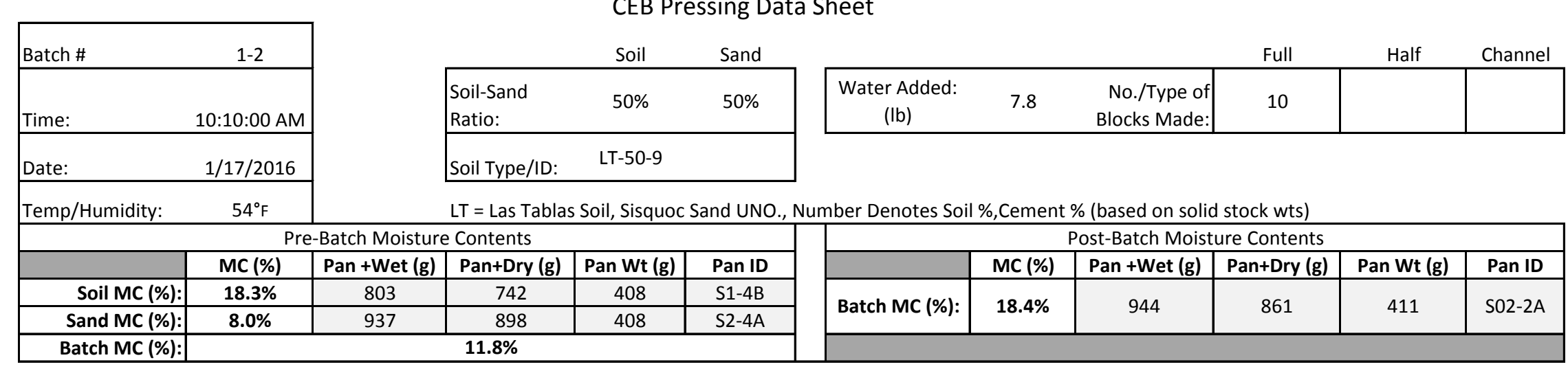

Penetrometer Readings:

\begin{tabular}{|c|c|c|c|c|c|}
\hline Block ID: & 1 & & & & \\
\hline Reading (psi): & $430 \mathrm{C}, 380 \mathrm{E}$ & & & & \\
\hline
\end{tabular}

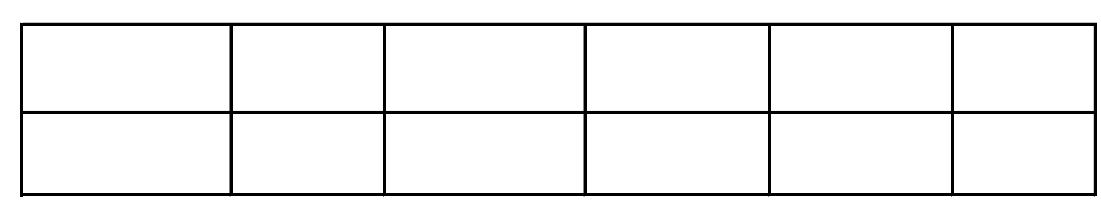

Batching Notes:

$\mathrm{C}=$ Center, $\mathrm{E}=$ Edge (Corner)

$15.1 \mathrm{lb} /$ charge

\begin{tabular}{|l|c|c|c|c|}
\hline Material & $\begin{array}{c}\text { Measured } \\
\text { MC (\%) }\end{array}$ & $\begin{array}{c}\text { Stock Weight } \\
(\mathrm{lb})\end{array}$ & $\begin{array}{c}\text { OD Weight } \\
(\mathrm{lb})\end{array}$ & \% Total Mix \\
\hline Soil & $18.3 \%$ & 69.4 & 58.7 & $41 \%$ \\
\hline Sand & $8.0 \%$ & 69.4 & 64.3 & $45 \%$ \\
\hline Cement & - & 12.5 & 12.5 & $9 \%$ \\
\hline Water & - & 7.7 & 7.7 & $5 \%$ \\
\hline Total & - & 159.0 & 143.2 & $100 \%$ \\
\hline
\end{tabular}




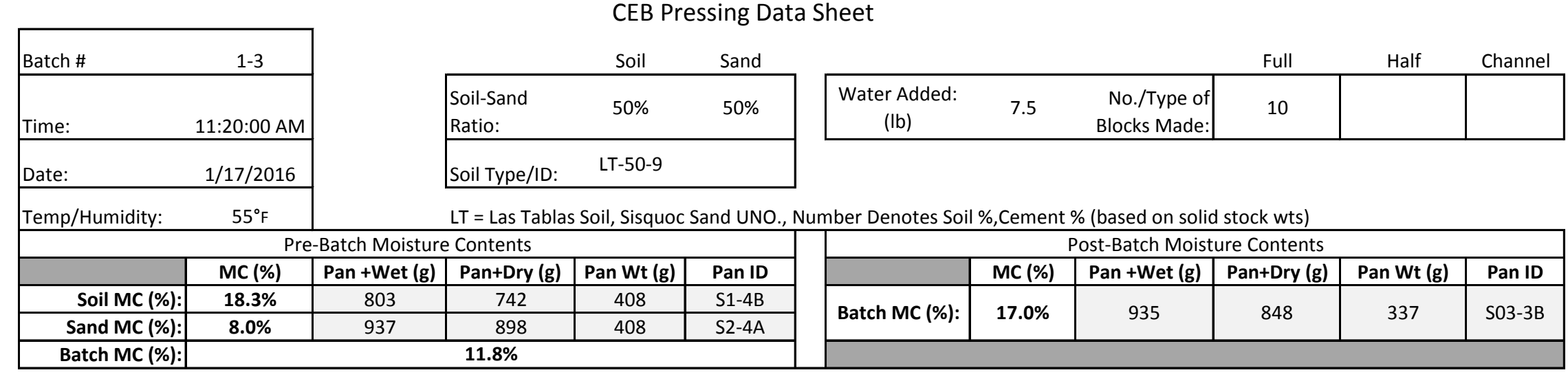

Penetrometer Readings:

\begin{tabular}{|c|c|c|c|c|c|}
\hline Block ID: & 1 & & & & \\
\hline Reading (psi): & $370 \mathrm{C}, 270 \mathrm{E}$ & & & & \\
\hline
\end{tabular}

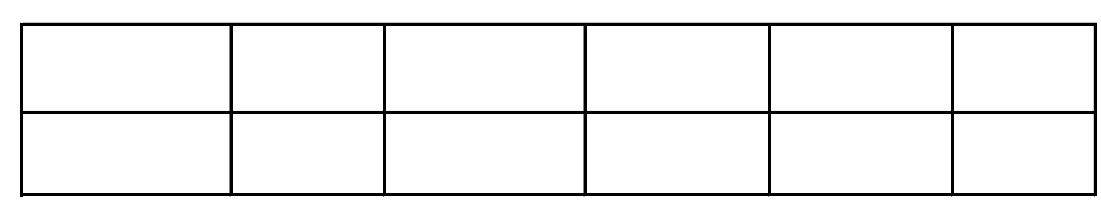

Batching Notes:

$\mathrm{C}=$ Center, $\mathrm{E}=\mathrm{Edge}$ (Corner)

$15.1 \mathrm{lb} /$ charge

\begin{tabular}{|l|c|c|c|c|}
\hline Material & $\begin{array}{c}\text { Measured } \\
\text { MC (\%) }\end{array}$ & $\begin{array}{c}\text { Stock Weight } \\
(\mathrm{lb})\end{array}$ & $\begin{array}{c}\text { OD Weight } \\
(\mathrm{lb})\end{array}$ & \% Total Mix \\
\hline Soil & $18.3 \%$ & 69.4 & 58.7 & $41 \%$ \\
\hline Sand & $8.0 \%$ & 69.4 & 64.3 & $45 \%$ \\
\hline Cement & - & 12.5 & 12.5 & $9 \%$ \\
\hline Water & - & 7.7 & 7.7 & $5 \%$ \\
\hline Total & - & 159.0 & 143.2 & $100 \%$ \\
\hline
\end{tabular}




\begin{tabular}{|c|c|c|c|c|c|c|c|c|c|c|c|}
\hline \multicolumn{12}{|c|}{ CEB Pressing Data Sheet } \\
\hline Batch \# & $1-4$ & & & Soil & Sand & & & & Full & Half & Channel \\
\hline Time: & 1:15:00 AM & & \begin{tabular}{|l} 
Soil-Sand \\
Ratio: \\
\end{tabular} & $50 \%$ & $50 \%$ & $\begin{array}{l}\text { Water Added: } \\
\text { (lb) }\end{array}$ & 7.9 & $\begin{array}{r}\text { No./Type of } \\
\text { Blocks Made: }\end{array}$ & 10 & & \\
\hline Date: & $1 / 17 / 2016$ & & Soil Type/ID: & LT-50-9 & & & & & & & \\
\hline Temp/Humidity: & $55^{\circ} \mathrm{F}$ & & $\mathrm{LT}=\mathrm{Las}$ Tablas & Soil, Sisquoc & and UNO & ber Denotes So & \%,Cement & (based on solid & stock wts) & & \\
\hline \multicolumn{6}{|c|}{ Pre-Batch Moisture Contents } & \multicolumn{6}{|c|}{ Post-Batch Moisture Contents } \\
\hline & MC (\%) & Pan +Wet (g) & Pan+Dry (g) & Pan Wt (g) & Pan ID & & MC (\%) & Pan +Wet (g) & Pan+Dry (g) & Pan Wt (g) & Pan ID \\
\hline Soil MC (\%): & $18.3 \%$ & 803 & 742 & 408 & S1-4B & \multirow{2}{*}{ Batch MC (\%): } & \multirow{2}{*}{$15.5 \%$} & \multirow{2}{*}{1031} & \multirow{2}{*}{948} & \multirow{2}{*}{411} & \multirow{2}{*}{ S03-4B } \\
\hline Sand MC (\%): & $8.0 \%$ & 937 & 898 & 408 & S2-4A & & & & & & \\
\hline Batch MC (\%): & & & $11.8 \%$ & & & & & & & & \\
\hline
\end{tabular}

Penetrometer Readings:

\begin{tabular}{|c|c|c|c|c|c|}
\hline Block ID: & 1 & & & & \\
\hline Reading (psi): & $400 \mathrm{C}, 400 \mathrm{E}$ & & & & \\
\hline
\end{tabular}

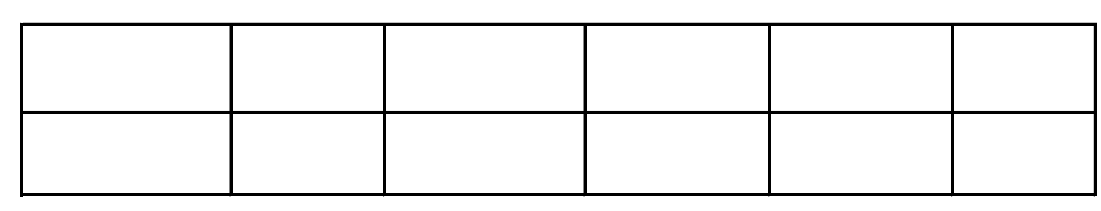

Batching Notes:

$\mathrm{C}=$ Center, $\mathrm{E}=\mathrm{Edge}$ (Corner)

$15.1 \mathrm{lb} /$ charge

\begin{tabular}{|l|c|c|c|c|}
\hline Material & $\begin{array}{c}\text { Measured } \\
\text { MC (\%) }\end{array}$ & $\begin{array}{c}\text { Stock Weight } \\
(\mathrm{lb})\end{array}$ & $\begin{array}{c}\text { OD Weight } \\
(\mathrm{lb})\end{array}$ & \% Total Mix \\
\hline Soil & $18.3 \%$ & 69.4 & 58.7 & $41 \%$ \\
\hline Sand & $8.0 \%$ & 69.4 & 64.3 & $45 \%$ \\
\hline Cement & - & 12.5 & 12.5 & $9 \%$ \\
\hline Water & - & 7.7 & 7.7 & $5 \%$ \\
\hline Total & - & 159.0 & 143.2 & $100 \%$ \\
\hline
\end{tabular}




\begin{tabular}{|lc|}
\hline Batch \# & $1-5(1)$ \\
\hline Time: & $10: 45: 00 \mathrm{AM}$ \\
\hline Date: & $1 / 18 / 2016$ \\
\hline Temp/Humidity: & $55^{\circ} \mathrm{F} / 100 \%$ \\
\hline
\end{tabular}

CEB Pressing Data Sheet

\begin{tabular}{|c|c|c|c|c|c|c|c|c|c|c|c|}
\hline \multicolumn{6}{|c|}{ Pre-Batch Moisture Contents } & \multicolumn{6}{|c|}{ Post-Batch Moisture Contents } \\
\hline & $\mathrm{MC}(\%)$ & Pan +Wet (g) & Pan+Dry (g) & Pan Wt (g) & Pan ID & & $\mathrm{MC}(\%)$ & Pan +Wet (g) & Pan+Dry (g) & Pan Wt (g) & Pan ID \\
\hline Soil MC (\%): & $18.3 \%$ & 803 & 742 & 408 & S1-4B & \multirow{2}{*}{ Batch MC (\%): } & \multirow{2}{*}{$14.2 \%$} & \multirow{2}{*}{1044} & \multirow{2}{*}{956} & \multirow{2}{*}{338} & \multirow{2}{*}{ S02-4B } \\
\hline Sand MC (\%): & $8.0 \%$ & 937 & 898 & 408 & S2-4A & & & & & & \\
\hline Batch MC (\%): & \multicolumn{5}{|c|}{$11.8 \%$} & & & & & & \\
\hline
\end{tabular}

Penetrometer Readings:

Penetrometer Readings:
\begin{tabular}{|c|c|c|c|c|c|}
\hline Block ID: & 1 & & & & \\
\hline Reading (psi): & $400 \mathrm{C}, 260 \mathrm{E}$ & & & & \\
\hline
\end{tabular}

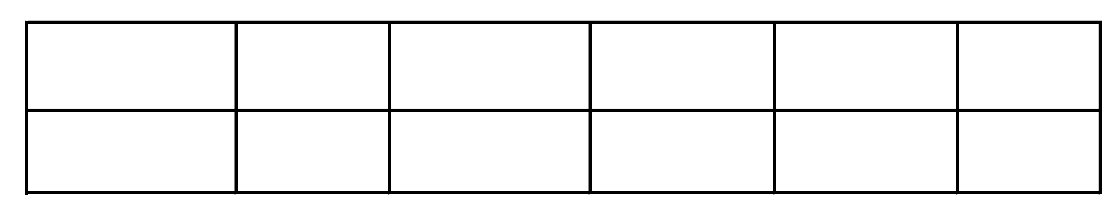

Batching Notes:

$\mathrm{C}=$ Center, $\mathrm{E}=\mathrm{Edge}$ (Corner)

$15.1 \mathrm{lb} /$ charge

\begin{tabular}{|l|c|c|c|c|}
\hline Material & $\begin{array}{c}\text { Measured } \\
\text { MC (\%) }\end{array}$ & $\begin{array}{c}\text { Stock Weight } \\
(\mathrm{lb})\end{array}$ & $\begin{array}{c}\text { OD Weight } \\
(\mathrm{lb})\end{array}$ & \% Total Mix \\
\hline Soil & $18.3 \%$ & 69.4 & 58.7 & $41 \%$ \\
\hline Sand & $8.0 \%$ & 69.4 & 64.3 & $45 \%$ \\
\hline Cement & - & 12.5 & 12.5 & $9 \%$ \\
\hline Water & - & 7.7 & 7.7 & $5 \%$ \\
\hline Total & - & 159.0 & 143.2 & $100 \%$ \\
\hline
\end{tabular}




\begin{tabular}{|c|c|c|c|c|c|c|c|c|c|c|c|}
\hline \multicolumn{12}{|c|}{ CEB Pressing Data Sheet } \\
\hline Batch \# & $1-6(2)$ & & & Soil & Sand & & & & Full & Half & Channel \\
\hline Time: & 12:00:00 PM & & \begin{tabular}{|l} 
Soil-Sand \\
Ratio:
\end{tabular} & $50 \%$ & $50 \%$ & $\begin{array}{l}\text { Water Added: } \\
\text { (lb) }\end{array}$ & 8.0 & $\begin{array}{r}\text { No./Type of } \\
\text { Blocks Made: }\end{array}$ & 10 & & \\
\hline Date: & $1 / 18 / 2016$ & & Soil Type/ID: & LT-50-9 & & & & & & & \\
\hline Temp/Humidity: & $55^{\circ} \mathrm{F}$ & & $\mathrm{LT}=\mathrm{Las}$ Tablas & Soil, Sisquoc & and UNO & ber Denotes So & \%,Cement & (based on solid & stock wts) & & \\
\hline \multicolumn{6}{|c|}{ Pre-Batch Moisture Contents } & \multicolumn{6}{|c|}{ Post-Batch Moisture Contents } \\
\hline & MC (\%) & Pan +Wet (g) & Pan+Dry (g) & Pan Wt (g) & Pan ID & & MC (\%) & Pan +Wet (g) & Pan+Dry (g) & Pan Wt (g) & Pan ID \\
\hline Soil MC (\%): & $18.3 \%$ & 803 & 742 & 408 & S1-4B & \multirow{2}{*}{ Batch MC (\%): } & \multirow{2}{*}{$14.5 \%$} & \multirow{2}{*}{1003} & \multirow{2}{*}{928} & \multirow{2}{*}{411} & \multirow{2}{*}{ S03-4B } \\
\hline Sand MC (\%): & $8.0 \%$ & 937 & 898 & 408 & S2-4A & & & & & & \\
\hline Batch MC (\%): & & & $11.8 \%$ & & & & & & & & \\
\hline
\end{tabular}

Penetrometer Readings:

\begin{tabular}{|c|c|c|c|c|c|}
\hline Block ID: & 1 & & & & \\
\hline Reading (psi): & $360 \mathrm{C}, 290 \mathrm{E}$ & & & & \\
\hline
\end{tabular}

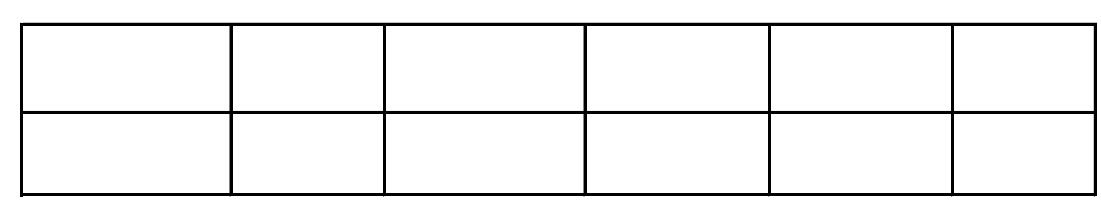

Batching Notes:

$\mathrm{C}=$ Center, $\mathrm{E}=\mathrm{Edge}$ (Corner)

$15.1 \mathrm{lb} /$ charge

\begin{tabular}{|l|c|c|c|c|}
\hline Material & $\begin{array}{c}\text { Measured } \\
\text { MC (\%) }\end{array}$ & $\begin{array}{c}\text { Stock Weight } \\
(\mathrm{lb})\end{array}$ & $\begin{array}{c}\text { OD Weight } \\
(\mathrm{lb})\end{array}$ & \% Total Mix \\
\hline Soil & $18.3 \%$ & 69.4 & 58.7 & $41 \%$ \\
\hline Sand & $8.0 \%$ & 69.4 & 64.3 & $45 \%$ \\
\hline Cement & - & 12.5 & 12.5 & $9 \%$ \\
\hline Water & - & 7.7 & 7.7 & $5 \%$ \\
\hline Total & - & 159.0 & 143.2 & $100 \%$ \\
\hline
\end{tabular}




\begin{tabular}{|c|c|c|c|c|c|c|c|c|c|c|c|}
\hline \multicolumn{12}{|c|}{ CEB Pressing Data Sheet } \\
\hline Batch \# & $1-7(3)$ & & \multicolumn{2}{|r|}{ Soil } & Sand & \multicolumn{4}{|r|}{ Full } & \multirow[t]{2}{*}{ Half } & \multirow[t]{2}{*}{ Channel } \\
\hline Time: & 1:30:00 PM & & $\begin{array}{l}\text { Soil-Sand } \\
\text { Ratio: }\end{array}$ & $50 \%$ & $50 \%$ & $\begin{array}{l}\text { Water Added: } \\
\text { (lb) }\end{array}$ & 7.9 & $\begin{array}{r}\text { No./Type of } \\
\text { Blocks Made: }\end{array}$ & 10 & & \\
\hline Date: & $1 / 18 / 2016$ & & Soil Type/ID: & \multicolumn{2}{|l|}{ LT-50-9 } & & & & & & \\
\hline \multirow{2}{*}{\multicolumn{11}{|c|}{\begin{tabular}{l|l|l|l}
$60^{\circ} \mathrm{F}$ & $\mathrm{LT}=$ Las Tablas Soil, Sisquoc Sand UNO., Number Denotes Soil \%,Cement \% (based on solid stock wts) \\
& Pre-Batch Moisture Contents
\end{tabular}}} & \\
\hline & & & & & & & & & & & \\
\hline & MC (\%) & Pan +Wet (g) & Pan+Dry (g) & Pan Wt (g) & Pan ID & & MC (\%) & Pan +Wet (g) & Pan+Dry (g) & Pan Wt (g) & Pan ID \\
\hline Soil MC (\%): & $18.3 \%$ & 803 & 742 & 408 & S1-4B & \multirow{2}{*}{ Batch MC (\%): } & \multirow{2}{*}{$16.2 \%$} & \multirow{2}{*}{873} & \multirow{2}{*}{798} & \multirow{2}{*}{336} & \multirow{2}{*}{ S03-3B } \\
\hline Sand MC (\%): & $8.0 \%$ & 937 & 898 & 408 & S2-4A & & & & & & \\
\hline Batch MC (\%): & \multicolumn{5}{|c|}{$11.8 \%$} & & & & & & \\
\hline
\end{tabular}

Penetrometer Readings:

\begin{tabular}{|c|c|c|c|c|c|}
\hline Block ID: & 1 & & & & \\
\hline Reading (psi): & $380 \mathrm{C}, 330 \mathrm{E}$ & & & & \\
\hline
\end{tabular}

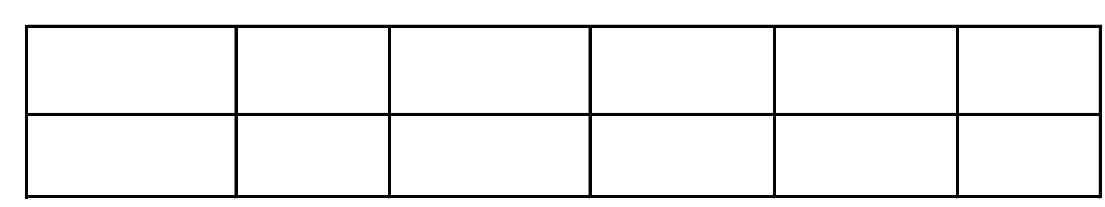

Batching Notes:

$\mathrm{C}=$ Center, $\mathrm{E}=$ Edge (Corner)

$15.1 \mathrm{lb} /$ charge

\begin{tabular}{|l|c|c|c|c|}
\hline Material & $\begin{array}{c}\text { Measured } \\
\text { MC (\%) }\end{array}$ & $\begin{array}{c}\text { Stock Weight } \\
(\mathrm{lb})\end{array}$ & $\begin{array}{c}\text { OD Weight } \\
(\mathrm{lb})\end{array}$ & \% Total Mix \\
\hline Soil & $18.3 \%$ & 69.4 & 58.7 & $41 \%$ \\
\hline Sand & $8.0 \%$ & 69.4 & 64.3 & $45 \%$ \\
\hline Cement & - & 12.5 & 12.5 & $9 \%$ \\
\hline Water & - & 7.7 & 7.7 & $5 \%$ \\
\hline Total & - & 159.0 & 143.2 & $100 \%$ \\
\hline
\end{tabular}




\begin{tabular}{|c|c|c|c|c|}
\hline & & & \multicolumn{2}{|c|}{ CEB Pressing Data } \\
\hline Batch \# & $1-8(1)$ & & Soil & Sand \\
\hline Time: & 8:30:00 AM & $\begin{array}{l}\text { Soil-Sand } \\
\text { Ratio: }\end{array}$ & $50 \%$ & $50 \%$ \\
\hline Date: & $1 / 20 / 2016$ & Soil Type/ID: & LT-50-9 & \\
\hline
\end{tabular}

\begin{tabular}{|c|c|c|c|c|c|}
\hline & & & Full & Half & Channel \\
\hline $\begin{array}{l}\text { Water Added: } \\
\text { (Ib) }\end{array}$ & 7.8 & $\begin{array}{r}\text { No./Type of } \\
\text { Blocks Made: }\end{array}$ & 10 & & \\
\hline
\end{tabular}

\begin{tabular}{|l|l|}
\hline Temp/Humidity: & \\
\hline Pre-Batch
\end{tabular}

LT = Las Tablas Soil, Sisquoc Sand UNO., Number Denotes Soil \%,Cement \% (based on solid stock wts)

\begin{tabular}{|c|c|c|c|c|c|c|c|c|c|c|c|}
\hline \multicolumn{6}{|c|}{ Pre-Batch Moisture Contents } & \multicolumn{6}{|c|}{ Post-Batch Moisture Contents } \\
\hline & MC (\%) & Pan +Wet (g) & Pan+Dry (g) & Pan Wt (g) & Pan ID & & MC (\%) & Pan +Wet (g) & Pan+Dry (g) & Pan Wt (g) & Pan ID \\
\hline Soil MC (\%): & $18.3 \%$ & 803 & 742 & 408 & S1-4B & \multirow{2}{*}{ Batch MC (\%): } & \multirow{2}{*}{$17.5 \%$} & \multirow{2}{*}{964} & \multirow{2}{*}{881} & \multirow{2}{*}{407} & \multirow{2}{*}{ S02-5B } \\
\hline Sand MC (\%): & $8.0 \%$ & 937 & 898 & 408 & S2-4A & & & & & & \\
\hline Batch MC (\%): & \multicolumn{5}{|c|}{$\begin{array}{c}090 \\
11.8 \% \\
\end{array}$} & & & & & & \\
\hline
\end{tabular}

Penetrometer Readings:

Penetrometer Readings:
\begin{tabular}{|c|c|c|c|c|c|}
\hline Block ID: & 1 & 7 & & & \\
\hline Reading (psi): & $280 \mathrm{C}, 200 \mathrm{E}$ & $250 \mathrm{C}, 200 \mathrm{E}$ & & & \\
\hline
\end{tabular}

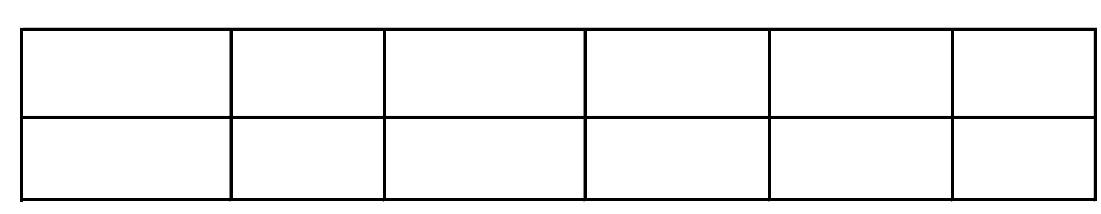

Batching Notes:

$\mathrm{C}=$ Center $\mathrm{E}=$ Edge $($ Corner $)$

\section{$15.3 \mathrm{lb} /$ charge}

Batch seemed a bit wet; some water had infiltrated soil

during rain

\begin{tabular}{|l|c|c|c|c|}
\hline Material & $\begin{array}{c}\text { Measured } \\
\text { MC (\%) }\end{array}$ & $\begin{array}{c}\text { Stock Weight } \\
(\mathrm{lb})\end{array}$ & $\begin{array}{c}\text { OD Weight } \\
(\mathrm{lb})\end{array}$ & \% Total Mix \\
\hline Soil & $18.3 \%$ & 69.4 & 58.7 & $41 \%$ \\
\hline Sand & $8.0 \%$ & 69.4 & 64.3 & $45 \%$ \\
\hline Cement & - & 12.5 & 12.5 & $9 \%$ \\
\hline Water & - & 7.7 & 7.7 & $5 \%$ \\
\hline Total & - & 159.0 & 143.2 & $100 \%$ \\
\hline
\end{tabular}




\begin{tabular}{|c|c|c|c|c|}
\hline & & & \multicolumn{2}{|c|}{ CEB Pressing Data } \\
\hline Batch \# & $1-9(2)$ & & Soil & Sand \\
\hline Time: & 9:45:00 AM & $\begin{array}{l}\text { Soil-Sand } \\
\text { Ratio: }\end{array}$ & $50 \%$ & $50 \%$ \\
\hline Date: & $1 / 20 / 2016$ & Soil Type/ID: & LT-50-9 & \\
\hline
\end{tabular}

\begin{tabular}{|c|c|c|c|c|c|}
\hline & & & Full & Half & Channel \\
\hline $\begin{array}{l}\text { Water Added: } \\
\text { (lb) }\end{array}$ & 7.4 & $\begin{array}{r}\text { No./Type of } \\
\text { Blocks Made: }\end{array}$ & 10 & & \\
\hline
\end{tabular}

Temp/Humidity: $\quad$ LT = Las Tablas Soil, Sisquoc Sand UNO., Number Denotes Soil \%,Cement \% (based on solid stock wts)

\begin{tabular}{|c|c|c|c|c|c|c|c|c|c|c|c|}
\hline \multicolumn{6}{|c|}{ Pre-Batch Moisture Contents } & \multicolumn{6}{|c|}{ Post-Batch Moisture Contents } \\
\hline & MC (\%) & Pan +Wet (g) & Pan+Dry (g) & Pan Wt (g) & Pan ID & & MC (\%) & Pan +Wet (g) & Pan+Dry (g) & Pan Wt (g) & Pan ID \\
\hline Soil MC (\%): & $18.3 \%$ & 803 & 742 & 408 & S1-4B & \multirow{2}{*}{ Batch MC (\%): } & \multirow{2}{*}{$19.2 \%$} & \multirow{2}{*}{636} & \multirow{2}{*}{588} & \multirow{2}{*}{338} & \multirow{2}{*}{ S01-5B } \\
\hline Sand MC (\%): & $8.0 \%$ & 937 & 898 & 408 & S2-4A & & & & & & \\
\hline Batch MC (\%): & \multicolumn{5}{|c|}{$11.8 \%$} & & & & & & \\
\hline
\end{tabular}

Penetrometer Readings:

Penetrometer Readings:
\begin{tabular}{|c|c|c|c|c|c|}
\hline Block ID: & 1 & 3 & & & \\
\hline Reading (psi): & $250 \mathrm{C}, 225 \mathrm{E}$ & $300 \mathrm{C}, 300 \mathrm{E}$ & & & \\
\hline
\end{tabular}

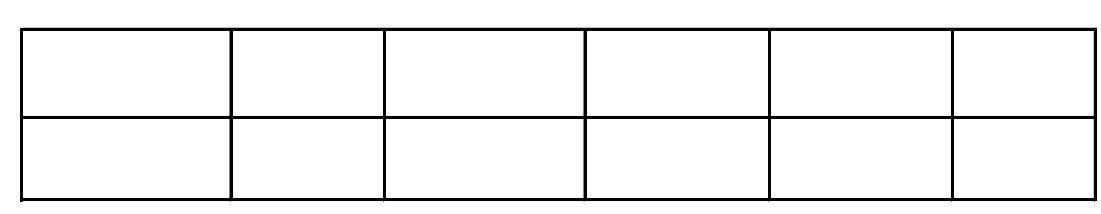

Batching Notes:

$\mathrm{C}=$ Center $\mathrm{E}=\mathrm{Edge}($ Corner $)$

$15.1 \mathrm{lb} /$ charge

\begin{tabular}{|l|c|c|c|c|}
\hline Material & $\begin{array}{c}\text { Measured } \\
\text { MC (\%) }\end{array}$ & $\begin{array}{c}\text { Stock Weight } \\
(\mathrm{lb})\end{array}$ & $\begin{array}{c}\text { OD Weight } \\
(\mathrm{lb})\end{array}$ & \% Total Mix \\
\hline Soil & $18.3 \%$ & 69.4 & 58.7 & $41 \%$ \\
\hline Sand & $8.0 \%$ & 69.4 & 64.3 & $45 \%$ \\
\hline Cement & - & 12.5 & 12.5 & $9 \%$ \\
\hline Water & - & 7.7 & 7.7 & $5 \%$ \\
\hline Total & - & 159.0 & 143.2 & $100 \%$ \\
\hline
\end{tabular}




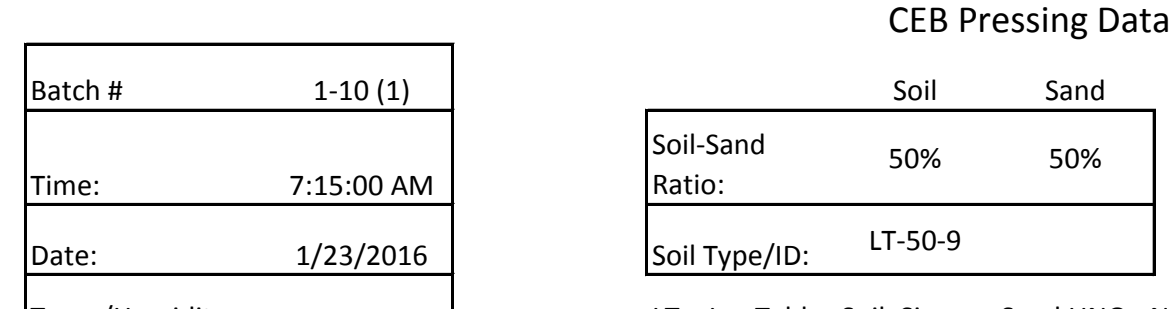

\begin{tabular}{|c|c|c|c|c|c|}
\hline & & & Full & Half & Channel \\
\hline $\begin{array}{l}\text { Water Added: } \\
\text { (lb) }\end{array}$ & 7.6 & $\begin{array}{r}\text { No./Type of } \\
\text { Blocks Made: }\end{array}$ & & 19 & 1 \\
\hline
\end{tabular}

Temp/Humidity: $\quad$ LT = Las Tablas Soil, Sisquoc Sand UNO., Number Denotes Soil \%,Cement \% (based on solid stock wts)

\begin{tabular}{|c|c|c|c|c|c|c|c|c|c|c|c|}
\hline \multicolumn{6}{|c|}{ Pre-Batch Moisture Contents } & \multicolumn{6}{|c|}{ Post-Batch Moisture Contents } \\
\hline & MC (\%) & Pan +Wet (g) & Pan+Dry (g) & Pan Wt (g) & Pan ID & & MC (\%) & Pan +Wet (g) & Pan+Dry (g) & Pan Wt (g) & Pan ID \\
\hline Soil MC (\%): & $18.3 \%$ & 803 & 742 & 408 & S1-4B & \multirow{2}{*}{ Batch MC (\%): } & \multirow{2}{*}{$18.9 \%$} & \multirow{2}{*}{901} & \multirow{2}{*}{811} & \multirow{2}{*}{336} & \multirow{2}{*}{ S03-3B } \\
\hline Sand MC (\%): & $8.0 \%$ & 937 & 898 & 408 & S2-4A & & & & & & \\
\hline Batch MC (\%): & \multicolumn{5}{|c|}{$11.8 \%$} & & & & & & \\
\hline
\end{tabular}

Penetrometer Readings:

Penetrometer Readings:
\begin{tabular}{|c|c|c|c|c|c|}
\hline Block ID: & 1 & Channel & & & \\
\hline Reading (psi): & $300 \mathrm{C}, 260 \mathrm{E}$ & $260 \mathrm{C}, 220 \mathrm{E}$ & & & \\
\hline
\end{tabular}

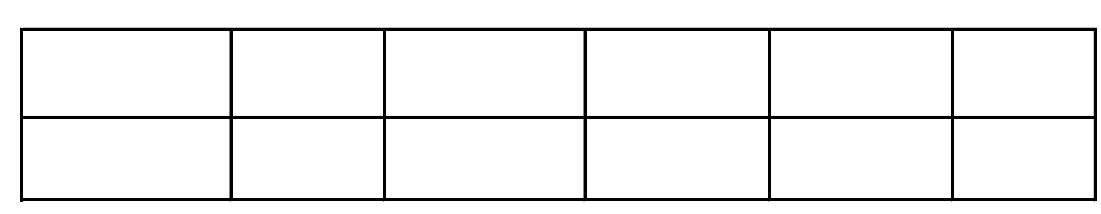

Batching Notes:

$\mathrm{C}=$ Center $\mathrm{E}=\mathrm{Edge}($ Corner $)$

$15.0 \mathrm{lb} /$ pair of half blocks

$12.5 \mathrm{lb} /$ channel block

\begin{tabular}{|l|c|c|c|c|}
\hline Material & $\begin{array}{c}\text { Measured } \\
\text { MC (\%) }\end{array}$ & $\begin{array}{c}\text { Stock Weight } \\
(\mathrm{lb})\end{array}$ & $\begin{array}{c}\text { OD Weight } \\
(\mathrm{lb})\end{array}$ & \% Total Mix \\
\hline Soil & $18.3 \%$ & 69.4 & 58.7 & $41 \%$ \\
\hline Sand & $8.0 \%$ & 69.4 & 64.3 & $45 \%$ \\
\hline Cement & - & 12.5 & 12.5 & $9 \%$ \\
\hline Water & - & 7.7 & 7.7 & $5 \%$ \\
\hline Total & - & 159.0 & 143.2 & $100 \%$ \\
\hline
\end{tabular}




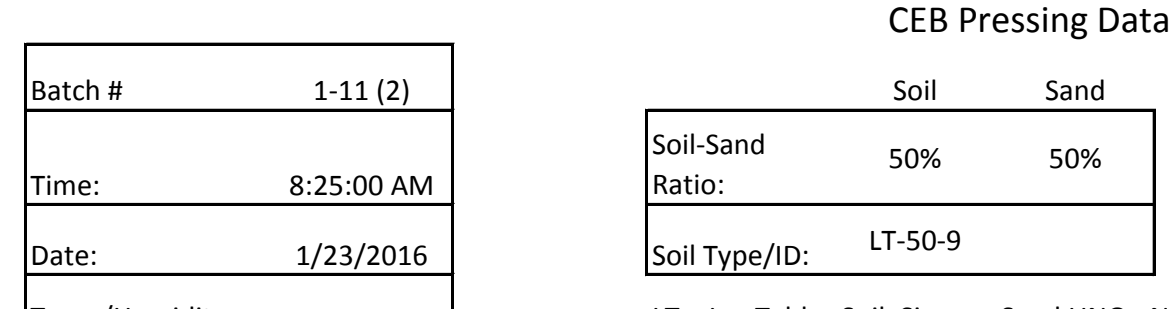

\begin{tabular}{|c|c|c|c|c|c|}
\hline & & & Full & Half & Channel \\
\hline $\begin{array}{l}\text { Water Added: } \\
\text { (lb) }\end{array}$ & 8.0 & $\begin{array}{r}\text { No./Type of } \\
\text { Blocks Made: }\end{array}$ & & 12 & 5 \\
\hline
\end{tabular}

Temp/Humidity: $\quad$ LT = Las Tablas Soil, Sisquoc Sand UNO., Number Denotes Soil \%,Cement \% (based on solid stock wts)

\begin{tabular}{|c|c|c|c|c|c|c|c|c|c|c|c|}
\hline \multicolumn{6}{|c|}{ Pre-Batch Moisture Contents } & \multicolumn{6}{|c|}{ Post-Batch Moisture Contents } \\
\hline & MC (\%) & Pan +Wet (g) & Pan+Dry (g) & Pan Wt (g) & Pan ID & & MC (\%) & Pan +Wet (g) & Pan+Dry (g) & Pan Wt (g) & Pan ID \\
\hline Soil MC (\%): & $18.3 \%$ & 803 & 742 & 408 & S1-4B & \multirow{2}{*}{ Batch MC (\%): } & \multirow{2}{*}{$18.1 \%$} & \multirow{2}{*}{1035} & \multirow{2}{*}{939} & \multirow{2}{*}{409} & \multirow{2}{*}{ S01-3B } \\
\hline Sand MC (\%): & $8.0 \%$ & 937 & 898 & 408 & S2-4A & & & & & & \\
\hline Batch MC (\%): & \multicolumn{5}{|c|}{$11.8 \%$} & & & & & & \\
\hline
\end{tabular}

Penetrometer Readings:

Penetrometer Readings:
\begin{tabular}{|c|c|c|c|l|l|}
\hline Block ID: & $3 \mathrm{~h}$ & $7 \mathrm{c}$ & $8 \mathrm{c}$ & & \\
\hline Reading (psi): & $450 \mathrm{C}, 350 \mathrm{E}$ & $260 \mathrm{C}, 330 \mathrm{E}$ & $300 \mathrm{C}, 320 \mathrm{E}$ & & \\
\hline
\end{tabular}
Batching Notes: $\mathrm{h}=$ half (pair), c = channel
$\mathrm{C}=$ Center, $\mathrm{E}=$ Edge (Corner)

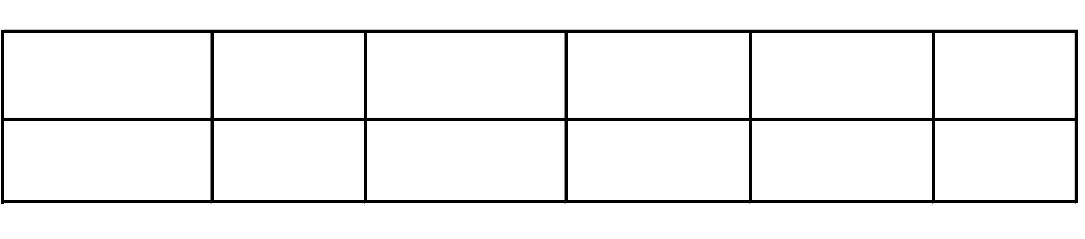

$15.0 \mathrm{lb} /$ pair of half blocks

$12.5 \mathrm{lb} /$ channel block 1 (7c)

$12.7 \mathrm{lb} /$ other channel blocks

\begin{tabular}{|l|c|c|c|c|}
\hline Material & $\begin{array}{c}\text { Measured } \\
\text { MC (\%) }\end{array}$ & $\begin{array}{c}\text { Stock Weight } \\
(\mathrm{lb})\end{array}$ & $\begin{array}{c}\text { OD Weight } \\
(\mathrm{lb})\end{array}$ & \% Total Mix \\
\hline Soil & $18.3 \%$ & 69.4 & 58.7 & $41 \%$ \\
\hline Sand & $8.0 \%$ & 69.4 & 64.3 & $45 \%$ \\
\hline Cement & - & 12.5 & 12.5 & $9 \%$ \\
\hline Water & - & 7.7 & 7.7 & $5 \%$ \\
\hline Total & - & 159.0 & 143.2 & $100 \%$ \\
\hline
\end{tabular}




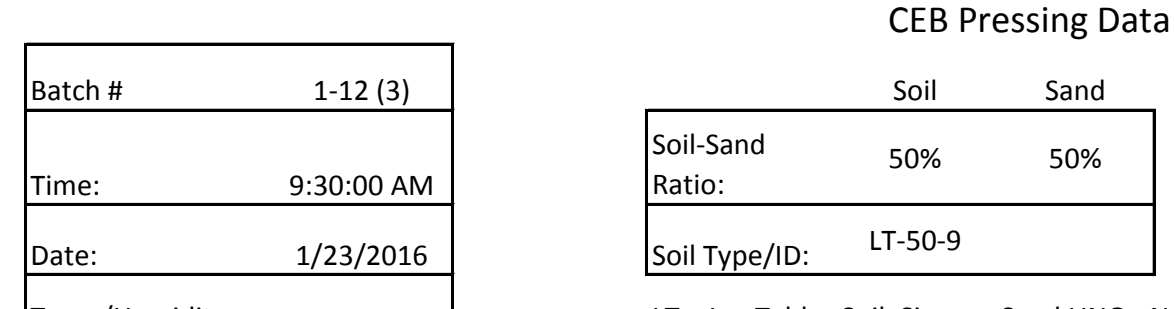

\begin{tabular}{|c|c|c|c|c|c|}
\hline & & & Full & Half & Channel \\
\hline $\begin{array}{l}\text { Water Added: } \\
\text { (lb) }\end{array}$ & 7.7 & $\begin{array}{r}\text { No./Type of } \\
\text { Blocks Made: }\end{array}$ & & & 11 \\
\hline
\end{tabular}

Temp/Humidity: $\quad$ LT = Las Tablas Soil, Sisquoc Sand UNO., Number Denotes Soil \%,Cement \% (based on solid stock wts)

\begin{tabular}{|c|c|c|c|c|c|c|c|c|c|c|c|}
\hline \multicolumn{6}{|c|}{ Pre-Batch Moisture Contents } & \multicolumn{6}{|c|}{ Post-Batch Moisture Contents } \\
\hline & MC (\%) & Pan +Wet (g) & Pan+Dry (g) & Pan Wt (g) & Pan ID & & MC (\%) & Pan +Wet (g) & Pan+Dry (g) & Pan Wt (g) & Pan ID \\
\hline Soil MC (\%): & $18.3 \%$ & 803 & 742 & 408 & S1-4B & \multirow{2}{*}{ Batch MC (\%): } & \multirow{2}{*}{$17.5 \%$} & \multirow{2}{*}{984} & \multirow{2}{*}{898} & \multirow{2}{*}{406} & \multirow{2}{*}{ S02-3A } \\
\hline Sand MC (\%): & $8.0 \%$ & 937 & 898 & 408 & S2-4A & & & & & & \\
\hline Batch MC (\%): & \multicolumn{5}{|c|}{$11.8 \%$} & & & & & & \\
\hline
\end{tabular}

Penetrometer Readings:

Penetrometer Readings:
\begin{tabular}{|c|c|c|l|l|l|}
\hline Block ID: & 1 & 3 [Damaged] & & & \\
\hline Reading (psi): & $250 \mathrm{C}, 240 \mathrm{E}$ & $330 \mathrm{C}, 200 \mathrm{E}$ & & & \\
\hline
\end{tabular}

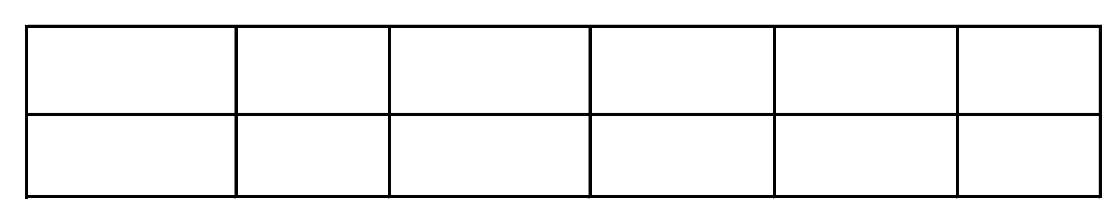

Batching Notes:

$\mathrm{C}=$ Center $\mathrm{E}=\mathrm{Edge}($ Corner $)$

$12.9 \mathrm{lb} /$ channel block 1

$13.1 \mathrm{lb} /$ other channel blocks

\begin{tabular}{|l|c|c|c|c|}
\hline Material & $\begin{array}{c}\text { Measured } \\
\text { MC (\%) }\end{array}$ & $\begin{array}{c}\text { Stock Weight } \\
(\mathrm{lb})\end{array}$ & $\begin{array}{c}\text { OD Weight } \\
(\mathrm{lb})\end{array}$ & \% Total Mix \\
\hline Soil & $18.3 \%$ & 69.4 & 58.7 & $41 \%$ \\
\hline Sand & $8.0 \%$ & 69.4 & 64.3 & $45 \%$ \\
\hline Cement & - & 12.5 & 12.5 & $9 \%$ \\
\hline Water & - & 7.7 & 7.7 & $5 \%$ \\
\hline Total & - & 159.0 & 143.2 & $100 \%$ \\
\hline
\end{tabular}




\begin{tabular}{|lc|}
\hline Batch \# & $3-1$ \\
\hline Time: & $10: 30: 00 \mathrm{AM}$ \\
\hline Date: & $4 / 3 / 2016$ \\
\hline Temp/Humidity: & $55^{\circ} \mathrm{F}$, Cloudy \\
\hline
\end{tabular}

CEB Pressing Data Sheet

\begin{tabular}{|c|c|c|c|c|c|c|c|c|c|c|c|}
\hline \multicolumn{6}{|c|}{ Pre-Batch Moisture Contents } & \multicolumn{6}{|c|}{ Post-Batch Moisture Contents } \\
\hline & $\mathrm{MC}(\%)$ & Pan +Wet (g) & Pan+Dry (g) & Pan Wt (g) & Pan ID & & $\mathrm{MC}(\%)$ & Pan +Wet (g) & Pan+Dry (g) & Pan Wt (g) & Pan ID \\
\hline Soil MC (\%): & $15.8 \%$ & 1207 & 1098 & 408 & S01-4B & \multirow{2}{*}{ Batch MC (\%): } & \multirow{2}{*}{-} & \multirow{2}{*}{1917} & \multirow{2}{*}{-} & \multirow{2}{*}{411} & \multirow{2}{*}{ S03-4B } \\
\hline Sand MC (\%): & $4.2 \%$ & 1389 & 1350 & 411 & S03-4B & & & & & & \\
\hline Batch MC (\%): & \multicolumn{5}{|c|}{$8.9 \%$} & & & & & & \\
\hline
\end{tabular}

MC sample disappeared from inside kiln

Penetrometer Readings:

Penetrometer Readings:
\begin{tabular}{|c|c|c|c|c|c|}
\hline Block ID: & 1 & 2 & 3 & $9 \mathrm{~h}$ & \\
\hline Reading (psi): & $410 \mathrm{C}, 310 \mathrm{E}$ & $390 \mathrm{C}, 330 \mathrm{E}$ & $460 \mathrm{C}, 390 \mathrm{E}$ & $510 \mathrm{C}, 300 \mathrm{E}$ & \\
\hline
\end{tabular}
Batching Notes: $\begin{aligned} & \mathrm{h}=\text { half (pair) } \\
& \text { C Center, E = Edge (Corner) }\end{aligned}$

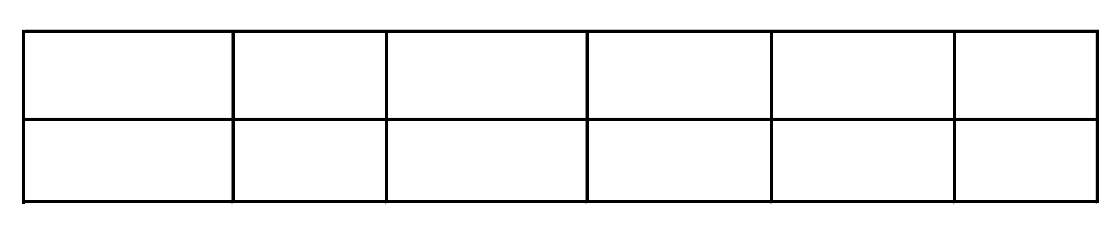

$15.7 \mathrm{lb}$ - 1st Block

$15.5 \mathrm{lb}$ - 1st half blocks (9h)

Noticeably dryer; probably undershot water more than expected

\begin{tabular}{|l|c|c|c|c|}
\hline Material & $\begin{array}{c}\text { Measured } \\
\text { MC (\%) }\end{array}$ & $\begin{array}{c}\text { Stock Weight } \\
(\mathrm{lb})\end{array}$ & $\begin{array}{c}\text { OD Weight } \\
(\mathrm{lb})\end{array}$ & \% Total Mix \\
\hline Soil & $15.8 \%$ & 69.9 & 60.4 & $40 \%$ \\
\hline Sand & $4.2 \%$ & 69.9 & 67.1 & $44 \%$ \\
\hline Cement & - & 12.6 & 12.6 & $8 \%$ \\
\hline Water & - & 12.1 & 12.1 & $8 \%$ \\
\hline Total & - & 164.5 & 152.1 & $100 \%$ \\
\hline
\end{tabular}




\begin{tabular}{|lc|}
\hline Batch \# & $3-2$ \\
\hline Time: & $11: 35: 00 \mathrm{AM}$ \\
\hline Date: & $4 / 3 / 2016$ \\
\hline Temp/Humidity: & $57^{\circ} \mathrm{F}$, Cloudy \\
\hline
\end{tabular}

CEB Pressing Data Sheet

\begin{tabular}{|c|c|c|c|c|c|c|c|c|c|c|c|}
\hline \multicolumn{6}{|c|}{ Pre-Batch Moisture Contents } & \multicolumn{6}{|c|}{ Post-Batch Moisture Contents } \\
\hline & $\mathrm{MC}(\%)$ & Pan +Wet (g) & Pan+Dry (g) & Pan Wt (g) & Pan ID & & $\mathrm{MC}(\%)$ & Pan +Wet (g) & Pan+Dry (g) & Pan Wt (g) & Pan ID \\
\hline Soil MC (\%): & $15.8 \%$ & 1207 & 1098 & 408 & S01-4B & \multirow{2}{*}{ Batch MC (\%): } & \multirow{2}{*}{$19.7 \%$} & \multirow{2}{*}{1568} & \multirow{2}{*}{1377} & \multirow{2}{*}{409} & \multirow{2}{*}{ S01-4B } \\
\hline Sand MC (\%): & $4.2 \%$ & 1389 & 1350 & 411 & S03-4B & & & & & & \\
\hline Batch MC (\%): & \multicolumn{5}{|c|}{$8.9 \%$} & & & & & & \\
\hline
\end{tabular}

MC sample disappeared from inside kiln

Penetrometer Readings:

Penetrometer Readings:
\begin{tabular}{|c|c|c|c|c|c|}
\hline Block ID: & 1 & 2 & $9 \mathrm{~h}$ & $10 \mathrm{~h}$ & \\
\hline Reading (psi): & $260 \mathrm{C}, 300 \mathrm{E}$ & $320 \mathrm{C}, 320 \mathrm{E}$ & $400 \mathrm{C}, 360 \mathrm{E}$ & $350 \mathrm{C}, 200 \mathrm{E}$ & \\
\hline
\end{tabular}
Batching Notes: $\begin{aligned} & \mathrm{h}=\text { half (pair) } \\
& \text { C Center, E = Edge (Corner) }\end{aligned}$

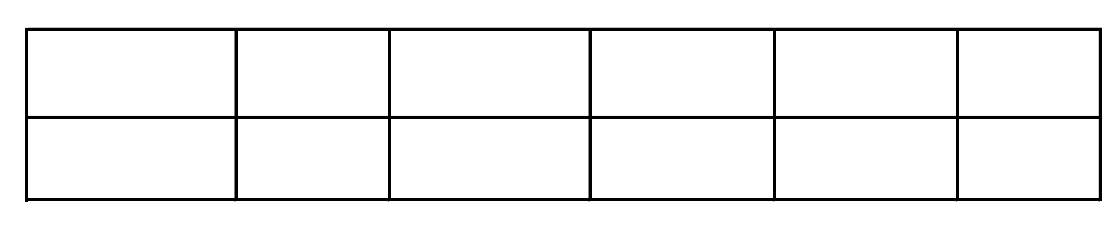

15.7 lb - 1st Block

$15.5 \mathrm{lb}$ - Half blocks

\begin{tabular}{|l|c|c|c|c|}
\hline Material & $\begin{array}{c}\text { Measured } \\
\text { MC (\%) }\end{array}$ & $\begin{array}{c}\text { Stock Weight } \\
(\mathrm{lb})\end{array}$ & $\begin{array}{c}\text { OD Weight } \\
(\mathrm{lb})\end{array}$ & \% Total Mix \\
\hline Soil & $15.8 \%$ & 69.9 & 60.4 & $40 \%$ \\
\hline Sand & $4.2 \%$ & 69.9 & 67.1 & $44 \%$ \\
\hline Cement & - & 12.6 & 12.6 & $8 \%$ \\
\hline Water & - & 12.1 & 12.1 & $8 \%$ \\
\hline Total & - & 164.5 & 152.1 & $100 \%$ \\
\hline
\end{tabular}




\begin{tabular}{|lc|}
\hline Batch \# & $3-4$ \\
\hline Time: & $2: 45: 00$ PM \\
\hline Date: & $4 / 3 / 2016$ \\
\hline Temp/Humidity: & $64^{\circ} \mathrm{F}$, Sunny \\
\hline
\end{tabular}

CEB Pressing Data Sheet

\begin{tabular}{|c|c|c|c|c|c|c|c|c|c|c|c|}
\hline \multicolumn{6}{|c|}{ Pre-Batch Moisture Contents } & \multicolumn{6}{|c|}{ Post-Batch Moisture Contents } \\
\hline & $\mathrm{MC}(\%)$ & Pan +Wet (g) & Pan+Dry (g) & Pan Wt (g) & Pan ID & & $\mathrm{MC}(\%)$ & Pan +Wet (g) & Pan+Dry (g) & Pan Wt (g) & Pan ID \\
\hline Soil MC (\%): & $15.8 \%$ & 1207 & 1098 & 408 & S01-4B & \multirow{2}{*}{ Batch MC (\%): } & \multirow{2}{*}{$17.8 \%$} & \multirow{2}{*}{1203} & \multirow{2}{*}{1083} & \multirow{2}{*}{407} & \multirow{2}{*}{ SO2-4A } \\
\hline Sand MC (\%): & $4.2 \%$ & 1389 & 1350 & 411 & S03-4B & & & & & & \\
\hline Batch MC (\%): & \multicolumn{5}{|c|}{$8.9 \%$} & & & & & & \\
\hline
\end{tabular}

Penetrometer Readings:

Penetrometer Readings:
\begin{tabular}{|c|c|c|c|c|c|}
\hline Block ID: & 1 & 2 & $9 \mathrm{~h}$ & $10 \mathrm{~h}$ & \\
\hline Reading (psi): & $310 \mathrm{C}, 240 \mathrm{E}$ & $410 \mathrm{C}, 360 \mathrm{E}$ & $460 \mathrm{C}, 430 \mathrm{E}$ & $500 \mathrm{C}, 340 \mathrm{E}$ & \\
\hline
\end{tabular}
Batching Notes:
$\begin{aligned} & \mathrm{C}=\text { half (pair) } \\
& \text { Center, E = Edge (Corner) }\end{aligned}$

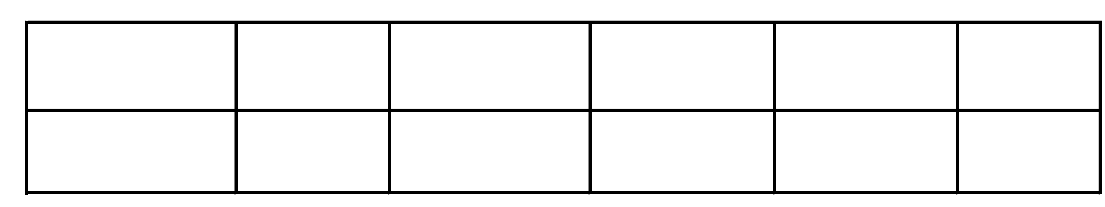

$15.4 \mathrm{lb}$ - Block $9 \mathrm{~h}$

$15.5 \mathrm{lb}$ - Block $10 \mathrm{~h}$

\begin{tabular}{|l|c|c|c|c|}
\hline Material & $\begin{array}{c}\text { Measured } \\
\text { MC (\%) }\end{array}$ & $\begin{array}{c}\text { Stock Weight } \\
(\mathrm{lb})\end{array}$ & $\begin{array}{c}\text { OD Weight } \\
(\mathrm{lb})\end{array}$ & \% Total Mix \\
\hline Soil & $15.8 \%$ & 69.9 & 60.4 & $40 \%$ \\
\hline Sand & $4.2 \%$ & 69.9 & 67.1 & $44 \%$ \\
\hline Cement & - & 12.6 & 12.6 & $8 \%$ \\
\hline Water & - & 12.1 & 12.1 & $8 \%$ \\
\hline Total & - & 164.5 & 152.1 & $100 \%$ \\
\hline
\end{tabular}




\begin{tabular}{|lc|}
\hline Batch \# & $3-6(2)$ \\
\hline Time: & $11: 45: 00$ AM \\
\hline Date: & $4 / 10 / 2016$ \\
\hline Temp/Humidity: & $64^{\circ} \mathrm{F}$, Cloudy \\
\hline
\end{tabular}

CEB Pressing Data Sheet

\begin{tabular}{|c|c|c|c|c|c|c|c|c|c|c|c|}
\hline \multicolumn{6}{|c|}{ Pre-Batch Moisture Contents } & \multicolumn{6}{|c|}{ Post-Batch Moisture Contents } \\
\hline & $\mathrm{MC}(\%)$ & Pan +Wet (g) & Pan+Dry (g) & Pan Wt (g) & Pan ID & & $\mathrm{MC}(\%)$ & Pan +Wet (g) & Pan+Dry (g) & Pan Wt (g) & Pan ID \\
\hline Soil MC (\%): & $15.8 \%$ & 1207 & 1098 & 408 & S01-4B & \multirow{2}{*}{ Batch MC (\%): } & \multirow{2}{*}{$17.2 \%$} & \multirow{2}{*}{924} & \multirow{2}{*}{838} & \multirow{2}{*}{339} & \multirow{2}{*}{ SO2-4B } \\
\hline Sand MC (\%): & $4.2 \%$ & 1389 & 1350 & 411 & S03-4B & & & & & & \\
\hline Batch MC (\%): & \multicolumn{5}{|c|}{$8.9 \%$} & & & & & & \\
\hline
\end{tabular}

Penetrometer Readings:

Penetrometer Readings:
\begin{tabular}{|c|c|c|c|c|c|}
\hline Block ID: & 1 & 2 & 3 & $9 \mathrm{~h}$ & $10 \mathrm{~h}$ \\
\hline Reading (psi): & $310 \mathrm{C}, 310 \mathrm{E}$ & $400 \mathrm{C}, 350 \mathrm{E}$ & $410 \mathrm{C}, 350 \mathrm{E}$ & $500 \mathrm{C}, 450 \mathrm{E}$ & $470 \mathrm{C}, 430 \mathrm{E}$ \\
\hline
\end{tabular}
Batching Notes:
$\begin{aligned} & \mathrm{C}=\text { half (pair) } \\
& \text { C Center, E = Edge (Corner) }\end{aligned}$

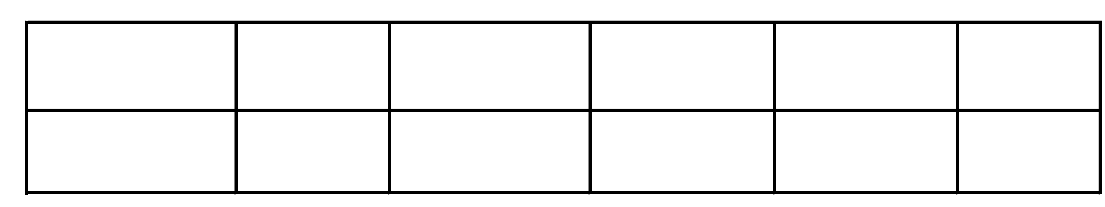

$15.7 \mathrm{lb}$ - Full blocks

$15.5 \mathrm{lb}$ - Half blocks

\begin{tabular}{|l|c|c|c|c|}
\hline Material & $\begin{array}{c}\text { Measured } \\
\text { MC (\%) }\end{array}$ & $\begin{array}{c}\text { Stock Weight } \\
(\mathrm{lb})\end{array}$ & $\begin{array}{c}\text { OD Weight } \\
(\mathrm{lb})\end{array}$ & \% Total Mix \\
\hline Soil & $15.8 \%$ & 69.9 & 60.4 & $40 \%$ \\
\hline Sand & $4.2 \%$ & 69.9 & 67.1 & $44 \%$ \\
\hline Cement & - & 12.6 & 12.6 & $8 \%$ \\
\hline Water & - & 12.1 & 12.1 & $8 \%$ \\
\hline Total & - & 164.5 & 152.1 & $100 \%$ \\
\hline
\end{tabular}




\begin{tabular}{|lc|}
\hline Batch \# & $3-7$ (3) \\
\hline & \\
Time: & $1: 50: 00$ PM \\
\hline Date: & $4 / 10 / 2016$ \\
\hline Temp/Humidity: & $64^{\circ} \mathrm{F}$, Sunny \\
\hline
\end{tabular}

CEB Pressing Data Sheet

\begin{tabular}{|c|c|c|c|c|c|c|c|c|c|c|c|}
\hline \multicolumn{2}{|c|}{\begin{tabular}{|l|l|} 
Date: & $4 / 10 / 2016$ \\
\end{tabular}} & & \multicolumn{3}{|l|}{ OII Туре/ID: } & & & & & & \\
\hline Temp/Humidity: & $64^{\circ} \mathrm{F}$, Sunny & \multicolumn{4}{|c|}{$\mathrm{LT}=$ Las Tablas Soil, Sisquoc Sand UNO., } & ber Denotes Sc & $\%$,Ceme & 6 (based on soli & stock wts) & & \\
\hline \multicolumn{6}{|c|}{ Pre-Batch Moisture Contents } & \multicolumn{6}{|c|}{ Post-Batch Moisture Contents } \\
\hline & $\mathrm{MC}(\%)$ & Pan +Wet (g) & Pan+Dry (g) & Pan Wt (g) & Pan ID & & MC (\%) & Pan +Wet (g) & Pan+Dry (g) & Pan Wt (g) & Pan ID \\
\hline Soil MC (\%): & $15.8 \%$ & 1207 & 1098 & 408 & S01-4B & \multirow{2}{*}{ Batch MC (\%): } & \multirow{2}{*}{$17.6 \%$} & \multirow{2}{*}{1036} & \multirow{2}{*}{942} & \multirow{2}{*}{408} & \multirow{2}{*}{ S02-4A } \\
\hline Sand MC (\%): & $4.2 \%$ & 1389 & 1350 & 411 & S03-4B & & & & & & \\
\hline Batch MC (\%): & \multicolumn{5}{|c|}{$8.9 \%$} & & & & & & \\
\hline
\end{tabular}

Penetrometer Readings:

Penetrometer Readings:
\begin{tabular}{|c|c|c|c|c|c|}
\hline Block ID: & 1 & 2 & 3 & $9 \mathrm{~h}$ & $10 \mathrm{~h}$ \\
\hline Reading (psi): & $370 \mathrm{C}, 340 \mathrm{E}$ & $400 \mathrm{C}, 350 \mathrm{E}$ & $370 \mathrm{C}, 350 \mathrm{E}$ & $550 \mathrm{C}, 430 \mathrm{E}$ & $500 \mathrm{C}, 435 \mathrm{E}$ \\
\hline
\end{tabular}
Batching Notes:
\begin{tabular}{l} 
C $=$ half (pair) Center, E = Edge (Corner) \\
\hline
\end{tabular}

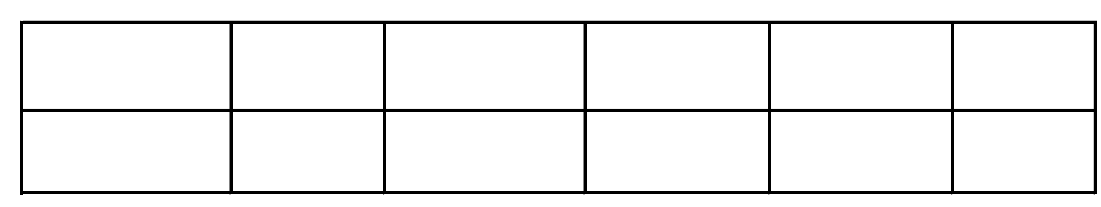

\begin{tabular}{|l|c|c|c|c|}
\hline Material & $\begin{array}{c}\text { Measured } \\
\text { MC (\%) }\end{array}$ & $\begin{array}{c}\text { Stock Weight } \\
(\mathrm{lb})\end{array}$ & $\begin{array}{c}\text { OD Weight } \\
(\mathrm{lb})\end{array}$ & \% Total Mix \\
\hline Soil & $15.8 \%$ & 69.9 & 60.4 & $40 \%$ \\
\hline Sand & $4.2 \%$ & 69.9 & 67.1 & $44 \%$ \\
\hline Cement & - & 12.6 & 12.6 & $8 \%$ \\
\hline Water & - & 12.1 & 12.1 & $8 \%$ \\
\hline Total & - & 164.5 & 152.1 & $100 \%$ \\
\hline
\end{tabular}

$15.7 \mathrm{lb}$ - Full blocks

$15.5 \mathrm{lb}$ - Half blocks

\begin{tabular}{|lcc|}
\multicolumn{1}{l}{} & Soil & Sand \\
\hline $\begin{array}{l}\text { Soil-Sand } \\
\text { Ratio: }\end{array}$ & $50 \%$ & $50 \%$ \\
\hline Soil Type/ID: & LT-50-9 & \\
\hline
\end{tabular}

\begin{tabular}{|c|c|c|c|c|c|}
\hline & & & Full & Half & Channel \\
\hline $\begin{array}{l}\text { Water Added: } \\
\text { (Ib) }\end{array}$ & 11.4 & $\begin{array}{r}\text { No./Type of } \\
\text { Blocks Made: }\end{array}$ & 8 & 4 & \\
\hline
\end{tabular}

Soil Type/ID: 


\begin{tabular}{|c|c|}
\hline Batch \# & $3-8(1)$ \\
\hline Time: & 11:55:00 AM \\
\hline Date: & $5 / 19 / 2016$ \\
\hline
\end{tabular}

CEB Pressing Data Sheet

\begin{tabular}{|c|c|c|c|c|c|c|c|c|c|c|c|}
\hline \multicolumn{6}{|c|}{ Pre-Batch Moisture Contents } & \multicolumn{6}{|c|}{ Post-Batch Moisture Contents } \\
\hline & MC (\%) & Pan +Wet (g) & Pan+Dry (g) & Pan Wt (g) & Pan ID & & MC (\%) & Pan +Wet (g) & Pan+Dry (g) & Pan Wt (g) & Pan ID \\
\hline Soil MC (\%): & $10.0 \%$ & 688 & 656 & 336 & S01-1A & \multirow{2}{*}{ Batch MC (\%): } & \multirow{2}{*}{$17.2 \%$} & \multirow{2}{*}{1027} & \multirow{2}{*}{933} & \multirow{2}{*}{387} & \multirow{2}{*}{ S03-3A } \\
\hline Sand MC (\%): & $1.7 \%$ & 1266 & 1251 & 387 & S03-3A & & & & & & \\
\hline Batch MC (\%): & \multicolumn{5}{|c|}{$5.2 \%$} & & & & & & \\
\hline
\end{tabular}

Penetrometer Readings:

Penetrometer Readings:
\begin{tabular}{|c|c|c|c|c|c|}
\hline Block ID: & 1 & 2 & & & \\
\hline Reading (psi): & $320 \mathrm{C}, 285 \mathrm{E}$ & $350 \mathrm{C}, 330 \mathrm{E}$ & & & \\
\hline
\end{tabular}
Batching Notes: $\begin{aligned} & \mathrm{h}=\text { half (pair) } \\
& \mathrm{C}=\text { Center, E = Edge (Corner) }\end{aligned}$

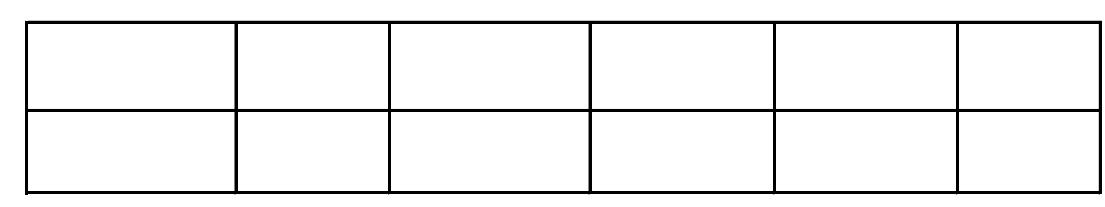

$15.7 \mathrm{lb}$ - 1st block

$15.5 \mathrm{lb}-10 \mathrm{~h}$

\begin{tabular}{|l|c|c|c|c|}
\hline Material & $\begin{array}{c}\text { Measured } \\
\text { MC (\%) }\end{array}$ & $\begin{array}{c}\text { Stock Weight } \\
(\mathrm{lb})\end{array}$ & $\begin{array}{c}\text { OD Weight } \\
(\mathrm{lb})\end{array}$ & \% Total Mix \\
\hline Soil & $10.0 \%$ & 67.6 & 61.4 & $39 \%$ \\
\hline Sand & $1.7 \%$ & 67.6 & 66.4 & $42 \%$ \\
\hline Cement & - & 12.2 & 12.2 & $8 \%$ \\
\hline Water & - & 17.2 & 17.2 & $11 \%$ \\
\hline Total & - & 164.5 & 157.2 & $100 \%$ \\
\hline
\end{tabular}




\begin{tabular}{|c|c|}
\hline Batch \# & $3-9(2)$ \\
\hline Time: & 1:25:00 PM \\
\hline Date: & $5 / 19 / 2016$ \\
\hline
\end{tabular}

CEB Pressing Data Sheet

\begin{tabular}{|c|c|c|c|c|c|c|c|c|c|c|c|}
\hline \multicolumn{6}{|c|}{ Pre-Batch Moisture Contents } & \multicolumn{6}{|c|}{ Post-Batch Moisture Contents } \\
\hline & $\mathrm{MC}(\%)$ & Pan +Wet (g) & Pan+Dry (g) & Pan Wt (g) & Pan ID & & $\mathrm{MC}(\%)$ & Pan +Wet (g) & Pan+Dry (g) & Pan Wt (g) & Pan ID \\
\hline Soil MC (\%): & $10.0 \%$ & 688 & 656 & 336 & S01-1A & \multirow{2}{*}{ Batch MC (\%): } & \multirow{2}{*}{$17.4 \%$} & \multirow{2}{*}{884} & \multirow{2}{*}{803} & \multirow{2}{*}{337} & \multirow{2}{*}{ S01-1A } \\
\hline Sand MC (\%): & $1.7 \%$ & 1266 & 1251 & 387 & S03-3A & & & & & & \\
\hline Batch MC (\%): & \multicolumn{5}{|c|}{$5.2 \%$} & & & & & & \\
\hline
\end{tabular}

Penetrometer Readings:

Penetrometer Readings:
\begin{tabular}{|c|c|c|c|c|c|}
\hline Block ID: & 1 & 2 & 3 & 4 [Damaged] & $10 \mathrm{~h}$ \\
\hline Reading (psi): & $380 \mathrm{C}, 380 \mathrm{E}$ & $300 \mathrm{C}, 300 \mathrm{E}$ & $330 \mathrm{C}, 285 \mathrm{E}$ & $300 \mathrm{C}, 330 \mathrm{E}$ & $480 \mathrm{C}, 320 \mathrm{E}$ \\
\hline
\end{tabular}
Batching Notes:
$\begin{aligned} & \mathrm{h}=\text { half (pair) } \\
& \text { C Center, E = Edge (Corner) }\end{aligned}$

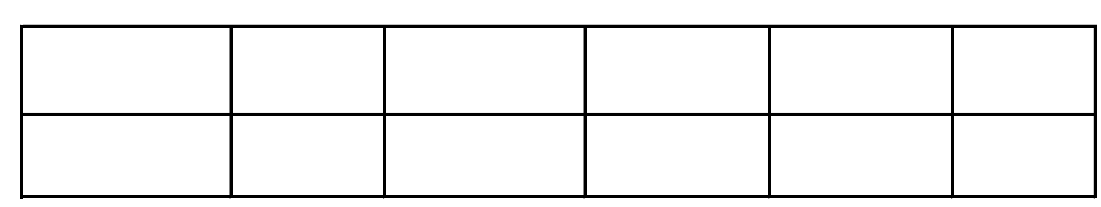

$15.7 \mathrm{lb}$ - 1st block

\begin{tabular}{|l|c|c|c|c|}
\hline Material & $\begin{array}{c}\text { Measured } \\
\text { MC (\%) }\end{array}$ & $\begin{array}{c}\text { Stock Weight } \\
(\mathrm{lb})\end{array}$ & $\begin{array}{c}\text { OD Weight } \\
(\mathrm{lb})\end{array}$ & \% Total Mix \\
\hline Soil & $10.0 \%$ & 67.6 & 61.4 & $39 \%$ \\
\hline Sand & $1.7 \%$ & 67.6 & 66.4 & $42 \%$ \\
\hline Cement & - & 12.2 & 12.2 & $8 \%$ \\
\hline Water & - & 17.2 & 17.2 & $11 \%$ \\
\hline Total & - & 164.5 & 157.2 & $100 \%$ \\
\hline
\end{tabular}




\begin{tabular}{|lc|}
\hline Batch \# & $3-10(3)$ \\
\hline Time: & $3: 00: 00 \mathrm{PM}$ \\
\hline Date: & $5 / 19 / 2016$ \\
\hline Temp/Humidity: & $65^{\circ} \mathrm{F}$, Sunny \\
\hline
\end{tabular}

CEB Pressing Data Sheet

\begin{tabular}{|c|c|c|c|c|c|c|c|c|c|c|c|}
\hline \multicolumn{6}{|c|}{ Pre-Batch Moisture Contents } & \multicolumn{6}{|c|}{ Post-Batch Moisture Contents } \\
\hline & $\mathrm{MC}(\%)$ & Pan +Wet (g) & Pan+Dry (g) & Pan Wt (g) & Pan ID & & $\mathrm{MC}(\%)$ & Pan +Wet (g) & Pan+Dry (g) & Pan Wt (g) & Pan ID \\
\hline Soil MC (\%): & $10.0 \%$ & 688 & 656 & 336 & S01-1A & \multirow{2}{*}{ Batch MC (\%): } & \multirow{2}{*}{$18.5 \%$} & \multirow{2}{*}{1100} & \multirow{2}{*}{989} & \multirow{2}{*}{388} & \multirow{2}{*}{ S03-2A } \\
\hline Sand MC (\%): & $1.7 \%$ & 1266 & 1251 & 387 & S03-3A & & & & & & \\
\hline Batch MC (\%): & \multicolumn{5}{|c|}{$5.2 \%$} & & & & & & \\
\hline
\end{tabular}

Penetrometer Readings:

\begin{tabular}{|} 
Penetrometer Readings: \\
\begin{tabular}{|c|c|c|c|c|c|}
\hline Block ID: & 1 & 2 & 3 & 4 & \\
\hline Reading (psi): & $320 \mathrm{C}, 230 \mathrm{E}$ & $230 \mathrm{C}, 240 \mathrm{E}$ & $310 \mathrm{C}, 300 \mathrm{E}$ & $302 \mathrm{C}, 270 \mathrm{E}$ & \\
\hline
\end{tabular}
\end{tabular}

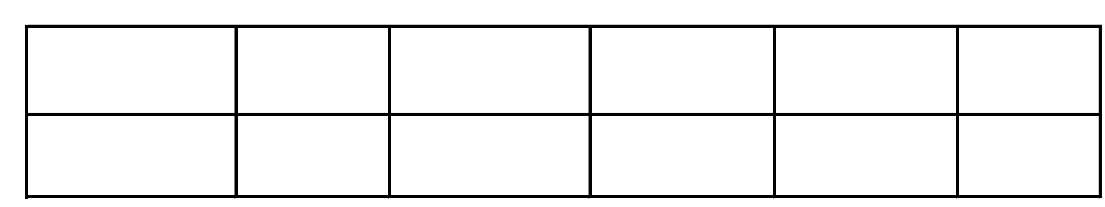

Batching Notes:

$\mathrm{C}=$ Center, $\mathrm{E}=$ Edge (Corner)

$15.7 \mathrm{lb}$ - 1st block

$15.7 \mathrm{lb}$ - 2nd block

$15.9 \mathrm{lb}$ - 3rd block

\begin{tabular}{|l|c|c|c|c|}
\hline Material & $\begin{array}{c}\text { Measured } \\
\text { MC (\%) }\end{array}$ & $\begin{array}{c}\text { Stock Weight } \\
(\mathrm{lb})\end{array}$ & $\begin{array}{c}\text { OD Weight } \\
(\mathrm{lb})\end{array}$ & \% Total Mix \\
\hline Soil & $10.0 \%$ & 67.6 & 61.4 & $39 \%$ \\
\hline Sand & $1.7 \%$ & 67.6 & 66.4 & $42 \%$ \\
\hline Cement & - & 12.2 & 12.2 & $8 \%$ \\
\hline Water & - & 17.2 & 17.2 & $11 \%$ \\
\hline Total & - & 164.5 & 157.2 & $100 \%$ \\
\hline
\end{tabular}




\begin{tabular}{|lc|}
\hline Batch \# & $3-11(1)$ \\
\hline Time: & $12: 20: 00 \mathrm{PM}$ \\
\hline Date: & $5 / 21 / 2016$ \\
\hline Temp/Humidity: & $58^{\circ} \mathrm{F}$, Sunny \\
\hline
\end{tabular}

CEB Pressing Data Sheet

\begin{tabular}{|c|c|c|c|c|c|c|c|c|c|c|c|}
\hline \multicolumn{6}{|c|}{ Pre-Batch Moisture Contents } & \multicolumn{6}{|c|}{ Post-Batch Moisture Contents } \\
\hline & MC (\%) & Pan +Wet (g) & Pan+Dry (g) & Pan Wt (g) & Pan ID & & MC (\%) & Pan +Wet (g) & Pan+Dry (g) & Pan Wt (g) & Pan ID \\
\hline Soil MC (\%): & $10.0 \%$ & 688 & 656 & 336 & S01-1A & \multirow{2}{*}{ Batch MC (\%): } & \multirow{2}{*}{$17.1 \%$} & \multirow{2}{*}{665} & \multirow{2}{*}{617} & \multirow{2}{*}{337} & \multirow{2}{*}{ S01-1A } \\
\hline Sand MC (\%): & $1.7 \%$ & 1266 & 1251 & 387 & S03-3A & & & & & & \\
\hline Batch MC (\%): & \multicolumn{5}{|c|}{$5.2 \%$} & & & & & & \\
\hline
\end{tabular}

Penetrometer Readings:

\begin{tabular}{|c|c|c|c|c|c|}
\hline Block ID: & Reject & 1 & 2 & 3 & \\
\hline Reading (psi): & $390 \mathrm{C}, 330 \mathrm{E}$ & $400 \mathrm{C}, 360 \mathrm{E}$ & $430 \mathrm{C}, 410 \mathrm{E}$ & $450 \mathrm{C}, 330 \mathrm{E}$ & \\
\hline
\end{tabular}

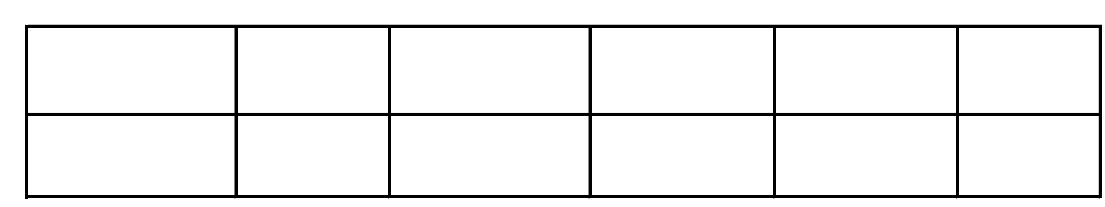

Batching Notes:

$\mathrm{C}=$ Center, $\mathrm{E}=\mathrm{Edge}$ (Corner)

$13.1 \mathrm{lb}-1 \mathrm{st}$ block

\begin{tabular}{|l|c|c|c|c|}
\hline Material & $\begin{array}{c}\text { Measured } \\
\text { MC (\%) }\end{array}$ & $\begin{array}{c}\text { Stock Weight } \\
(\mathrm{lb})\end{array}$ & $\begin{array}{c}\text { OD Weight } \\
(\mathrm{lb})\end{array}$ & \% Total Mix \\
\hline Soil & $10.0 \%$ & 67.6 & 61.4 & $39 \%$ \\
\hline Sand & $1.7 \%$ & 67.6 & 66.4 & $42 \%$ \\
\hline Cement & - & 12.2 & 12.2 & $8 \%$ \\
\hline Water & - & 17.2 & 17.2 & $11 \%$ \\
\hline Total & - & 164.5 & 157.2 & $100 \%$ \\
\hline
\end{tabular}




\begin{tabular}{|c|c|}
\hline Batch \# & $3-12(2)$ \\
\hline Time: & 2:00:00 PM \\
\hline Date: & $5 / 21 / 2016$ \\
\hline
\end{tabular}

CEB Pressing Data Sheet

\begin{tabular}{|c|c|c|c|c|c|c|c|c|c|c|c|}
\hline \multicolumn{6}{|c|}{ Pre-Batch Moisture Contents } & \multicolumn{6}{|c|}{ Post-Batch Moisture Contents } \\
\hline & $\mathrm{MC}(\%)$ & Pan +Wet (g) & Pan+Dry (g) & Pan Wt (g) & Pan ID & & $\mathrm{MC}(\%)$ & Pan +Wet (g) & Pan+Dry (g) & Pan Wt (g) & Pan ID \\
\hline Soil MC (\%): & $10.0 \%$ & 688 & 656 & 336 & S01-1A & \multirow{2}{*}{ Batch MC (\%): } & \multirow{2}{*}{$17.1 \%$} & \multirow{2}{*}{791} & \multirow{2}{*}{732} & \multirow{2}{*}{387} & \multirow{2}{*}{ S03-3A } \\
\hline Sand MC (\%): & $1.7 \%$ & 1266 & 1251 & 387 & S03-3A & & & & & & \\
\hline Batch MC (\%): & \multicolumn{5}{|c|}{$5.2 \%$} & & & & & & \\
\hline
\end{tabular}

Penetrometer Readings:

Penetrometer Readings:
\begin{tabular}{|c|c|c|c|c|c|}
\hline Block ID: & $1 \mathrm{c}$ & $2 \mathrm{c}$ & $6 f$ & $7 f$ & \\
\hline Reading (psi): & $430 \mathrm{C}, 330 \mathrm{E}$ & $360 \mathrm{C}, 360 \mathrm{E}$ & $410 \mathrm{C}, 380 \mathrm{E}$ & $430 \mathrm{C}, 380 \mathrm{E}$ & \\
\hline
\end{tabular}
Batching Notes: channel, f = full
C = Center, E = Edge (Corner)

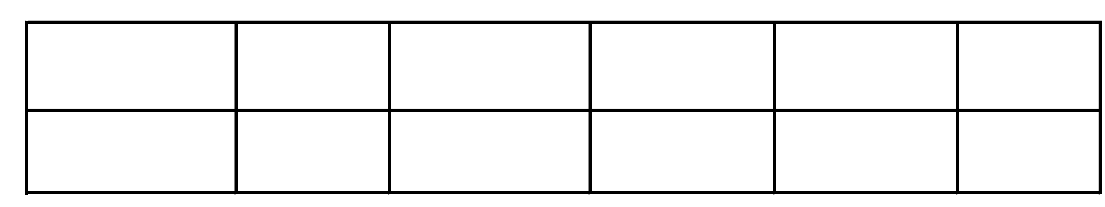

\begin{tabular}{|l|c|c|c|c|}
\hline Material & $\begin{array}{c}\text { Measured } \\
\text { MC (\%) }\end{array}$ & $\begin{array}{c}\text { Stock Weight } \\
(\mathrm{lb})\end{array}$ & $\begin{array}{c}\text { OD Weight } \\
(\mathrm{lb})\end{array}$ & \% Total Mix \\
\hline Soil & $10.0 \%$ & 67.6 & 61.4 & $39 \%$ \\
\hline Sand & $1.7 \%$ & 67.6 & 66.4 & $42 \%$ \\
\hline Cement & - & 12.2 & 12.2 & $8 \%$ \\
\hline Water & - & 17.2 & 17.2 & $11 \%$ \\
\hline Total & - & 164.5 & 157.2 & $100 \%$ \\
\hline
\end{tabular}




\section{C.2. Grout}

GROUT BATCH SHEET

$\begin{array}{ll}\text { Wall: } & 1 \\ \text { Batch: } & 1 \\ \text { Date: } & 2 / 23 / 16\end{array}$

\begin{tabular}{|l|l|c|c|c|c|c|}
\hline Material & Description & $\begin{array}{c}\text { Absorption } \\
(\%)\end{array}$ & $\begin{array}{c}\text { Water } \\
\text { Content (\%) }\end{array}$ & $\begin{array}{c}\text { Stock } \\
\text { Mass (kg) }\end{array}$ & $\begin{array}{c}\text { SSD Mass } \\
(\mathrm{kg})\end{array}$ & $\begin{array}{c}\text { Percent of } \\
\text { Total Batch }\end{array}$ \\
\hline Cement & CalPortland Type II/V & - & - & 4.376 & 4.376 & $12.8 \%$ \\
\hline Lime & Chemstar Type S & - & - & 1.432 & 1.432 & $4.17 \%$ \\
\hline Sand & Sisquoc C33 & $2.0 \%$ & $5.47 \%$ & 21.6 & 20.9 & $60.9 \%$ \\
\hline Water & Tap & - & - & 6.898 & 7.6 & $22.2 \%$ \\
\hline Total & & & & 34.3 & 34.3 & $100.0 \%$ \\
\hline
\end{tabular}

SSD = Saturated Surface Dry

${ }^{1}$ Sand absorption based on supplier data sheet

Water/Cementitious Materials

1.3

Water/Portland Cement

1.7

Flow Diameter $(\mathrm{cm})$

17

GROUT BATCH SHEET

Wall: $\quad 1$

Batch: 2

Date: $\quad 2 / 25 / 16$

\begin{tabular}{|l|l|c|c|c|c|c|}
\hline Material & Description & $\begin{array}{c}\text { Absorption } \\
(\%)\end{array}$ & $\begin{array}{c}\text { Water } \\
\text { Content (\%) }\end{array}$ & $\begin{array}{c}\text { Stock } \\
\text { Mass (kg) }\end{array}$ & $\begin{array}{c}\text { SSD Mass } \\
(\mathrm{kg})\end{array}$ & $\begin{array}{c}\text { Percent of } \\
\text { Total Batch }\end{array}$ \\
\hline Cement & CalPortland Type II/V & - & - & 5.82 & 5.82 & - \\
\hline Lime & Chemstar Type S & - & - & 1.90 & 1.90 & - \\
\hline Sand & Sisquoc C33 & $2.0 \%$ & $5.47 \%$ & 28.7 & 27.8 & - \\
\hline Water & Tap & - & - & - & - & - \\
\hline Total & & & & - & - & - \\
\hline
\end{tabular}

SSD = Saturated Surface Dry

${ }^{1}$ Sand absorption based on supplier data sheet

Water/Cementitious Materials _ Water/Portland Cement -

Flow Diameter $(\mathrm{cm}) \quad 18$ 
Wall: $\quad 1$

Batch: 3

Date: $\quad 2 / 25 / 16$

\begin{tabular}{|l|l|c|c|c|c|c|}
\hline Material & Description & $\begin{array}{c}\text { Absorption } \\
(\%)\end{array}$ & $\begin{array}{c}\text { Water } \\
\text { Content (\%) }\end{array}$ & $\begin{array}{c}\text { Stock } \\
\text { Mass (kg) }\end{array}$ & $\begin{array}{c}\text { SSD Mass } \\
(\mathrm{kg})\end{array}$ & $\begin{array}{c}\text { Percent of } \\
\text { Total Batch }\end{array}$ \\
\hline Cement & CalPortland Type II/V & - & - & 5.82 & 5.82 & - \\
\hline Lime & Chemstar Type S & - & - & 1.90 & 1.90 & - \\
\hline Sand & Sisquoc C33 & $2.0 \%$ & $5.47 \%$ & 28.7 & 27.8 & - \\
\hline Water & Tap & - & - & - & - & - \\
\hline Total & & & & - & - & - \\
\hline
\end{tabular}

SSD = Saturated Surface Dry

${ }^{1}$ Sand absorption based on supplier data sheet

Water/Cementitious Materials Water/Portland Cement -

Flow Diameter $(\mathrm{cm}) \quad 18$

Wall: $\quad 1$

Batch: 4

Date: $\quad 2 / 28 / 16$

\begin{tabular}{|l|l|c|c|c|c|c|}
\hline Material & Description & $\begin{array}{c}\text { Absorption } \\
(\%)\end{array}$ & $\begin{array}{c}\text { Water } \\
\text { Content (\%) }\end{array}$ & $\begin{array}{c}\text { Stock } \\
\text { Mass (kg) }\end{array}$ & $\begin{array}{c}\text { SSD Mass } \\
(\mathrm{kg})\end{array}$ & $\begin{array}{c}\text { Percent of } \\
\text { Total Batch }\end{array}$ \\
\hline Cement & CalPortland Type II/V & - & - & 5.824 & 5.824 & $12.9 \%$ \\
\hline Lime & Chemstar Type S & - & - & 1.90 & 1.90 & $4.22 \%$ \\
\hline Sand & Sisquoc C33 & $2.0 \%$ & $5.47 \%$ & 28.76 & 27.8 & $61.8 \%$ \\
\hline Water & Tap & - & - & 8.51 & 9.5 & $21.0 \%$ \\
\hline Total & & & & 45.0 & 45.0 & $100.0 \%$ \\
\hline
\end{tabular}

SSD = Saturated Surface Dry

${ }^{1}$ Sand absorption based on supplier data sheet

Water/Cementitious Materials Water/Portland Cement

Flow Diameter (cm) 
Wall: 1

Batch: 5

Date: $\quad 3 / 1 / 16$

\begin{tabular}{|l|l|c|c|c|c|c|}
\hline Material & Description & $\begin{array}{c}\text { Absorption } \\
(\%)\end{array}$ & $\begin{array}{c}\text { Water } \\
\text { Content (\%) }\end{array}$ & $\begin{array}{c}\text { Stock } \\
\text { Mass (kg) }\end{array}$ & $\begin{array}{c}\text { SSD Mass } \\
(\mathrm{kg})\end{array}$ & $\begin{array}{c}\text { Percent of } \\
\text { Total Batch }\end{array}$ \\
\hline Cement & CalPortland Type II/V & - & - & 3.486 & 3.486 & - \\
\hline Lime & Chemstar Type S & - & - & 1.318 & 1.318 & - \\
\hline Sand & Sisquoc C33 & $2.0 \%$ & $5.47 \%$ & 17.15 & 16.6 & - \\
\hline Water & Tap & - & - & - & - & - \\
\hline Total & & & & - & - & - \\
\hline
\end{tabular}

SSD = Saturated Surface Dry

${ }^{1}$ Sand absorption based on supplier data sheet

Water/Cementitious Materials -

Water/Portland Cement -

Flow Diameter $(\mathrm{cm}) \quad 17$

\section{GROUT BATCH SHEET}

Wall: 2

Batch: 1

Date: $\quad 5 / 5 / 16$

\begin{tabular}{|l|l|c|c|c|c|c|}
\hline Material & Description & $\begin{array}{c}\text { Absorption } \\
(\%)\end{array}$ & $\begin{array}{c}\text { Water } \\
\text { Content (\%) }\end{array}$ & $\begin{array}{c}\text { Stock } \\
\text { Mass (kg) }\end{array}$ & $\begin{array}{c}\text { SSD Mass } \\
(\mathrm{kg})\end{array}$ & $\begin{array}{c}\text { Percent of } \\
\text { Total Batch }\end{array}$ \\
\hline Cement & CalPortland Type II/V & - & - & 8.309 & 8.309 & $12.8 \%$ \\
\hline Lime & Chemstar Type S & - & - & 2.718 & 2.718 & $4.20 \%$ \\
\hline Sand & Sisquoc C33 & $2.0 \%$ & $2.79 \%$ & 41.0 & 40.7 & $62.8 \%$ \\
\hline Water & Tap & - & - & 12.751 & 13.1 & $20.2 \%$ \\
\hline Total & & & & 64.8 & 64.8 & $100.0 \%$ \\
\hline
\end{tabular}

SSD = Saturated Surface Dry

${ }^{1}$ Sand absorption based on supplier data sheet

Water/Cementitious Materials $\quad 1.2$

Water/Portland Cement $\quad 1.6$

Flow Diameter $(\mathrm{cm}) \quad 20$ 
Wall: 2

Batch: 2

Date: $\quad 5 / 5 / 16$

\begin{tabular}{|l|l|c|c|c|c|c|}
\hline Material & Description & $\begin{array}{c}\text { Absorption } \\
(\%)\end{array}$ & $\begin{array}{c}\text { Water } \\
\text { Content (\%) }\end{array}$ & $\begin{array}{c}\text { Stock } \\
\text { Mass (kg) }\end{array}$ & $\begin{array}{c}\text { SSD Mass } \\
(\mathrm{kg})\end{array}$ & $\begin{array}{c}\text { Percent of } \\
\text { Total Batch }\end{array}$ \\
\hline Cement & CalPortland Type II/V & - & - & 8.311 & 8.311 & $12.9 \%$ \\
\hline Lime & Chemstar Type S & - & - & 2.719 & 2.719 & $4.23 \%$ \\
\hline Sand & Sisquoc C33 & $2.0 \%$ & $2.79 \%$ & 41.0 & 40.7 & $63.3 \%$ \\
\hline Water & Tap & - & - & 12.198 & 12.5 & $19.5 \%$ \\
\hline Total & & & & 64.2 & 64.2 & $100.0 \%$ \\
\hline
\end{tabular}

SSD = Saturated Surface Dry

${ }^{1}$ Sand absorption based on supplier data sheet

Water/Cementitious Materials

Wall: 2

Batch: 3

Date: $\quad 5 / 5 / 16$

\begin{tabular}{|l|l|c|c|c|c|c|}
\hline Material & Description & $\begin{array}{c}\text { Absorption } \\
(\%)\end{array}$ & $\begin{array}{c}\text { Water } \\
\text { Content (\%) }\end{array}$ & $\begin{array}{c}\text { Stock } \\
\text { Mass (kg) }\end{array}$ & $\begin{array}{c}\text { SSD Mass } \\
(\mathrm{kg})\end{array}$ & $\begin{array}{c}\text { Percent of } \\
\text { Total Batch }\end{array}$ \\
\hline Cement & CalPortland Type II/V & - & - & 8.311 & 8.311 & $12.9 \%$ \\
\hline Lime & Chemstar Type S & - & - & 2.725 & 2.725 & $4.22 \%$ \\
\hline Sand & Sisquoc C33 & $2.0 \%$ & $2.79 \%$ & 41.1 & 40.8 & $63.1 \%$ \\
\hline Water & Tap & - & - & 12.474 & 12.8 & $19.8 \%$ \\
\hline Total & & & & 64.6 & 64.6 & $100.0 \%$ \\
\hline
\end{tabular}

SSD = Saturated Surface Dry

${ }^{1}$ Sand absorption based on supplier data sheet

Water/Cementitious Materials $\quad 1.2$

Water/Portland Cement $\quad 1.5$

Flow Diameter $(\mathrm{cm}) \quad 20$ 
Wall: 2

Batch: 4

Date: $\quad 5 / 6 / 16$

\begin{tabular}{|l|l|c|c|c|c|c|}
\hline Material & Description & $\begin{array}{c}\text { Absorption } \\
(\%)\end{array}$ & $\begin{array}{c}\text { Water } \\
\text { Content (\%) }\end{array}$ & $\begin{array}{c}\text { Stock } \\
\text { Mass (kg) }\end{array}$ & $\begin{array}{c}\text { SSD Mass } \\
(\mathrm{kg})\end{array}$ & $\begin{array}{c}\text { Percent of } \\
\text { Total Batch }\end{array}$ \\
\hline Cement & CalPortland Type II/V & - & - & 8.310 & 8.31 & $13.1 \%$ \\
\hline Lime & Chemstar Type S & - & - & 2.720 & 2.720 & $4.28 \%$ \\
\hline Sand & Sisquoc C33 & $2.0 \%$ & $2.79 \%$ & 41.0 & 40.7 & $64.0 \%$ \\
\hline Water & Tap & - & - & 11.574 & 11.9 & $18.7 \%$ \\
\hline Total & & & & 63.6 & 63.6 & $100.0 \%$ \\
\hline
\end{tabular}

SSD = Saturated Surface Dry

${ }^{1}$ Sand absorption based on supplier data sheet

Water/Cementitious Materials

Wall: 2

Batch: 5

Date: $\quad 5 / 6 / 16$

\begin{tabular}{|l|l|c|c|c|c|c|}
\hline Material & Description & $\begin{array}{c}\text { Absorption } \\
(\%)\end{array}$ & $\begin{array}{c}\text { Water } \\
\text { Content (\%) }\end{array}$ & $\begin{array}{c}\text { Stock } \\
\text { Mass (kg) }\end{array}$ & $\begin{array}{c}\text { SSD Mass } \\
(\mathrm{kg})\end{array}$ & $\begin{array}{c}\text { Percent of } \\
\text { Total Batch }\end{array}$ \\
\hline Cement & CalPortland Type II/V & - & - & 8.316 & 8.316 & $13.0 \%$ \\
\hline Lime & Chemstar Type S & - & - & 2.719 & 2.719 & $4.26 \%$ \\
\hline Sand & Sisquoc C33 & $2.0 \%$ & $2.79 \%$ & 41.0 & 40.7 & $63.8 \%$ \\
\hline Water & Tap & - & - & 11.78 & 12.1 & $19.0 \%$ \\
\hline Total & & & & 63.8 & 63.8 & $100.0 \%$ \\
\hline
\end{tabular}

SSD = Saturated Surface Dry

${ }^{1}$ Sand absorption based on supplier data sheet

Water/Cementitious Materials Water/Portland Cement

Flow Diameter (cm)
1.1

1.5 
Wall: 2

Batch: 6

Date: $\quad 5 / 6 / 16$

\begin{tabular}{|l|l|c|c|c|c|c|}
\hline Material & Description & $\begin{array}{c}\text { Absorption } \\
(\%)\end{array}$ & $\begin{array}{c}\text { Water } \\
\text { Content (\%) }\end{array}$ & $\begin{array}{c}\text { Stock } \\
\text { Mass (kg) }\end{array}$ & $\begin{array}{c}\text { SSD Mass } \\
(\mathrm{kg})\end{array}$ & $\begin{array}{c}\text { Percent of } \\
\text { Total Batch }\end{array}$ \\
\hline Cement & CalPortland Type II/V & - & - & 7.475 & 7.475 & - \\
\hline Lime & Chemstar Type S & - & - & 2.460 & 2.460 & - \\
\hline Sand & Sisquoc C33 & $2.0 \%$ & $2.79 \%$ & 36.9 & 36.6 & - \\
\hline Water & Tap & - & - & - & - & - \\
\hline Total & & & & - & - & - \\
\hline
\end{tabular}

SSD = Saturated Surface Dry

${ }^{1}$ Sand absorption based on supplier data sheet

Water/Cementitious Materials Water/Portland Cement -

Flow Diameter $(\mathrm{cm})$

Wall: 2

Batch: 7

Date: $\quad 5 / 6 / 16$

\begin{tabular}{|l|l|c|c|c|c|c|}
\hline Material & Description & $\begin{array}{c}\text { Absorption } \\
(\%)\end{array}$ & $\begin{array}{c}\text { Water } \\
\text { Content (\%) }\end{array}$ & $\begin{array}{c}\text { Stock } \\
\text { Mass (kg) }\end{array}$ & $\begin{array}{c}\text { SSD Mass } \\
(\mathrm{kg})\end{array}$ & $\begin{array}{c}\text { Percent of } \\
\text { Total Batch }\end{array}$ \\
\hline Cement & CalPortland Type II/V & - & - & 4.161 & 4.161 & $12.8 \%$ \\
\hline Lime & Chemstar Type S & - & - & 1.358 & 1.358 & $4.19 \%$ \\
\hline Sand & Sisquoc C33 & $2.0 \%$ & $2.79 \%$ & 20.5 & 20.3 & $62.8 \%$ \\
\hline Water & Tap & - & - & 6.385 & 6.5 & $20.2 \%$ \\
\hline Total & & & & 32.4 & 32.4 & $100.0 \%$ \\
\hline
\end{tabular}

SSD = Saturated Surface Dry

${ }^{1}$ Sand absorption based on supplier data sheet

Water/Cementitious Materials Water/Portland Cement

Flow Diameter $(\mathrm{cm}) \quad 20$

1.2

1.6 
Wall: $\quad 3$

Batch: 1

Date: $\quad 6 / 6 / 16$

\begin{tabular}{|l|l|c|c|c|c|c|}
\hline Material & Description & $\begin{array}{c}\text { Absorption } \\
(\%)\end{array}$ & $\begin{array}{c}\text { Water } \\
\text { Content (\%) }\end{array}$ & $\begin{array}{c}\text { Stock } \\
\text { Mass (kg) }\end{array}$ & $\begin{array}{c}\text { SSD Mass } \\
(\mathrm{kg})\end{array}$ & $\begin{array}{c}\text { Percent of } \\
\text { Total Batch }\end{array}$ \\
\hline Cement & CalPortland Type II/V & - & - & 4.374 & 4.374 & $12.8 \%$ \\
\hline Lime & Chemstar Type S & - & - & 1.440 & 1.440 & $4.21 \%$ \\
\hline Sand & Sisquoc C33 & $2.0 \%$ & $1.07 \%$ & 21.6 & 21.8 & $63.7 \%$ \\
\hline Water & Tap & - & - & 6.789 & 6.6 & $19.3 \%$ \\
\hline Total & & & & 34.2 & 34.2 & $100.0 \%$ \\
\hline
\end{tabular}

SSD = Saturated Surface Dry

${ }^{1}$ Sand absorption based on supplier data sheet

Water/Cementitious Materials

Flow Diameter (cm)

Wall: $\quad 3$

Batch: 2

Date: $\quad 6 / 7 / 16$

\begin{tabular}{|l|l|c|c|c|c|c|}
\hline Material & Description & $\begin{array}{c}\text { Absorption } \\
(\%)\end{array}$ & $\begin{array}{c}\text { Water } \\
\text { Content (\%) }\end{array}$ & $\begin{array}{c}\text { Stock } \\
\text { Mass (kg) }\end{array}$ & $\begin{array}{c}\text { SSD Mass } \\
(\mathrm{kg})\end{array}$ & $\begin{array}{c}\text { Percent of } \\
\text { Total Batch }\end{array}$ \\
\hline Cement & CalPortland Type II/V & - & - & 3.28 & 3.28 & $12.7 \%$ \\
\hline Lime & Chemstar Type S & - & - & 1.08 & 1.08 & $4.18 \%$ \\
\hline Sand & Sisquoc C33 & $2.0 \%$ & $1.07 \%$ & 16.2 & 16.3 & $63.2 \%$ \\
\hline Water & Tap & - & - & 5.289 & 5.1 & $19.9 \%$ \\
\hline Total & & & & 25.8 & 25.8 & $100.0 \%$ \\
\hline
\end{tabular}

SSD = Saturated Surface Dry

${ }^{1}$ Sand absorption based on supplier data sheet

$\begin{array}{rr}\text { Water/Cementitious Materials } & 1.2 \\ \text { Water/Portland Cement } & 1.6\end{array}$

Flow Diameter $(\mathrm{cm}) \quad 19$ 
Wall: 3

Batch: 3

Date: $\quad 6 / 8 / 16$

\begin{tabular}{|l|l|c|c|c|c|c|}
\hline Material & Description & $\begin{array}{c}\text { Absorption } \\
(\%)\end{array}$ & $\begin{array}{c}\text { Water } \\
\text { Content (\%) }\end{array}$ & $\begin{array}{c}\text { Stock } \\
\text { Mass (kg) }\end{array}$ & $\begin{array}{c}\text { SSD Mass } \\
(\mathrm{kg})\end{array}$ & $\begin{array}{c}\text { Percent of } \\
\text { Total Batch }\end{array}$ \\
\hline Cement & CalPortland Type II/V & - & - & 3.284 & 3.284 & $12.8 \%$ \\
\hline Lime & Chemstar Type S & - & - & 1.083 & 1.083 & $4.23 \%$ \\
\hline Sand & Sisquoc C33 & $2.0 \%$ & $1.07 \%$ & 16.2 & 16.3 & $63.8 \%$ \\
\hline Water & Tap & - & - & 5.043 & 4.9 & $19.1 \%$ \\
\hline Total & & & & 25.6 & 25.6 & $100.0 \%$ \\
\hline
\end{tabular}

SSD = Saturated Surface Dry

${ }^{1}$ Sand absorption based on supplier data sheet

Water/Cementitious Materials

1.1

Water/Portland Cement

Flow Diameter $(\mathrm{cm})$

GROUT BATCH SHEET

Wall: $\quad 3$

Batch: 4

Date: $\quad 6 / 9 / 16$

\begin{tabular}{|l|l|c|c|c|c|c|}
\hline Material & Description & $\begin{array}{c}\text { Absorption } \\
(\%)\end{array}$ & $\begin{array}{c}\text { Water } \\
\text { Content (\%) }\end{array}$ & $\begin{array}{c}\text { Stock } \\
\text { Mass (kg) }\end{array}$ & $\begin{array}{c}\text { SSD Mass } \\
(\mathrm{kg})\end{array}$ & $\begin{array}{c}\text { Percent of } \\
\text { Total Batch }\end{array}$ \\
\hline Cement & CalPortland Type II/V & - & - & 3.282 & 3.282 & $12.9 \%$ \\
\hline Lime & Chemstar Type S & - & - & 1.080 & 1.080 & $4.24 \%$ \\
\hline Sand & Sisquoc C33 & $2.0 \%$ & $1.07 \%$ & 16.2 & 16.3 & $64.1 \%$ \\
\hline Water & Tap & - & - & 4.932 & 4.8 & $18.8 \%$ \\
\hline Total & & & & 25.5 & 25.5 & $100.0 \%$ \\
\hline
\end{tabular}

SSD = Saturated Surface Dry

${ }^{1}$ Sand absorption based on supplier data sheet

$\begin{array}{rr}\text { Water/Cementitious Materials } & 1.1 \\ \text { Water/Portland Cement } & 1.5\end{array}$

Flow Diameter $(\mathrm{cm}) \quad 18$ 
Wall: $\quad 3$

Batch: 5

Date: 6/9/16

\begin{tabular}{|l|l|c|c|c|c|c|}
\hline Material & Description & $\begin{array}{c}\text { Absorption } \\
(\%)\end{array}$ & $\begin{array}{c}\text { Water } \\
\text { Content (\%) }\end{array}$ & $\begin{array}{c}\text { Stock } \\
\text { Mass (kg) }\end{array}$ & $\begin{array}{c}\text { SSD Mass } \\
(\mathrm{kg})\end{array}$ & $\begin{array}{c}\text { Percent of } \\
\text { Total Batch }\end{array}$ \\
\hline Cement & CalPortland Type II/V & - & - & 2.46 & 2.46 & $12.7 \%$ \\
\hline Lime & Chemstar Type S & - & - & 0.81 & 0.81 & $4.18 \%$ \\
\hline Sand & Sisquoc C33 & $2.0 \%$ & $1.07 \%$ & 12.2 & 12.3 & $63.5 \%$ \\
\hline Water & Tap & - & - & 3.909 & 3.8 & $19.6 \%$ \\
\hline Total & & & & 19.4 & 19.4 & $100.0 \%$ \\
\hline
\end{tabular}

SSD = Saturated Surface Dry

${ }^{1}$ Sand absorption based on supplier data sheet

$\begin{array}{rr}\text { Water/Cementitious Materials } & 1.2 \\ \text { Water/Portland Cement } & 1.5\end{array}$

Flow Diameter (cm)

\section{C.3. Concrete}

CONCRETE BATCH SHEET

Wall: $\quad 1$

Date: $\quad 3 / 3 / 16$

\begin{tabular}{|l|l|c|c|c|c|c|}
\hline Material & Description & $\begin{array}{c}\text { Absorption } \\
(\%)\end{array}$ & $\begin{array}{c}\text { Water } \\
\text { Content (\%) }\end{array}$ & $\begin{array}{c}\text { Stock } \\
\text { Weight (Ib) }\end{array}$ & $\begin{array}{c}\text { SSD Weight } \\
\text { (Ib) }\end{array}$ & $\begin{array}{c}\text { Percent of } \\
\text { Total Batch }\end{array}$ \\
\hline Cement & CalPortland Type II/V & - & - & 19.502 & 19.502 & $19.8 \%$ \\
\hline Sand & Sisquoc C33 & $2.0 \%$ & $4.43 \%$ & 38.95 & 38.0 & $38.7 \%$ \\
\hline Gravel & $3 / 8$ " Nominal, Rounded & $1.1 \%$ & $1.16 \%$ & 29.24 & 29.2 & $29.7 \%$ \\
\hline Water & Tap & - & - & 10.644 & 11.6 & $11.8 \%$ \\
\hline Total & & & & 98.3 & 98.3 & $100.0 \%$ \\
\hline
\end{tabular}

SSD = Saturated Surface Dry

${ }^{1}$ Sand absorption based on supplier data sheet

${ }^{2}$ Gravel absorption assumed 


\section{CONCRETE BATCH SHEET}

Wall: $\quad 2$

Date: $\quad 5 / 10 / 16$

\begin{tabular}{|l|l|c|c|c|c|c|}
\hline Material & Description & $\begin{array}{c}\text { Absorption } \\
(\%)\end{array}$ & $\begin{array}{c}\text { Water } \\
\text { Content (\%) }\end{array}$ & $\begin{array}{c}\text { Stock } \\
\text { Weight (lb) }\end{array}$ & $\begin{array}{c}\text { SSD Weight } \\
\text { (Ib) }\end{array}$ & $\begin{array}{c}\text { Percent of } \\
\text { Total Batch }\end{array}$ \\
\hline Cement & CalPortland Type II/V & - & - & 48.9 & 48.9 & $19.8 \%$ \\
\hline Sand & Sisquoc C33 & $2.0 \%$ & $2.79 \%$ & 97.8 & 97.0 & $39.4 \%$ \\
\hline Gravel & $3 / 8$ " Nominal, Mixed & $1.1 \%$ & $1.46 \%$ & 73.45 & 73.2 & $29.7 \%$ \\
\hline Water & Tap & - & - & 26.43 & 27.4 & $11.1 \%$ \\
\hline Total & & & & 246.6 & 246.6 & $100.0 \%$ \\
\hline
\end{tabular}

SSD = Saturated Surface Dry

${ }^{1}$ Sand absorption based on supplier data sheet

Water/Cementitious Materials

0.6

${ }^{2}$ Gravel absorption assumed

CONCRETE BATCH SHEET

Wall: $\quad 3$

Date: $\quad 6 / 12 / 16$

\begin{tabular}{|l|l|c|c|c|c|c|}
\hline Material & Description & $\begin{array}{c}\text { Absorption } \\
(\%)\end{array}$ & $\begin{array}{c}\text { Water } \\
\text { Content (\%) }\end{array}$ & $\begin{array}{c}\text { Stock } \\
\text { Weight (lb) }\end{array}$ & $\begin{array}{c}\text { SSD Weight } \\
\text { (lb) }\end{array}$ & $\begin{array}{c}\text { Percent of } \\
\text { Total Batch }\end{array}$ \\
\hline Cement & CalPortland Type II/V & - & - & 19.516 & 19.516 & $18.8 \%$ \\
\hline Sand & Sisquoc C33 & $2.0 \%$ & $1.07 \%$ & 39.1 & 39.5 & $38.0 \%$ \\
\hline Gravel & $3 / 8$ " Nominal, Rounded & $1.1 \%$ & $0.24 \%$ & 29.25 & 29.5 & $28.4 \%$ \\
\hline Water & Tap & - & - & 15.9 & 15.3 & $14.7 \%$ \\
\hline Total & & & & 103.8 & 103.8 & $100.0 \%$ \\
\hline
\end{tabular}

SSD = Saturated Surface Dry

${ }^{1}$ Sand absorption based on supplier data sheet

${ }^{2}$ Gravel absorption assumed 


\section{APPENDIX D. MATERIAL PROPERTY TEST RESULTS}

Std. Dev. $=$ Standard Deviation, $\mathrm{CoV}=$ Coefficient of Variation

\section{D.1. Compressed Earth Blocks}

Section 3.2.4 outlines the procedure used to test compressive strength of individual compressed earth blocks and prisms. All tested Rhino blocks were half blocks, while the V-Lock samples were full blocks. Each wall's single block samples used different conventions for sample ID. Wall 1 samples follow the pattern "[Wall][Number in Testing]", so sample 1-3 is the third block tested for Wall 1. Wall 2 samples made from Las Tablas soil follow the format "LT-[Batch Number]-[Block Number]" with "LT" denoting Las Tablas soil. A few of blocks were unmarked and were probably made with a different soil; these samples are identified with "UN-[Number in Testing]" with "UN" representing "Unknown," so UN-2 is the second tested block made with unknown soil. Wall 3 samples follow the convention "[Batch Number]-[Block Number]", so 4-9a is the "a" half of the ninth block pressed in the fourth batch of Wall 3.

Table D.1: Individual Block Compressive Strength

\begin{tabular}{|c|c|c|c|c|c|c|}
\hline Wall (Block Type) & $\begin{array}{c}\text { Sample } \\
\text { ID }\end{array}$ & $\begin{array}{c}\mathrm{f}_{\mathrm{m}} \\
(\mathrm{MPa})\end{array}$ & $\begin{array}{c}\text { Area } \\
\left(\mathrm{mm}^{2}\right)\end{array}$ & $\begin{array}{l}\text { Mean } \\
(\mathrm{MPa})\end{array}$ & $\begin{array}{c}\text { Std. Dev. } \\
(\mathrm{MPa})\end{array}$ & $\mathrm{CoV}$ \\
\hline \multirow{6}{*}{1 (Rhino) } & $1-1$ & 3.87 & $1.92 \times 10^{4}$ & \multirow{6}{*}{3.95} & \multirow{6}{*}{0.571} & \multirow{6}{*}{$14.4 \%$} \\
\hline & $1-2$ & 3.04 & $1.92 \times 10^{4}$ & & & \\
\hline & $1-3$ & 4.25 & $1.92 \times 10^{4}$ & & & \\
\hline & $1-4$ & 3.62 & $1.92 \times 10^{4}$ & & & \\
\hline & $1-5$ & 4.66 & $1.92 \times 10^{4}$ & & & \\
\hline & $1-6$ & 4.26 & $1.92 \times 10^{4}$ & & & \\
\hline \multirow{5}{*}{2 (V-Lock) } & UN-1 & 7.17 & $4.80 \times 10^{4}$ & \multirow{5}{*}{8.26} & \multirow{5}{*}{1.455} & \multirow{5}{*}{$17.6 \%$} \\
\hline & LT-12-5 & 10.64 & $4.80 \times 10^{4}$ & & & \\
\hline & LT-10-1 & 7.29 & $4.80 \times 10^{4}$ & & & \\
\hline & LT-11-7 & 7.53 & $4.80 \times 10^{4}$ & & & \\
\hline & UN-2 & 8.66 & $4.80 \times 10^{4}$ & & & \\
\hline
\end{tabular}


Table D.1: Individual Block Compressive Strength (continued)

\begin{tabular}{|c|c|c|c|c|c|c|}
\hline Wall (Block Type) & $\begin{array}{c}\text { Sample } \\
\mathrm{ID}\end{array}$ & $\begin{array}{c}\mathrm{f}_{\mathrm{m}} \\
(\mathrm{MPa})\end{array}$ & $\begin{array}{c}\text { Net Area } \\
\left(\mathrm{mm}^{2}\right)\end{array}$ & $\begin{array}{c}\text { Mean } \\
(\mathrm{MPa})\end{array}$ & $\begin{array}{c}\text { Std. Dev. } \\
(\mathrm{MPa})\end{array}$ & CoV \\
\hline \multirow{5}{*}{3 (Rhino) } & $1-9 \mathrm{a}$ & 5.16 & $2.16 \times 10^{4}$ & & & \\
\cline { 2 - 5 } & $2-10 \mathrm{a}$ & 5.42 & $2.16 \times 10^{4}$ & & & \\
\cline { 2 - 5 } & $2-10 \mathrm{~b}$ & 5.26 & $2.16 \times 10^{4}$ & \multirow{4}{*}{4.93} & 0.513 & \multirow{3}{*}{$10.4 \%$} \\
\cline { 2 - 5 } & $4-9 \mathrm{a}$ & 4.32 & $2.16 \times 10^{4}$ & & & \\
\cline { 2 - 5 } & $4-10 \mathrm{a}$ & 5.18 & $2.16 \times 10^{4}$ & & & \\
\cline { 2 - 4 } & $7-10 \mathrm{~b}$ & 4.24 & $2.16 \times 10^{4}$ & & & \\
\hline
\end{tabular}

Prism samples follow the naming convention of "[Wall]-[Grout Batch]", so sample 2-3 is the prism for Wall 2 made and grouted with the third grout batch for that wall.

Table D.2: Compressed Earth Block Prism Compressive Strength

\begin{tabular}{|c|c|c|c|c|c|c|}
\hline Wall & $\begin{array}{c}\text { Sample } \\
\text { ID }\end{array}$ & $\begin{array}{c}\mathrm{f}_{\mathrm{m}} \\
(\mathrm{MPa}) \\
\end{array}$ & $\begin{array}{c}\begin{array}{c}\text { Net Area } \\
\left(\mathrm{mm}^{2}\right)\end{array} \\
\end{array}$ & $\begin{array}{l}\text { Mean } \\
(\mathrm{MPa}) \\
\end{array}$ & $\begin{array}{c}\text { Std. Dev. } \\
(\mathrm{MPa})\end{array}$ & $\mathrm{CoV}$ \\
\hline \multirow{3}{*}{1} & $1-2$ & 1.55 & $2.07 \times 10^{4}$ & \multirow{3}{*}{1.47} & \multirow{3}{*}{0.0901} & \multirow{3}{*}{$6.1 \%$} \\
\hline & $1-4$ & 1.48 & $2.07 \times 10^{4}$ & & & \\
\hline & $1-5$ & 1.37 & $2.07 \times 10^{4}$ & & & \\
\hline \multirow{3}{*}{2} & $2-1$ & 3.29 & $6.24 \times 10^{4}$ & \multirow{3}{*}{3.32} & \multirow{3}{*}{0.1433} & \multirow{3}{*}{$4.3 \%$} \\
\hline & $2-3$ & 3.19 & $6.24 \times 10^{4}$ & & & \\
\hline & $2-5$ & 3.48 & $6.24 \times 10^{4}$ & & & \\
\hline \multirow{3}{*}{3} & $3-1$ & 2.01 & $2.13 \times 10^{4}$ & \multirow{3}{*}{1.93} & \multirow{3}{*}{0.0956} & \multirow{3}{*}{$5.0 \%$} \\
\hline & $3-3$ & 1.95 & $2.13 \times 10^{4}$ & & & \\
\hline & $3-5$ & 1.82 & $2.13 \times 10^{4}$ & & & \\
\hline
\end{tabular}

\section{D.2. Grout}

Section 3.3.2 outlines the testing procedure for grout samples. Both porous and non-porous samples follow the naming convention of "[Wall]-[Grout Batch].[Sample Number]", so sample 2-4.1 is the first sample from the fourth grout batch for Wall 2. 
Table D.3: Non-Porous Cube Grout Compressive Strength

\begin{tabular}{|c|c|c|c|c|c|c|c|c|c|}
\hline & \multicolumn{3}{|c|}{ Sample } & \multicolumn{3}{|c|}{ Batch (MPa) } & \multicolumn{3}{|c|}{ Wall (MPa) } \\
\hline Wall & $\begin{array}{c}\text { Sample } \\
\text { ID }\end{array}$ & $\begin{array}{c}\mathrm{f}_{\mathrm{g}} \\
(\mathrm{MPa})\end{array}$ & $\begin{array}{c}\text { Area } \\
\left(\mathrm{mm}^{2}\right)\end{array}$ & Mean & $\begin{array}{c}\text { Std. } \\
\text { Dev. }\end{array}$ & $\mathrm{COV}$ & Mean & $\begin{array}{c}\text { Std. } \\
\text { Dev. }\end{array}$ & $\mathrm{CoV}$ \\
\hline \multirow{15}{*}{1} & $1-1.1$ & 4.90 & 2580 & \multirow{3}{*}{4.78} & \multirow{3}{*}{0.105} & \multirow{3}{*}{$2.2 \%$} & \multirow{15}{*}{4.93} & \multirow{15}{*}{0.683} & \multirow{15}{*}{$13.9 \%$} \\
\hline & $1-1.2$ & 4.69 & 2580 & & & & & & \\
\hline & $1-1.3$ & 4.76 & 2580 & & & & & & \\
\hline & $1-2.1$ & 4.21 & 2580 & \multirow{3}{*}{4.32} & \multirow{3}{*}{0.144} & \multirow{3}{*}{$3.3 \%$} & & & \\
\hline & $1-2.2$ & 4.27 & 2580 & & & & & & \\
\hline & $1-2.3$ & 4.48 & 2580 & & & & & & \\
\hline & $1-3.1$ & 5.79 & 2580 & \multirow{3}{*}{5.42} & \multirow{3}{*}{0.326} & \multirow{3}{*}{$6.0 \%$} & & & \\
\hline & $1-3.2$ & 5.17 & 2580 & & & & & & \\
\hline & $1-3.3$ & 5.31 & 2580 & & & & & & \\
\hline & $1-4.1$ & 5.17 & 2580 & \multirow{3}{*}{5.79} & \multirow{3}{*}{0.547} & \multirow{3}{*}{$9.4 \%$} & & & \\
\hline & $1-4.2$ & 6.21 & 2580 & & & & & & \\
\hline & $1-4.3$ & 6.00 & 2580 & & & & & & \\
\hline & $1-5.1$ & 3.79 & 2580 & \multirow{3}{*}{4.34} & \multirow{3}{*}{0.497} & \multirow{3}{*}{$11.4 \%$} & & & \\
\hline & $1-5.2$ & 4.48 & 2580 & & & & & & \\
\hline & $1-5.3$ & 4.76 & 2580 & & & & & & \\
\hline \multirow{21}{*}{2} & $2-1.1$ & 3.24 & 2580 & \multirow{3}{*}{4.14} & \multirow{3}{*}{0.813} & & & & \\
\hline & $2-1.2$ & 4.83 & 2580 & & & $19.6 \%$ & & & \\
\hline & $2-1.3$ & 4.34 & 2580 & & & & & & \\
\hline & $2-2.1$ & 6.27 & 2580 & & & & & & \\
\hline & $2-2.2$ & 6.21 & 2580 & 6.41 & 0.301 & $4.7 \%$ & & & \\
\hline & $2-2.3$ & 6.76 & 2580 & & & & & & \\
\hline & $2-3.1$ & 3.93 & 2580 & & & & & & \\
\hline & $2-3.2$ & 4.14 & 2580 & 4.23 & 0.354 & $8.4 \%$ & & & \\
\hline & $2-3.3$ & 4.62 & 2580 & & & & & & \\
\hline & $2-4.1$ & 5.65 & 2580 & & & & & & \\
\hline & $2-4.2$ & 5.58 & 2580 & 5.75 & 0.222 & $3.9 \%$ & 5.31 & 0.878 & $16.6 \%$ \\
\hline & $2-4.3$ & 6.00 & 2580 & & & & & & \\
\hline & $2-5.1$ & 5.31 & 2580 & & & & & & \\
\hline & $2-5.2$ & 5.45 & 2580 & 5.65 & 0.483 & $8.5 \%$ & & & \\
\hline & $2-5.3$ & 6.21 & 2580 & & & & & & \\
\hline & $2-6.1$ & 6.00 & 2580 & & & & & & \\
\hline & $2-6.2$ & 5.86 & 2580 & 5.79 & 0.249 & $4.3 \%$ & & & \\
\hline & $2-6.3$ & 5.52 & 2580 & & & & & & \\
\hline & $2-7.1$ & 5.24 & 2580 & & & & & & \\
\hline & $2-7.2$ & 5.03 & 2580 & 5.17 & 0.119 & $2.3 \%$ & & & \\
\hline & $2-7.3$ & 5.24 & 2580 & & & & & & \\
\hline
\end{tabular}


Table D.3: Non-Porous Cube Grout Compressive Strength (continued)

\begin{tabular}{|c|c|c|c|c|c|c|c|c|c|}
\hline & \multicolumn{3}{|c|}{ Sample } & \multicolumn{3}{|c|}{ Batch (MPa) } & \multicolumn{3}{|c|}{ Wall (MPa) } \\
\hline Wall & $\begin{array}{l}\text { Sample } \\
\text { ID }\end{array}$ & $\begin{array}{c}\mathrm{f}_{\mathrm{g}} \\
(\mathrm{MPa})\end{array}$ & $\begin{array}{l}\text { Area } \\
\left(\mathrm{mm}^{2}\right)\end{array}$ & Mean & $\begin{array}{l}\text { Std. } \\
\text { Dev. }\end{array}$ & $\mathrm{COV}$ & Mean & $\begin{array}{l}\text { Std. } \\
\text { Dev. }\end{array}$ & $\mathrm{CoV}$ \\
\hline \multirow{14}{*}{3} & $3-1.1$ & 6.23 & 2580 & \multirow{3}{*}{5.84} & \multirow{3}{*}{0.338} & \multirow{3}{*}{$5.8 \%$} & \multirow{14}{*}{5.72} & \multirow{14}{*}{0.835} & \multirow{14}{*}{$14.6 \%$} \\
\hline & $3-1.2$ & 5.63 & 2580 & & & & & & \\
\hline & $3-1.3$ & 5.65 & 2580 & & & & & & \\
\hline & $3-2.1$ & 5.68 & 2580 & \multirow{3}{*}{5.46} & \multirow{3}{*}{0.278} & \multirow{3}{*}{$5.1 \%$} & & & \\
\hline & $3-2.2$ & 5.15 & 2580 & & & & & & \\
\hline & $3-2.3$ & 5.56 & 2580 & & & & & & \\
\hline & $3-3.1$ & 5.78 & 2580 & & & & & & \\
\hline & $3-3.2$ & 7.76 & 2580 & 6.77 & 1.399 & $20.7 \%$ & & & \\
\hline & $3-4.1$ & 6.33 & 2580 & & & & & & \\
\hline & $3-4.2$ & 6.14 & 2580 & 6.22 & 0.098 & $1.6 \%$ & & & \\
\hline & $3-4.3$ & 6.21 & 2580 & & & & & & \\
\hline & $3-5.1$ & 4.92 & 2580 & & & & & & \\
\hline & $3-5.2$ & 4.41 & 2580 & 4.66 & 0.252 & $5.4 \%$ & & & \\
\hline & $3-5.3$ & 4.65 & 2580 & & & & & & \\
\hline
\end{tabular}

Table D.4: Porous Grout "Cube" Compressive Strength

\begin{tabular}{|c|c|c|c|c|c|c|c|c|c|}
\hline & \multicolumn{3}{|c|}{ Sample } & \multicolumn{3}{|c|}{ Batch (MPa) } & \multicolumn{3}{|c|}{ Wall (MPa) } \\
\hline Wall & $\begin{array}{c}\text { Sample } \\
\text { ID }\end{array}$ & $\begin{array}{c}\mathrm{f}_{\mathrm{g}} \\
(\mathrm{MPa}) \\
\end{array}$ & $\begin{array}{r}\text { Area } \\
\left(\mathrm{mm}^{2}\right) \\
\end{array}$ & Mean & $\begin{array}{l}\text { Std. } \\
\text { Dev. }\end{array}$ & $\mathrm{CoV}$ & $\begin{array}{l}\text { Wall } \\
\text { Mean }\end{array}$ & $\begin{array}{l}\text { Std. } \\
\text { Dev. }\end{array}$ & $\mathrm{CoV}$ \\
\hline \multirow{5}{*}{1} & $1-1.1$ & 15.58 & 2210 & 15.58 & - & - & \multirow{5}{*}{11.11} & \multirow{5}{*}{3.066} & \multirow{5}{*}{$27.6 \%$} \\
\hline & $1-2.1$ & 9.79 & 2450 & 9.79 & - & - & & & \\
\hline & $1-3.1$ & 8.55 & 2330 & 8.55 & - & - & & & \\
\hline & $1-4.1$ & 8.69 & 2090 & 8.69 & - & - & & & \\
\hline & $1-5.1$ & 12.96 & 1980 & 12.96 & - & - & & & \\
\hline \multirow{12}{*}{2} & $2-1.1$ & 10.27 & 2710 & \multirow{2}{*}{11.17} & \multirow{2}{*}{1.268} & \multirow{2}{*}{$11.3 \%$} & \multirow{12}{*}{12.26} & \multirow{12}{*}{1.465} & \multirow{12}{*}{$11.9 \%$} \\
\hline & $2-1.2$ & 12.07 & 2850 & & & & & & \\
\hline & $2-2.1$ & 13.72 & 2710 & \multirow{2}{*}{12.65} & \multirow{2}{*}{1.511} & \multirow{2}{*}{$11.9 \%$} & & & \\
\hline & $2-2.2$ & 11.58 & 2450 & & & & & & \\
\hline & $2-4.1$ & 13.79 & 3120 & \multirow{2}{*}{14.44} & \multirow{2}{*}{0.926} & \multirow{2}{*}{$6.4 \%$} & & & \\
\hline & $2-4.2$ & 15.10 & 2710 & & & & & & \\
\hline & $2-5.1$ & 10.82 & 2980 & \multirow{2}{*}{11.00} & \multirow{2}{*}{0.244} & \multirow{2}{*}{$2.2 \%$} & & & \\
\hline & $2-5.2$ & 11.17 & 2850 & & & & & & \\
\hline & $2-6.1$ & 12.07 & 2980 & \multirow{2}{*}{11.65} & \multirow{2}{*}{0.585} & \multirow{2}{*}{$5.0 \%$} & & & \\
\hline & $2-6.2$ & 11.24 & 2850 & & & & & & \\
\hline & $2-7.1$ & 13.65 & 3120 & \multirow{2}{*}{12.65} & \multirow{2}{*}{1.414} & \multirow{2}{*}{$11.2 \%$} & & & \\
\hline & $2-7.1$ & 11.65 & 2580 & & & & & & \\
\hline
\end{tabular}


Table D.4: Porous Grout "Cube" Compressive Strength (continued)

\begin{tabular}{|c|c|c|c|c|c|c|c|c|c|}
\hline & \multicolumn{3}{|c|}{ Sample } & \multicolumn{3}{|c|}{ Batch (MPa) } & \multicolumn{3}{|c|}{ Wall (MPa) } \\
\hline Wall & $\begin{array}{c}\text { Sample } \\
\text { ID }\end{array}$ & $\begin{array}{c}\mathrm{f}_{\mathrm{g}} \\
(\mathrm{MPa}) \\
\end{array}$ & $\begin{array}{l}\text { Area } \\
\left(\mathrm{mm}^{2}\right)\end{array}$ & Mean & $\begin{array}{l}\text { Std. } \\
\text { Dev. }\end{array}$ & $\mathrm{CoV}$ & $\begin{array}{r}\text { Wall } \\
\text { Mean }\end{array}$ & $\begin{array}{r}\text { Std. } \\
\text { Dev }\end{array}$ & $\mathrm{CoV}$ \\
\hline \multirow{10}{*}{3} & $3-1.1$ & 11.78 & 2580 & 120 & 81 & 1500 & \multirow{10}{*}{13.66} & \multirow{10}{*}{1.331} & \multirow{10}{*}{$9.7 \%$} \\
\hline & $3-1.2$ & 14.75 & 2580 & 15.26 & 2.101 & $15.8 \%$ & & & \\
\hline & $3-2.1$ & 15.65 & 2710 & \multirow{2}{*}{14.69} & \multirow{2}{*}{1.360} & \multirow{2}{*}{$9.3 \%$} & & & \\
\hline & $3-2.2$ & 13.73 & 2850 & & & & & & \\
\hline & $3-3.1$ & 11.38 & 2710 & \multirow{2}{*}{12.85} & \multirow{2}{*}{2.082} & \multirow{2}{*}{$16.2 \%$} & & & \\
\hline & $3-3.2$ & 14.32 & 2850 & & & & & & \\
\hline & $3-4.1$ & 13.75 & 3120 & \multirow{2}{*}{14.27} & \multirow{2}{*}{0.731} & \multirow{2}{*}{$5.1 \%$} & & & \\
\hline & $3-4.2$ & 14.78 & 2850 & & & & & & \\
\hline & $3-5.1$ & 13.26 & 2850 & \multirow{2}{*}{13.25} & \multirow{2}{*}{0.010} & \multirow{2}{*}{$0.1 \%$} & & & \\
\hline & $3-5.2$ & 13.24 & 2850 & & & & & & \\
\hline
\end{tabular}

Table D.5: Porous Grout Cylinder Compressive Strength

\begin{tabular}{|c|c|c|c|c|c|c|c|c|c|}
\hline & \multicolumn{3}{|c|}{ Sample } & \multicolumn{3}{|c|}{ Batch (MPa) } & \multicolumn{3}{|c|}{ Wall (MPa) } \\
\hline Wall & $\begin{array}{l}\text { Sample } \\
\text { ID }\end{array}$ & $\begin{array}{c}f_{g} \\
(\mathrm{MPa})\end{array}$ & $\begin{array}{c}\text { Area } \\
\left(\mathrm{mm}^{2}\right)\end{array}$ & Mean & $\begin{array}{l}\text { Std. } \\
\text { Dev. }\end{array}$ & $\mathrm{CoV}$ & Mean & $\begin{array}{l}\text { Std. } \\
\text { Dev. }\end{array}$ & $\mathrm{CoV}$ \\
\hline \multirow{14}{*}{1} & $1-1.1$ & 4.06 & 1550 & \multirow{3}{*}{4.22} & \multirow{3}{*}{0.382} & \multirow{3}{*}{$9.0 \%$} & \multirow{14}{*}{4.05} & \multirow{14}{*}{1.190} & \multirow{14}{*}{$29.4 \%$} \\
\hline & $1-1.2$ & 3.95 & 1550 & & & & & & \\
\hline & $1-1.3$ & 4.66 & 1550 & & & & & & \\
\hline & $1-2.1$ & 4.94 & 1550 & \multirow{3}{*}{3.65} & \multirow{3}{*}{1.183} & \multirow{3}{*}{$32.5 \%$} & & & \\
\hline & $1-2.2$ & 2.61 & 1550 & & & & & & \\
\hline & $1-2.3$ & 3.39 & 1550 & & & & & & \\
\hline & $1-3.1$ & 2.99 & 1550 & \multirow{3}{*}{3.18} & \multirow{3}{*}{0.654} & \multirow{3}{*}{$20.6 \%$} & & & \\
\hline & $1-3.2$ & 3.90 & 1550 & & & & & & \\
\hline & $1-3.3$ & 2.63 & 1550 & & & & & & \\
\hline & $1-4.2$ & 3.69 & 1550 & \multirow{2}{*}{5.05} & \multirow{2}{*}{1.926} & \multirow{2}{*}{$38.1 \%$} & & & \\
\hline & $1-4.3$ & 6.41 & 1550 & & & & & & \\
\hline & $1-5.1$ & 3.56 & 1550 & \multirow{3}{*}{4.48} & \multirow{3}{*}{1.634} & \multirow{3}{*}{$36.5 \%$} & & & \\
\hline & $1-5.2$ & 3.51 & 1550 & & & & & & \\
\hline & $1-5.3$ & 6.36 & 1550 & & & & & & \\
\hline
\end{tabular}


Table D.5: Porous Grout Cylinder Compressive Strength (continued)

\begin{tabular}{|c|c|c|c|c|c|c|c|c|c|}
\hline & $2-1.1$ & 4.48 & 1550 & & & & & & \\
\hline & $2-1.2$ & 2.85 & 1550 & 4.35 & 1.432 & $32.9 \%$ & & & \\
\hline & $2-1.3$ & 5.71 & 1550 & & & & & & \\
\hline & $2-2.1$ & 5.14 & 1550 & & & & & & \\
\hline & $2-2.2$ & 2.99 & 1550 & 4.94 & 1.866 & $37.8 \%$ & & & \\
\hline & $2-2.3$ & 6.70 & 1550 & & & & & & \\
\hline & $2-3.1$ & 4.28 & 1550 & & & & & & \\
\hline & $2-3.2$ & 4.25 & 1550 & 4.03 & 0.408 & $10.1 \%$ & & & \\
\hline & $2-3.3$ & 3.56 & 1550 & & & & & & \\
\hline & $2-4.1$ & 2.84 & 1550 & & & & & & \\
\hline 2 & $2-4.2$ & 4.85 & 1550 & 4.21 & 1.187 & $28.2 \%$ & 4.32 & 1.033 & $23.9 \%$ \\
\hline & $2-4.3$ & 4.94 & 1550 & & & & & & \\
\hline & $2-5.1$ & 3.56 & 1550 & & & & & & \\
\hline & $2-5.2$ & 4.97 & 1550 & 4.30 & 0.709 & $16.5 \%$ & & & \\
\hline & $2-5.3$ & 4.36 & 1550 & & & & & & \\
\hline & $2-6.1$ & 4.65 & 1550 & & & & & & \\
\hline & $2-6.2$ & 4.54 & 1550 & 4.72 & 0.223 & $4.7 \%$ & & & \\
\hline & $2-6.3$ & 4.97 & 1550 & & & & & & \\
\hline & $2-7.1$ & 2.63 & 1550 & & & & & & \\
\hline & $2-7.2$ & 3.49 & 1550 & 3.73 & 1.231 & $33.0 \%$ & & & \\
\hline & $2-7.3$ & 5.06 & 1550 & & & & & & \\
\hline & 3-1.1 & 3.12 & 1550 & & & & & & \\
\hline & $3-1.2$ & 2.70 & 1550 & 3.05 & 0.323 & $10.6 \%$ & & & \\
\hline & 3-1.3 & 3.33 & 1550 & & & & & & \\
\hline & 3-2.1 & 5.25 & 1550 & & & & & & \\
\hline & $3-2.2$ & 4.16 & 1550 & 4.40 & 0.760 & $17.2 \%$ & & & \\
\hline & 3-2.3 & 3.79 & 1550 & & & & & & \\
\hline & 3-3.1 & 4.81 & 1550 & & & & & & \\
\hline 3 & $3-3.2$ & 3.22 & 1550 & 4.30 & 0.934 & $21.7 \%$ & 4.79 & 1.680 & $35.1 \%$ \\
\hline & 3-3.3 & 4.86 & 1550 & & & & & & \\
\hline & 3-4.1 & 6.47 & 1550 & & & & & & \\
\hline & $3-4.2$ & 7.56 & 1550 & 5.96 & 1.902 & $31.9 \%$ & & & \\
\hline & $3-4.3$ & 3.86 & 1550 & & & & & & \\
\hline & 3-5.1 & 7.40 & 1550 & & & & & & \\
\hline & $3-5.2$ & 7.43 & 1550 & 6.22 & 2.078 & $33.4 \%$ & & & \\
\hline & $3-5.3$ & 3.82 & 1550 & & & & & & \\
\hline
\end{tabular}




\section{D.3. Concrete}

Concrete cylinders were tested in general compliance with ASTM C39. Samples are identified with the format "[Wall]-[Sample Number]", so sample 3-1 is the first cylinder cast for Wall 3.

Table D.6: Concrete Compressive Strength

\begin{tabular}{|c|c|c|c|c|c|}
\hline Wall & $\begin{array}{c}\text { Sample } \\
\text { ID }\end{array}$ & $\begin{array}{c}\mathrm{f}_{\mathrm{c}} \\
(\mathrm{MPa})\end{array}$ & $\begin{array}{l}\text { Mean } \\
(\mathrm{MPa})\end{array}$ & $\begin{array}{c}\text { Std. } \\
\text { Dev. } \\
(\mathrm{MPa})\end{array}$ & $\mathrm{CoV}$ \\
\hline \multirow{3}{*}{1} & $1-1$ & 41.77 & \multirow{3}{*}{38.42} & \multirow{3}{*}{3.727} & \multirow{3}{*}{$9.7 \%$} \\
\hline & $1-2$ & 39.09 & & & \\
\hline & $1-3$ & 34.40 & & & \\
\hline \multirow{3}{*}{2} & $2-1$ & 32.37 & \multirow{3}{*}{32.62} & \multirow{3}{*}{0.222} & \multirow{3}{*}{$0.7 \%$} \\
\hline & $2-2$ & 32.69 & & & \\
\hline & $2-3$ & 32.80 & & & \\
\hline \multirow{3}{*}{3} & $3-1$ & 35.49 & \multirow{3}{*}{35.27} & \multirow{3}{*}{0.374} & \multirow{3}{*}{$1.0 \%$} \\
\hline & $3-2$ & 34.84 & & & \\
\hline & $3-3$ & 35.48 & & & \\
\hline
\end{tabular}

\section{D.4. Steel}

Samples of the three types of steel were subjected to tensile testing. Samples are identified with an abbreviated form of the steel type followed by a number or letter indicating its position in the testing sequence, sometimes separated by a hyphen. For example, sample PRD is the fourth ("D”) sample of pencil rod tested. For the \#3 deformed bar, all but one sample slipped from the testing apparatus between yield and rupture. For these samples, the stated ultimate value is the highest stress reached during testing. 
Table D.7: Steel Tensile Strength

\begin{tabular}{|c|c|c|c|c|c|c|c|c|c|c|}
\hline & \multicolumn{2}{|c|}{ Sample } & \multicolumn{4}{|c|}{ Yield (MPa) } & \multicolumn{4}{|c|}{ Ultimate (MPa) } \\
\hline Bar Type & $\begin{array}{c}\text { Sample } \\
\text { ID }\end{array}$ & $\begin{array}{c}\text { Area } \\
\left(\mathrm{mm}^{2}\right)\end{array}$ & $f_{y}$ & Mean & $\begin{array}{l}\text { Std. } \\
\text { Dev. }\end{array}$ & $\mathrm{CoV}$ & $\mathrm{f}_{\mathrm{u}}$ & Mean & $\begin{array}{l}\text { Std. } \\
\text { Dev. }\end{array}$ & $\mathrm{CoV}$ \\
\hline \multirow{6}{*}{$\# 3$, Gr. 40} & No3-A & 71 & 365 & \multirow{6}{*}{361} & \multirow{6}{*}{8.21} & \multirow{6}{*}{$2.3 \%$} & $>526$ & \multirow{6}{*}{ - } & \multirow{6}{*}{ - } & \multirow{6}{*}{ - } \\
\hline & No3-B & 71 & 367 & & & & 552 & & & \\
\hline & No3-C & 71 & 361 & & & & $>526$ & & & \\
\hline & No3-D & 71 & 351 & & & & $>519$ & & & \\
\hline & No3-E & 71 & 370 & & & & $>528$ & & & \\
\hline & No3-F & 71 & 351 & & & & $>508$ & & & \\
\hline \multirow{5}{*}{ Pencil Rod } & PRA & 31.7 & 590 & \multirow{5}{*}{445} & \multirow{5}{*}{132} & \multirow{5}{*}{$29.8 \%$} & 629 & \multirow{5}{*}{522} & \multirow{5}{*}{99.2} & \multirow{5}{*}{$19.0 \%$} \\
\hline & PRB & 31.7 & 520 & & & & 577 & & & \\
\hline & PRC & 31.7 & 309 & & & & 427 & & & \\
\hline & PRD & 31.7 & 506 & & & & 570 & & & \\
\hline & PRE & 31.7 & 299 & & & & 406 & & & \\
\hline \multirow{2}{*}{$\begin{array}{c}\text { Ladder } \\
\text { Reinforcement }\end{array}$} & LR-1 & 12.2 & 455 & \multirow{2}{*}{447} & \multirow{2}{*}{11.6} & \multirow{2}{*}{$2.6 \%$} & 462 & \multirow{2}{*}{456} & \multirow{2}{*}{8.78} & \multirow{2}{*}{$1.9 \%$} \\
\hline & LR-2 & 12.2 & 438 & & & & 449 & & & \\
\hline
\end{tabular}

